\title{
A NOVEL METHOD OF ATOMIZING COAL-WATER SLURRY FUELS
}

Final Report

By

P. E. Soika

A. H. Lefebvre

May 1990

Work Performed Under Contract FG22-87PC79913

For

U.S. Department of Energy

Pittsburgh Energy Technology Center

Pittsburgh, Pennsylvania

By

Purdue University

West Lafayette, Indiana 


\section{DISCLAIMER}

This report was prepared as an account of work sponsored by an agency of the Unted States Government. Neither the United States Government nor any agency thereof. nor any of thell employees. makes any warranty, express or implied, or assumes any egal liability or responsibility for the accuraci. completeness. or usefulness of any information. apparatus. product. or process disciosed. or represents that its use would nor infringe privately owned rights. Reference herein to any specific commerclal product. process. or service by rrade name. trademark. manufacturet, or otherwise does not necessarity constitute or imply its endorsement, recommendation. or favoring b) the United Siates Gowernment or ant agencs thereof The view's and opinions of authors ex. pressed herein do not necessarily state or reflect those of the Unted States Government or any agenc! thereof

This report has been reproduced directly from the best available copy.

A vailable to DOE and DOE contractors from the Office of Scientific and Technical Information. P.O. Box 62, Oak Ridge, TN 37831; prices available from $16151576 \cdot 8401$. FTS 626.8401.

A vailable to the public from the National Technical Information Service. U.S. Department of Commerce, 5285 Port Royal Rd., Springfield, VA 22161.

Price: Printed Copy A07

Microfiche A01 


\section{A NOVEL METHOD OF ATOMIZING COAL-WATER SLURRY FUELS}

Final Report for Grant No.

DE-FG22-87PC79913

U.S. Department of Energy

Pittsburgh Energy Technology Center

by

P.E. Sojka and A.H. Lefebvre Thermal Sciences and Propulsion Center School of Mechanical Engineering

Purdue University

West Lafayette, IN 47907

May 1990 
TABLE OF CONTENTS

Page

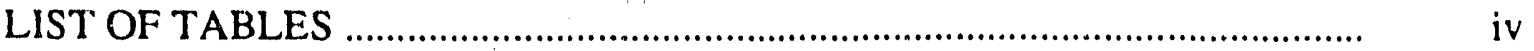

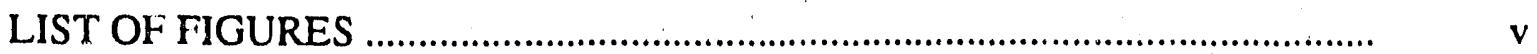

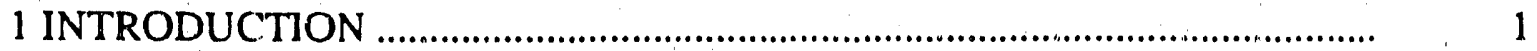

2 LITERATURE REVIEW ...................................................................... 5

2.1 Introduction ........................................................................

2.2 Internal Mixing Atomization .................................................... 6

2.3 Flashing Atomization ............................................................. 10

2.4 Effervescent Atomization ......................................................... $\quad 12$

2.5 Correlations ........................................................................... 12

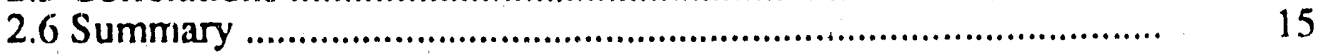

3 EXPERIMENTAL APPARATUS AND INSTRUMENTATION …................. 17

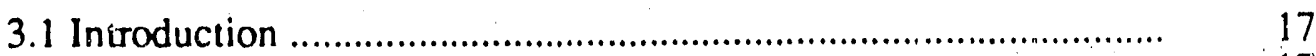

3.2 Atomizer Design ............................................................... 17

3.3 Air and Liquid Supply Systems ................................................ 20

3.4 Calibration of Instrumentation ................................................... 23

3.5 Particle Sizing Systems .............................................................. 24

3.5.1 Purdue Laser Diffraction System ............................. 25

3.5.2 Malvern Particle Sizing System ............................. 27

3.6 Photographes ............................................................................ 29

3.7 Shadowgraphes ................................................................... 29

3.8 Viscosity Measurements ........................................................... 30

3.9 Surface Tension Measurements ............................................... 32

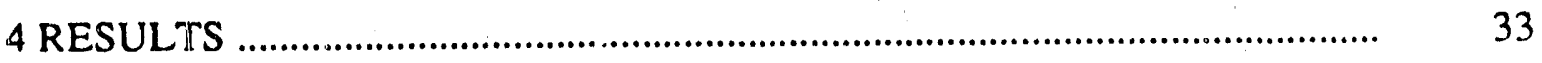

4.1 Introduction ........................................................................... 33

4.2 Fluid Physical Properties .................................................................

4.2.1 Single Phase Liquids .......................................... 35

4.2.2 Coal-Water Siurries .............................................. $\quad 37$

4.3 Newtonian Liquid Spray Data .................................................. 37

4.4 Non-Newtonian Spray Data ................................................... 41

4.5 Coal-Water Slurry Spray Data .................................................. 50

4.6 Summary ............................................................................. 55 


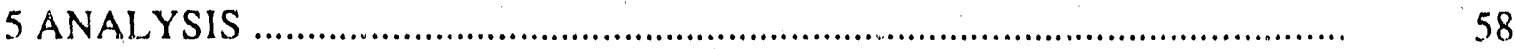

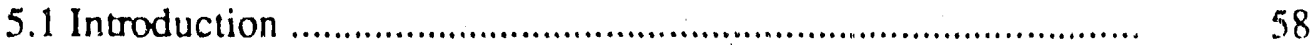

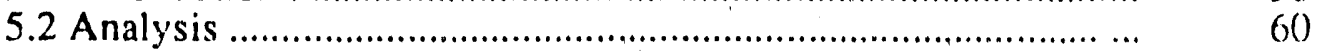

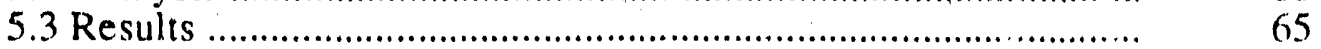

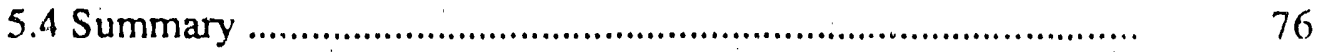

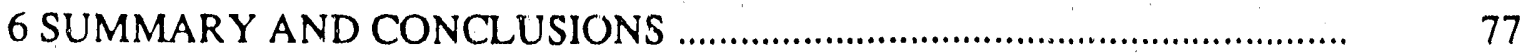

6.1 Summary ......................................................................... 77

6.2 Conclusions and Recommendations for Future Work .............. . 81

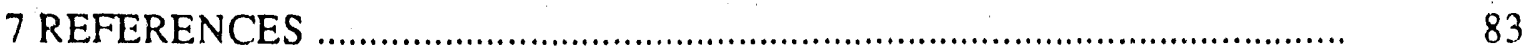




\section{LIST OF TABLES}

Table

1

2

3

4

1.

2

Glycerine-Water Mixture Physical Properties .

Page

Glycerine-Warer-Polymer Mixture Physical Properties 36 Coal-Water Slurry Physical Properties 37

Coefficients $A$ and $B$ for all fluids 66 


\section{LIST OF FIGURES}

Figures Page

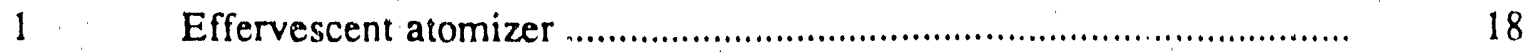

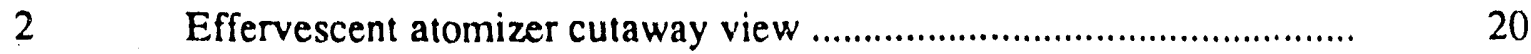

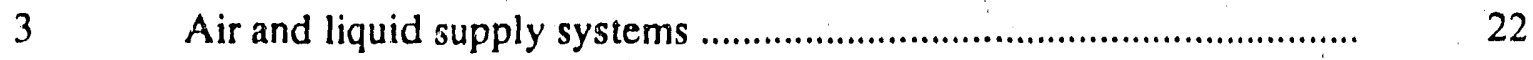

$4 \quad$ Purdue drop, size measurement system ........................................... 26

5 Schematic of the Malvern Particle Size Analyzer, Knoll [1989] ......... . 28

6 Sauter mean diameter versus air liquid ratio for glycerine-water mixture $6, K=400 c P$

Sauter mean diameter versus air liquid ratio for glycerine-water mixtures 2,4 , and 6 , varying $K$

Sauter mean diameter versus pressure for glycerine-water mixture 9 , $\mathrm{ALR}=0.340$

Sauter mean diameter versus pressure for glycerine-water mixture 9 , $\mathrm{ALR}=0.085$

10 Sauter mean diameter versus air liquid ratio for glycerine-waterpolymer mixture $6, \mathrm{~K}=850 \mathrm{cP}-\sec ^{\mathrm{n}-1}$

11 Sauter mean diameter versus air liquid ratio for glycerine-waterpolymer mixture $7, \mathrm{~K}=420 c P-\sec ^{n-1}$

12 Sauter mean diameter versus consistency index for mixtures 1,2 , and $3, \mathrm{P}=1.75 \mathrm{MPa}$

13 Sauter mean diameter versus consistency index for mixtures 7,8 , and $9, \mathrm{P}=1.4 \mathrm{MPa}$

14 Sauter mean diameter versus consistency index for mixtures 1, 2, and $3, \mathrm{P}=1.4 \mathrm{MPa}$

15 Sauter mean diameter versus consistency index for mixtures 1,2 , and $3, \mathrm{P}=1.05 \mathrm{MPa}$ 
16 Sauter mean diameter versus flow behavior index for mixtures 1,4 , and $7, \mathrm{P}=1.75 \mathrm{MPa}$.

17 Sauter mean diameter versus flow behavior index for mix ures 1,4 , and $7, \mathrm{P}=1.4 \mathrm{MPa}$.

18 Sauter mean diameter versus discharge pressure for mixtures 1,4 , and 7. $\mathrm{ALR}=0.344$

19 Sauter mean diameter versus discharge pressure for mixtures 1,4 , and $7, \mathrm{ALR}=0.255$

20 Sauter mean diameter versus discharge pressure for mixtures 1,4 , and $7, \mathrm{ALR}=0.170$

21 Sauter mean diameter versus discharge pressure for mixtures 1,4 , and $7, \mathrm{ALR}=0.085$

22 Sauter mean diameter versus discharge pressure for mixtures 1,4 , and $7, \mathrm{ALR}=0.043$

23 Sauter mean diameter versus air liquid ratio for slurries 1,2 , and $3 \ldots .$.

24 Sauter mean diameter versus air liquid ratio for slurry 3 undiluted, diluted with glycerine, and diluted with glycerine and polymer

Sauter mean diameter versus discharge pressure for slurry 1

Sauter mean diameter versus discharge pressure for slurry 2

Sauter mean diameter versus discharge pressure for slurry 3

Sauter mean diameter versus discharge pressure for slurry 3 diluted with glycerine

Sauter mean diameter versus discharge pressure for slurry 3 diluted with glycerine and polymer.

Illustration of the control volume considered in the analysis

Epsilon versus air liquid ratio for undiluted coal-water slumies 1, 2, and 3

32 Calculated Sauter mean diameter versus measured Sauter nean diameter for glycerine-water test 1 .

33 Calculated Sauter mean diameter versus measured Sauter mean diameter for the glycerine-water polymer fluids

Calculated Sauter mean diameter versus measured Sauter mean diameter for the undiluted coal-water slurries 
35 Calculated Sauter mean diameter versus Sauter mean diameter for the coal-water slurry diluted with glycerine

36 Calculated Sauter mean diameter versus Sauter mean diameter for the coal-water slurry diluted with glycerine and polymer

37 Calculated Sauter mean diameter versus Sauter mean diameter for coal-water slurry undiluted and diluted with glycerine

38 Calculated Sauter mean diameter versus measured Sauter mean diameter for water, Roesler [1988]

39 Epsilor versus air liquid ratio for data extracted from glycerine and water test 1

40 Epsilon versus air liquid ratio for water data extracted from Roesler [1988]

41 IEsilon versus air liquid ratio for combined glycerine and water test 1 data and that of Roesler [1988] 


\section{INTRODUCTION}

The need for cheap and plentiful energy has brought the United States to depend heavily on imports of petroleum products that are of limited supply and may soon be scarce and expensive. One energy source that is still plentiful in the United States, however, is coal but its use is severely limited since transport can be accomplished only by barge, train or truck. This eliminates the vast infrastructure of pipelines and tankers that already exist to transport liquid fuels such as petroleım. Another limitation is the difficulty in injecting coal into the gas turbine and internai combustion engines that provide a large percentage of the power used in this country.

One development with potential for making coal easier to use is coal-water slurry (CWS). By suspending microscopic coal particles in water or some other fluid the coal is "liquified" and can be easily transported thereby facilitating its use in pipelines, tankers and the combustion zones of gas turbine and internal combustion engines.

Unfortunatcly, the properties of CWS introduce another set of problems. Coalwater slurry is a highly viscous, non-Newtonian, two-phase fluid that sometimes contains polymers in order to maintain suspension of the coal particles. The theological properties and polymers make slurries iard to atomize, and the coal particles make it abrasive and prone to clogging orifices.

The difficulty in atomizing CWS exacerbates the problem of efficiently burning the fuel. Efficiency can be increased by exposing more surface area of the fuel to the hot combustion gases, but it is necessary to produce small drop sizes in onder to accomplish that goal.

The majority of atomizers are incapable of efficiently atomizing CWS since they are sensitive to slurry rheological properties. In order to overcome rheological effects, 
some atomizers require that the injection velocity be increased. This is often accomplished by raising injection pressure and decreasing orifice diameter. Increasing exit velocity is detrimental to nozzle operation since the abrasive effect of CWS increases. In addition, the probability of clogging increases with decreasing nozzle diameter. Other nozzles attempt to produce small drops by increasing the air liquid ratio (ALR). Increasing ALR is undesirable due to the increase in cost associated with pumping large volumes of air at high pressure.

In recent years, several techniques have been developed that have met with limited success when atomizing CWS. One technique, termed air assist atomization, uses high velocity air streams to shear the liquid and transform it into small drops. Another technique, termed flashing atomization, uses superheated liquid to generate bubbles that rapidly expand iminediately outside the nozzle. In both methods, energy in a high ptessure or high velocity gas is used to break the liquid into small droplets.

Air assist and flashing atomization do have drawbacks. Air assist atomization requires a substantial flow of high pressure air, often necessitating costly pumping equipment. Flashing atomization requires that nuclei be present in the liquid to ensure bubble formation and, in addition, the rate of bubble expansion is limited by mass transfer from the surrounding liquid. An alternative method of producing small mean drop size sprays is obviously desirable. Effervescent atomization is such a method.

Effervescent atomization is being developed at Purdue University. An effervescent atomizer combines air and a liquid inside a mixing tube such that a bubbly flow is created within the nozzle body. The two-phase flow exits the nozzle final orifice where the bubbles rapidly expand and shatter the liquid. The process is unique in that the nozzle creates and maintains a mixture such that the air is always in intimate contact with the liquid. 
Previous works have shown that effervescent atomization is not affected by changes in orifice diameter, solving the dilemma of clogging. They have also shown that quality atomization can be achieved with low injection pressures and low ALR thereby minimizing the energy required. Effervescent atomization possesses these advantages because the sonic velocity of the mixture decreases ciramatically as air is bubbled into the liquid with the result that choking occurs at the final exit orifice. Once the nozzle is thoked a nearly instantaneous pressure drop occurs across the orifice which in turn produces a rapid expansion of the gas and results in break up of the liquid. Fortunately, choking is not a function of the orifice diameter; therefore, spray quality is not a function of orifice diameter either. As a result, the nozzle final exit orifice can be made as large as necessary to eliminate clogging with no reduction in atomizer performance.

Despite the body of work describing the performance of effervescent atomizers, its potential for use with CWS had not been evaluated prior to this study. This program was therefor undertaken

- to demonstrate that effervescent atomizalion can produce CWS sprays with mean drop sizes below $50 \mu m$

- to determine a lower size limit for effervescent atomizer produced CWS sprays

- to determine the mechanism(s) responsible for the formation of effervescent atomizer produced sprays.

Application of effervescent atcmization to coal slumies requires an analysis of the effects of slurry rheological properties (as indicated by the consistency index and the flow behavior index) and formulation (in terms of loading and coal particle top size) on 
the spray formation process. This was accomplished in three steps. First, Newtonian liquids, derived from solutions of glycerine and water, were sprayed with Sauter mean diameter (SMD) measurements obtained at various nozzle pressures and ALR values. This provided information on the effect of consistency index (or viscosity). Next, SMD measurements of non-Newtonian liquids consisting of glycerine, water and polymer were acquired to assess the effect of flow behavior index. Finally, spray data for five coal water slurry mixtures was collected, again at varying nozzle pressures and ALR values. This provided information on the relationship between drop size and coal loading and top size.

The experimental data reported were then analyzed to explain the physical processes responsibie for spray formation. The analysis began by considering an energy balance across a control volume that extended from the nozzle exit plane to the line of spray measurement. The inlet conditions were calculated using two-phase flow techniques and the outlet conditions were calculated by using conservation of momentum and assuming that the final velocities of the air and liquid were equal. Entrainment was considered negligible and losses were accounted for by realizing that only a small fraction of the atomizing air participated in the spray formation process with the remainder passing through the control volume unperturbed.

The esults showed that effervescent nozzles effectively atomized CWS, as weil as Newtonian and non-Newtonian fluids, while eliminating clogging and erosion problems. In addition, effervescent atomization produced small CWS drop sizes at low discharge pressures and low values of ALR and was insensitive to changes in consistency index, flow behavior index, and loading and particle top size. The report ends with suggestions for future work. 


\section{LITERATURE REVIEW}

\subsection{Introduction}

The technique of effervescent atomization has been influenced by two methods of forming sprays, internal mixing atomization and flashing atomization. In each of these methods, a gas assists the liquid break up process with the energy stored in the gas used to increase the surface energy of the liquid, thereby transforming it into drops. Internal mixing atomizers commonly inject gas and liquid into a chamber where a two-phase bubbly or separated flow is produced. Flashing atonization uses bubbles generated by either flashing a superheated liquid or nucleation of a dissolved gas in the liquid.

Mixing of the two phases is critical for achieving good atomization. An even distribution of bubbles squeezes the liquid into a matrix of thin films or fragments that are easily broken apart. Flashing atomization accomplishes this goal through formation of numerous tiny bubbles. The small bubble size and high number density provide intimate contact between the vapor and the liquid, an arrangement important during the bubble expansion process if small drops are to be formed. In contrast, internal mixing atomizers do not provide good mixing and, as a result, alternating slugs of liquid and gas often exit the nozzle along with the air. The alternating slug geometry is less efficient at transforming the liquid into small drops.

Despite the potential for forming numerous small bubbles distributed uniformly throughout the fluid, flashing atomization also has disadvantages. In particular, it requires heating of the liquid thereby consuming large amounts of energy. In addition, it can cause plugging problems if the substance to be sprayed is prone to thermally induced decomposition. Heating is not required with internal mixing atomization. 
Effervescent atomization incorporates the virtues of both methods; it gives particular consideration to how the phases are mixed, but does not require heating to generate bubbles. Instead air is injected into the liquid as in an internal mixing atomizer, but the bubbles are made as small as possible and are maintained such that they spread the liquid matrix into numerous thin films as in a flashing atomizer. The resulting bubbly mixture exits the orifice where the expanding gas shatters the liquid in the same fashion as in tlashing atomization. The advantages of effervescent atomization are that it needs no nucleation sites to form bubbles and the flow at the exit orifice is choked. The latter leads to a nozzle whose performance is independent of its geometry.

\subsection{Internal Mixing Atomization}

Sakai et al. [1978] describe a nozzle where air and water are ducted into 2 large diameter mixing chamber in order to enhance the atomization quality. The two fluids enter parallel and on axis with the exit orifice and impinge on the wall over the orifice where chuming mixes them. A portion of the mixed fluid exits through the orifice and the remainder circulates inside the chamber. Sakai et al. suggest that internal mixing atomization can be used to atomize high viscosity fluids and slurries over a wide turn down ratio and suggest that the major obstacle in this technique is the mixing of the two phases.

The data of Sakai et al. is summarized by the correlation

$D_{32}=14.0 \cdot D_{n}^{0.75} \cdot A L R^{-0.75}$

where $D_{32}$ is the Sauter mean diameter, in microns, $D_{n}$ is the nozzle diameter, in mm, and ALR is the air-liquid ratio. Equation (1) indicates SMD decreases with increasing ALR and decriasing nozzle diameter. If the nozzle diameter is fixed at $2 \mathrm{~mm}$ and 
$A L R$ varied, it is found that $S M D=740 \mu \mathrm{m}$ when $A L R=0.01$ and $S M D=80 \mu \mathrm{m}$ when ALR increases to 0.2. Obviously, while SMD does decrease with increasing ALR, spray quality is very poor at low ALR. Surprisingly, the low ALR reported corresponds to the bubbly flow regime for this nozzle where mixing should be at its best and drop sizes should be small. In contrast, an effervescent atomizer operating under identical conditions does a much better job of breaking up the spray at low ALR. For example, Roesler [1988] showed effervescent atomization produces a spray of $35 \mu \mathrm{m}$ at an ALR of 0.01 using the same flow conditions and orifice geometry as Sakai et al. This discrepancy may result from the manner in which the internal mixing nozzle mixes the two fluids. According to Sakai et al., bubbly flow is generated in the mix. ing chamber at low ALR and a swirling action is generated on the sides of the mixing chamber; pockets form at the top of the mixing chamber as ALR is increased and the turbulent swirl eventually grows into large voids. It is possible that these voids, along with the swirl, produce areas of low velocity that cause small bubbles to coalesce into iarge bubbles, which are in tum less efficient in breaking up the liquid. Sakai et. al. made no mention of the size of the bubbles and do not clarify whether bubbly, slug or separated flow exits the nozzle. Bubble coalescence and impingement of the two streams on the orifice would inhibit the formation of the liquid matrix and resulting thin films that are important for producing quality atomization.

Another property of the design employed by Sakai et al. is the strong dependence of SMD on nozzie diameter. Sauter mean diameter changes by $300 \mu \mathrm{m}$ when orifice diameter is changed from 1 to $2 \mathrm{~mm}$ and ALR is held constant at 0.01 . In flashing atomization studies under conditions of bubbly flow similar to those of Sakai et al., there was no dependence on nozzle diameter. The same is true for effervescent atomizers. The dependence of SMD on nozzle geometry is an obvious disadvantage 
of internal mixing atomizers when spraying fluids such as CWS that are prone to clogging small orifices.

Chawla [1985], described a two-phase atomizer that had limited success in atomizing water and coal-water slurry. The design incorporated a mixing chamber with a liquid inlet parallel and on axis with the nozzle exit orifice. The air was injected perpendicular to the axis of the nozzle and the two fluids were allowed to mix within the nozzle body.

Although the atomizer could spray slurries, it contained design flaws that prevented it from achieving the small mean drop sizes necessary for efficient coal burnout. The major flaw was swirl, introduced into the mixing chamber because the gas was injected tangential to the liquid flow. S wirl results in separated flow, a condition that is detrimental to the formation of the liquid matrix and resulting small mean drop sizes. A lesser flaw was the large quantity of air the nozzle consumed, a requirement that made it less efficient than an effervescent nozzle. For instance, ALR values as low as 0.004 produce drop sizes lower than $50 \mu \mathrm{m}$ when atomizing water with an effervescent atomizer while Chawla's design required an ALR of 0.016 to obtain the same mean drop size.

Regardless of the merits of Chawla's design, his paper did provide an important contribution: the realization that choking could occur at the nozzle exit when spraying a two-phase mixture since addition of even small amounts of gas to a liquid stream dramatically reduce the sonic velocity. Chawla recognized that this occurred and attributed the break up process to the pressure jump experienced at the choked orifice.

There is uncertainty as to the two-phase flow pattern existing in Chawla's nozzle. The most desirable situation is, of course, bubbly flow. However, calculation 
of void fraction values indicates they were above the limiting value of 0.8 for transition to annular flow. Further evidence for the existence of annular flow was supplied by Whitlow [1990], who studied a design similar to Chawla's where air was injected perpendicular to the axis to intentionally produce swirl. Under all flow conditions the swirling action produced a centrifuge effect that caused the air to migrate to the center line of the nozzle. The bubbly flow was transformed to annular flow with a jet of air flowing through the nozzle core. As a result of these two analyses, the flow in Chawla's nozzle was almost surely separated, and therefor outside the regime employed by effervescent atomizers.

Lefebvre et al. [1988] studied an internal mixing nozzle that was the preliminary work to effervescent atomization. The concept arose from an attempt to imitate flashing atomization by mixing nitrogen and water in a chamber that creates the bubbly flow found by Solomon et al. [1985], but without having to heat the fluid. The design used a drilled tube suspended in a mixing chamber to inject air outward into the liquid. The liquid was supposed to shear bubbles from the surface of the tube and form a two-phase flow.

Results of the study of Lefebvre et al. showed that SMD values as low as $42 \mu \mathrm{m}$ could be achieved at pressure differentials as low as $35 \mathrm{kPa}$. The effect of pressure was illustrated when SMD decreased to $20 \mu \mathrm{m}$ while the pressure increased to $635^{\circ}$ $\mathrm{kPa}$. This result is expected since the energy available for atomization increases with pressure.

Air-liquid ratio had a strong influence on atornization as well. Sauter mean diameters as low as $35 \mu \mathrm{m}$ were reported at ALR values above 0.10 and by decreasing ALR to 0.015, an SMD of $70 \mu m$ was achieved.

One weakness of the study of Lefebvre et al. was that the nozzle was opaque 
and the flow regime could not be ascertained. Unfortunately, subsequent work by Roosler and Lefebvre [1987] using a transparent nozzle demonstrated that some of the ALR values employed by Lefebvre et al. [1988] did indeed result in annular flow. This does not detract from the results of their study, however, which showed that excellent atomization could be obtained at very low pressures and ALR values when using effervescent atomization.

A study similar to that of Lefebrre et al. was reported by Wang et al. [1987] who modified the air injector to feed air from a single hole located on the axis of the nozzle final orifice. Their results demonstrated that the method of injecting gas had no significant effect on SMD.

\subsection{Flashing Atomization}

Flashing atomization is a technique where a spray is produced by transforming a portion of the liquid into vapor. The rapid expansion of the vapor imparts kinetic energy to the remaining liquid and shatters it into droplets. Flashing occurs when a superheated liquid suddenly experiences a drop in pressure to a value below saturation. This creates a non-equilibrium situation, and in order for the liquid to stabilize itself it gives off latent heat which forms vapor bubbles. Flashing also occurs when a gas and a liquid are mixed under great pressure allowing the gas to dissolve into the liquid. Subsequently, the gas comes out of solution after undergoing rapid decompression at the nozzle exit.

Several studies have been published describing flashing atomization. One of the first was by Brown and York [1962] where the authors atomized superheated water. Their results demonstrated that drop sizes smaller than $40 \mu \mathrm{m}$ could be achieved at pressures below those required to operate a pressure swirl nozzle. Photographs showed the liquid jet exiting the nozzle and suddenly bursting into droplets a short 
distance downstream of the final orifice, revealing the sudden and violent effect the expanding bubbles have on the jel.

Sher and Elata [1977] reported a flashing atomization study where a Freon-22 propellant and toluene mixture was atomized. The Freon propellant flashed and atomized the liquid toluene when the mixture passed through the final orifice. Sher and Elata noted the same explosive atomization process as Brown and York. In addition, their results showed that the spray mean diameter decreased with an increase in discharge pressure, but that this effect diminished with pressure until it disappeared completely. They also found that nozzle orifice size had no effect on mean drop size.

Solomon et al. [1985] discussed a design where air was dissolved into Jet-A fuel under high pressure. The resulting mixture was fed to a nozzle where it passed through an orifice and into an expansion chamber. As the air came out of solution, it formed a two-phase flow in the expansion chamber with the result that the mixture atomized upon exiting the final orifice. Solomon et al. found that the effect of dissolved air was negligible when the bubbles were not allowed to diffuse out of solution in the expansion chamber, but as more air diffused out, mean diameter decreased. This gave the nozzle the peculiar property that as discharge p essure decreased mean diameter decreased since more air diffused out as the pressuri was lowered. Solomon et al. also found that SMD values as low as $20 \mu \mathrm{m}$ could be achieved with a dissolved air content of $15 \%$ mole fraction and found that there was no dependence of SMD on nozzle diameter.

Consideration of the flashing atomization studies shows that drop sizes less than $50 \mu m$ could be achieved using this technique. Its drawbacks are the requirements of either a heating source or premixing of the gas with the liquid in order to generate the gas bubbles. Heating adds the additional problem of clogging since some fuels break 
down and coat supply lines and orifices; premixing gases with the liquid can be cumbersome and time consuming. As a result, neither flashing nor dissolved gas atomization has attracted much interest.

\subsection{Effervescent Atomization}

Roesler and Lefebvre [1987] were the first to investigate effervescent ntomization. They employed a design similar to that of Lefebvre et al. [1988] except that a sintered plastic acrator tube was used in place of the aerator tube containing drilled holes, water flowed inside the porous tube rather than outside, and air was injected toward the axis of the nozzle instead of away from it. The air was injected at low velocity, therefore requiring very little pressure drop in order to generate the bubbly flow. The results were very similar to those of Lefebvre et al. [1988] except that Roesler studied a lower range of ALR values, which corresponded to the bubbly flow region of operation.

The results showed that SMD was a strong function of pressure and ALR. Mean drop sizes of $80 \mu \mathrm{m}$, achievable at a pressure drop of $173 \mathrm{kPa}$ and an ALR of 0.01 , were reduced to $35 \mu \mathrm{m}$ when the pressure drop was increased to $690 \mathrm{kPa}$. Quality atomization was achieved over an ALR range of 0.001 to 0.025 with SMD changing from 100 to $25 \mu \mathrm{m}$ over this range.

\subsection{Correlations}

Many correlations describing SMD have been proposed witt. most investigators approaching the process by describing the break up of a viscous jet or sheet in a viscous medium. In such a model, shearing forces between the liquid and the surrounding air cause the liquid to become unstable and break up into ligaments which are then pulled into droplets by surface tension forces. This approach could not be applied to effervescent atomization, however, since it is not affected by fluid rheology, as will be 
shown in Section 4. Instead, the spray formation process was analy ${ }^{\text {red following }}$ Lefebvre [1990].

Lefebvre [1990] suggests an alternative approach to predicting SMD. He considers the break up of a liquid stream, either sheet or jet, to be caused by impingement of an air jet on the liquid at soine angle in order to impart a significant normal force on it. He argues that the break up mechanism shifts from wavy sheet to a momentum transfer due to collision of the air and liquid jets as the air jet impinges normal to the liquid stream. The break up process is then considered to be controlled by the norma! component of the air velocity, the air-liquid ratio and the surface tension of the liquid.

The analysis begins by considering the energy required to overcome surface tension forces while transforming the liquid stream into droplets. The change in energy of the liquid is the product of its surface tension and the change in surface area, as represented by Equation (2):

$E_{L}=2 \cdot \sigma \cdot \frac{m_{l}}{\rho_{l}} \cdot\left(\frac{3}{D}-\frac{1}{t}\right)$

where $A_{L 1}$ is the surface area of the liquid sheet and $A_{L 2}$ is the surface area of the droplets as given by

$$
\begin{aligned}
& A_{L 1}=2 \frac{m_{L}}{\rho_{L} t} \\
& A_{L 2}=6 \frac{m_{L}}{\rho_{L} D}
\end{aligned}
$$


Here, $t$ is the liquid sheet thickness, $m_{L}$ is the liquid mass, $D$ is the droplet mean diameter, $E_{L}$ is the change in surface energy of the liquid, $\rho_{L}$ is the liquid density, and $\sigma$ is the liquid surface tension. The energy of the air is now taken into consideration and is equal to

$E_{a}=m_{A} \cdot \frac{V_{a}^{2}}{2}$

where $V_{A}$ is the air velocity, $E_{A}$ ir the air kinetic energy, and $m_{A}$ is the air mass.

By equating the energy required for atomization and the energy of the air times the efficiency of the atomization process

$E_{L}=C \cdot E_{\Lambda}$

it is found that

$S M D=3 \cdot\left(\frac{1}{1}+\frac{C \rho_{L} V_{a}^{2} A L R}{4 \sigma}\right)^{-1}$

where C represents the efficiency of the process. Lefebvre [1990] altered this expression by first substituting $\left(1+\frac{1}{N R}\right)^{-1}$ for ALR, since studies have shown that SMD for prefilming air blast atomizers is proportional to (1+1/ALR), and then substituting $C^{\prime}$ for $C$. This suggests that $C$ is a function of ALR and can be expressed as

$C=\frac{C^{\prime}}{A L R+1}$

The resulting expression 
$S M D=3 \cdot\left(\frac{1}{t}+\frac{C^{\prime} P_{L} V_{a}^{2}}{4 \sigma\left(1+\frac{1}{A L R}\right)}\right)^{-1}$

fits his data very well and shows great promise when correlating data for various types of atomizers.

\subsection{Summary}

In summary, flashing atomization has the detrimental quality of requiring a heat source or a mixing tank where a gas can be dissolved into the liquid. Heating the liquid not only consumes energy but can cause clogging problems. Furthermore, the mixing tank is cumbersome and requires high pressures, often for extended periods of time.

Internal mixing atomization circumvents these problems by mixing the air and liquid in a region just prior to the orifice so that dissolution is not necessary. But internal mixing atomizers have the disadvantage of poor mixing such that separated or annular flow is often the result.

Effervescent atomization incorporates the beneficial qualities of flashing atomization, where a matrix of bubbles under pressure is used to spread the liquid into thin sheets and then blast it into droplets in an explosive expansion process. The force on the liquid created by the expansion is responsible for the atomization quality; therefore, it is imperative that the flow not be separated. Effervescent atomization mixes a gas and liquid in such a manner as to sustain a well mixed flow that atomizes in the same manner as tlashing atomization, but without the need for a heat source or a mixing tank.

Finally, effervescent atomization allows SMD values of $40 \mu \mathrm{m}$ to be achieved at 
ALR values lower than 0.01 and pressures under $100 \mathrm{kPa}$. In addition, spray quality is unaffected by nozzle diameter and liquid viscosity making it an attractive method of atomizing CWS. 


\section{EXPERIMENTAL APPARATUS AND INSTRUMENTATION}

\subsection{Introduction}

This section explains in detail the design and operation of the atomizer and experimental apparatus as well as the operation and calibration of the instrumentation used to acquire data. The description of the nozzle begins at the liquid and air inlets and proceeds to the final orifice. It includes descriptions of the various components and the flow path of the fluids. The description of the experimental apparatus begins with the air and liquid supply systems and ends at the nozzle inlets. The systems used to analyze the spray are then described and the theory behind their operation summarized. This is followed by a description of the equipment used to determine the properties of the test liquids. Equipment calibration procedures are also included.

\subsection{Atomizer Design}

The effervescent atomizer employed in this study is illustrated in Figure 1. Two primary requirements were established that constrained the design: the nozzle had to withstand $3.4 \mathrm{MPa}$ in order to achieve the maximum flow rates allc:vable, and the two-phase flow within the nozzle had to be observable and photographable. Both requirements were met by using glass and acrylic to construct portions of the nozzle.

The acrylic containment tube, with a wall thickness of $6.4 \mathrm{~mm}$, inner diameter of $25 \mathrm{~mm}$ and length of $300 \mathrm{~mm}$, served a dual role: it acted as a reservoir for the liquid and carried the pressure load produced by the $3.4 \mathrm{MPa}$ air supply. By pressurizing the liquid within the acry:ic shell, the intemal parts were relieved of the pressure load. O-ring groves cut into the top and bottom provided high pressure seals at the joints.

The mixing chamber was the most significant nozzle element. It consisted of a plenum, termed the aerator shell, surrounding a porous plastic aerator tube which in turn served as the mixing zone. The aerator shell was made of brass since it had to 


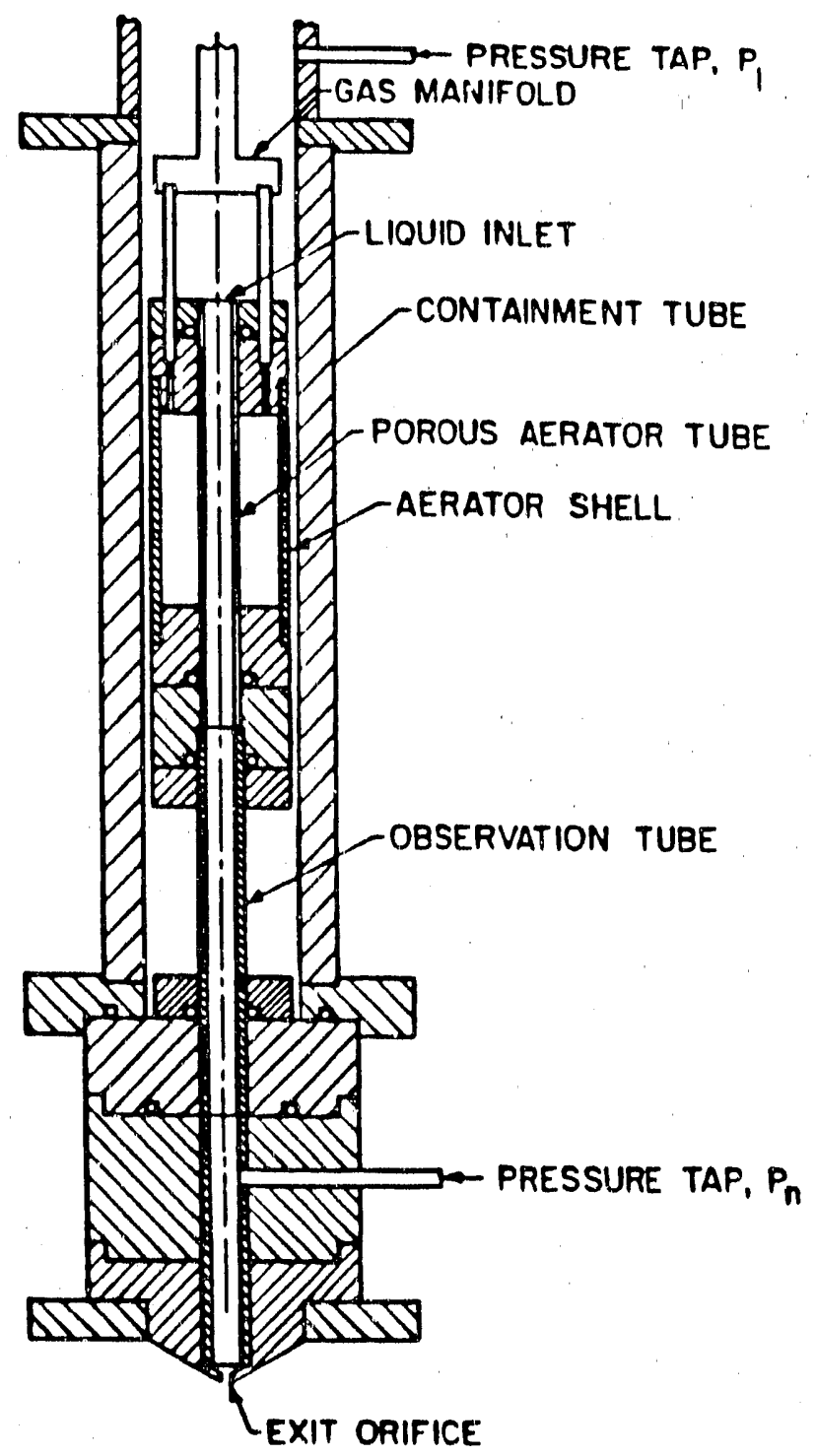

Figure 1. Effervescent atomizer.

withstand the sudden shock of high pressure air entering the mixing chamber during stait up. Air was supplied to the plenum through a stainless steel tee-shaped gas manifold and two short lines.

A glass observation tube followed the mixing zone to provide easy viewing of 
the two-phase flow. The tube was $5 \mathrm{~mm}$ in diameter and $82 \mathrm{~mm}$ long. The glass tube was replaced with one made of stainless steel when spraying coal-water slurry.

A multipurpose spool section, made of brass, was located between the observation tube and the exit orifice. This component was origina!ly designed to position an electronic bubble probe within the flow. The bubble probe was omitted during this study so the attachment served instead as a pressure tap, allowing accurate measurement of the static pressure immediately upstream of the exit orifice.

Two brass nozzle final orifices were used in this study. Both were of the sharp edged plain orifice type, one having an inner diameter of $1.5 \mathrm{~mm}$ and the other an inner diameter of $2.5 \mathrm{~mm}$. The $1.5 \mathrm{~mm}$ orifice was used exclusively with the Newtonian fluids and the single phase non-Newtonian fluids. The $2.5 \mathrm{~mm}$ orifice was used when atomizing coal-water slurries in order to avoid plugging.

The nozzle operated by spilling liquid into the acrylic containment tube through a port $430 \mathrm{~mm}$ upstream. As shown in Figure 2, the liquid collected in the containment tube, filling it until it reached a level such that it would flow into the inlet of the porous aerator tube. The air flowed into the aerator shell, then through the porous plastic aerator tube where it mixed with the liquid flow. Finally, the two-phase mixture flowed through the clear glass observation tube, shown in Figure 1, and then through the exit orifice where it formed the spray.

During operation, it was often important to determine the two-phase flow pattern exiting the nozzle. As a result, an acrylic exit orifice was substituted for the brass exit orifice shown in Figure 1. The channel leading to this orifice consisted of a $5 \mathrm{~mm}$ diameter bore that was $25 \mathrm{~mm}$ long and terminated with a $1.5 \mathrm{~mm}$ diameter orifice. Two parallel outer surfaces were milled flat to minimize visual distortion of the flow inside the channel. 


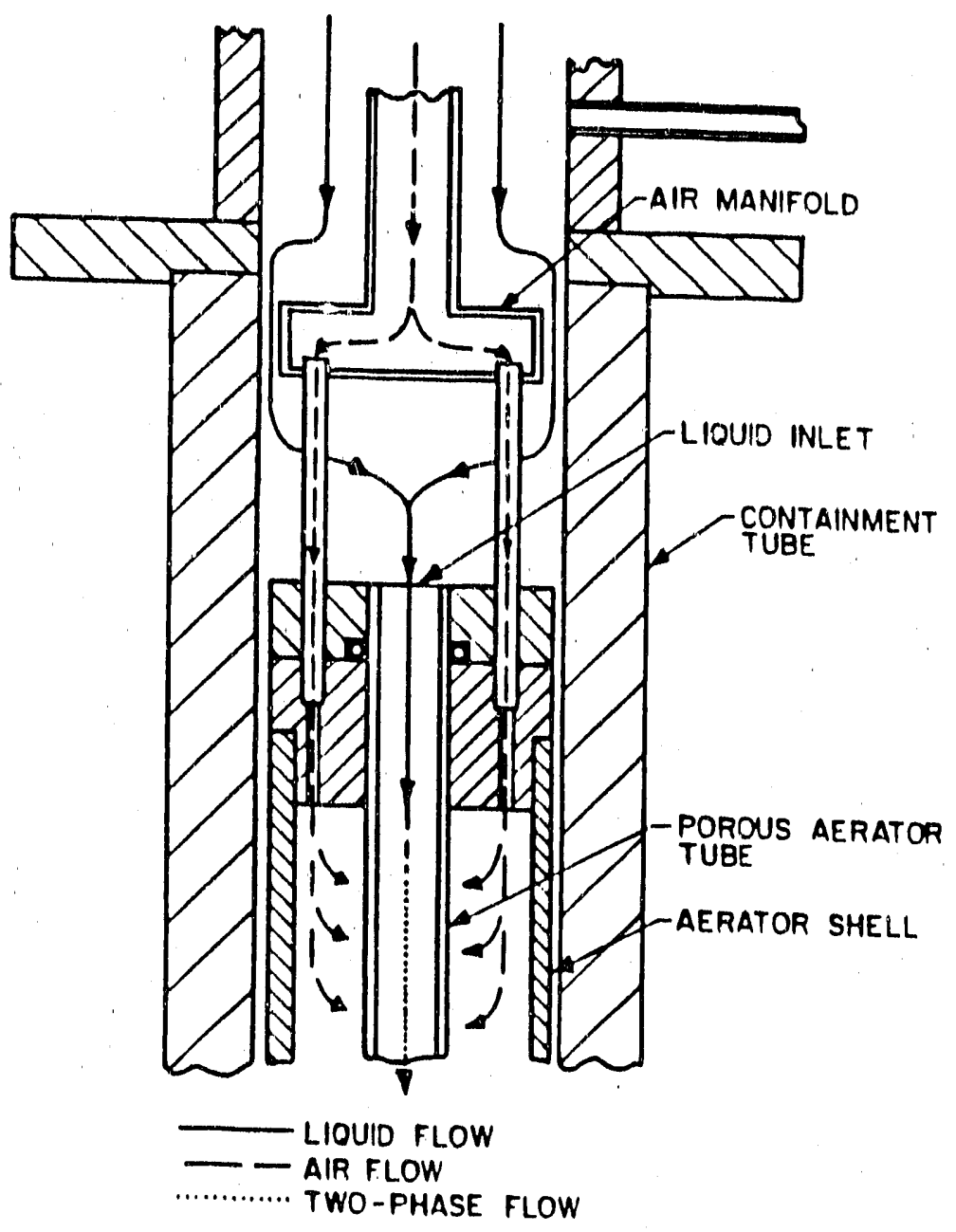

Figure 2. Effervescent atomizer cutaway view.

\subsection{Air and Liquid Supply Systems}

The separate air and liquid supply systems are shown in Figure 3. Stainless steel tubing and flex line were used throughout. Air from the $13.7 \mathrm{MPa}$ facility supply was regulated to $3.4 \mathrm{MPa}$ and provided atomizing air plus air to pressurize the free surface of the liquid storage reservoir that was used during the single phase Newtonian and non-Newtonian fluid studies. The atomizing air passed through a three-way valve which diverted it through one of two rotameter mass flow rate monitors (Brooks). 
The configuration of the rotameters was chosen to allow accurate flow measurements in a low flow regime (0 to $1.44 \mathrm{~g} / \mathrm{s})$ and a high flow regime $(1.22$ to $7.6 \mathrm{~g} / \mathrm{s})$. The low range flow meter incorporated a tube (Brooks model R-2-15-C) with a tantalum ball while the high range meter incorporated a tube (Brooks model 8M-25-3) with a stainless steel float. Air exited the rotameters past a dial pressure gauge (Duragauge) and flowed through a pair of needle valves arranged in parallel. These valves controlled the atomizing air mass flow rate and were located downstream of the rotameters to eliminate errors due to changes in air pressure and temperature. Air flowed through the needle valves and then passed through a ball type shut off valve before finally entering the tee-shaped manifold located in the nozzle body.

Liquid was stored in an 83 liter stainless steel pressure vessel when atomizing the Newtonian and the single phase non-Newtonian fluids. As mentioned in the previous paragraph, the liquid free surface was pressurized to $3.4 \mathrm{MPa}$ which forced it through the liquid delivery system. This configuration also had the advantage that unsteady flows and vibrations associated with mechanical pumps were eliminated. After leaving the reservoir, the liquid flowed through two parallel needle valves which served to control the flow rate. Liquid then passed though a Micromotion mass flow meter (model D-25) and a ball type shut off valve before finally entering the nozzle via the liquid supply tube.

When coal-water slurry was sprayed, the 83 liter stainless steel sphere shown in Figure 3 was removed and replaced with a standard 208 liter storage drum whose outlet was connected to a nine-stage progressive cavity pump (Moyno mndel 9P3CDQ). The pump drew slurry from the drum and forced it through a pair of ball valves arranged in parallel, one serving the nozzle and the other serving a closed loop return to the pump inlet. Small changes in mass flow rate were realized by manipulating 
these valves. Large changes in flow rate were realized by increasing the pump drive speed. The flow rate was measured by a Micromotion flow meter (model D-25) positioned upstream of the nozzle liquid supply tube.

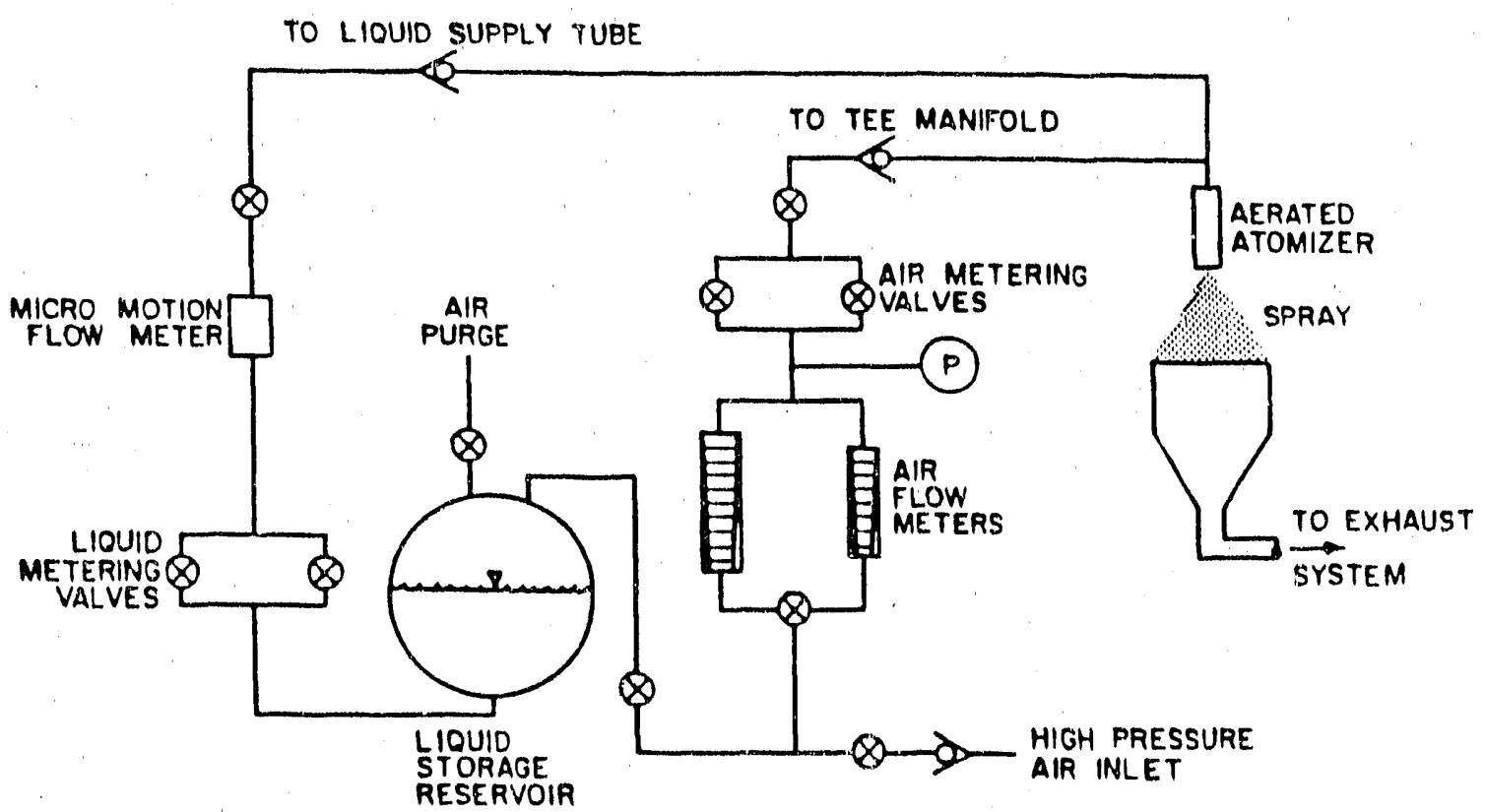

Figure 3. Air ald liquid supply systems.

When spraying single phase liquids, spent fluid was removed via an evacuation system consisting of a $270 \mathrm{~mm}$ diameter conical collection funnel, a section of 100 Inm diameter PVC tubing and a pair of $1.7 \mathrm{~kW}$ (Craftsman) vacuum cleaners. The 
flow rate through the evacuation system was approximately the volume flow rate exiting the nozzle, thus reducing droplet recirculation.

The nozzle assembly during the coal slurry part of this study was suspended over a $102 \mathrm{~cm}$ wide, $65 \mathrm{~cm}$ high, $153 \mathrm{~cm}$ long aluminum spray box by a frame (Unistrut). The box served as a collection vessel. Spray recirculation was minimized by exhausting the atomized fluid via a $61 \mathrm{~cm}$ by $63 \mathrm{~cm}$ rectangular duct and a centrifugal blower whose volume flow rate was sufficient to draw all the atomizing air out of the laboratory.

\subsection{Calibration of Instrumentation}

Calibrations were performed on the Micromotion flow meter and the rotameters. The Micromotion flow meter operates on the principle of Coriolis effects as noted in the Micromotion operations manual. To summarize, as fluid flows through the $U$ shaped tubing, Coriolis forces cause the tubing to twist. The magnitude of the displacement caused by the twisting motion is determined via Newton's second law and is insensitive to changes in temperature, pressure, and viscosity. The insensitivity of the device to fluid properties allows fluids other than those employed in the experiment to be used during calibration. This was verified by calibrating first with water, then recalibrating with air.

Calibration of the Micromotion was performed by collecting and timing tap water as it flowed through the device. The accumulated water was then weighed on a beam balance (Fairbanks Morse model 532) and the flow rate determined. Adjustment of the span and zero on the Micromotion A/D converter allowed the measured and predicted flow rates to be matched at high, moderate and low values. After calibration, the Micromotion measured the flow rate with an accuracy of $\pm 0.1 \mathrm{~g} / \mathrm{s}$.

The rotameters measure flow rate in terms of the drag produced by the flow of a 
fluid past a float located in a tapered tube. Since drag depends on the density and viscosity of the fluid flowing past the float, it is sensitive to temperature and pressure; therefore, the rotameter must be calibrated at the temperature and pressure at which it is to be used. In addition, since viscosity is fluid dependent, rotameters must also be calibrated using fluid that is to be employed in the experiment.

The rotameter was calibrated by connecting it in series with a dry gas volume flow meter (American Meter DTM 115). Air pressurized to $3.4 \mathrm{MPa}$ was passed through the rotameter and then through the gas flow meter where time and volume displaced were measured. This procedure was performed on both rotameters for high, intermediate and low flow rates. The calibration proved to be linear and was fitted to the equation

$\dot{m}=A \cdot R+B$

where $A$ and $B$ are coefficients and $R$ is the scale reading. For the large flow meter $A$ $=0.145 \mathrm{~g} / \mathrm{s}$ and $\mathrm{B}=0.35 \mathrm{~g} / \mathrm{s}$ and for the small rolameter $\mathrm{A}=0.15 \mathrm{~g} / \mathrm{s}$ and $\mathrm{B}=0.0 \mathrm{~g} / \mathrm{s}$. In order to correct for errors in the measured flow rate due to slight changes in the system pressure, the flow rate was multiplied by the square root of the ratio of actual pressure to calibration pressure, as recommended by the rotameter manufacturer and verified by Roesler [1987].

All pressure gauges were dial type and were calibrated using a portable gauge tester (Ashcroft model 1305).

\subsection{Particle Sizing Systems}

Droplets of CWS consist of a multitude of coal particles suspended in water. When heated, the water evaporates leaving a non-spherical, opaque particle. The nonsphericity precludes the use of several types of particle sizing instruments, including 
the Phase-Doppler Particle Analyzer. Fortunately, forward diffraction instruments circumvent this problem since they do not require spherical particles in order to provide a measure of mean drop size and drop size distribution [Hirleman and Wittig, 1977]. Details of the theory underlying these instruments are outlined by Van de Hulst [1981] with a practical application discussed by Swithenbank et al. [1976].

This study employed two particle sizing systems: the Malvern Particle Analyzing System and a second system that was developed at the Purdue Thermal Sciences and Propulsion Center. Both are described in this section.

\subsubsection{Purdue Laser Diffraction System}

The diffraction based particle sizing instrument shown in Figure 4 was used to obtain spray drop sizes and is based on the Fraunhofer diffraction technique. This particular system was developed by Rizk and Lefebvre [1984] and modified by Roesler [1988]. It provided line-of-sight measurements of mean drop size and drop size distribution.

The instrument consisted of a He-Ne laser (Melles-Griot (05-LHR-151), whose output was mcihanically chopped (Stanford Research SR540) and then spatially filtered (Newport Research 900 assembly, $25 \mathrm{\mu m}$ pin-hole and 10X microscope objective). The beam was then collimated using a $25 \mathrm{~mm}$ diameter $\mathrm{f} / 4$ lens. The resulting $12 \mathrm{~mm}$ beam traversed the spray along a diameter where some of it was scattered. Scattered and unscattered light was collected by a $50 \mathrm{~mm}$ diameter $\mathrm{f} / 10$ lens and focused on a $5 \mathrm{\mu m}$ pin-hole. The coliecting lens was located not more than $500 \mathrm{~mm}$ from the most distant edge of the spray.

The scattered light energy profile collected by the lens was scanned horizontally in its Fourier transform plane using a photo-mulkiplier tube (EMI 9658R) that was attached to the $5 \mu \mathrm{m}$ pin-hole. The photo-multiplier tube (PMT) and 


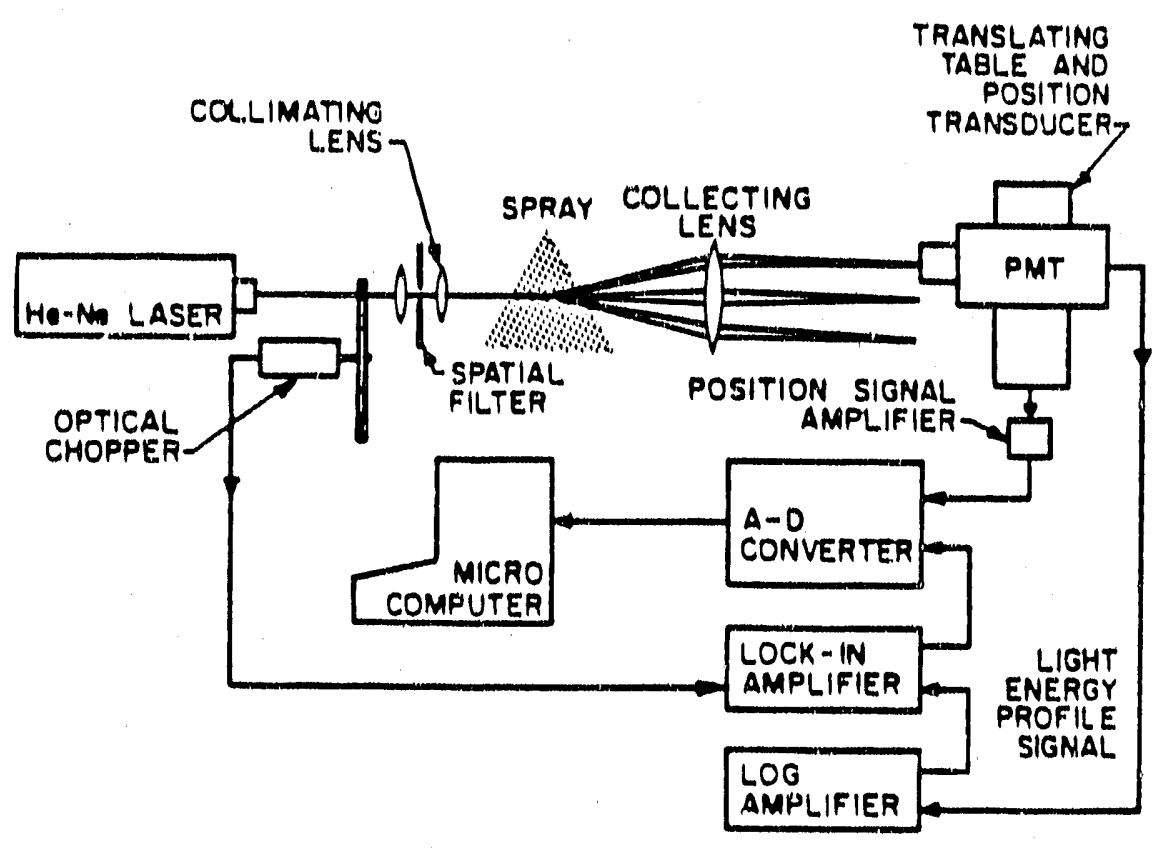

Figure 4. Purdue drop size measurement system.

pin-hole were mounted on a translation stage (Newport 430) whose position was monitored by a linear potentiometer. The PMT output signal was then amplified by an analog signal processor (Stanford Research SR235), with phase sensitive detection (Stanford Research SR510 lockin amplifier) employed to improve the signal-to-noise ratio. The amplified signal was processed using an $A / D$ converter (located in a Hewleti-Packard HP7090A Measurement Plotting System) and fed to a dedicated micro-computer (Zenith Z-158). The output from the position sensitive linear potentiometer located on the translation stage was also fed to the microcomputer. The computer reduced the data and determined Rosin-Rammler 
parameters using software developed by Roesler [1988].

A comparison of the diffraction system performance with that of the Malvern was made by Roesler and is outlined in his thesis [Roesler 1988], Roesler's proce. dure was as follows. First, the Purdue instrument was used to obtain drop size data from a water spray produced by a pressure swirl atomizer (Hago 15-80). The data was compared to drop size measurements made using the Malvern Spray Analyzer with the result that the Malvern consistently over predicted the value retumed by the Purdue instrument by approximately $10 \mu \mathrm{m}$. Second, theoretical light intensity profiles were generated and then reduced using the Purdue instrument software. Repeatability for the Purdue instrument was within $2 \%$ of the theoretical SMD and within $4 \%$ of the two Rosin-Rammler size distribution parameters. The Malvem, in contrast, could not approach the $2 \%$ repeatability of the Purdue system and repeatability became worse as the theoretical SMD exceeded $100 \mu \mathrm{m}$.

Instrument repeatability and day-to-day variation was determined using a standard calibration reticle [Hirleman 1983]. Repeatability and day-to-day variation were both $\pm 3 \mu \mathrm{m}$.

\subsubsection{Malvern Particle Sizing Systern}

As the study progressed, it became evident that scatter associated with the Purdue instrument was unacceptable in too many cases. The Malvern Spray Analyzer (model $2600 \mathrm{D}$ ), being able to provide more repeatable results, was ihus employed to alleviate this problem.

The Malvern, shown in Figure 5, operates on the sarne principle as the Purdue system with the myost significant difference being that the Malvern incorporates a circular photo-detector containing 32 diode rings to record the scattered 
light distribution. The Malvern also uses an additional diode, located at the center of the detector, to measure the amount of light being scattered thus providing an indication of when multiple scattering is occurring. The existence of multiple scaltering is important, as shown by Dodge [1986], since the measured value of the mean drop size begins to deviate substantially from the actual mean drop size when multiple scattering is preseni. A correlation was derived by Dodge to correct for this deviation. A similar correction scheme has been incorp rated into the Malvern software, but its details are obscure since the software is proprietary.

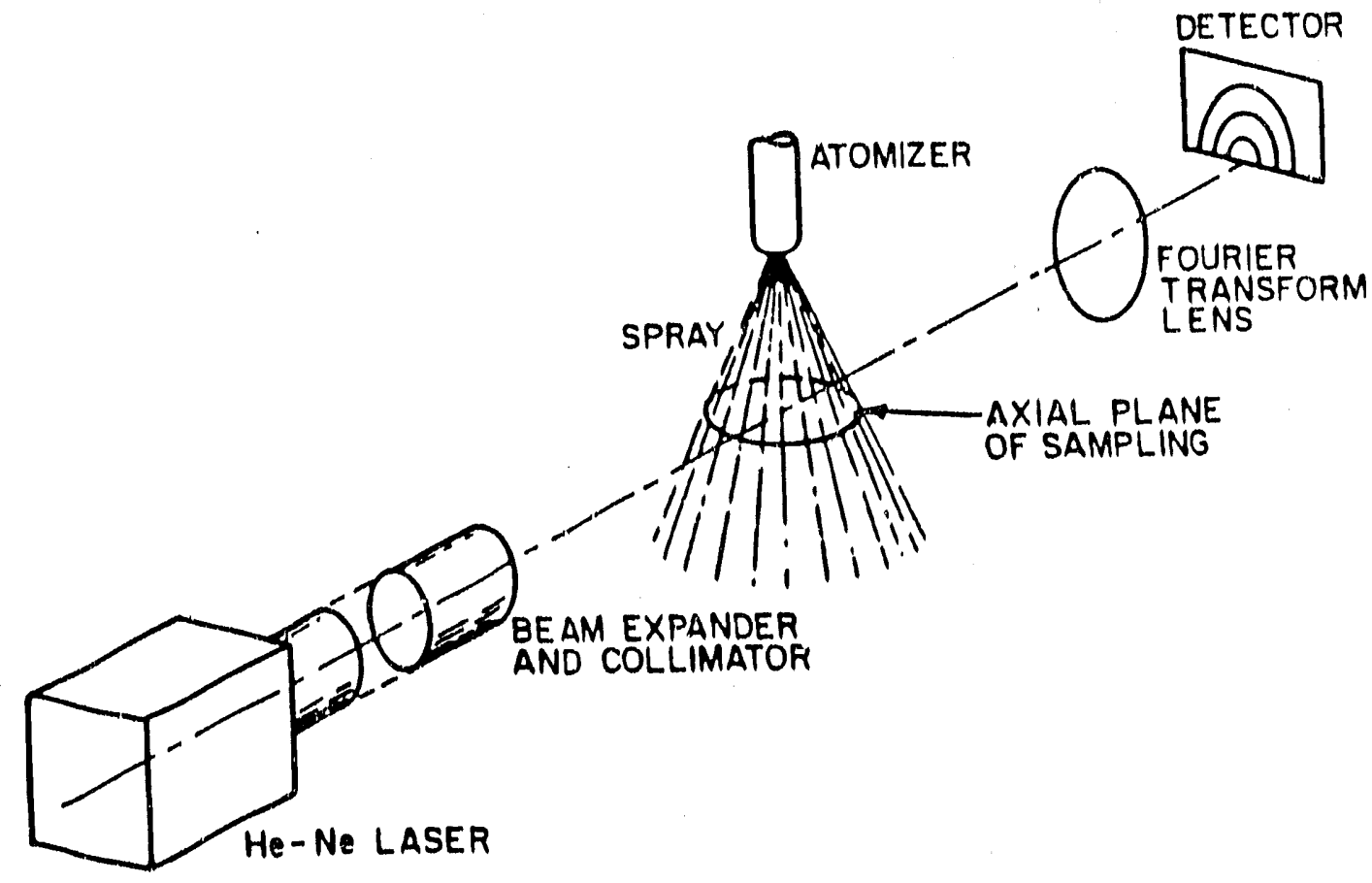

Figure 5. Schematic of the Malvern Particle Size Analyzer, Knoll [1989]. 


\subsection{Photographs}

A photographic study was undertaken to determine the flow structure in the nozzle and to photograph the formation of the spray in order to better understand the atomization process. Photographs of the flow structure in the nozzle were taken 30 $\mathrm{mm}$ upstream of the final orifice. Photographs of the spray formation process were taken immediately downstream of the final orifice, $150 \mathrm{~mm}$ downstream of the final orifice and $250 \mathrm{~mm}$ downstream of the final orifice.

Photographs were obtained using a $35 \mathrm{~mm}$ single lens reflex camera (Nikon F2) and a $135 \mathrm{~mm}$ lens (Nikkor-Q) mounted on a bellows (Nikon II). This combination of lens and camera allowed photographs to be made at a magnification of 2 . Images were recorded on black-and-white film (Kodak Tmax 400), push processed to ASA 3200). Illumination was provided by a micro-flash (EG\&G model 549 ) which had a flash duration of $0.5 \mu \mathrm{s}$. Further details are provided in Roesler's thesis [Roesler 1988].

\subsection{Shadowgraphs}

Shadowgraphs of the spray immediately downstream of the nozzle were obtained in order to record the density gradients produced when the flow underwent rapid expansion after exiting through the final orifice. The objective of these photographs was to verify the premise that supersonic flow was being generated at the nozzle exit, the information being necessary to determine if choked low existed.

Shadow photographs were obtained using a pair of $2.03 \mathrm{~m}$ radius of curvature, $254 \mathrm{~mm}$ diameter, parabolic, front silvered mirrors to collimate and then refocus the output from a high pressure mercury arc lamp. Images were recorded using the 35 $\mathrm{mm}$ single lens reflex camera mentioned above with film normally processed. "Further details of this system are provided by Richards [1987]. 


\subsection{Viscosity Measurements}

Newtonian liquids of high viscosity were formulated for use in this study by decanting a known volume of $99.5 \%$ pure natural glycerine (Van Waters \& Rogers, Industrial Grade USP) into a 114 liter drum and then diluting it with tap water until the desired composition was obtained. Homogeneity was insured by agitating the mixture with a three fin stirrer (Neptune Mixer Co. D-1.4 with MP1 $11 \times 11$ propeller driven by a Gast Manufacturing. Corp. 4AM-NRV-50C air motor). After complete mixing was obtained, the viscosity and surface tension were evaluated.

Non-Newtonian fluids were formulated from mixtures of glycerine, tap water, and Xanthan gum. The consistency index and the flow behavior index were altered by manipulating the glycerine and polymer levels. Experience indicated that the flow behavior index was relatively insensitive to the glycerine level, so this parameter was successfully altered by adding polymer. Conversely, the consistency index was sensitive to both polymer and glycerine content. By starting with a base mixture whose consistency index was significantly below the desired value, the target value was achieved by first adding polymer until the desired flow behavior index was reached and then adding glycerine until the consistency index rose to its target value.

An attempt was made to establish a protocol for formulating the non-Newtonian liquids, but large variations in the rheological properties were found with mixtures of the same polymer and glycerine content. As a result, the development of each mixture was more an than science, but each mixture was repeatedly tested before it was spayed in order to determine its rheological properties.

The coal-water slurries used consisted of three commercially available slurries of varying grinds and loadings. The effects of reduced coal loading and polymer addition were analyzed by diluting one slurry with glycerine and later diluting this 
same slumy with glycerine and polymer. A total of five separate fluids were thus employed.

Viscosity measurements were made using a rotary viscometer (Haake-Buchler RV20 with PG242 controller, PT100 digital thermometer, F3 temperature controller and associated constant temperature bath). A cup and rotor measuring system (Haake-Buchler MV SP) was employed. Three silicon based oils (polyDIMETHYLSILOXANE, Petrarch Systems Inc.) having viscosities of 10,100, and $1000 \mathrm{cS}$ were used to calibrate the rheological instrumentation. The procedure used was to calibrate the instrument over the entire strain rate range that was allowed by the fluid. The measured values fe!l within $20 \%$ of the standard with the percent error being constant for each fluid. After calibration, the viscosity of each fluid veing sprayed was determined by fitting the measured shear stress-strain rate curve to an assumed power law expression. This was accomplished by routing the analog output of the rheometer controller to the A/D converter with the resulting digitized signal input into the microcomputer for analysis.

The rheological data were reduced from 1000 to 200 points by combining thèm in groups of five and averaging. The data were then transformed into a pair of column vectors and analyzed using a curve fit analysis outlined in Chapra and Canale [1985]. The analysis fitted the data to the Hierschel-Bulkley viscosity model

$$
\tau=\tau_{s}+K \dot{\gamma}
$$


where $\tau$ is the shear stress in $\mathrm{Pa}, \tau$, is the yield stress in $\mathrm{Pa}, \dot{\gamma}$ is the shear rate in $1 / \mathrm{s}, \mathrm{K}$ is the consistency index in $\mathrm{Pa} \cdot s^{(1-n)}$, and $\mathrm{n}$ is the dimensionless flow behavior index. The advantage of using this model was that it accurately represented the rheological properties of the three classes of fluids used in this study.

The incorporation of the yield stress term in Equation (11) was necessary to minimize the error when curve-fiting the equation to the data. When the yield stress was not iliwaded, the curve-fit was forced to predict a zero shear stress at a zero strain rate which produced a poor fit. Unfortunately, the magnitude of the yield stress varied from one mixture to the next with no consistency between fluids. It was therefore concluded that the instrumentation could not accurately measure the yield stress, but that the analysis could not accurately predict $\mathrm{n}$ and $\mathrm{K}$ without it. As a result, yield stress values were used to facilitate curve fitting but were considered unreliable for analyzing the spray data.

\subsection{Surface Tension Measurements}

Surface tension was measured using a du-Nuoy type ring tensiometer (Cenco 70535). The tensiometer was calibrated by placing known weights (as determined by a Mettler P1200 balance) on the instrument's Pt-Ir ring and measuring the resulting gravitational force. The instrument's performance was verified by determining the surface tension of deionized water. Excellent agreement was observed as long as care was taken to keep the equipment clean. The following procedure proved satisfactory. After each measurement, the ring was washed in a water bath, dipped in alcohol, and heated thoroughly over a Bunsen burner flame and the vessel containing the test fluid was washed thoroughly with water and alcohol. 


\section{RESULTS}

\subsection{Introduction}

The goals of this research were to demonstrate that effervescent atomization can produce CWS sprays with mean drop sizes below $50 \mu \mathrm{m}$, to determine a lower size limit for effervescent atomizer produced CWS sprays, and to determine the mechanism(s) responsible for the formation of effervescent atomizer produced sprays. Accomplishment of these goals required an analysis of the effect of coal-water slurry fluid properties and nozzle operating parameters on spray quality, specifically on the Sauter mean diameter (SMD). The liquid properties necessary for the analysis consisted of flow behavior index $(\mathrm{n})$, consistency index $(\mathrm{K})$, slurry coal loading, coal farticle top size, the addition of polymers, surface tension and density. The flow behavior index and the consistency index were derived from the Herschel-Bulkley expression shown in Equation (11), and their effect on SMD was analyzed by manipulating them and observing changes in SMD. Coal loading was studied by diluting CWS with glycerine and top size was studied by analyzing three mixtures containing particles with maximum sizes of 15,45 and $100 \mathrm{l} \mathrm{m}$. Polymer addition effects were observed by analyzing a CWS mixture containing glycerine and polymer. Surface tension and density were measured for each test; however, they were not systematically changed in order to observe their influence on SMD.

The operating parameters of significance included the air-liquid ratio (ALR) and the nozzle discharge pressure. These parameters were systematically varied and their effects observed.

The study began with mixtures of glycerine and water to simplify the analysis, minimize the number of variables and facilitate data collection. Glycerine-water mixtures are highly viscous Newtonian fluids that have densities and surface tensions near 
those of CWS. By using these mixtures, the influence of flow behavior index and particle suspension were remoyed while viscosity (or consistency index) was widely varied.

Polymer was added to the glycerine-water mixtures in order to form non-Newtonian fluids and investigate the effects of $\mathrm{n}$ and $\mathrm{K}$ on SMD. The use of glycerine-waterpolymer mixtures is a common practice among those who study the atomization of CWS; note Knoll [1989] and Rosfjord [1985]. By dissolving Xanthan gum into the glycerine-water mixture, the flow behavior index was decreased thereby simulating the non-Newtonian behavior of CWS. These results completed the analysis of rheological effects on SMD while eliminating effects associated with coal particles.

Addition of polymer to the glycerine-water mixtures also provided insight into the effects of varying slumy additive packages since stabilizers such as "Flocon" contain substantial concentrations of polymer. The glycerine-water data is of special interest in this respect since it indicates how additives affect effervescent atomization in the absence of complicating effects such as slurry loading and coal particle top size.

The program concluded with the spraying of five coal-water slurries. Included were three commercially available slurries, each possessing a different coal loading and coal particle top size, plus two additional slurry mixtures formulated by adding glycerine, then glycerine plus polymer to one of the neat slurries. In this way, large changes in consistency index, flow bchavior index, loading, and coal particle size were achieved and their effects on SMD determined.

The results obtained are presented in the graphs below, with all raw data tabulated in the Appendix. In each figure, Sauter mean diameter is plotted versus one of the parameters mentioned above with the remaining parameters held within a defined range 
represented by a nominal value (values listed in subheadings and legends represent this nominal value). The ordinate of a plot represents actual values to provide a true representation of the data and an accurate determination of trends.

\subsection{Fluid Physical Properties}

Data describing the physical properties of the 24 different liquids sprayed during this study are reported in Tables 1 to 3 . These liquids consisted of glycerine-water solutions used to investigate Newtonian fluid behavior, glycerine-water-polymer (Xanthan gum) solutions used to investigate non-Newtonian fluid behavior and coal-water slurries used to investigate two-phase fluid behavior. The properties of relevance to this study were: consistency index, flow behavior index, particle top size, coal loading, surface tension and density.

\subsubsection{Single Phase Liquids}

Ten Newtonian liquids were tested. Their properties are listed in Table 1 and a marker is provided that denotes the test series each fluid was associated with. Viscosities for the Newtonian liquids varied from 384 to $968 \mathrm{cP}$. They were divided into 3 groups: $400 \mathrm{cP}, 520 \mathrm{cP}$ and $800 \mathrm{cP}$. These are nominal values used mainly to designate low, medium and high viscosity. Surface tension and density for all of the liquids was approximately 64 dynes $/ \mathrm{cm}$ and $1.26 \mathrm{~g} / \mathrm{cm}^{3}$, respectively, since glycerine content dominated these properties.

Table 2 lists the properties of the non-Newtonian liquids. Flow behavior indices varied from 0.85 to 0.95 . Consistency indices were approxı alately matched with the viscosities of the Newtonian mixtures and ranged from 400 to $930 c P-s^{n-1}$. 
Table 1: Glycerine-Water Mixture Physical Properties

$\begin{array}{lcccc}\text { Mixture } & \begin{array}{c}\mathrm{K}, \\ c P-\sec ^{n-1}\end{array} & \mathrm{n}, & \begin{array}{c}\sigma, \\ \text { dynes } / \mathrm{cm}\end{array} & \begin{array}{c}\rho, \\ \mathrm{g} / \mathrm{cm}^{3}\end{array} \\ 1 \text { (test 1) } & 384 & 1.0 & 64 & 1.26 \\ 2 \text { (test 1) } & 420 & 1.0 & 64 & 1.26 \\ 3(\text { test 1) } & 520 & 1.0 & 64 & 1.26 \\ 4(\text { test 1) } & 537 & 1.0 & 64 & 1.26 \\ 5(\text { test 1) } & 874 & 1.0 & 64 & 1.26 \\ 6(\text { test 1) } & 968 & 1.0 & 64 & 1.26 \\ 7 \text { (test 2) } & 487 & 1.0 & 64 & 1.26 \\ 8(\text { test 2) } & 586 & 1.0 & 64 & 1.26 \\ 9(\text { test 2) } & 800 & 1.0 & 64 & 1.26 \\ 10(\text { test 2) } & 852 & 1.0 & 64 & 1.26\end{array}$

Table 2: Glycerine-Water-Polymur Mixture Physical Properties

$\begin{array}{ccccc}\text { Mixture } & \begin{array}{c}\mathrm{K}, \\ c P-\mathrm{sec}^{\mathrm{n}-1}\end{array} & \mathrm{n}, & \begin{array}{c}\sigma, \\ \text { dynes } / \mathrm{cm}\end{array} & \begin{array}{c}\rho, \\ g / \mathrm{cm}^{3}\end{array} \\ 1 & 400 & 0.85 & 68 & 1.13 \\ 2 & 510 & 0.85 & 68 & 1.13 \\ 3 & 930 & 0.86 & 68 & 1.13 \\ 4 & 420 & 0.90 & 66 & 1.20 \\ 5 & 570 & 0.90 & 66 & 1.20 \\ 6 & 780 & 0.90 & 66 & 1.20 \\ 7 & 450 & 0.95 & 65 & 1.22 \\ 8 & 520 & 0.94 & 65 & 1.22 \\ 9 & 840 & 0.94 & 65 & 1.22\end{array}$




\subsubsection{Coal-Water Slurries}

A total of five coal-water slurries were sprayed during this study. Three of the slurries were commercially available and had varying grinds and loadings. They were identi-

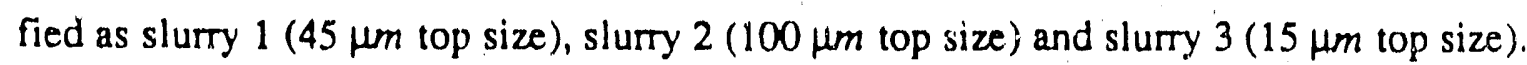
The other two slumies were derived from slurry 3 by either diluting it with $99.5 \%$ pure USP glycerine or with glycerine plus a polymer (Xanthan gum). The rheology of all five slurries, in terms of the consistency index, K, which ranged from 133 to 1964 $c P-\sec ^{n-1}$, and the flow behavior index, $n$, which ranged from 0.603 to 1.03 , is reported in Table 3. Slurry surface tension was measured and varied from 54 to 78 dyne $/ \mathrm{cm}$ as shown. Yield stresses were not reported since they were not used in any analysis and were therefore unimportant to the study.

Table 3: Coal-Water Slurry Physical Properties

$\begin{array}{ccccccc}\text { Slurry } & \begin{array}{c}\text { Top Size, } \\ \mu m\end{array} & \begin{array}{c}\text { Loading, } \\ \text { wt } \%\end{array} & \begin{array}{c}\mathrm{K}, \\ c P-\sec ^{n-1}\end{array} & \mathrm{n}, & \begin{array}{c}\sigma, \\ \text { dyne/cm }\end{array} & \begin{array}{c}\rho, \\ 8 / \mathrm{cm}^{3}\end{array} \\ 1 & 45 & 65 & 181 & 1.03 & 54 & 1.2 \\ 2 & 100 & 57 & 1777 & 0.603 & 78 & 1.2 \\ 3 & 15 & 58 & 1964 & 0.763 & 72 & 1.2 \\ 3+\text { gly } & 15 & 49 & 133 & 0.961 & 70 & 1.2 \\ 3+\text { gly+ply } & 15 & 49 & 630 & 0.878 & 71 & 1.2\end{array}$

\subsection{Newtonian Liquid Spray Data}

Two studies were undertaken using glycerine and water solutions. In the first study, six fluids were sprayed and drop size data were collected using the instrumentation described in Section 3.5.1. In the second study, the drop sizing instrumentation was 
changed to the Malvem and four additional fluids were sprayed with viscosities and flow conditions similar to those of the first study.

Spray data for the Newtonian fluids is shown below in Figures 6 through 9. Figure 6 shows air-liquid ratio has a significant effect on SMD over the range 0.04 to 0.15 . The influence diminishes, however, as ALR increases from 0.15 to 0.34 . This result is supported by the findings of Roesler [1988] and of Wang et al. [1987] and is explained by recognizing that entrainment losses become more severe as ALR is increased.

Figure 7 depicts the lack of an effect of consistency index (or viscosity for Newtonian fluids) on SMD where no correlation is observed for a two fold increase in $\mu$. This behavior is unique to effervescent atomization since most spray nozzles exhibit a significant dependence of SMD on viscosity. The absence of a relationship between SMD and viscosity is explained by considering the two mechanisms of liquid break up: shearing interaction between the liquid and the air, known as primary atomization, and competition between droplet surface tension and pressure forces caused by the velocity of the droplet relative to the air, known as secondary atomization. In general, liquid break up due to shearing action between fluids is a function of liquid viscosity. Effervescent atomization demonstrates no dependence of SMD on liquid viscosity; therefore, it is concluded that shearing action has no effect on the atomization process. However, the relative velocity between the droplets and air is very high which would produce large pressure forces on the droplets. This suggests that secondary atomization has a strong effect on the atomization process and is the controlling factor. This conclusion is supported by Brown and York [1962] who observed that the rapid expansion of vapor bubbles in flashing atomization tears the liquid into shreds much like the air bubbies of effervescent atomization. 


\section{Souter Mean Diameter versus Air/Liquid Rolio vorying Supply Pressure \\ $k=400$ op}

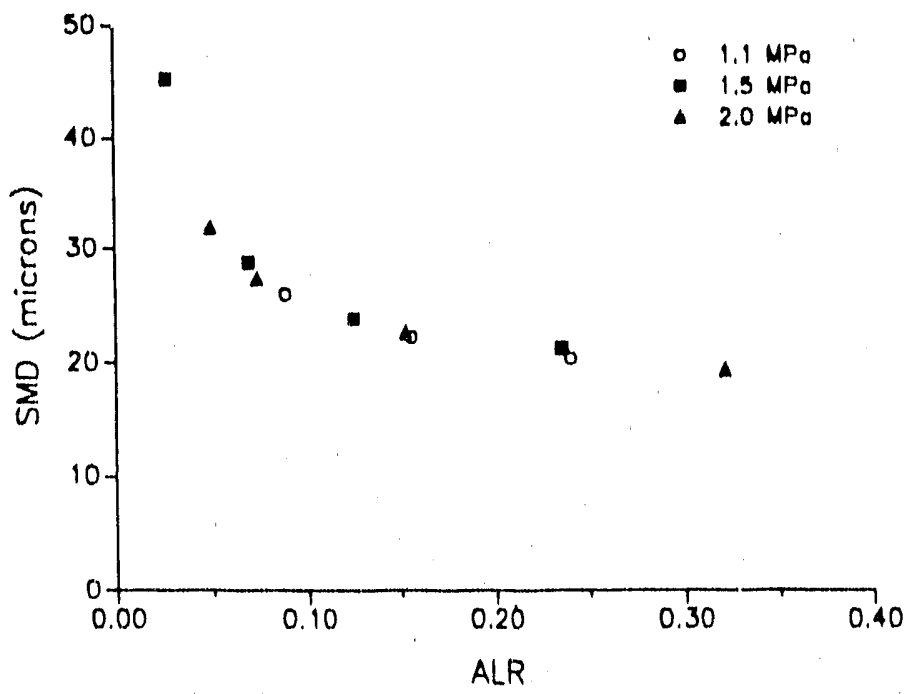

Figure 6. Sauter mean diameter versus air-liquid ratio for glycerine-water mixture $6, \mathrm{~K}=$ $400 \mathrm{cP}$.

Souter Mean Diameter versus Air/Liquid Ratio vorying Consistency Index

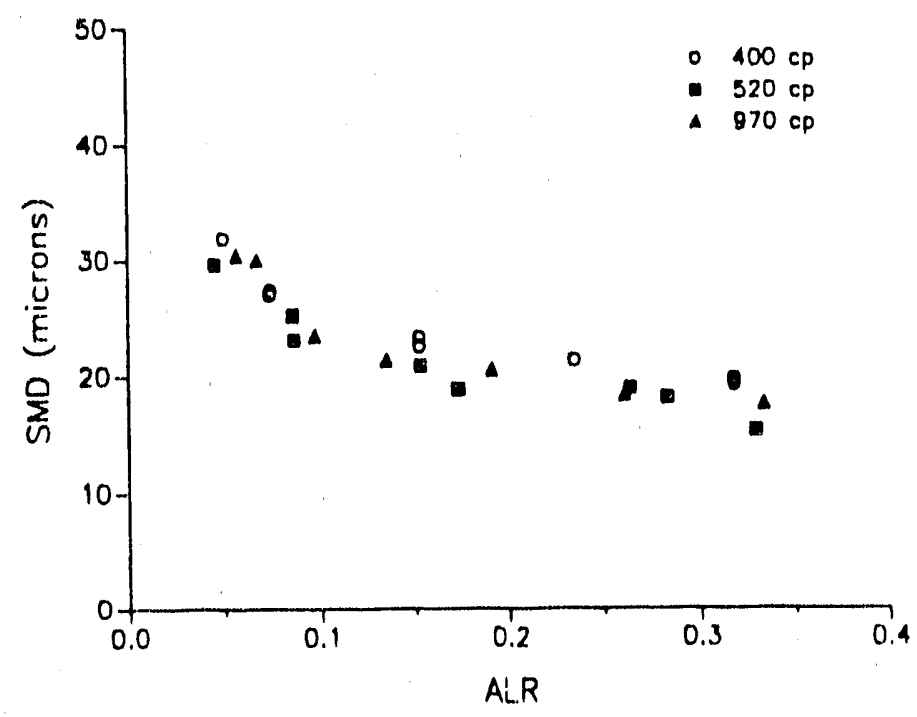

Figure 7. Sauter mean diameter versus air-liquid ratiu for glycerine-water mixtures 2,4 , and 6 , varying $K$. 
The effect of discharge pressure on SMD is shown in Figures 8 and 9. When ALR is as high as 0.34 , the effect of discharge pressure is very small. Notice that the profile in Figure 8 is flat over a pressure range of 1.1 to $2.4 \mathrm{MPa}$. This behavior changes when ALR is small; at an ALR of 0.085 , a change of $50 \mu \mathrm{m}$ is observed in Figure 9 when pressure changes from 0.75 to $1.5 \mathrm{MPa}$. The diminishing influence of pressure on SMD as ALR is increased was also observed by Roesler [1988] and Lefebvre et al. [1988] and can be explained by recognizing that at high ALR, energy losses associated with entrainment become so large that any increase in available energy associated with an increase in pressure is quickly lost to the ambient and has no effect on SMD. On the other hand, when ALR is low, a liquid shroud surrounds the expanding gas shielding it from entrainment and associated losses; therefore, increased energy input due to an increase in pressure is not lost to the ambient but contributes to liquid break up.

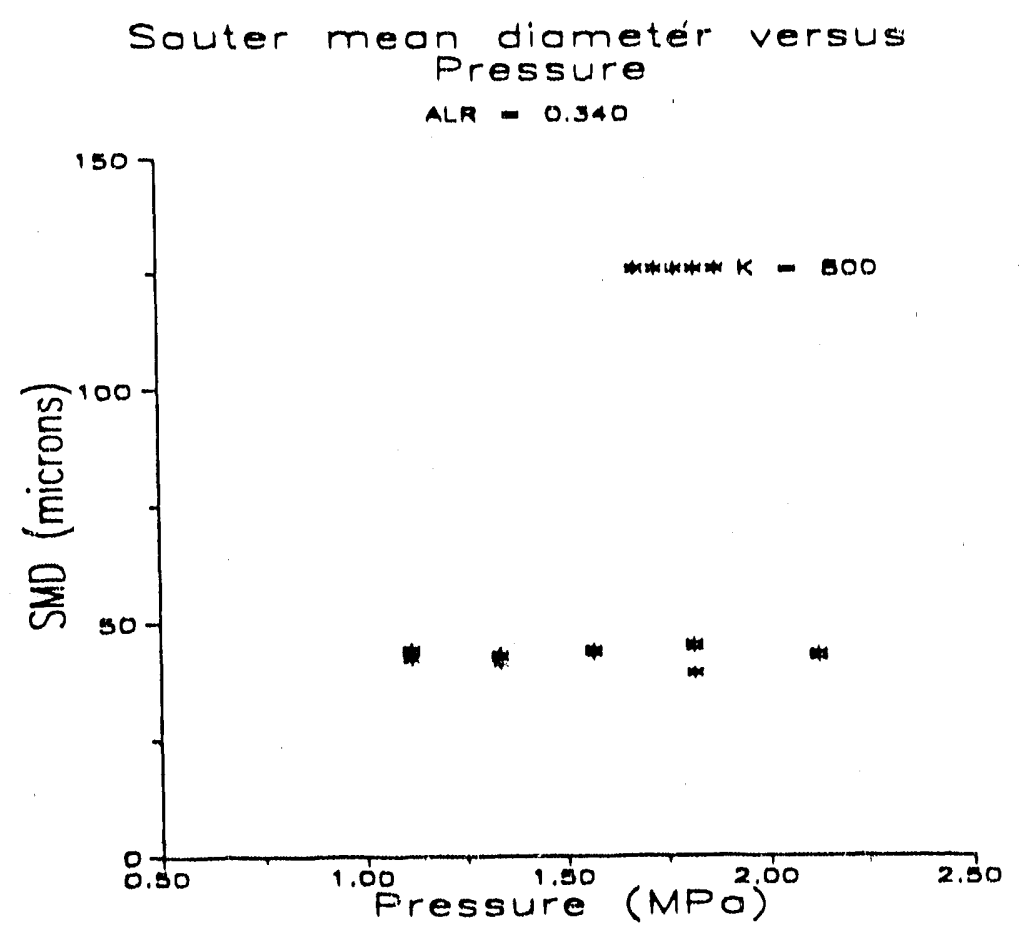

Figure 8. Sauter mean diameter versus pressure for glycerine-water mixture $9, A L R=$ 0.340 . 

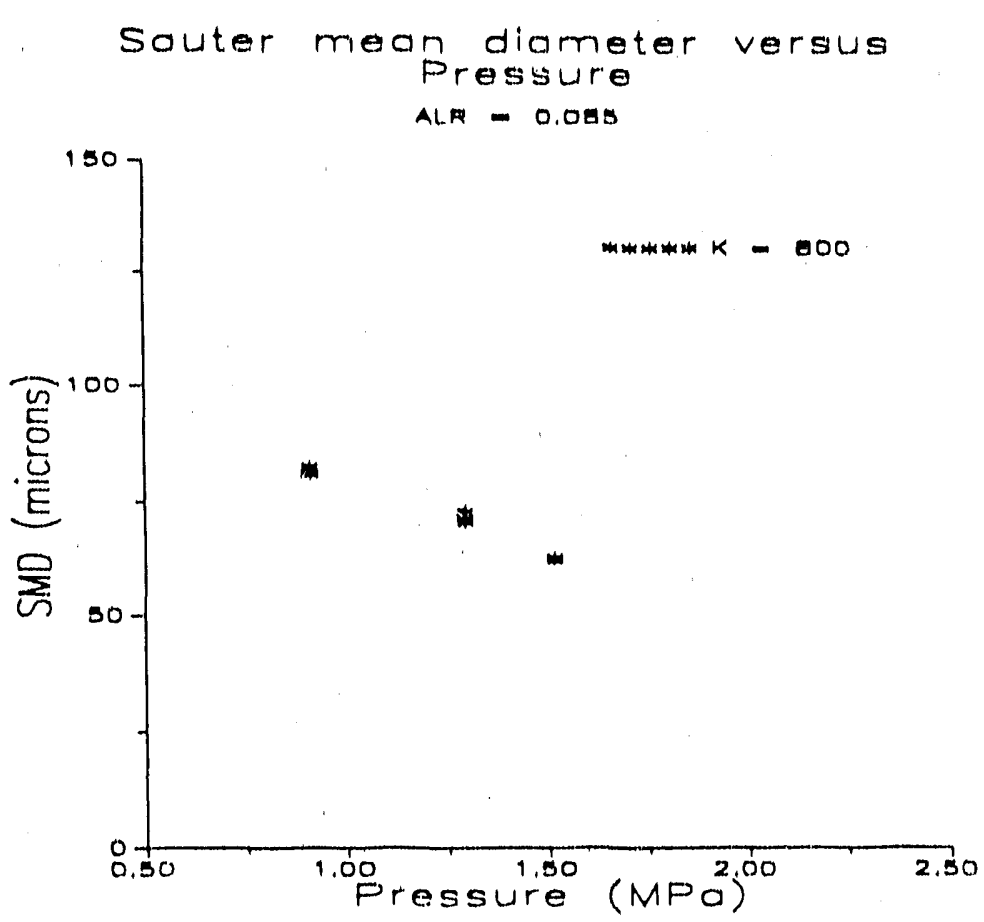

Figure 9. Sauter mean diameter versus pressure for glycerine-water mixture 9, ALR = 0.085 .

\subsection{Non-Newtonian Spray Data}

Figures 10 through 12 show data obtained when atomizing nine non-Newtonian glycerine-water-polymer solutions. The results of this study were similar to the Newtonian results previously shown.

The effect of ALR on SMD is shown in Figures 10 and 11 for $K$ values of 850 and $420 c P-\sec ^{n-1}$. There are only slight differences between these results and those shown in the preceding section: when atomizing solutions containing polymer, SMD increased, especially in the low ALR region. A change in ALR had a smaller effect on SMD in the low ALR range than for fluids containing no polymer, changing the slope of the SMD versus ALR curve, while at high ALR the polymer solutions atomize in the sarne manner as the non-polymer solutions. 


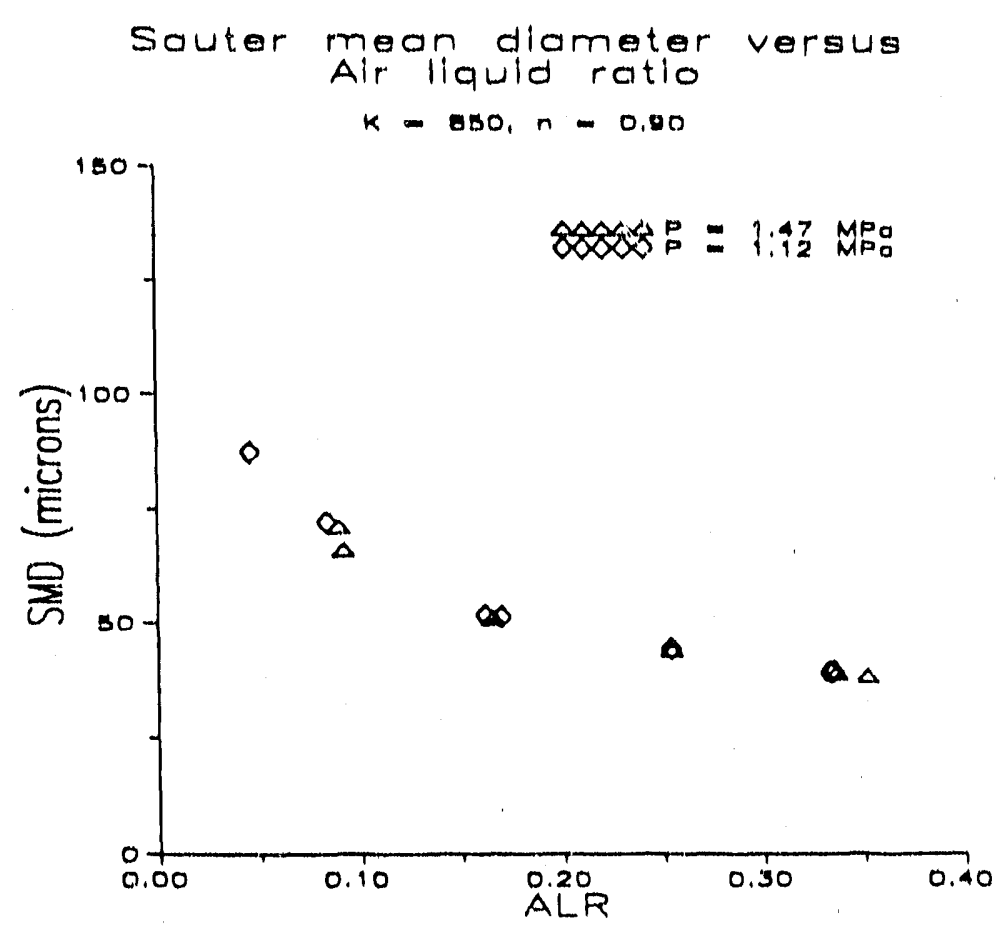

Figure 10. Sauter mean diameter versus air-liquid ratio for glycerine-water-polymer mixture 6, $K=850 c P-\sec ^{n-1}$.

Souter mean diorneter versus
Air liquid rotio

$k-420, n-0.05$

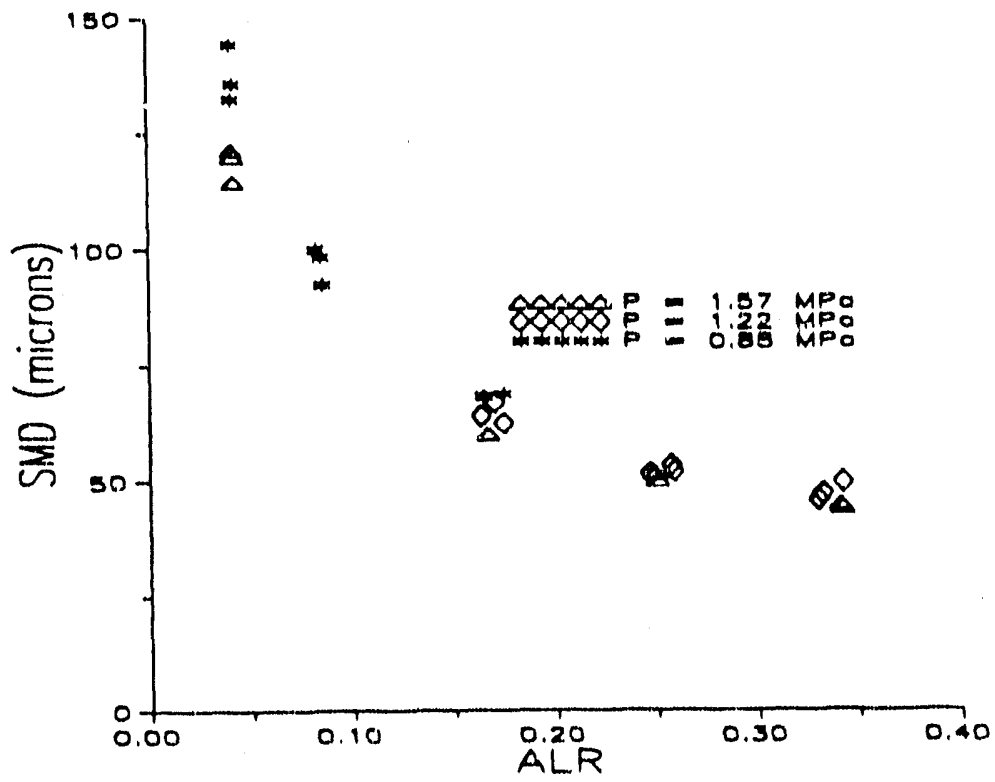

Figure 11. Sauter mean diameter versus air-liquid ratio for glycerine-water-polymer mixture $7, \mathrm{~K}=420 c P-\sec ^{n-1}$. 
Figures 12 through 15 show SMD versus consistency index and indicate no consistent change in SMD for a two fold increase in K. Similarly, no consistent effect of flow behavior index could be found as $n$ changed from 0.85 to 0.95 , as shown in Figures 16 and 17. These results conclusively demonstrate that non-Newtonian rheology, as characterized by $n$ and $K$, has no effect on the quality of effervescent atomization. This is evidence that effervescent atomization is not controlled by fluid mechanic instabilities, but is instead dominated by secondary atomization.
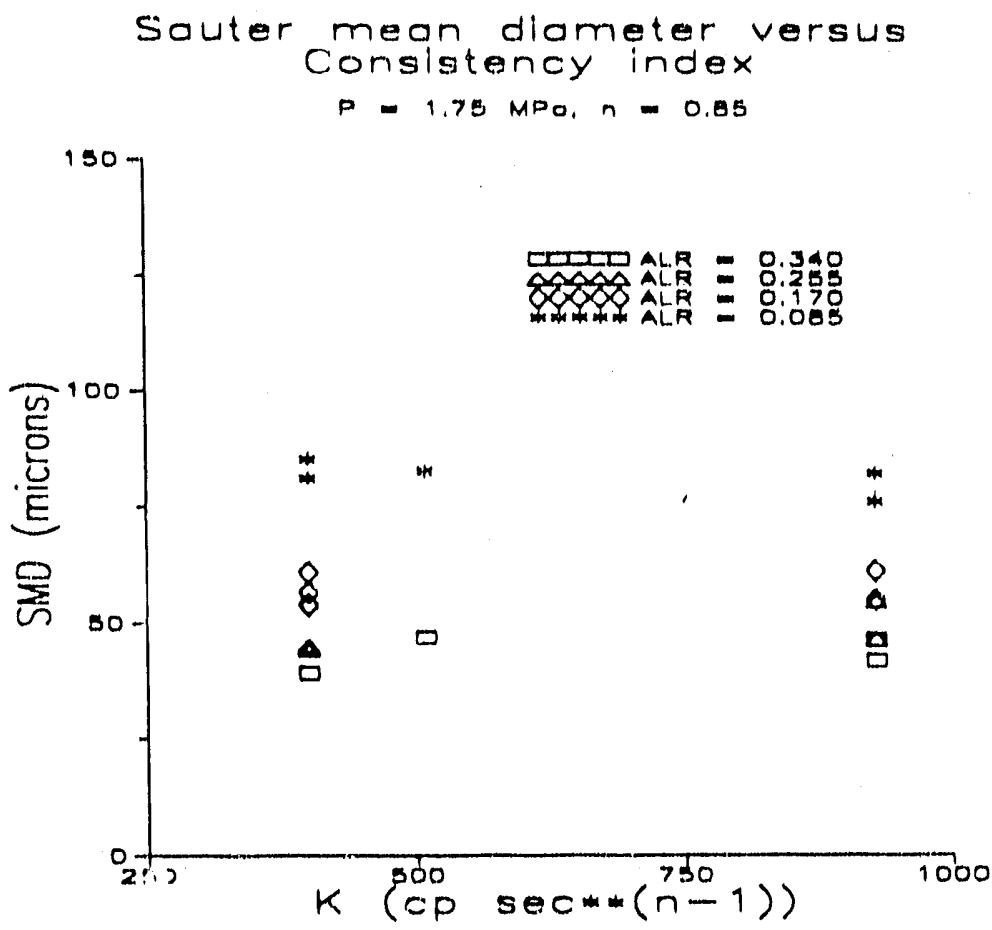

Figure 12. Sauter mean diameter versus consistency index for mixtures 1,2 , and $3, P=$ $1.75 \mathrm{MPa}$. 


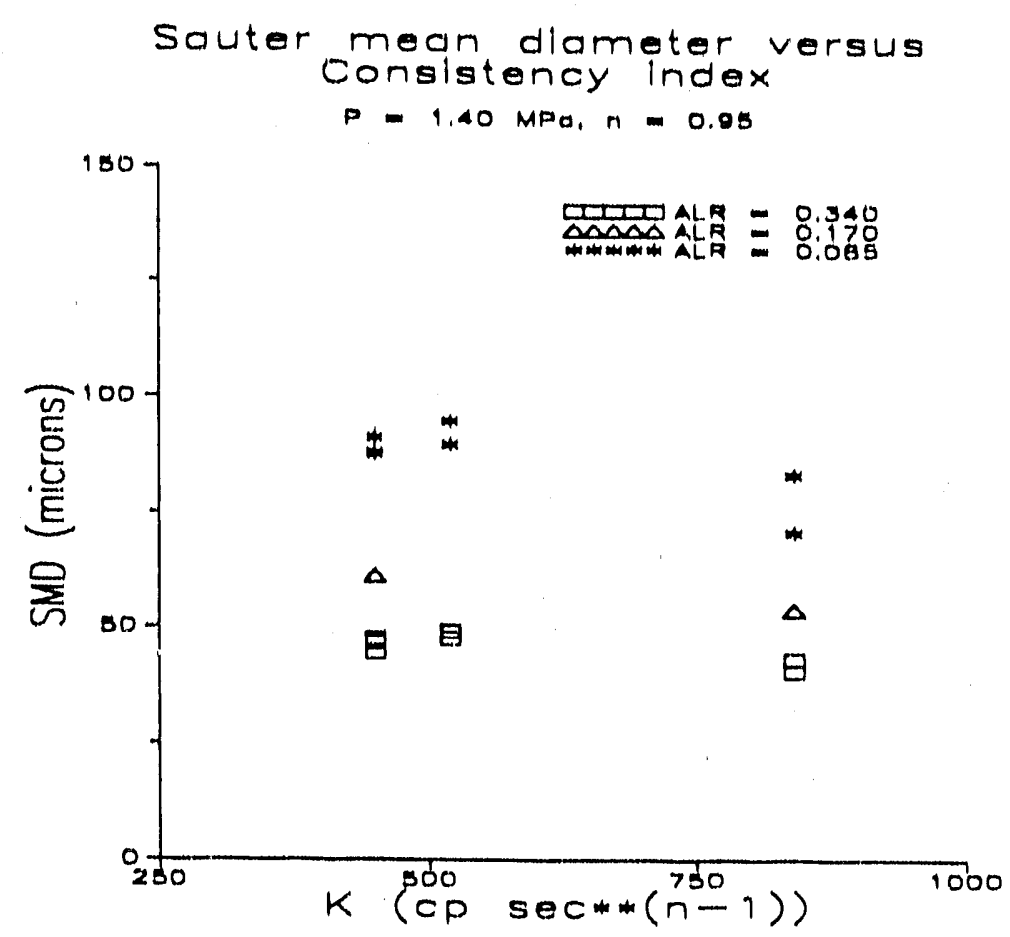

Figure 13. Sauter mean diameter versus consistency index for mixtures 7,8 , and $9, P=$ $1.4 \mathrm{MPu}$.
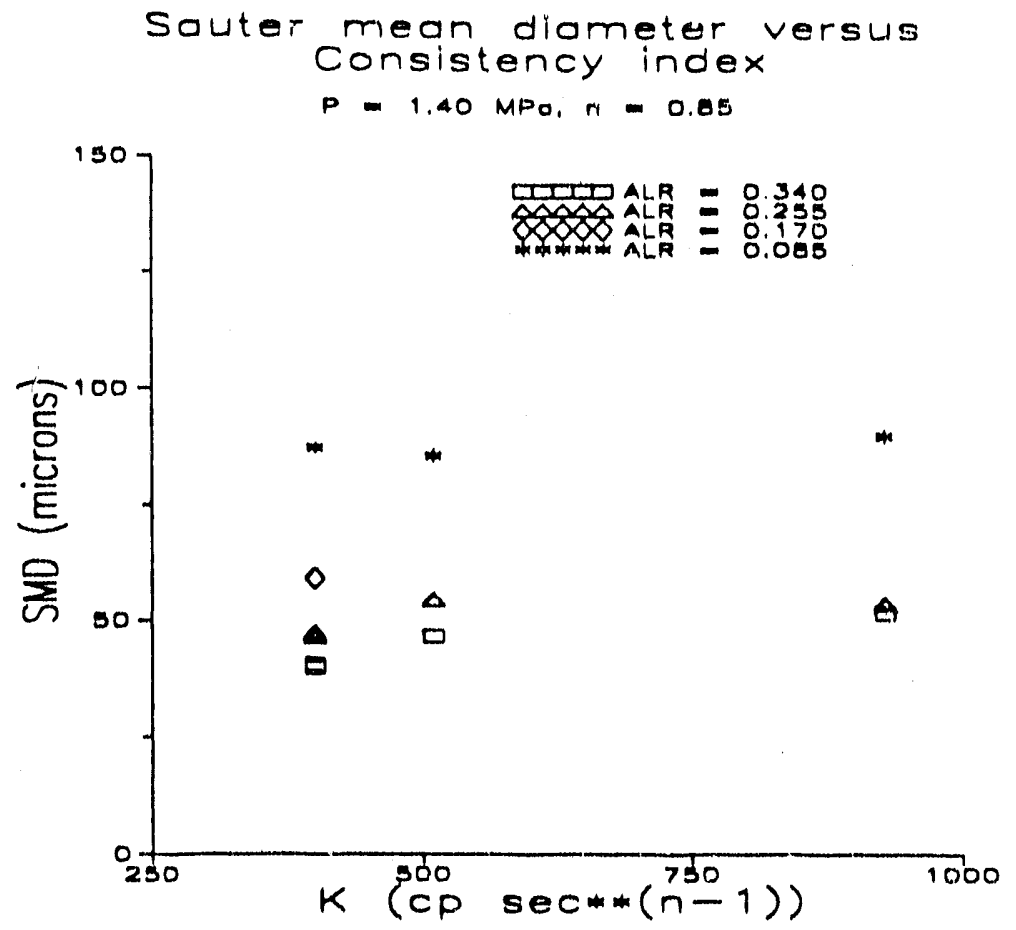

Figure 14. Sauter mean diameter versus consistency index for mixtures 1,2 , and $3, P=$ $1.4 \mathrm{MPa}$. 


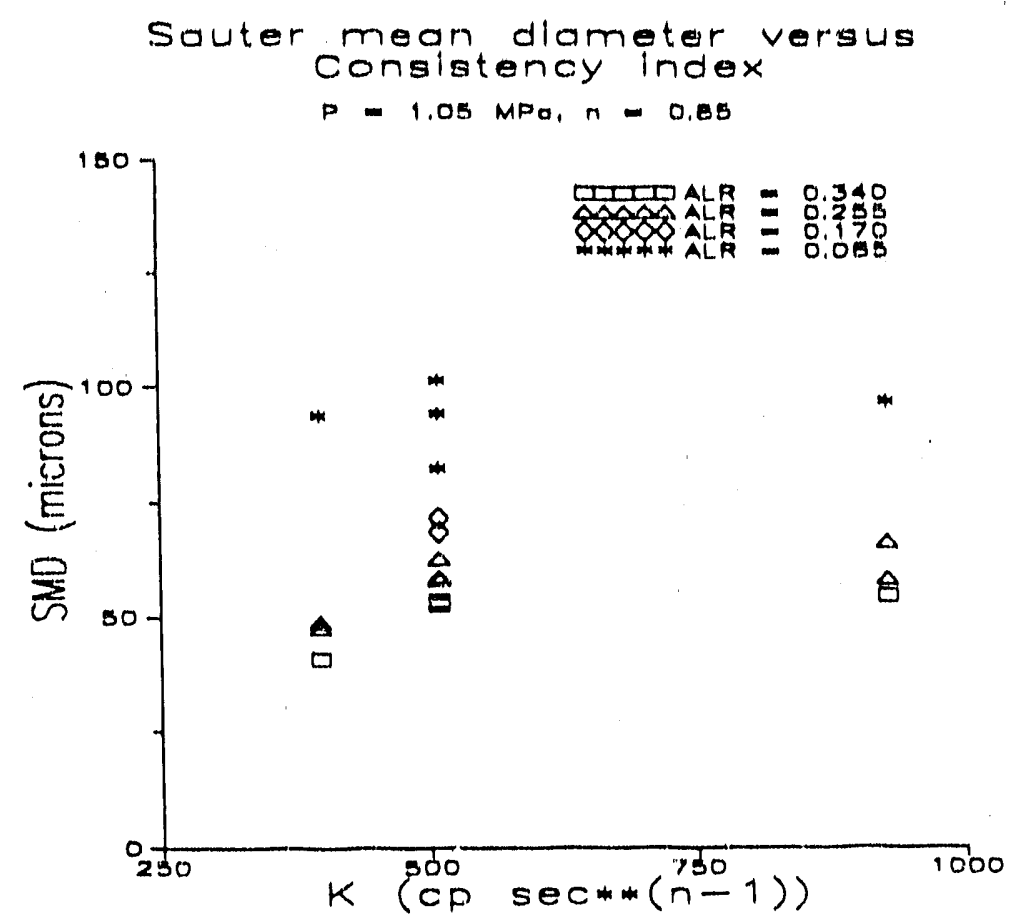

Figure 15. Sauter mean diameter versus consistency index for mixtures 1,2 , and $3, P=$ $1.05 \mathrm{MPa}$.

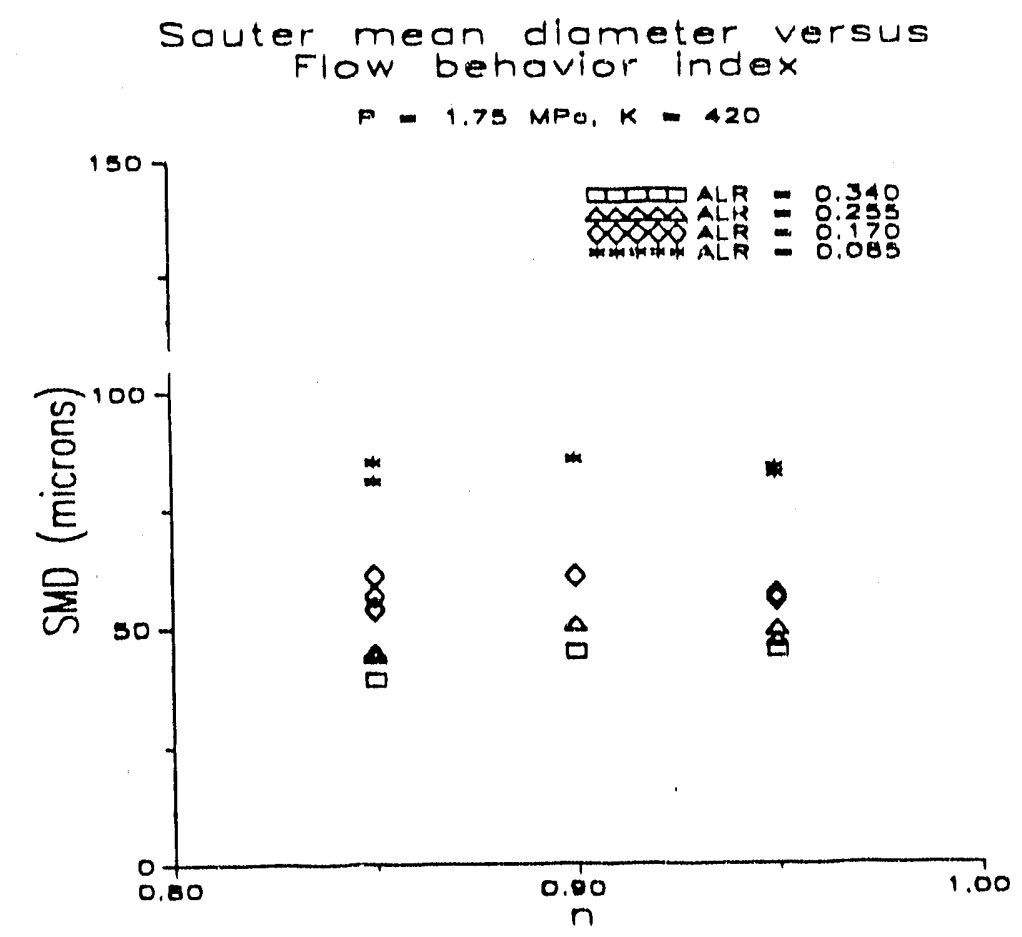

Figure 16. Sauter mean diameter versus flow behavior index for mixtures 1,4 , and $7, P=$ $1.75 \mathrm{MPa}$. 


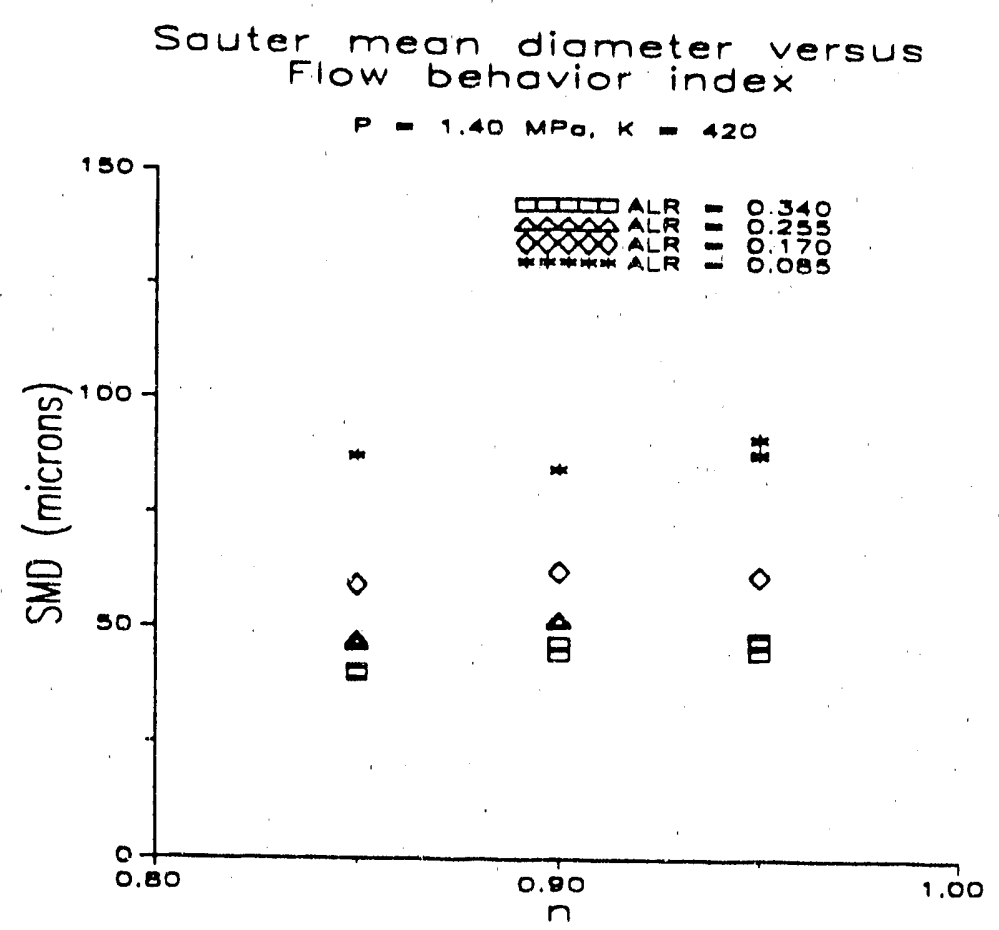

Figure 17. Sauter mean diameter versus flow behavior index for mixtures 1,4 , and $7, P=$ $1.4 \mathrm{MPa}$.

The effect of discharge pressure on SMD is shown in Figures 18 through 22, where SMD versus pressure is presented for decreasing values of ALR. The results are the same as in the Newtonian study showing that changes in pressure at high ALR (above about 0.2 ) have no effect on SMD, while an increase in pressure at low ALR (below about 0.2 ) leads to a slight decrease in SMD. When comparing these results with those of Figures 8 and 9, it is obvious that non-Newtonian flow behavior does not change the influence of pressure on $\mathrm{SMD}$. It is therefore concluded from the Newtonian data describing the effect of consistency index and discharge pressure on SMD, plus the nonNewtonian data describing the effects of consistency index, flow behavior index and discharge pressure on SMD, that the dominant mechanism of atomization is the same for both Newtonian and non-Newtonian fluids. 
Sauter mean diameter versus

ALR $-0.340 . K=420$

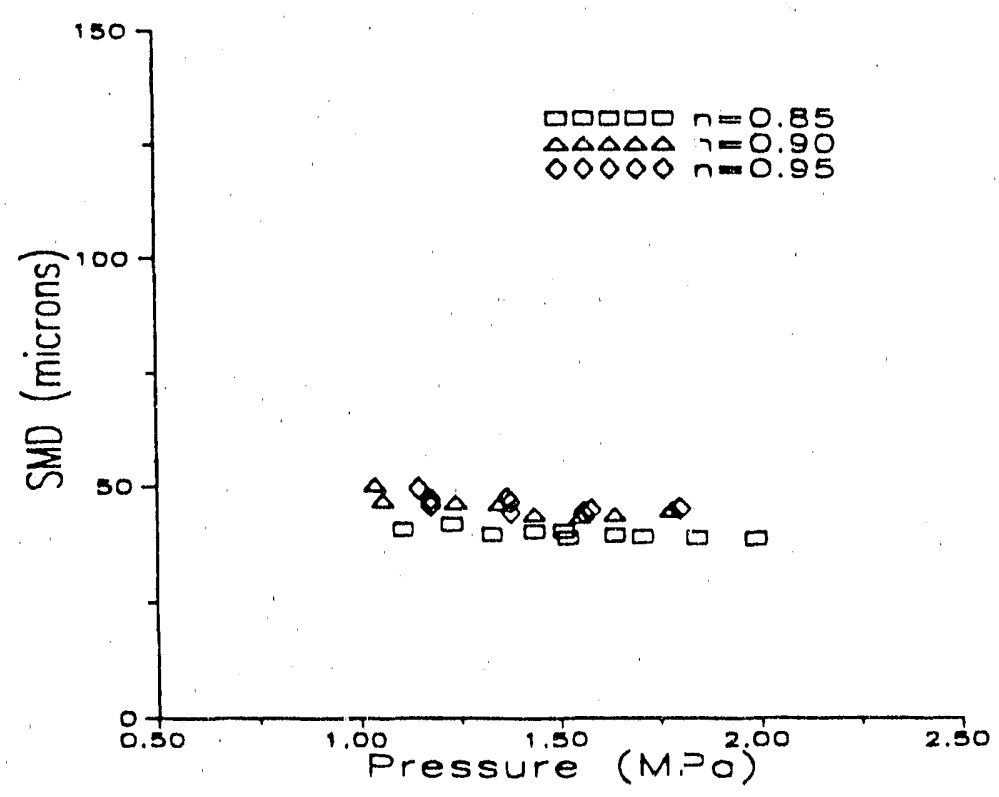

Figure 18. Sauter mean diameter versus discharge pressure for mixtures 1,4 , and 7, ALR $=0.344$.

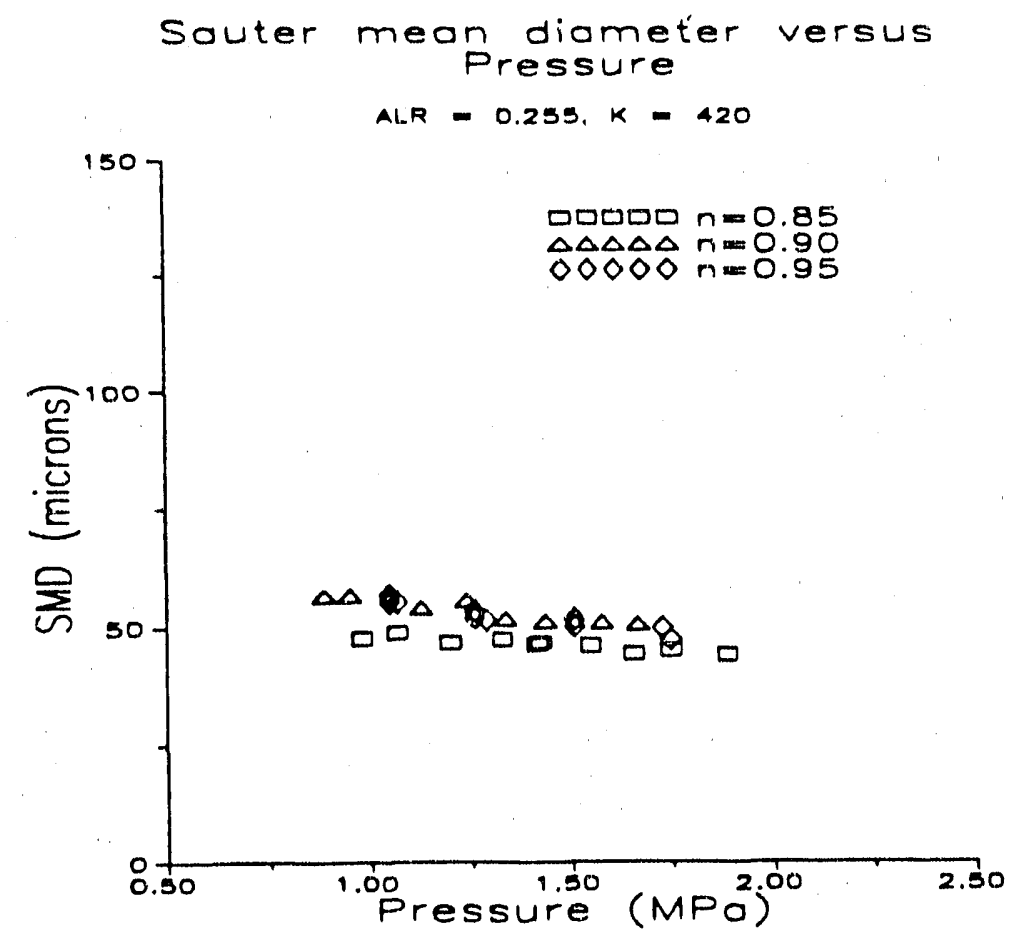

Figure 19. Sauter mean diameter versus discharge pressure for mixtures 1,4 , and 7, ALR $=0.255$. 


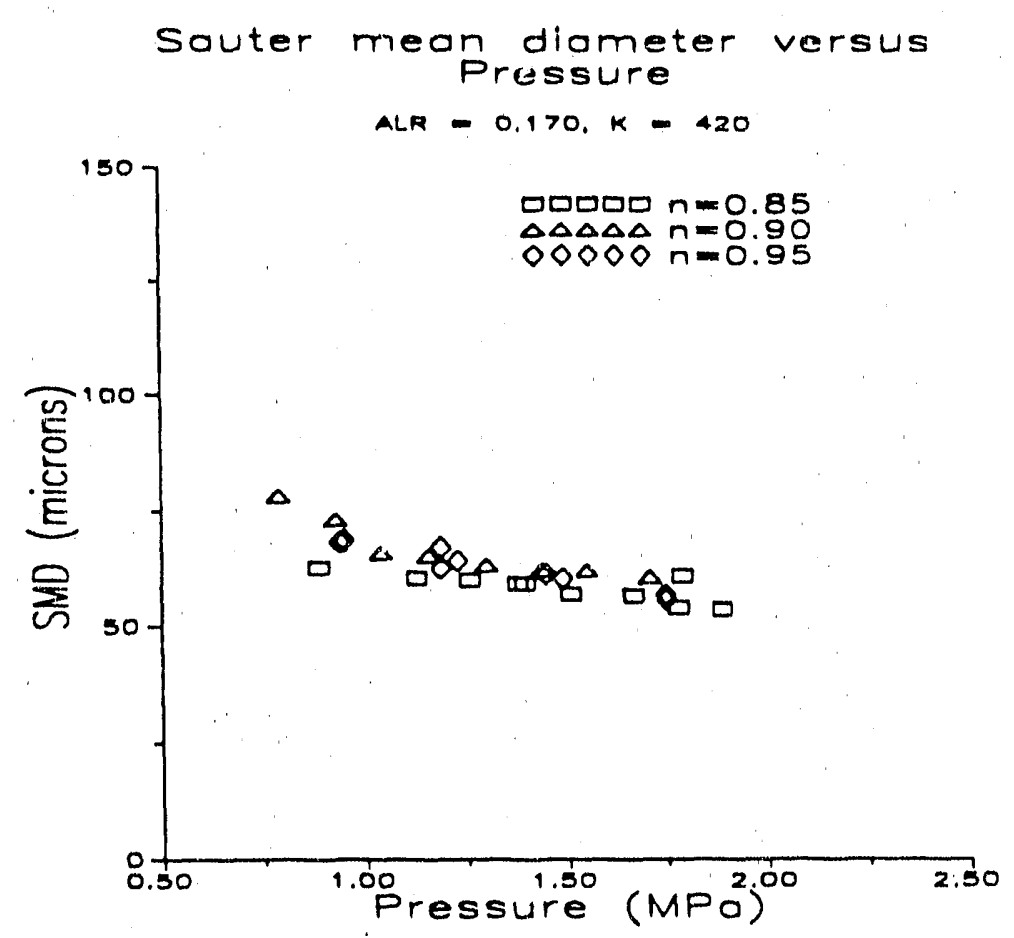

Figure 20. Sauter mean diameter versus discharge pressure for mixtures 1,4 , and 7, ALR $=0.170$.

Sauter meon diometer versus

ALP $=0.085, K=420$

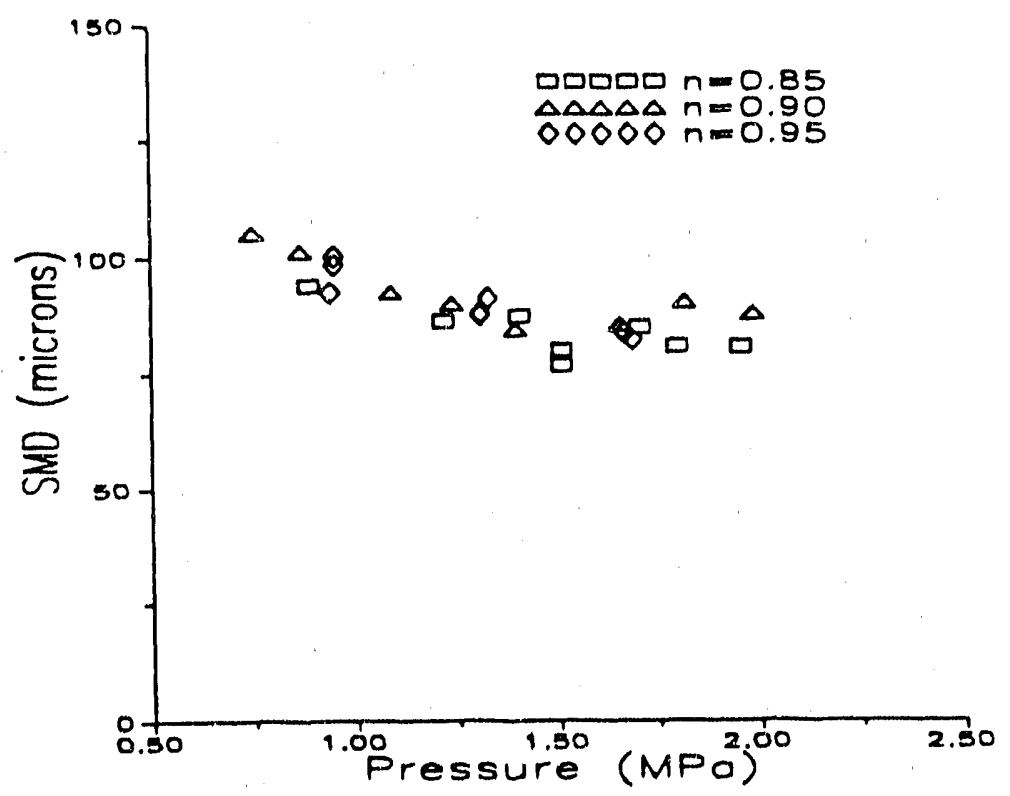

Figure 21. Sauter mean diameter versus discharge pressure for mixtures 1,4 , and 7, ALR $=0.085$. 


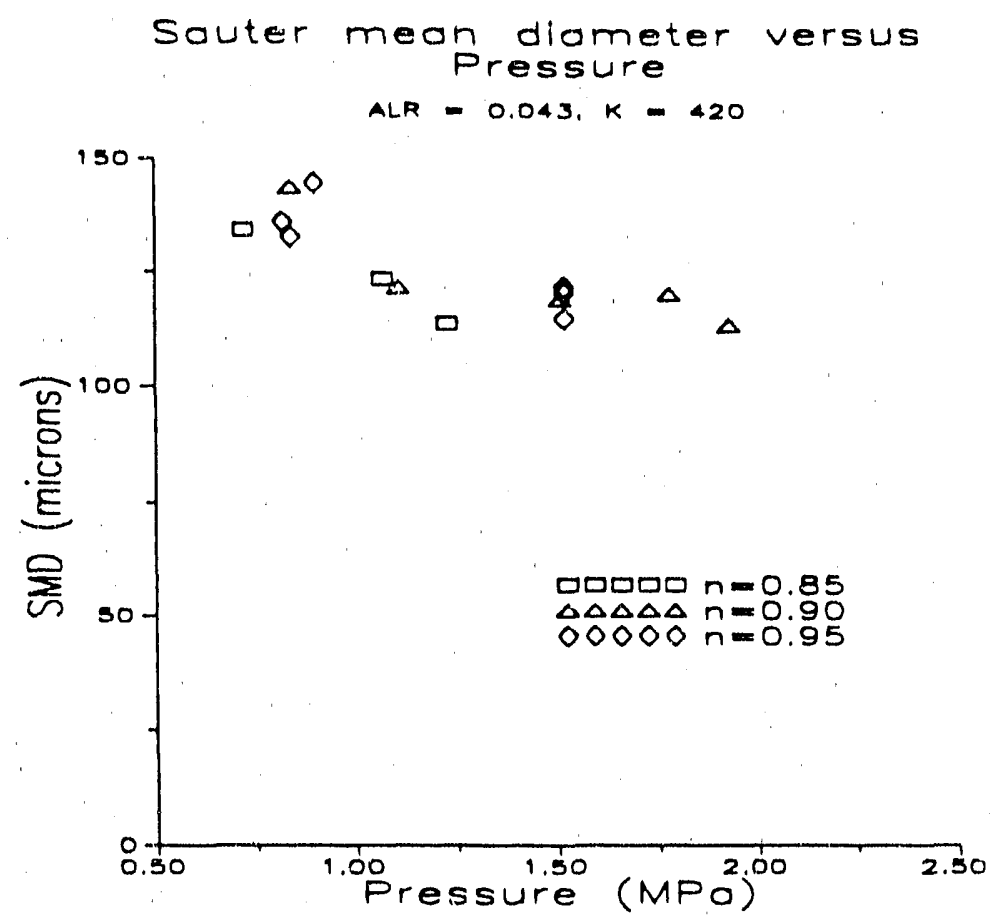

Figure 22. Sauter mean diameter versus discharge pressure for mixtures 1,4 , and 7 , ALR $=0.043$.

The data of Figures 10 through 22 show how operating parameters and liquid properties affect atomization quality, but they do not show why SMD increased in the low ALR region when polymer was added to the glycerine-water solutions. One possible explanation is that the viscoelastic and yield stress characteristics of Xanthan gum solutions have an effect on the atomization quality. Assuming this hypothesis is true, more energy would be required to overcome the forces associated with viscoelasticity and yield stress and therefore an increase in SMD would be observed. At low ALR, the effect of the fluid properties predominates, but as ALR increases, the energy associated with the large mass of air is able to dominate the atomization process and overcome the effect of the polymer. As a result, mean drop sizes at high ALR are smaller and resemble those of the Newtonian data. 
Unfortunately, it was not possible to test this hypothesis since the available rheological instrumentation was incapable of providing the necessary data. This topic should, however, be pursued in future studies because of the relationship between polymers and stabilizers and the necessity of adding stabilizers to CWS.

\subsection{Coal-Water Slurry Spray Data}

Five coal-water slurries were sprayed using the Malvern for drop size measurements. During the coal-water slurry study, some equipment changes were made in order to eliminate problems associated with flowing CWS in small diameter tubing. The glass observation tube in the atomizer was replaced with an equivalent stainless steel rnodel and the diameter of the final orifice was increased to $2.5 \mathrm{~mm}$. In addition, the spray collection system was changed to a spray box and the slurry was driven by a 9 stage positive displacement pump as described in Section 3.3.

The drop size data obtained when spraying coal-water slurry are presented in Figures 23 through 29. Figures 23 and 24 show the effect of ALR on SMD. The results are the same as in the single phase fluid studies: there was a diminishing effect of ALR on SMD as ALR was increased. Notice, that with ALR as low as 0.045, SMD was as low as $55 \mu \mathrm{m}$. It would take an ALR of approximately unity to achieve similar SMD values using a conventional air-assist nozzle. Furthermore, an increase in ALR to 0.15 decreases SMD to about $33 \mu \mathrm{m}$. Sauter mean diameters this low cannot be readily achieved using even advanced design air-assist nozzles. The data also suggest that mean drop sizes below $25 \mu \mathrm{m}$ are obtainable using effervescent atomization. Equipment limitations precluded attaining this value, however, because the minimum liquid flow rate increased from $10 \mathrm{~g} / \mathrm{s}$ during the single phase fluid tests to $40 \mathrm{~g} / \mathrm{s}$ during the CWS tests; therefore, an ALR greater than 0.17 could not be achieved when spraying CWS. It is 
exciting to note that when sub-25 $\mu \mathrm{m}$ mean drop sizes are obtained, substantial increases in coal burnout will result, along with increased combustion efficiency and smaller heat engines for a fixed power rating.

In summary, the results of Figures 23 and 24 demonstrate that (1) effervescent atomizers can achieve quality coal-water slurry atomization even at low values of ALR, and (2) the performance of even a prototype effervescent atomizer is superior to that of advanced design air-assist nozzles.

In addition to illustrating the excellent SMD values achievable using effervescent atomization, Figures 23 and 24 also demonstrate that slurry formulation had little effect on atomizer performance. See Figure 23 where the loading of the 45 and $100 \mu \mathrm{m}$ slurries differed by $14 \%$, yet no change in SMD was observed, and Figure 24 where coal loading varied by $19 \%$ between undiluted slurry 3 and slurry 3 diluted with glycerine while SMD changed only slightly. The change in SMD resulting from changes in particle top size was also slight. No change in SMD was observed between the 45 and $100 \mu \mathrm{m}$ rop size slurries, as shown in Figure 23, while the change in SMD between the 100 and $15 \mu \mathrm{m}$ top size slurries was less than $15 \mu \mathrm{m}$.

Figures 25 through 29 show discharge pressure had the same effect on CWS mean drop size as shown in Sections 4.2 and 4.3: a slight decrease in SMD with discharge pressure at low ALR values and no dependence of SMD on ALR at air-liquid ratios. Figures 28 and 29 show the dependence at low ALR to be more pronounced in the slurry mixtures containing glycerine and glycerine with polymer. The reasons for these differences are not entirely understood at the present time; however, based on single phase fluid results, it is concluded that yield stress or viscoelasticity are the source of the observed variations since all fluid properties were recorded with the exception of these. 


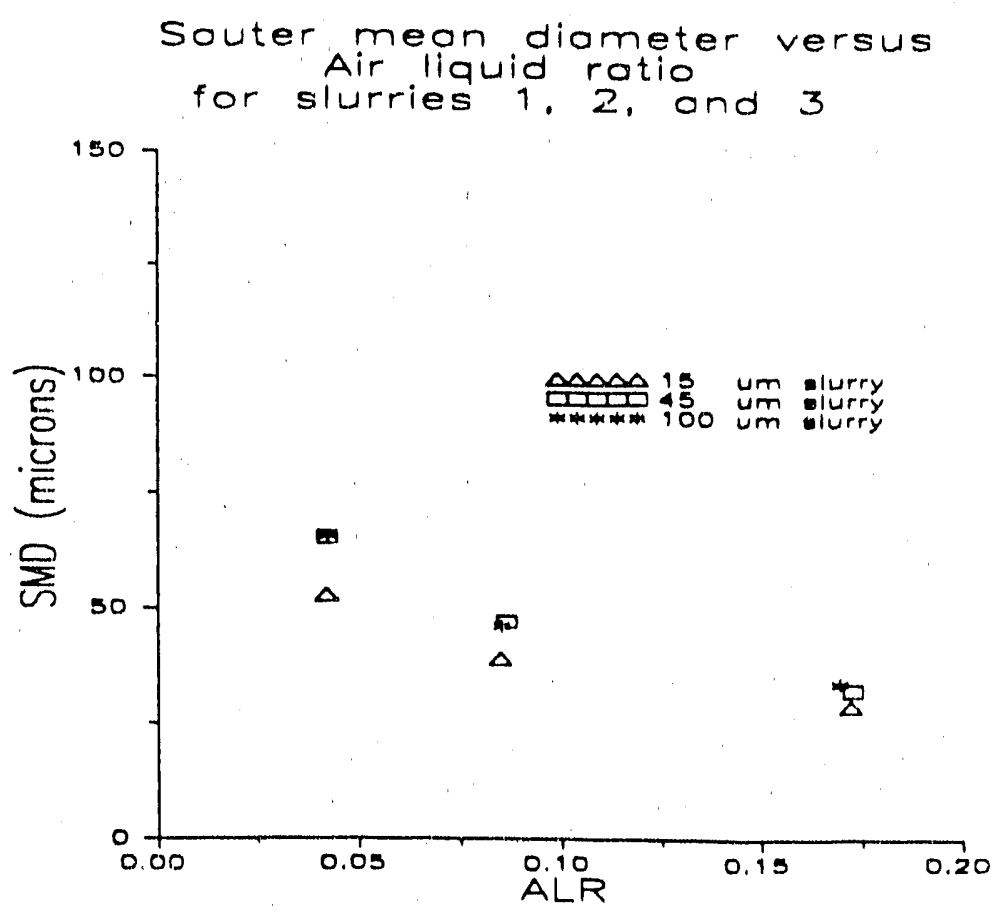

Figure 23. Sauter mean diameter versus air-liquid ratio for slurries 1,2 , and 3 .

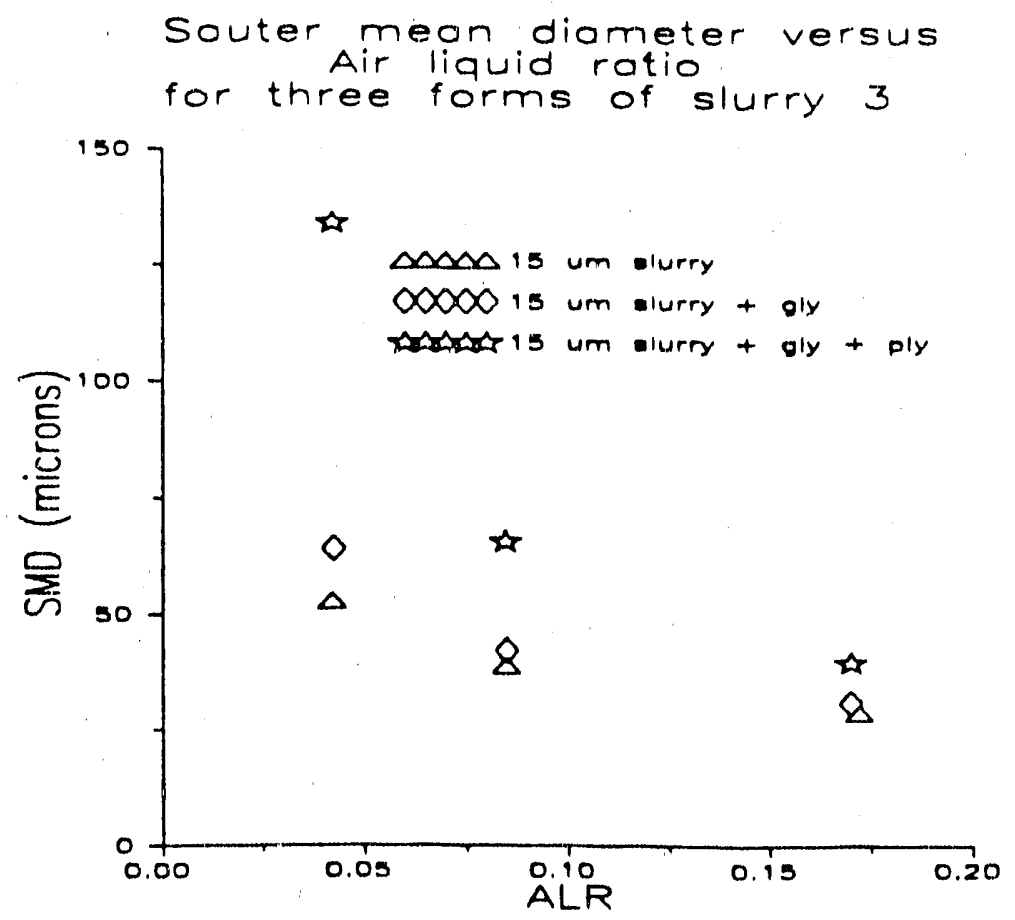

Figure 24. Sauter mean diameter versus air-liquid ratio for slurry 3 undiluted, diluted with glycerine, and diluted with glycerine and polymer. 


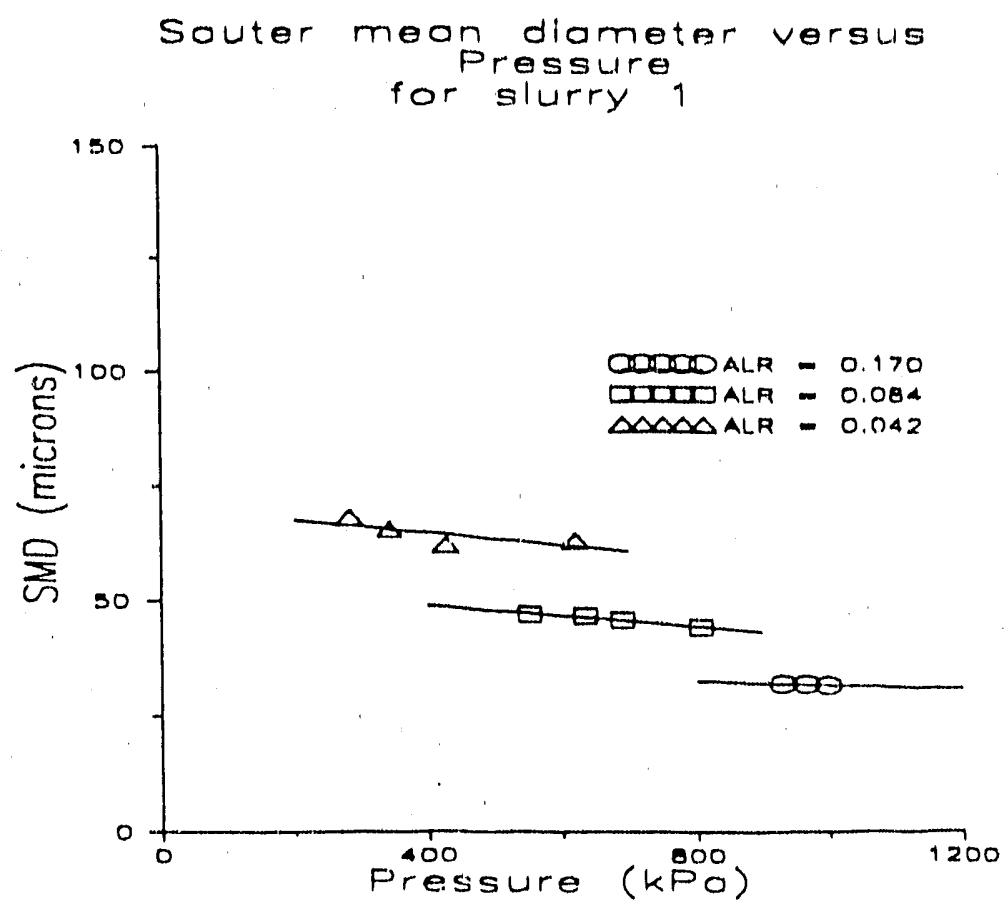

Figure 25. Sauter mean diameter versus discharge pressure for slurry 1.

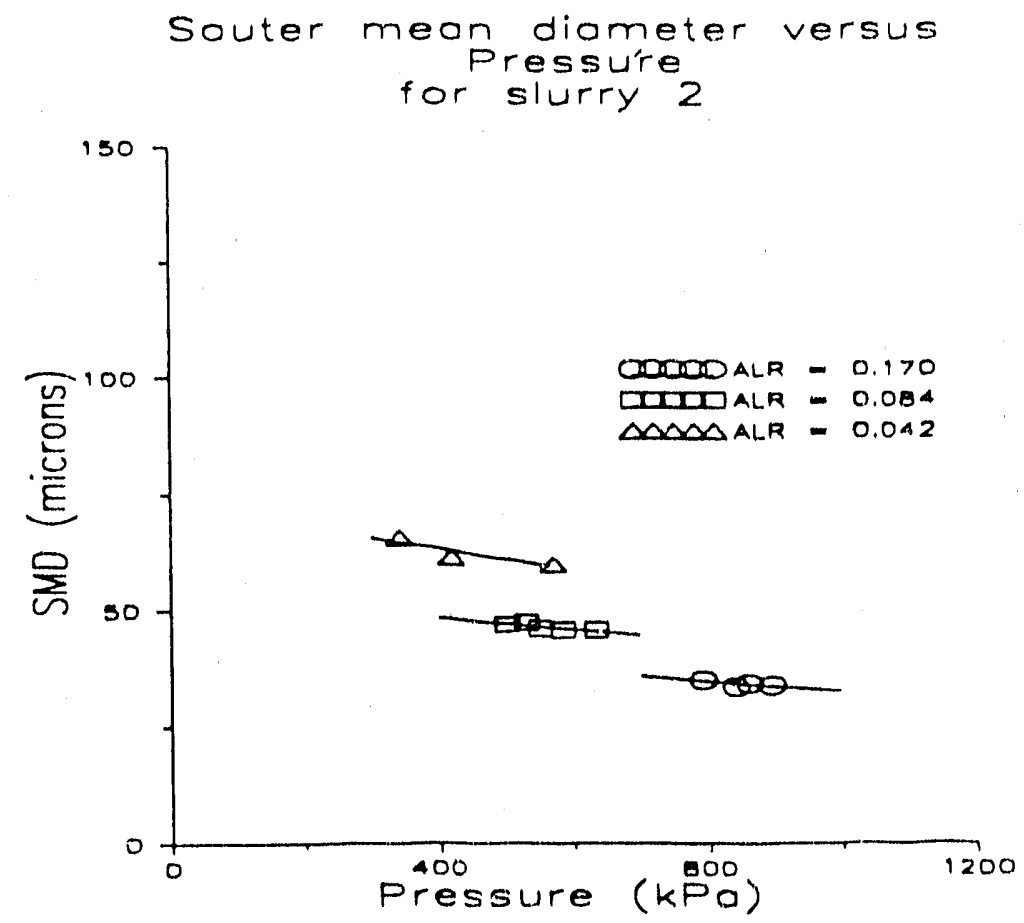

Figure 26. Sauter mean diameter versus discharge pressure for slurry 2. 


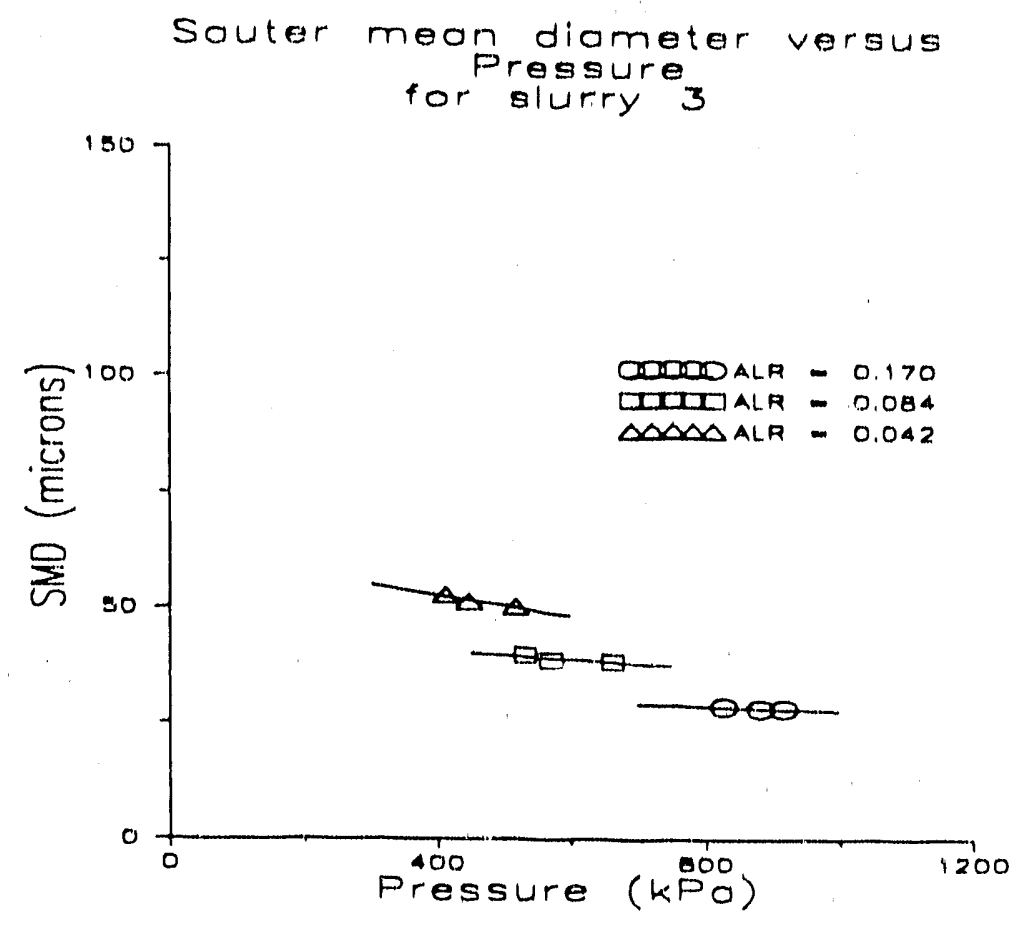

Figure 27. Sauter mean diameter versus discharge pressure for slurry 3.

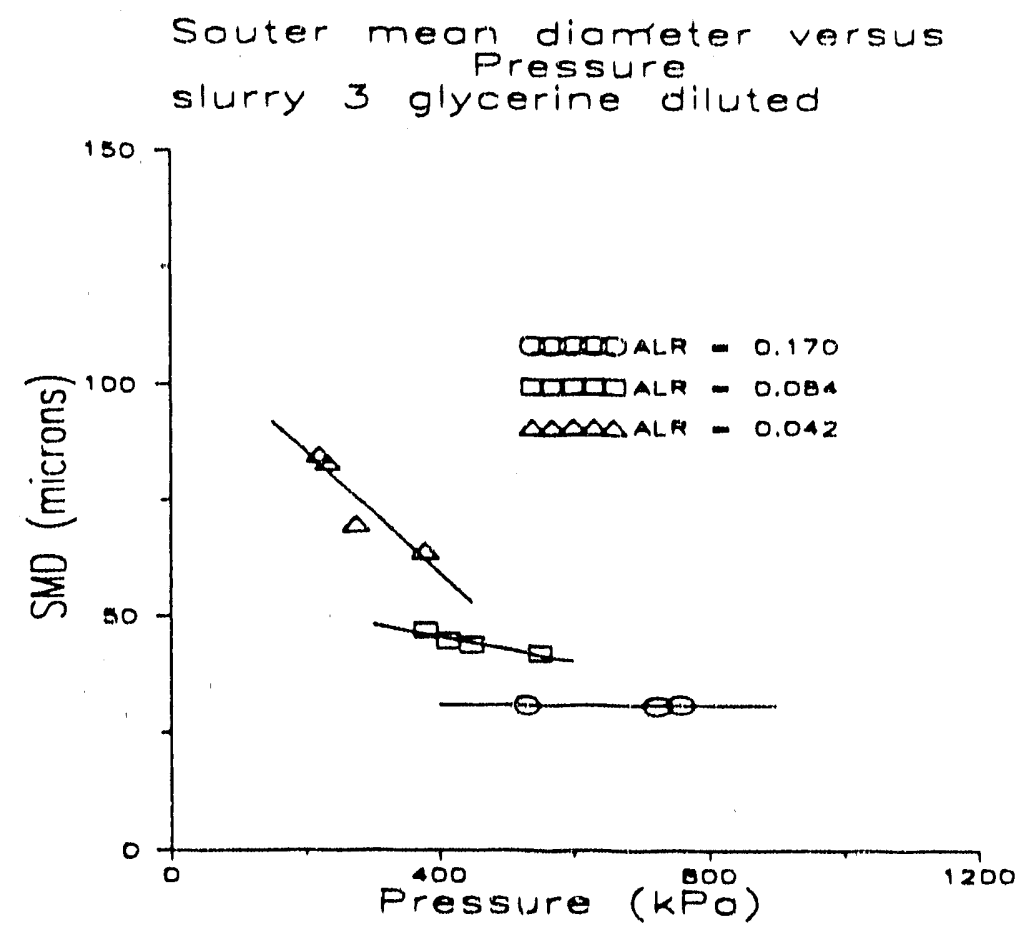

Figure 28. Sauter mean diameter versus discharge pressure for slurry 3 diluted with glycerine. 


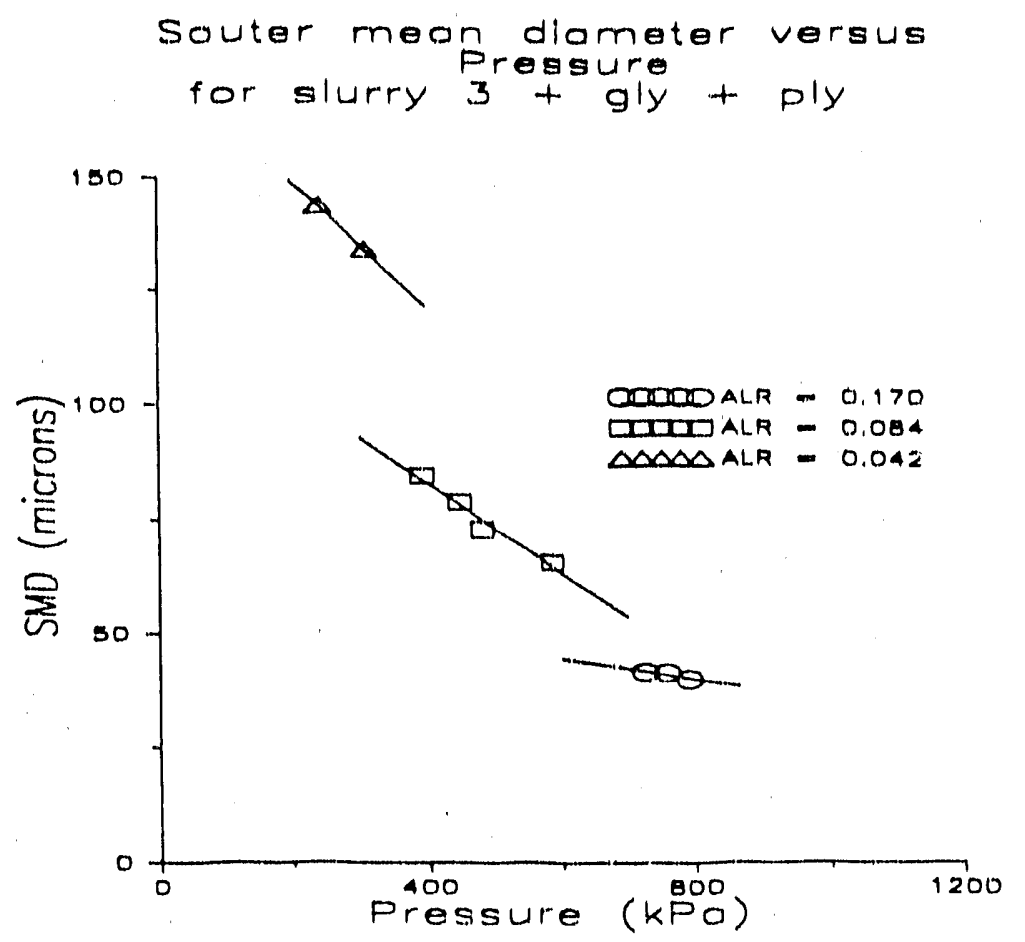

Figure 29. Sauter mean diameter versus discharge pressure for slurry 3 diluted with glycerine and polymer.

\subsection{Summary}

The results of all tests show that ALR has the strongest influence on atomization with the largest effect occurring at low ALR. This influence diminishes as ALR is increased and is explained by considcring the losses associated with entrainment. When ALR is small, a liquid shroud encases the expanding air, reducing entrainment losses. As ALR is increased, the shroud is ineffectual or nonexistent and entrainment losses become more severe.

There was no change in mean drop size as consistency index was changed two fold. The flow behavior index had no effect either; therefore, Newtonian and non-Newtonian rheological properties, as indicated by $\mathrm{n}$ and $\mathrm{K}$, have no effect on the atomization process. This result is explained by considering the two mechanisms of liquid break up: the shearing interaction between the liquid and the air and the competition between droplet 
surface tension and pressure forces caused by the relative velocity. Liquid break up due to shearing action is a function of the liquid viscosity, but for effervescent atomization fluid viscosity has no influence on SMD; therefore, atomization is not influenced by shear. However, the relative velosity between the droplets and air is very high suggesting that the spray formation process is controlled by secondary atomization.

Pressure had little effect on SMD at high ALR values (above about 0.20). High values of ALR increase losses to the ambient; therefore, any increase in available energy due to an increase in pressure is dissipated. The situation changes at low ALR values (below about 0.20 ) since a liquid shroud encompasses the expanding gas protecting it from losses to the ambient air. Here, an increase in pressure assists break up since the energy is not lost to the entrained air.

When atomizing solutions containing polymer, SMD increases, especially in the low ALR region. A change in ALR has a smaller effect on SMD in the low ALR range when spraying fluids containing polymers, as compared to fluids containing no polymer. This changes the slope of the SMD versus ALR curve. At high ALR, the polymer solutions atomize in the same manner as the non-polymer solutions. It is believed that these effects are caused by either viscoelastic properties or the yield stress of the polymer solutions.

No effect of slurry formulation on SMD was found for three slurries whose particle top size changed by a factor of 6 and whose loading varied from 49 to $65 \%$. The only change in SMD between the different slurries occurred when atomizing CWS with added polymer. Sauter mean diameter increased with polymer addition similar to the manner in which SMD increased when polymer was added to glycerine-water solutions.

In conclusion, the data substantiates the effectiveness of effervescent atomization in 
forming low SMD sprays from highly viscous Newtonian and non.Newtonian fluids. Most importantly, the ultimate goal of this study, to successfully atomize coal-water slurry using an effervescent nozzle, was achieved. 


\section{ANALYSIS}

\subsection{Introduction}

An anaiysis of the effervescent atomization process was performed to better understand the physical merhanisms responsible for the results reported in Section 4. To that end, an expression for SMD was developed using the techniques of two-phase separated flow plus mass, momentum, and energy conservation. It embodies the physics of effervescent atomization, adequately representing the dynamics of this process.

Previous models describing atomization processes using two-phase flows have been divided into two areas. Internal mixing atomization models describe the mixing of air and liquid within the nozzle in order to form a two-phase bubbly or slug flow. The gas expands upon exiting the nozzle and produces a spray. Flashing atomization models incorporate either dissolution of gas into a liquid or superheating a liquid such that gas comes out of solution during the atomization process thus breaking the liquid into drops. Both types of models are summarized in the following paragraphs.

Chawla [1985] investigated internal mixing atomization and developed an expression for the maximum droplet diameter as a function of the pressure jump experienced at the throat of a choked converging nozzle. He noted that a two-phase mixture possesses a very low velocity for sonic flow thereby making the pressure jump required for choking easily attainable. However, Chawla erred when developing his model by oversimplifying the atomization process and incorrectly postulating that the maximum droplet diameter is proportional solely to the inverse of the pressure jump. Thus, Chawla ignored the fact that maximum drop size is a function of the relative velocity between the liquid and the air, and as a result the thermodynamic process by which the gas expands must be considered. Furthermore, Chawla's model is of only limited utility since it attempts to predict 
only the maximum drop size when drop size distribution or Sauter Mean Diameter is a more useful parameter for describing a spray.

Sher and Elata [1977] developed an expression for the mean diameter of a flashing spray. Their analysis began by considering the nucleation of minute bubbles caused by the surface roughness of the nozzle wall. The bubbles increased in volume through evaporation of the Freon propellant due to a drop in the pressure of the liquid, growing until their outer edges touched and caused the film between them to rupture. The remaining energy of the bubble accelerated the vapor past the liquid shredding it into droplets.

Sher and Elata's correlation incorporated assumptions that give the solution many degrees of freedom. First, a factor expressing the number of nucleation sights was assumed. Second, a bubble growth rate was assumed in order to predict the number and size of the bubbles at the time they burst. Third, a close-packed cubic array of bubbles was assumed in order to calculate the mass of liquid at bursting per unit volume of twophase fluid. Fourth, the mean drop size was assumed to follow the log normal size distribution. Finally, an efficiency term was determined by dividing the surface energy of the drops by the energy in the bubbles just prior to bursting. These assumptions provided a gosd correlation to their data but restricted its applicability to other systems.

Solomon et al. [1985] considered dissolved gas atomization, a second type of flashing atomization. They analyzed their system by incorporating a correlation developed.by Lefebvre [1980] for prefilming air blast injectors. The expression was empirical in nature and was developed by considering the operating parameters and physical properties of the fluids that most strongly influenced spray formation. In order to generalize the expression, two experimentally determined constants were inserted into the equation. The weakness of their expression was its empirical nature and the number of degrees of freedom it possessed. 
Dissolved gas and flashing atomization are similar to aerated atomization in that all use the expansion of gas bubbles to increase the liquid surface energy, thereby forming droplets. Both dissolved gas and flashing atomization, however, require the presence of nucleation sites for the formation and subsequent growth of bubbles. Aerated atomization, in contrast, requires no nucleation stes because bubbles are formed automatically when gas enters the liquid via the aeration tube. As a result, the present analysis is not limited by the assumption that the number of droplets formed in the spray is directly proportional to the number of nuclei, as proposed by Sher and Elata [1977], nor does it require the assumption of a bubble packing geometry or a drop size distribution.

This analysis also differs from that of Solomon et al. [1982] in two significant respects. First, the current analysis is developed from first principles instead of being based on a correlation developed from dimensional arguments. Second, it is not restricted to sprays controlled by sheet or jet break up processes, although it has been extended to such processes by Lefebvre [1990].

The expression derived in this report relates spray mean drop size, in terms of the Sauter mean diameter, to the liquid surface tension and density, the initial air and liquid velocities, and the air-liquid mass ratio. It was applied to both the aerated atomization data presented in Section 4 and the data of Roesler [1988] in order to illustrate the relative importance of the physical mechanisms responsible for aerated atomization. The analysis was inspired by Lefebvre [1990] and follows his basic premise that a simple energy balance can be applied to the spray.

\subsection{Analysis}

The analysis begins by considering conservation of energy for the two phases. The region of interest extends from the nozzle exit plane to the line of spray measurements 
(See Figure 30). The flow is assumed to be one-dimensional and steady, and evaporation is ignored. The latter assumption may provide a source of error when analyzing the water data of Roesler [1988], but is acceptable when analyzing the data of Section 4 because of the low vapor pressures associated with mixtures containing water and glycerine.

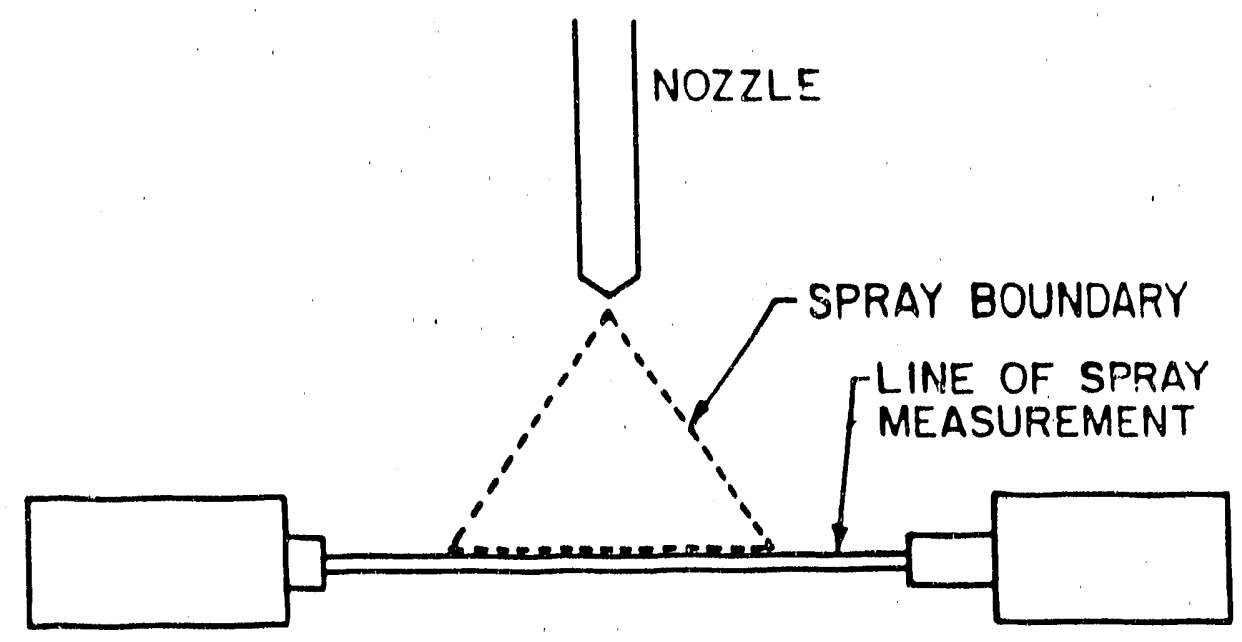

Figure 30. Illustration of the control volume considered in the analysis.

The mixture is modeled as a two-phase separated flow with the liquid treated as an isentropic incompressible substance and the air assumed to be an ideal gas. The thermodynamic process describing the expansion of the air must lie between the limiting isothermal and isentropic cases. Elliot [1960] derived an expression for the temperature of the two-phase mixture during an expansion where infinite heat transfer occurs between the fluids 


$$
\frac{T_{a}}{T_{n}}=\left(\frac{P_{a}}{P_{n}}\right)^{N L R} \frac{n}{\left(C_{1}+C_{p} N R\right)}
$$

where $T_{a}$ is the mixture temperature after expansion, $T_{n}$ is the initial mixture temperature, $P_{a}$ is the mixture pressure after expansion, $P_{n}$ is the initial mixture pressure, $R$ is the ideal gas constant, $C_{1}$ is the liquid specific heat, and $C_{p}$ is the gas constant pressure specific heat.

Equation (12) indicates the change in mixture temperature ranges from 3 to $16^{\circ} \mathrm{K}$ for the conditions under which this study was performed. As a result, the velocity of the gas is no more than 10 to $25 \%$ higher for the infinite heat transfer case than for the isothermal case. However, based on the work of Elliot [1960] and Netzer [1962], and because of the small errors noted above, the gas will be assumed to undergo an isothermal expansion. (Note that regardless of the exact thermodynamic path traveled by the expanding air, the experimental results of Eddington, Elliot and Netzer show that actual velocities deviate only slightly from the isothermal case for ALR values up to 0.22.)

After undergcing expansion, the air and liquid are assumed to reach a common velocity before crossing the line of spray measurement. Losses due to entrainment, viscous dissipation, and irreversibilities during the expansion of the air are incorporated by defining $\varepsilon$ to be the fraction of air directly participating in the atomization process. The remaining air $(1-\varepsilon)$ passes through the control volume undisturbed such that its energy is lost to the ambient and thus need not be considered in the analysis.

Under these assumptions, the energy flowing into the control volume includes the initial air and liquid kinetic energies, plus the initial surface energy of the bubbles. The energy flowing out of the control volume includes the final air and liquid kinetic ener- 
gies, plus the surface energy of the drops. Equating the energy fluxes results in

$\frac{\varepsilon \dot{m}_{A} V_{A 1}^{2}}{2}+\frac{\dot{m}_{L} V_{L 1}^{2}}{2}+\frac{6 \sigma \dot{m}_{L}}{\rho_{L} S M D_{b}}=\frac{\varepsilon \dot{m}_{A} V_{A 2}^{2}}{2}+\frac{\dot{m}_{L} V_{L 2}^{2}}{2}+\frac{6 \sigma \dot{m}_{L}}{\rho_{L} S M D_{d}}$

where $\dot{m}_{L}$ is the liquid mass flow rate, $\dot{m}_{A}$ is the air mass flow rate, $V_{A 1}$ is the initial air velocity, $V_{L 1}$ is the initial liquid velocity, $V_{A 2}$ is the final air velocity, $V_{L 2}$ is the final liquid velocity, $\rho_{L}$ is the liquid density, $\sigma_{L}$ is the liquid surface tension, $S M D_{b}$ is the Sauter mean diameter for the bubbles, and $S M D_{d}$ is the Sauter mean diameter for the droplets.

Conservation of momentum is then used to determine the final air and liquid velocity

$V_{A 2}=V_{L 2}=\frac{\left(\varepsilon \dot{m}_{A} V_{A 1}+\dot{m}_{L} V_{L 1}\right)}{\varepsilon \dot{m}_{A}+\dot{m}_{L}}$

An order of magnitude analysis allows elimination of the bubble surface energy term. The resulting equation can be rewritten using the air-liquid ratio to yield

$$
S M D_{d}=\frac{12 \sigma}{\rho_{L}\left(V_{L 1}^{2}+\varepsilon A L R V_{A 1}^{2}-\frac{\left(V_{L 1}+C A L R V_{A 1}\right)^{2}}{1+E A L R}\right)}
$$

Equation (15) indicates that SMD depends on ALR, liquid surface tension and density, the air and liquid velocities at the control volume inlet, plus the parameter $\varepsilon$. The determination of $V_{A 1}$ and $V_{L 1}$ is discussed in the following paragraphs. An expression for $\varepsilon$ is presented in Section 5.3.

The initial air and liquid velocities are calculated using a separated flow analysis. According to Wallis [1969], the velocity of the air within the flow tube is 
$V_{A 0}=C_{1} j$

where $C_{1}$ is an empirical coefficient that expresses the degree of slip between the gas and liquid and $\mathrm{j}$ is the volumetric flux of the two-phase flow. The velocity of the liquid in the flow tube is

$V_{L 0}=\frac{j_{L}}{1-\alpha}$

where $j_{L}$ is the volumetric flux of the liquid and $\alpha$ is the void fraction.

The velocities $V_{A O}$ and $V_{L O}$ are determined at the point upstream of the converging section of the nozzle where the static pressure is known. Knowing the velocities and the static pressure allows the stagnation pressure of each constituent to be computed. This information is used to calculate the inlet velocities to the control volume.

The velocity of the air at the control volume inlet is found from the isothermal relationship

$V_{A 1}=\left(2 R T_{n} \ln \frac{P_{A 0}}{P_{\mathrm{atm}}}\right)^{1 / 2}$

The velocity of the liquid at the control volume inlet is

$V_{L 1}=\left[\frac{2\left(P_{L O}-P_{c m}\right)}{\rho_{l}}\right]^{1 / 2}$

It is important to note that Equation (15) is similar in form to other published expressions such as Equation (2.9) proposed by Lefebvre [1 9 今0]. For instance, it indi- 
cates that an increase in surface tension increases SMD by requiring a larger portion of the available energy to go into droplet surface energy. It also indicates that SMD decreases with ALR according to the relationship $[1+1 /(\varepsilon A L R)]$ which is similar to the 1+1/ALR dependence of Lefebvre [1990], Solomon [1982], and Knoll [1989]. In addition, there is an efficiency associated with the energy transfer between the expanding gas and the droplets as proposed by Sher and Elata [1977] and Lefebvre [1990].

\subsection{Results}

The model developed in Section 5.2 was applied to the data of Section 4 to further the understanding of the effervescent atomization process. The first step was to determine $\varepsilon$. The resulting $\varepsilon$ values were then used to calculate SMD with the calculated values compared with experimental results. As will be shown, the agreement obtained demonstrates the ability of the model to describe the effervescent atomization process. The final step was to use the model to explain the process of effervescent atomization.

Calculation of SMD requires the fraction of air participating in the atomization process. This quantity is not expected to remain constant over the entire test matrix. Consideration of the spray mean drop size at the limiting ALR values of 0 and $\infty$ indicates ${ }^{\circ}$ that $\varepsilon$ must decrease with ALR. As a result, a power law form for $\varepsilon$ was chosen and determined by fitting Equation (20) to the experimental data in Section 4. The resulting dependence of $\varepsilon$ on ALR for CWS is illustrated in Figure 31. The coefficients A and B are tabulated in Table 4 for the various fluids sprayed.

$$
\varepsilon=10^{4} \cdot A L R^{B}
$$




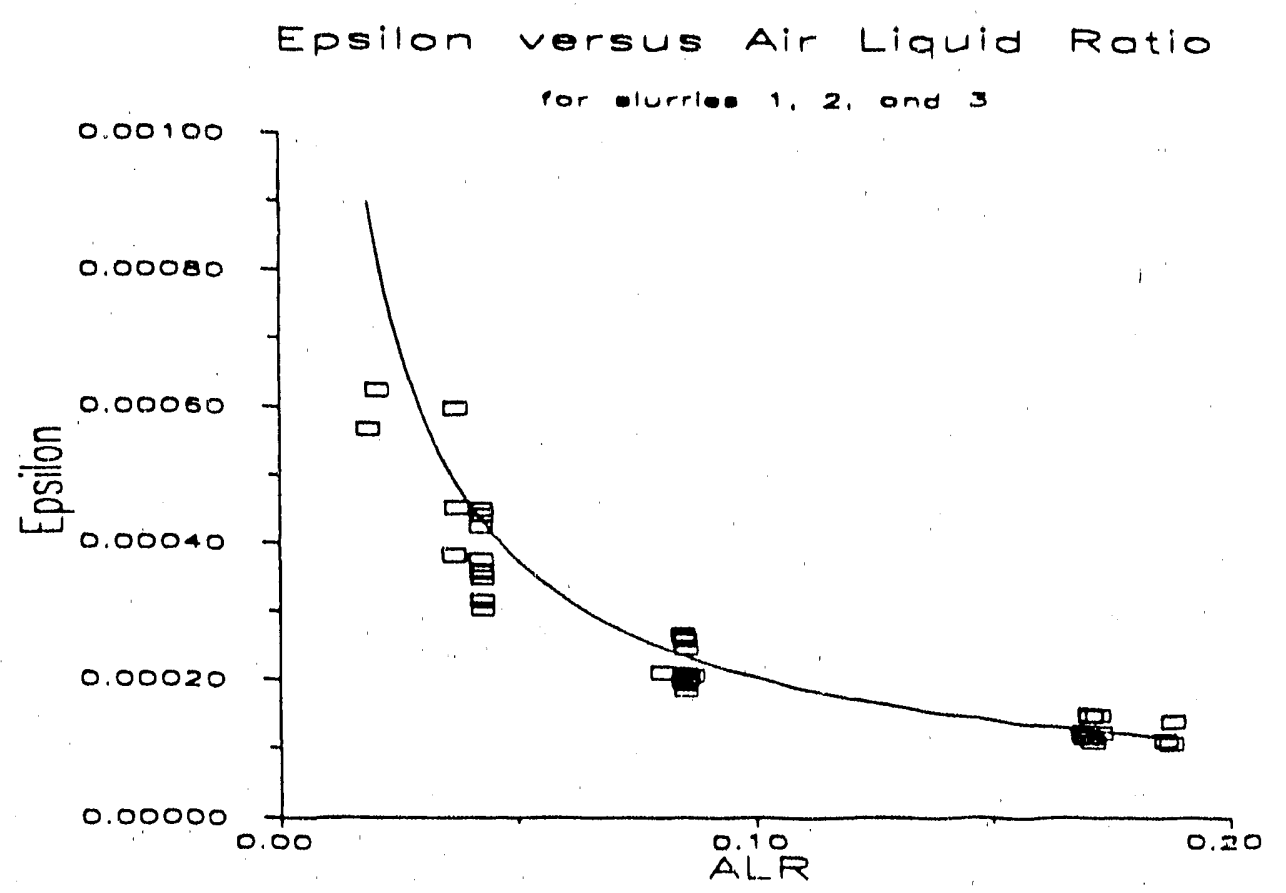

Figure 31. Epsilon versus air-liquid ratio for undiluted coal-water slurries 1, 2, and 3.

Table 4: Coefficients $A$ and $B$ for all fluids

Fluid

glycerine and water test 1

glycerine and water test 2

glycerine, water and polymer

CWS undiluted

CWS and glycerine

CWS, glycerine and polymer

CWS undiluted and CWS diluted with glycerine

water, Roesler [1988]

glycerine and water of test 1 plus water of Roesler
A

$-3.89$

$-4.33$

$-4.21$

$-4.50$

$-4.34$

$-4.34$

.4 .46

$-3.18$

$-3.83$
B

$-0.78$

$-0.67$

$-0.56$

$-0.78$

$-0.64$

$-0.44$

$-0.74$

$-0.46$

$-0.74$ 
Figure 32 shows SMD calculated using Equations (15) and (20) versus measured SMD where the glycerine water data of test 1 was used. Notice that viscosity varies from 487 to $852 \mathrm{cP}$, as shown in Table 1, and that the correlation is able to accurately predict SMD. This indicates that the expression for SMD is accurate with no consideration given to changes in viscosity.

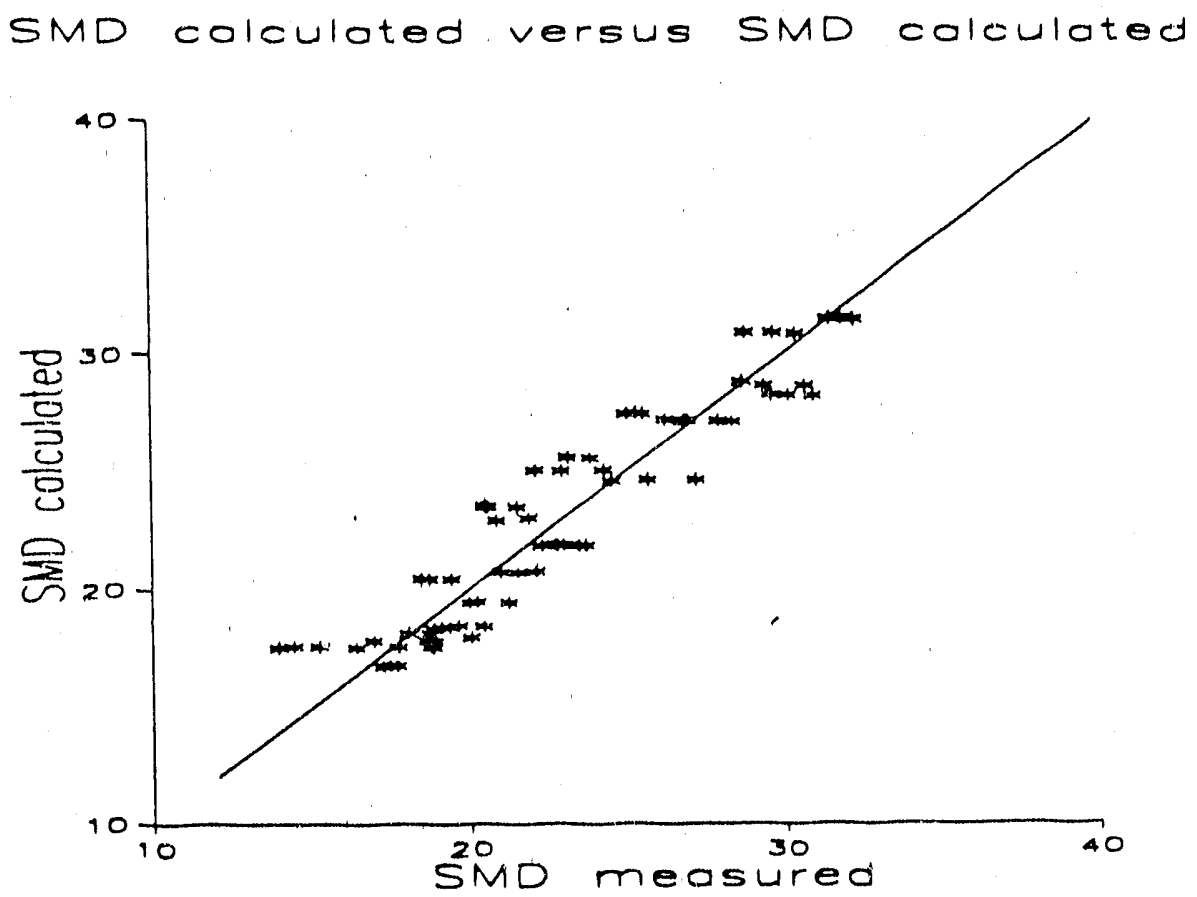

Figure 32. Calculated Sauter mean diameter versus measured Sauter mean diameter for glycerine-warer test 1 .

Figure 33 shows calculated SMD versus measured SMD using data taken from the non-Newtonian study. No variation is seen as consistency index varied from 400 to 930 $\mathrm{cP}-\mathrm{s}^{\mathrm{n} \cdot 1}$ and flow behavior index changed from 0.85 to 0.95 . This verifies that the expression for SMD need no correction for non-Newtonian rheological properties.

Figures 34 through 37 show calculated SMD versus measured SMD using data taken from the coal-water slurry portion of this study. Flow behavior index and consis- 


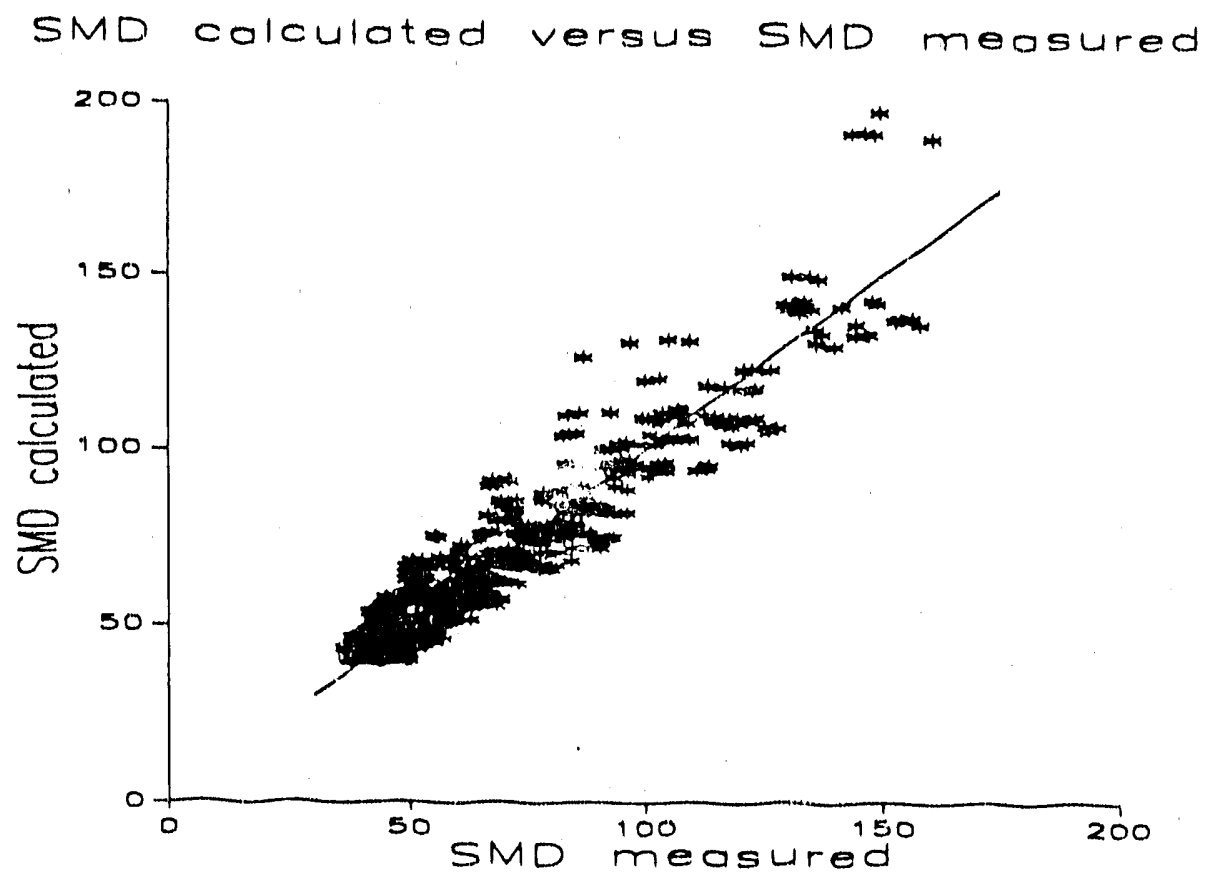

Figure 33. Calculated Sauter mean diameter versus measured Sauter mean diameter for the glycerine-water-polymer fluids.

tency index varied from 0.603 to 1.03 and 133 to $1964 \mathrm{cP}-\mathrm{s}^{\mathrm{n} \cdot 1}$, respectively, and no adjustment to the equations was necessary in order to obtain a good fit, thus supporting the conclusions drawn in the non-Newtonian single phase fluid portion of the study. This data also contained variations of $19 \%$ in coal loading, and variations of $85 \mu \mathrm{m}$ in particle top size yet the equations were able to accurately predict SMD with no adjustments necessary.

Figure 38 shows calculated SMD versus measured SMD using Roesler's water data. This figure indicates the expressions accurately predict SMD in a region of ALR much lower than that of this study and in a flow regime different from that of thi. study. 


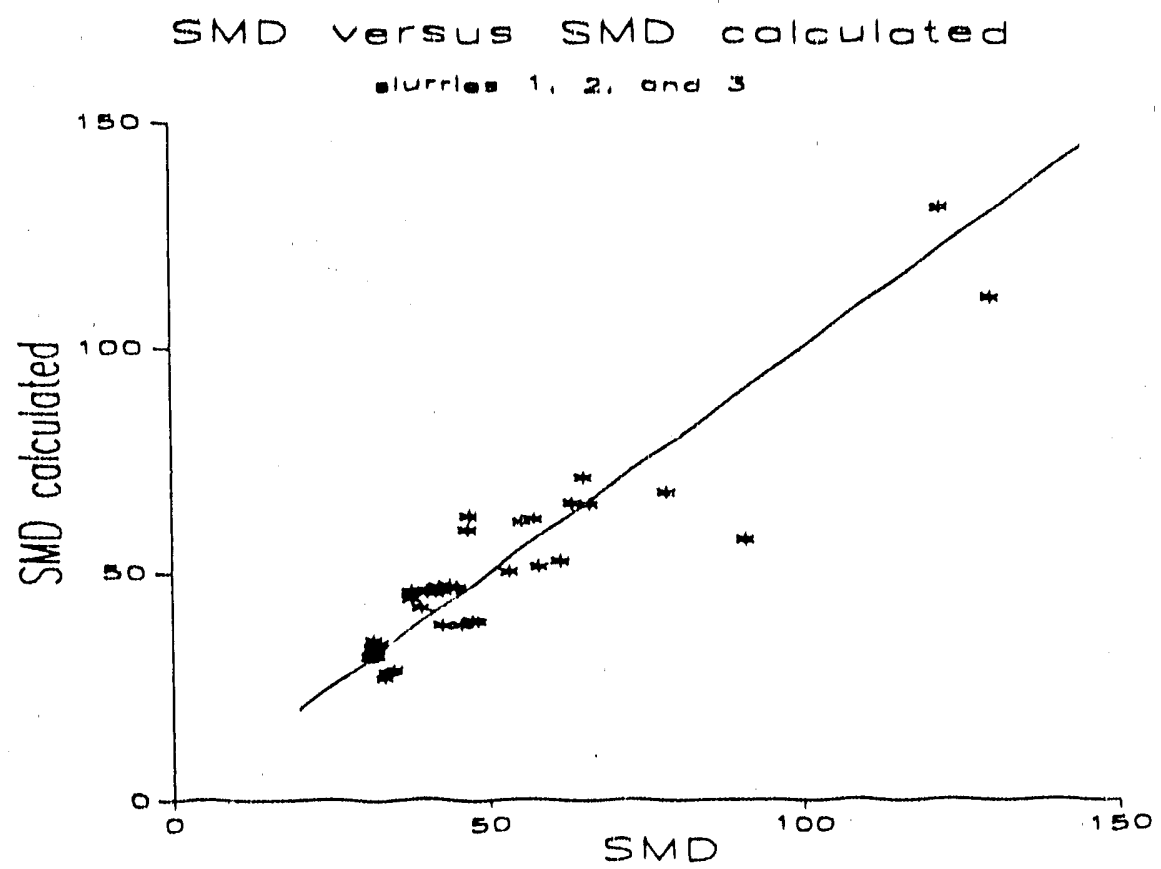

Figure 34. Calculated Sauter mean diameter versus measured Sauter mean diameter for the undiluted coal-water slurries.
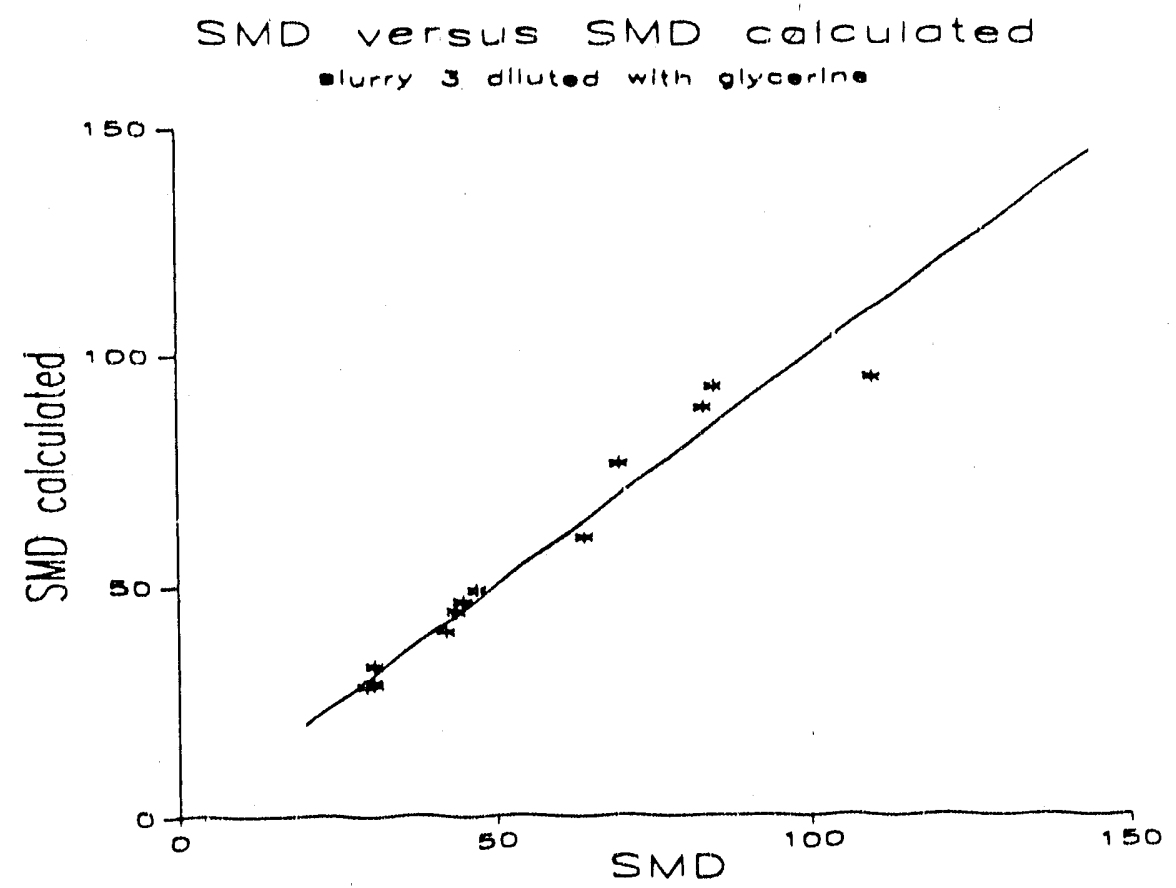

Figure 35. Calculated Sauter mean diameter versus measured Sauter mean diameter for the coal-water slurry diluted with glycerine. 


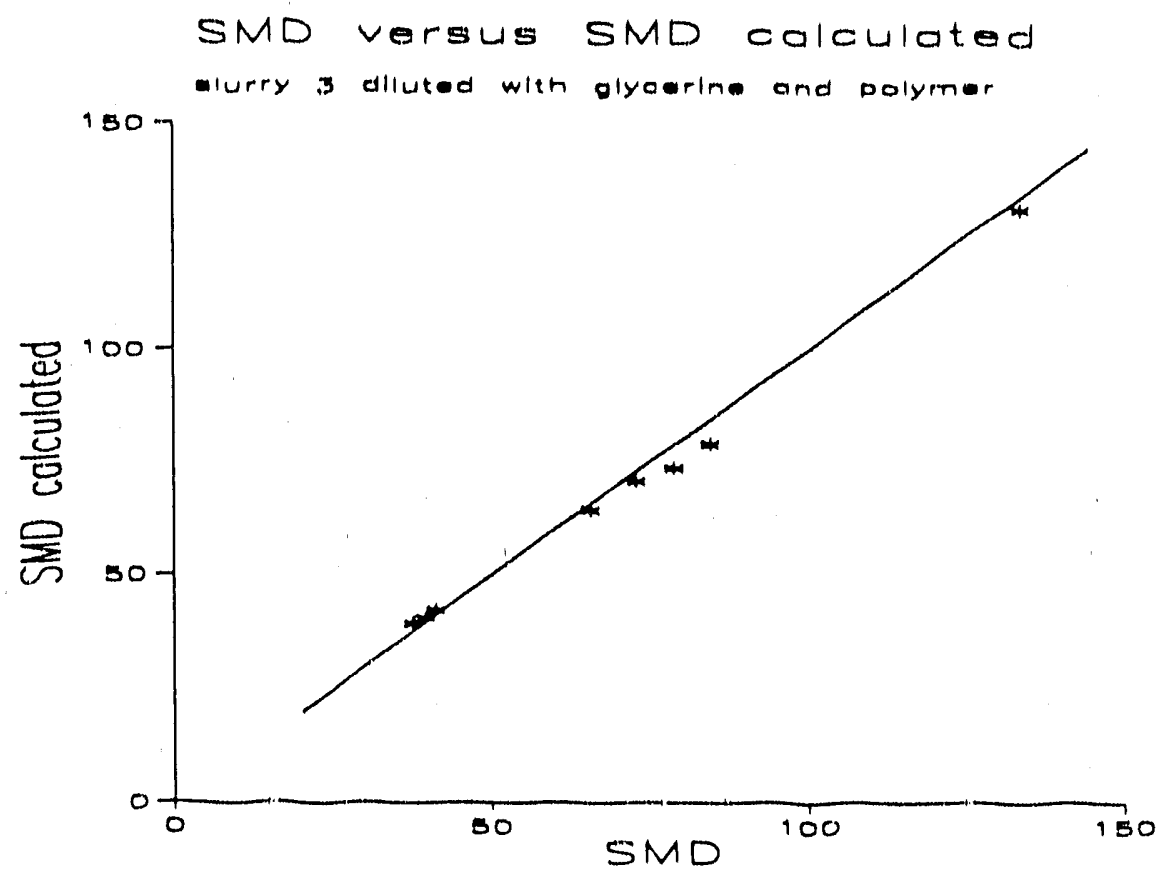

Figure 36. Calculated Sauter mean diameter versus measured Sauter mean diameter for coal-water slumy diluted with glycerine and polymer.

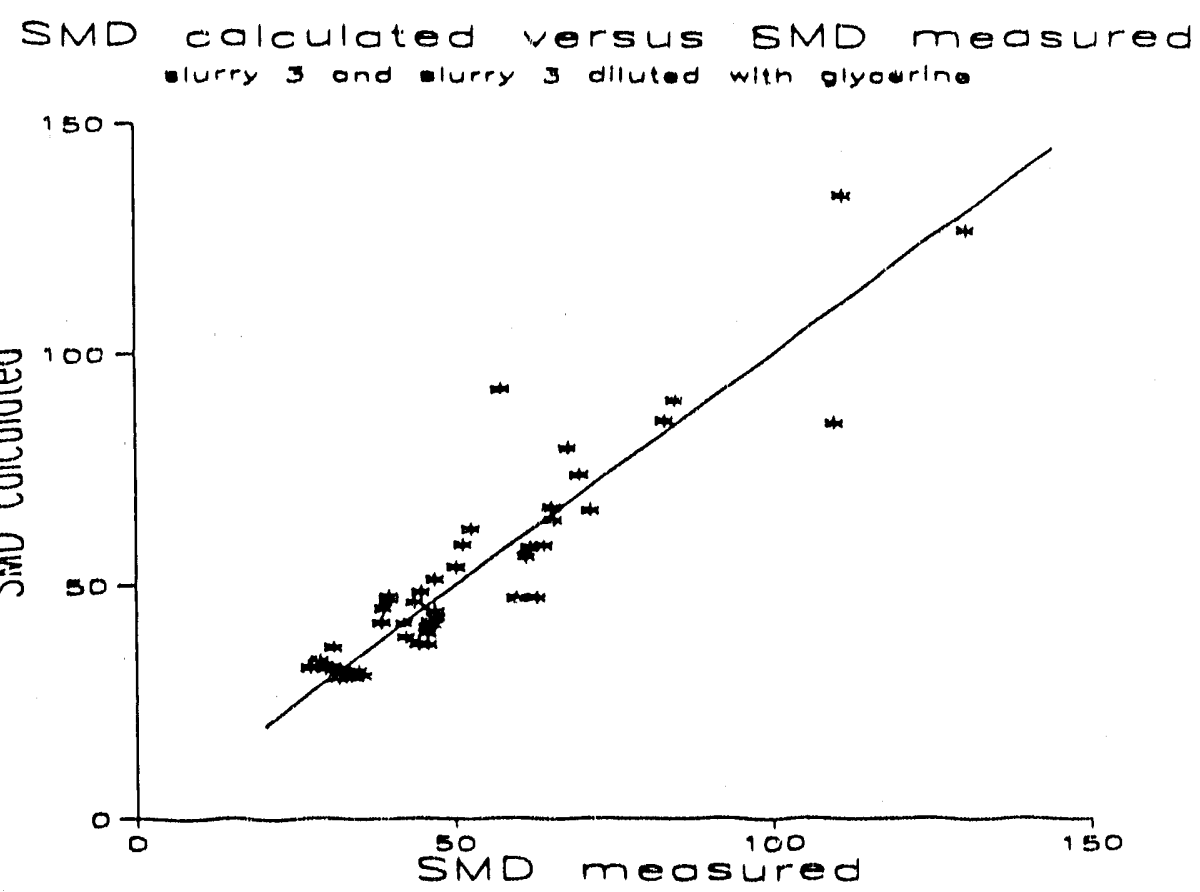

Figure 37. Calculated Sauter mean diameter yersus measured Sauter mean diameter for coal-water slurry undiluted and diluted with glycerine. 


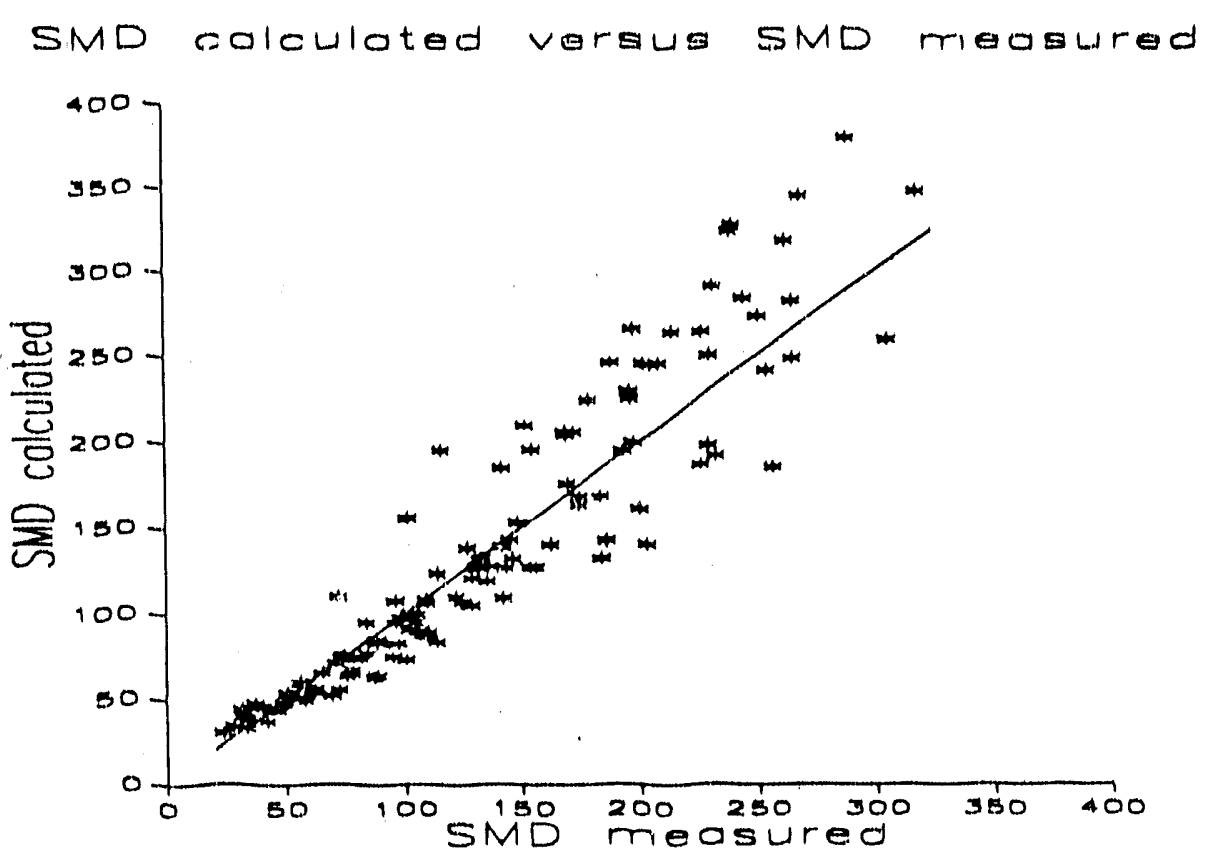

Figure 38. Calculated Sauter mean diameter versus measured Sauter mean diameter for water, Roesler [1988].

A comparison of the experimental data from glycerine and water test 1 with Roesler's water data correlation indicated a close match. A curve fit was performed on the combined data and is reported in Table 4. Figures 39 and 40 show $E$ versus ALR and a curve fit for the glycerine and water test 1 data and for Roesler's data, respectively. Figure 41 shows $\varepsilon$ versus Al.R for the combined data. A common correlation for the two sets together matches well with either data set even though viscosity changes by three orders of magnitude and the flow structure changes from bubbly to slug flow.

In summary, Figures 31 through 41 demonstrate that Equations (15) and (20) do indeed describe the data of Section 4. These equations, and the assumptions employed in their development, provide the following picture of effervescent atomization. 
Eipsilon versus Air liquld ratio

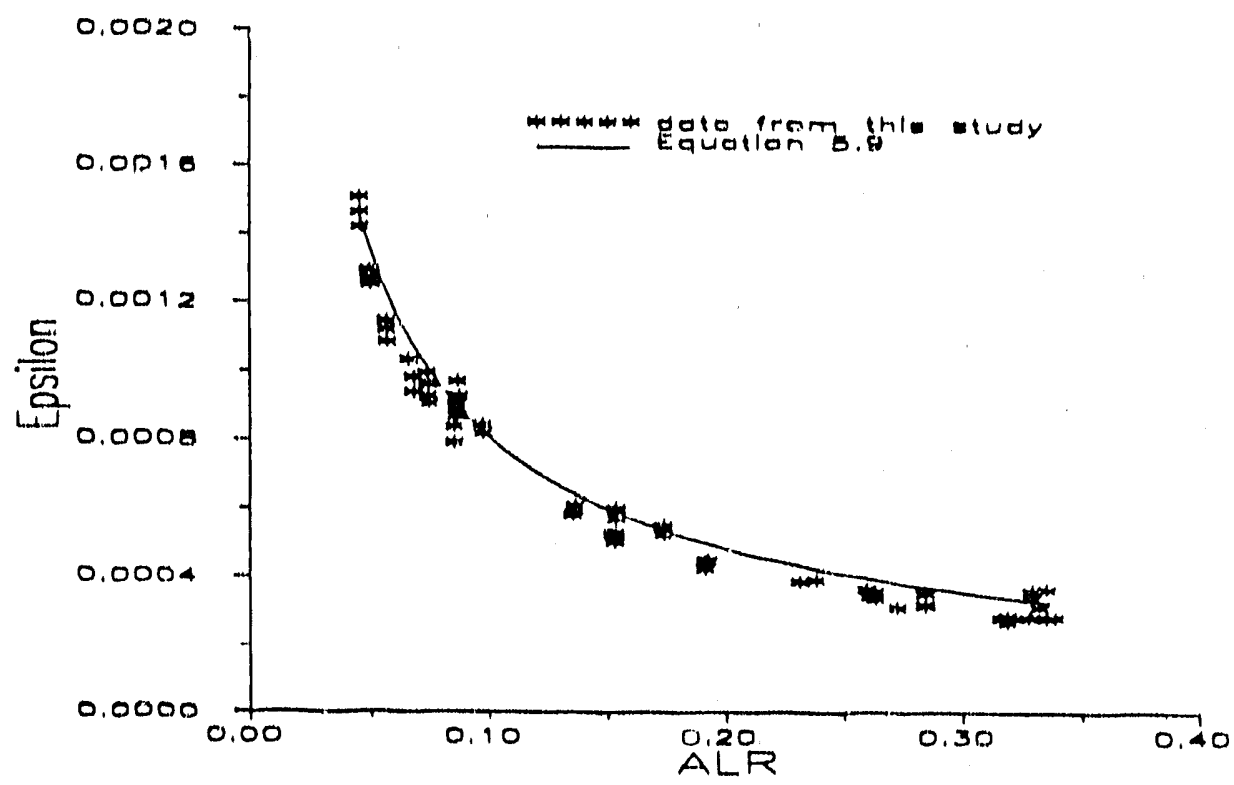

Figure 39. Epsilon versus air-liquid ratio for data extracted from glycerine and water test 1.

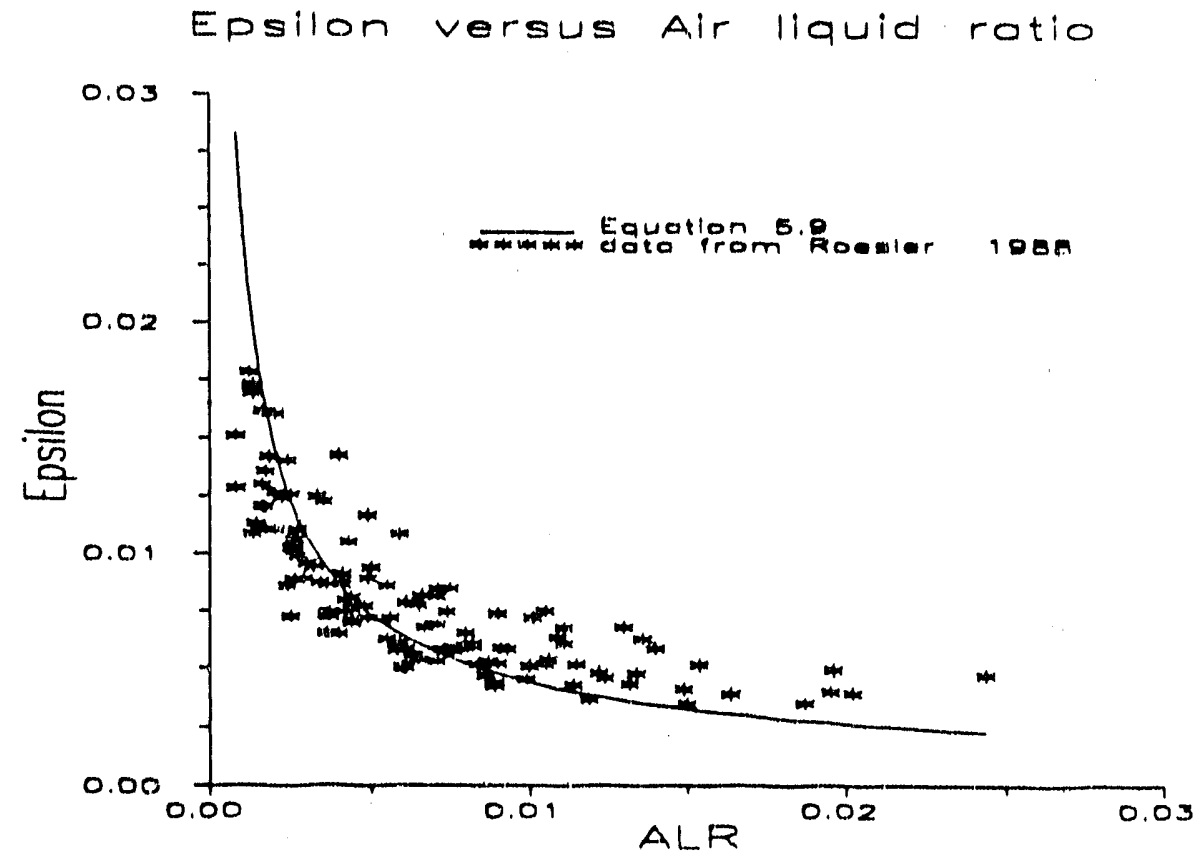

Figure 40. Epsilon versus air-liquid ratio for water data extracted from Roesler [1988]. 


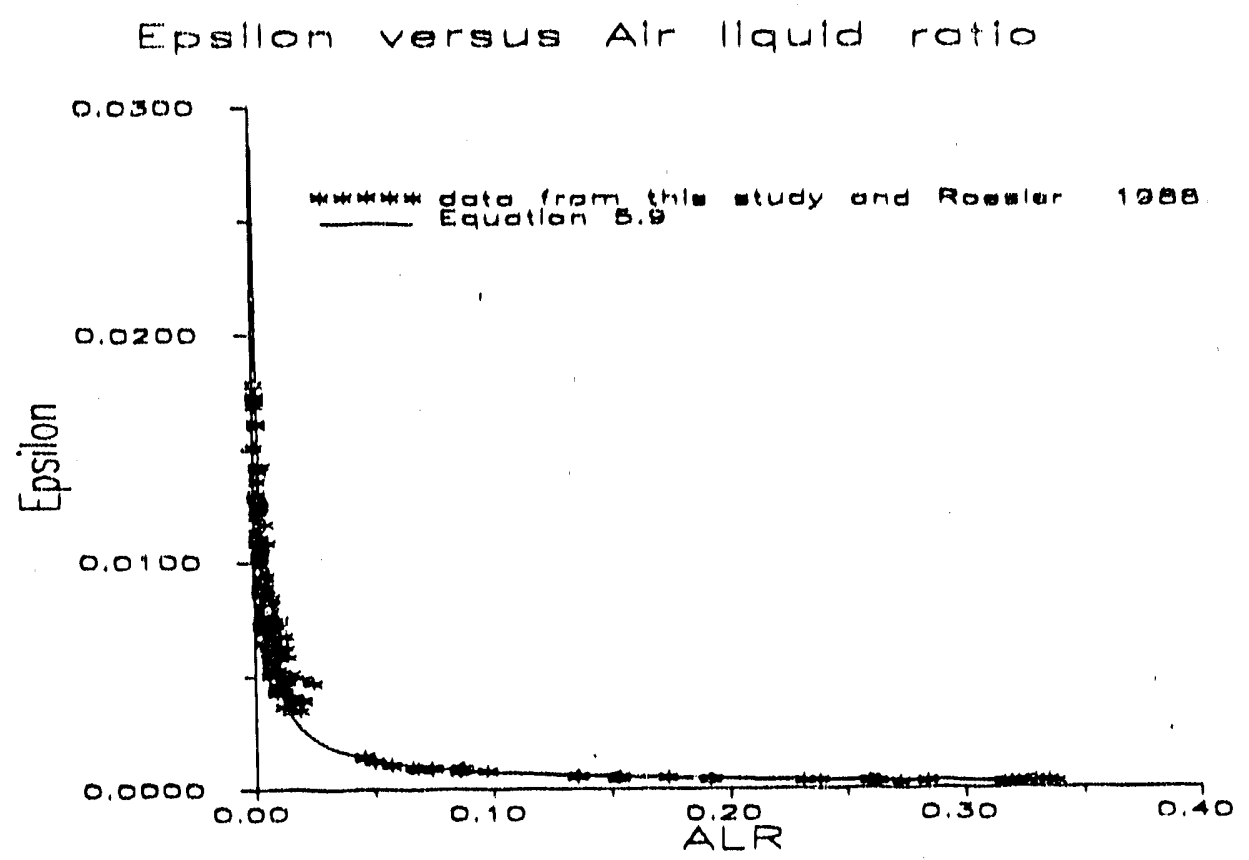

Figure 41. Epsilon versus air-liquid ratio for combined glycerine and water test 1 data, and that of Roesler [1988].

- The low values of $\varepsilon$ indicated in Figures 31 and 39 through 41 demonstrate that only a small portion of the air bubbled into the liquid actually participates in the atomization process. The rest simply passes through the control volume, neither helping nor hindering the droplet formation process. As a result, the process is inefficient, even though it produces very small mean drop sizes when spraying a wide variety of highly viscous fluids. Obviously, the cause for this inefficiency should be investigated. But it should not cause alarm for two reasons. First, atomizers in general have low elficiencies, with $\varepsilon$ values generally estimated to be below $1 \%$. Second, the effervescent nozzle employed in this investigation was designed to facilitate research into the spray formation process with no efrort expended to optimize its performance. As a result, a commercial device is expected to exhibit a significantly greater efficiency. 
- The efficiency of the nozzle, as indicated by the parameter $\varepsilon$, decreases with ALR.

The cause for this behavior is at present unknown, but two hypotheses must be considered.

First, the increase in ALR is leading to a coalescence of bubbles within the nozzle body because of the length of observation tube located between the aerator tube and the final orifice and because of the increase in bubble number density. A consequence is the formation of slugs within the nozzle. Bubbly flow is expected to be more efficient since it results in more intimate contact between the gas and the liquid, thus ensuring that more of the energy available during expansion goes into increasing the liquid surface energy.

Second, the increase in ALR will reduce the sheathing effect of the liquid, even in the absence of bubble coalescence. The reduction in sheathing will lead directly to a decrease in efficiency since the air will expand more freely, encounter less liquid during that expansion, and therefor contribute less of its energy to increasing the surface energy of the liquid.

- The efficiency of the nozzle, again as indicated by $\varepsilon$, decreases when polymer is added to a fluid. Note that this effect should not be attributed to a change in fluid rheology, as indicated by the power law parameters $\mathrm{n}$ and $\mathrm{K}$, since the data of Section 4:4 exhibit no $s_{\jmath}$ stematic correlation between SMD and either $n$ or K. Instead, two alternative explanations must be considered.

First, the addition of polymer could result in a rheological effect we are presently unable to det:rmin. Viscoelasticity and yield stress are two e.amples. Both are energy loss mechanisms and are expected to affect the spray formation process in much the same manner as surface tension. For instance, a yield stress resuits in a force that must be overcome by air flowing past a droplet before it will deform and 
break apart. As a result, a velocity difference that leads to droplet disintegration in the absence of a yield stress may not do so when the yield siress is present. Since droplets undergo rapid acceleration upon leaving the nozzle while the air is undergoing rapid deceleration, it is clear that the limited time during which a droplet is subject to relative velocities large enough to break it apart is decreased. The result is droplets of larger size. Viscoelastic effects are similar in that the restoring force must be overcome before a droplet can break up. Viscoelasticity can therefor reduce the interval during which a droplet is exposed to relative velocities large enough to break it apart with the result that larger droplets remain in the spray. Second, the addition of polymer may act to increase the surface tension with the obvious result that SMD increases. Support for this hypothesis is provided by investigations into the two-phase flow of mixtures of air and non-Newtonian liquids. Mahalingam and Valle [1972], for instance, suggest that fluids of increasing pseudoplasticity have lessened interaction between the phases. This would result in a decrease in the transfer of energy from the air to the liquid with a corresponding increase in mean drop size. Oliver and Young-Hoon [1968] also note that viscoelasticity damps waves that occur in air-Newtonian liquid flow suggesting a decrease in energy transfer upon addition of polymers.

- The process commonly referred to as secondary atomization dominates sprays formed using effervescent atomizers. This conclusion is supported by the lack of a relationship between liquid rheology (or viscosity) and $\mathrm{SMD}$, and by the form of the expression that describes the data of Section 4, namely Equation (15). This expression can be rewritten as 


$$
S M D_{d}=\frac{12 \sigma}{\rho_{L}\left(V_{L 1}-V_{A 1}\right)^{2}}\left(1+\frac{1}{\varepsilon A L R}\right)
$$

which is simply 12 times the quantity $\left(1+\frac{1}{C L R}\right)$ divided by the Weber number.

\subsection{Summary}

The analysis developed here showed that effervescent atomization can be described using two-phase separated flow theory, energy conservation, momentum conservation, and mass conservation, if ALR, $\sigma_{1}, \rho_{1}$, and the air and liquid velocities are known. Atomization was also shown to be insensitive to changes in viscosity, consistency index, and flow behavior index. The efficiency of the process, in terms of the parameter $\varepsilon$, is low, but consistent with other spray nozzles. The efficiency decreases with ALR and with the addition of polymers. Explanations were proposed for both effects. Finally, secondary atomization was shown to dominate the spray formation process, based on the absence of a dependence of SMD on fluid rheology and the reduction of the expression for SMD to a function of the Weber number. 


\section{SUMMARY AND CONCLUSIONS}

\subsection{Summary}

A rigorous study of the effervescent atomization of high viscosity Newtonian fluids has been completed. The emphasis was on the formation of CWS sprays using the effervescent technique. The unique feature of effervescent atomization, injection of gas bubbles into the liquid while still within the nozzle body, was introduced. The effect of gas injection, choking the flow at the nozzle exit and the resulting production of a pressure jump that ruptures the bubbles as they cross the exit plane, was noted.

The study was performed in three steps: first, Newtonian fluids were sprayed with viscosities varying from 300 to $1000 \mathrm{cP}$; second, non-Newtonian fluids were sprayed with consistency indices ranging from $400-968 \mathrm{cp}-s^{1-n}$ and flow behavior indices ranging form 0.85 to 0.95 ; finally, coal water slurries were sprayed with varying consistency index, flow behavior index, coal loading and top size. In each study, pressure and air-liquid ratio (ALR) were varied from 0.6 $\mathrm{MPa}$ to $2.1 \mathrm{MPa}$ and 0.043 to 0.34 , respectively, with exception of the CWS portion where ALR varied from 0.043 to 0.17 .

Three goals were to be met during this study. They were

- to demonstrate that effervescent atomization can produce CWS sprays with mean drop sizes below $50 \mu m$

- to determine a lower size limit for effervescent atomizer produced CWS sprays - to determine the mechanism(s) responsible for the formation of effervescent atomizer produced sprays

The first goal was accomplished using a three step approach, where single phase non-Newtonian and coal-water slurry sprays were formed using an effervescent atom- 
izer. The results were presented in Section 4 and clearly demonstrated that the effervescent technique successfully atomized each of the fluids. Several qualitative features were also evident upon inspection of the data.

First, ALR was shown to have the greatest impact on atomization quality, SMD dropping dramatically between ALR values of 0.043 and about 0.20 . Beyond an ALR of about 0.20 SMD dropped very little. Pressure had a significant effect on SMD in the ALR region below about 0.20 . However this effect diminished dramatically as ALR increased beyond about 0.20 .

The mechanism responsible for the influence of ALR is evident when one considers that to effectively transfer the energy of the air to the liquid, the two fluids must be in intimate contact. Therefor, at low ALR the atomizing air is surrounded with liquid that shields it from losses to the ambient so that a larger portion of the atomizing air energy goes into increasing the liquid surface energy. As ALR increases, however, the liquid film surrounding each bubble becomes thinner producing smaller droplets when the bubbles expand downstream of the final orifice. In addition, losses to the ambient increase since the liquid shield is less effective in insulating the expanding bubbles from the ambient at higher ALR. Eventually, the effect of ALR disappears since ambient losses dominate as ALR increases.

The effect of pressure on SMD is less substantial than that of ALR, but its effects are similar. At low ALR, the air is protected by a shroud of liquid as it expands. By increasing the pressure, the energy of the air is increased and the air is able to do more work on the liquid, therefor producing smaller droplets. As ALR is increased, however, the liquid shroud becomes less effective and losses to the ambient air become more substantial; therefore, a greater portion of the increase in energy of the air, due to an increase in its pressure, is lost to the ambient. The losses to the 
ambient at high ALR eventually dominate the process such that an increase in pressure has no observable effect on SMD.

Seconch, fluid rheology, as characterized by $\mathrm{n}$ and $\mathrm{K}$, had little to no effect on SMN For the Newtonian study, viscosity changed two fold with no change in SMD observed. The non-Newtonian fluids showed no consistent change in SMD even though flow behavior index varied between 0.85 and 0.95 and consistency index varied between 400 and $968 c p-s^{1-n}$. These results were repeated when spraying CWS.

The lack of an effect of $\mathrm{n}$ and $\mathrm{K}$ is explained by considering the two mechanisms of droplet formation. Primary atomization results from the shearing action between the liquid and air with liquid viscosity the controlling property. Secondary atomization results from pressure forces that arise from high velocity air passing over a ligament or drop. Surface tension resists this latter force. In effervescent atomization, the fluid rheological properties had no effect on the drop size; therefore, it was concluded that primary atomization was not the controlling process. However, the air velocities were very high, thus it was also concluded that secondary atomization was the mechanism controlling atomization.

Third, SMD increased when atomizing solutions that contained polymer, especially in the low ALR region. This effect is not to be attributed to a variation in either $\mathrm{n}$ or $\mathrm{K}$ since no consistent relationship between SMD and either parameter was observed. Instead, the increase is believed to resull from either the viscoelastic properties or yield stresses characteristic of the polymer solutions. This hypothesis could not be tested, how'ver, since the availacie rheological instrumentation was incapable of providing the riecessary data. 
The second goal was not accomplished, since the lower limit for effervescent atomization produced sprays has yet to be observed. It is likely that one does exist, but it must be below $25 \mu \mathrm{m}$ since such sprays were routinely produced during this study.

The third goal was accomplished by developing a model of the effervescent spray formation process and then using that model to determine the physical processes important to effervescent atomization. Several conclusions were reached.

The low values of $\varepsilon$ observed in Section 5 demonstrate that only a small portion of the air bubbled into the liquid actually participated in the atomization process. As a result, the process was inefficient, even though it produced very small mean drop sizes when spraying a wide variety of highly viscous fluids.

The efficiency of the nozzle, as indicated by the parameter $\varepsilon$, decreased with ALR. There are two possible explanations. First, the increase in ALR may have lead to a coalescence of bubbles within the nozzle body, the subsequent formation of slugs, and thus a decrease in efficiency because the less intimate contact between the gas and the liquid ensured less of the energy available during expansion went into increasing the liquid surface energy. Second, the increase in ALR may have reduced the sheathing effect of the liquid, even in the absence of bubble coalescence, leading directly to a decrease in efficiency since the air expanded more freely, encountered less liquid during that expansion, and therefor contributed less of its energy to increasing the surface energy of the liquid.

The efficiency of the nozzle, again as indicated by $\varepsilon$, decreased when polymer is added to a fluid. Note that this effect should not be attributed to a change in fluid rheology, as indicated by the power law parameters $n$ and $K$, since the data of Section 4.4 exhibited no systematic correlation between SMD and either $n$ or $K$. Instead, two 
alternative explanations were considered. First, the addition of polymer could have resulted in a rheological effect we are presently unable to determine. Viscoelasticity and yield stress are two examples. Both are energy loss mechanisms and are expected to affect the spray formation process in much the same manner as surface tension. Second, the addition of polymer may have acted to increase the surface tension with the obvious result that SMD increased. Support for this hypothesis is provided by investigations into the two-phase flow of mixtures of air and non-Newtonian liquids, notably Mahalingam and Valle [1972] and Oliver and Young-Hoon [1968], who noted that fluids of increasing pseudoplasticity have lessened interaction between the phases and that viscoelasticity damps waves that occur in air-Newtonian liquid flow, therefor suggesting a decrease in energy transfer upon addition of polymers.

Finally, the process commonly referred to as secondary atomization dominated sprays formed using effervescent atomizers. This conclusion is supported by the lack of a relationship beiween liquid rheology (or viscosity) and SMD, and by the form of the expression that describes the data of Section 4, narnely Equation (15), which can be rewritten as 12 times the quantity $\left(1+\frac{1}{C A L R}\right)$ divided by the Weber number.

\subsection{Conclusions and Recommendations for Future Work}

In conclusion, effervescent atomization is an effective means of atomizing highly viscous Newtonian and non-Newtonian fluids and can be applied in areas where orifice diameter must be large to circumvent clogging. It produces sprays using low pressures and low air-liquid ratios (ALR) making it attractive in many applications including the atomization of coal-water slurry in gas turbines and internal combustion engines.

Effervescent atomization can be commercialized upon solution of the following problems. 
First, the efficiency must be improved. Such an improvement will yield two benefits: smaller mean drop sizes at fixed ALR, or an equivalent mean drop size at a lower value of ALR. The former would improve combustion efficiency while the latter would reduce the cost associated with operating an effervescent injection system. Improvement of the efficiency can most easily be accomplished by a systematic investigation of the physical processes occurring immediately downstream of the nozzle final orifice.

Second, the effects of polymer addition must be understood. At present, the best that can be ciffered is that an as yet undetermined rheological property is responsible for the increase in SMD that occurs when spraying polymeric fluids at low ALR values. That property must be identified so slurry manufacturers can formulate additive packages which minimize its effect. Identification can be accomplished by more detailed rheological characterization of the test fluids in concert with test fluid selection which emphasizes differences in viscoelastic and yield stress behavior. 


\section{REFERENCES}

Brown, R. and York, J. L. [1962]. "Sprays Formed by Flashing Liquid Jets," Arnerican Institute Chemical Engineers Journal, 8(2), 149-153.

Chapra, S. C. and Canale, R. P. [1985]. Numerical Methods for Engineers with Personal Computer Applications, McGraw-Hill, New York

Chawla, J. B. [1985]. "Atomisation of Liquids Employing the Low Sonic Velocity of Liquid/Gas Mixtures," LP/1 A/5/1-LP/1A/5/7 in Proceedings 3rd International Conference on Liquid Atomisation and Spray Systems, Institute of Energy, London.

Dodge, L. [1984]. "Change of Calibration of Diffraction-Based Particle Sizers in Dense Sprays," Optical Engineering, 23(5), 212-217.

Elliot, D. G. [1960]. "Investigation of a Gas-Driven Jet Purnp for Rocket Engines, Li(1uid Rockets and Propellants, 2, 497-513.

Hirleman, H. D., [1983]. "On Line Calibration Techniques for Laser Diffraction Droplet Sizing Instruments," ASME paper 83-GT-232.

Knoll, K. E. [1989]. MS Thesis, Purdue University.

Lefebvre, A. H. [1980]. "Airblast Atomization," Progress Energy Combustion Science 6. 233-261.

Lefebvre, A. H., Wang, X. F., and Martin, C. A., [1988]. "Spray Characieristics of Aerated-Liquid Pressure Atomizers," AIAA Journal Propulsion and Power, 4, 293-298.

Lefebvre, Arthur H. [1990]. "Energy considerations in Twin-Fluid Atomization," ASME 90-GT-3.

Mahalingam, R. and Valle, M. A. [1972]. "Momentum Transfer in Two-Phase Flow of Gas-Pseudoplastic Mixtures," Industrial Engineering Chemistry Fundamentals 11(4), 470-477.

Netzer, D. W. [1962]. MS Thesis, Purdue University.

Oliver, D. R. and Young-Hoon, A. [1968]. "Two-Phase Non-Newtonian Flow Part I:

Pressure drop and hold-up," Transactions Institute Chemical Engineers, 46, T106-T115.

Richards, G. A. [1987]. Ph.D. Thesis, Purdue University.

Rizk, N. K. and Lefebvre, A. H. [1984]. "Mcasurements of Drop Size Distribution by a Light Scattering Technique," Liquid Particle Size Measuremert Techniques, ASTM STP $848,61-71$.

Roesler, T. C. [1987]. Personal communication.

Roesler, T. C. [1988]. Ph.D. Thesis, Purdue University. 
Roesler, T. C. and Lefebvre, A. H., [1987]. "Studies on Aerated-Liquid Atomization," ASME Paper 87-WA/HT-17.

Rosfjord, T. J. [1985]. "Atomization of Coal Water Mixtures: Evaluation of Fuel Nozzles and a Cellulose Gum Simulaint," ASME paper 85-GT-88.

Sakai, T., Kito M., Saito M., and Kanbe, T. [1978]. "Characteristics of Internal Mixing Twin-Fluid Atomizer," in Proceedings Ist International Conference on Liquid Atomisation and Spray Systems, 235-241.

Sher, E. and Elata, C. [1977]. "Spray Formation from Pressure Cans by Flashing," Industrial Engineering Chemistry and Process Design Reviews, 16(2), 237-242.

Solomon, A. S. P., Ruprecht, S. D., Chen, L. D., and Faeth, G. M., [1985]. "Flow and Atomization in Flashing Injectors," Atomization and Spray Technology, 1, 53-76.

Swithenbank, J., Beer, J. M., Taylor, D. S., Abbot, D., and McCreath, G. C. [1976]. "A Laser Diagnostic Technique for the Measurement of Droplet and Particle Size Distribution," paper 76-69, AiAA Aerospace Sciences Meeting, January.

Van de Hulst, H. C. [1981]. Light Scautering by Small Particles, Dover, New York.

G. B. Wallis [1969]. One-dimensional Two-phase Elow, McGraw-Hill, New York.

Wang, X. F., Chin, J. S., and Lefebure A. H., [1987]. "Influence of Gas-Injector Geometry on Atomization Performance of Aerated-liquid Nozzles," Heat Transfer in Furnaces, ASME 74, 11-18.

Whitlow, J. [1990]. Personal communication. 
Glycerine-Water Mixture Data From Test 1

$\begin{array}{ccccccccc}\mathbf{K} & \text { ALR } & \text { Pd } & \text { SMD } & \text { Liquid } & \text { Air } & \text { Surface } & \text { Ta } & \text { Density } \\ c p-s^{(n-1)} & & M P a & \mu m & \text { Mass } & \text { Mass } & \text { Tension } & C & g / \mathrm{cm}^{3} \\ & & & & g / s & g / s & d y n / c m & & \end{array}$

$\begin{array}{lllllllll}384 & 0.0493 & 0.7928 & 31.85 & 28.6 & 1.41 & 64 & 20 & 1.26 \\ 384 & 0.0500 & 0.7928 & 31.48 & 28.2 & 1.41 & 64 & 20 & 1.26 \\ 384 & 0.0500 & 0.7928 & 32.31 & 28.2 & 1.41 & 64 & 20 & 1.26 \\ 384 & 0.0741 & 0.8962 & 26.86 & 24.3 & 1.80 & 64 & 20 & 1.26 \\ 384 & 0.0741 & 0.8962 & 26.98 & 24.3 & 1.80 & 64 & 20 & 1.26 \\ 384 & 0.0747 & 0.8962 & 28.40 & 24.1 & 1.80 & 64 & 20 & 1.26 \\ 384 & 0.1517 & 1.0341 & 22.78 & 17.6 & 2.67 & 64 & 20 & 1.26 \\ 384 & 0.1534 & 1.0341 & 22.85 & 17.4 & 2.67 & 64 & 20 & 1.26 \\ 384 & 0.1534 & 1.0341 & 22.36 & 17.4 & 2.67 & 64 & 20 & 1.26 \\ 384 & 0.2311 & 0.8273 & 21.95 & 10.3 & 2.38 & 64 & 20 & 1.26 \\ 384 & 0.2380 & 0.8273 & 20.90 & 10.0 & 2.38 & 64 & 20 & 1.26 \\ 384 & 0.3161 & 1.1030 & 19.68 & 11.2 & 3.54 & 64 & 20 & 1.26 \\ 384 & 0.3218 & 1.1030 & 19.41 & 11.0 & 3.54 & 64 & 20 & 1.26 \\ 384 & 0.3218 & 1.1030 & 19.41 & 11.0 & 3.54 & 64 & 20 & 1.26 \\ 384 & 0.3278 & 1.1030 & 18.86 & 10.8 & 3.54 & 64 & 20 & 1.26 \\ 420 & 0.0496 & 0.7928 & 31.47 & 28.4 & 1.41 & 64 & 20 & 1.26 \\ 420 & 0.0498 & 0.7928 & 32.26 & 28.3 & 1.41 & 64 & 20 & 1.26 \\ 420 & 0.0498 & 0.7928 & 31.87 & 28.3 & 1.41 & 64 & 20 & 1.26 \\ 420 & 0.0735 & 0.8962 & 26.29 & 24.5 & 1.80 & 64 & 20 & 1.26 \\ 420 & 0.0741 & 0.8962 & 27.96 & 24.3 & 1.80 & 64 & 20 & 1.26 \\ 420 & 0.0741 & 0.8962 & 27.00 & 24.3 & 1.80 & 64 & 20 & 1.26 \\ 420 & 0.1526 & 1.0341 & 23.75 & 1 \% .5 & 2.67 & 64 & 20 & 1.26 \\ 420 & 0.1526 & 1.0341 & 23.02 & 17.5 & 2.67 & 64 & 20 & 1.26 \\ 420 & 0.1534 & 1.0341 & 23.52 & 17.4 & 2.67 & 64 & 20 & 1.26 \\ 420 & 0.3189 & 1.1030 & 20.46 & 11.1 & 3.54 & 64 & 20 & 1.26 \\ 420 & 0.3189 & 1.1030 & 19.14 & 11.1 & 3.54 & 64 & 20 & 1.26 \\ 520 & 0.0858 & 0.8273 & 25.35 & 17.6 & 1.51 & 64 & 20 & 1.26 \\ 520 & 0.0863 & 0.8273 & 25.05 & 17.5 & 1.51 & 64 & 20 & 1.26 \\ 520 & 0.0863 & 0.8273 & 25.55 & 17.5 & 1.51 & 64 & 20 & 1.26 \\ 520 & 0.1537 & 0.8962 & 20.64 & 13.6 & 2.09 & 64 & 20 & 1.26 \\ 520 & 0.1537 & 0.8962 & 21.59 & 13.6 & 2.09 & 64 & 20 & 1.26 \\ 520 & 0.1537 & 0.8962 & 20.51 & 13.6 & 2.09 & 64 & 20 & 1.26 \\ 520 & 0.2592 & 1.2065 & 18.06 & 10.3 & 2.67 & 64 & 20 & 1.26 \\ 520 & 0.2618 & 1.2065 & 18.75 & 10.2 & 2.67 & 64 & 20 & 1.26 \\ 520 & 0.2724 & 1.2065 & 20.06 & 9.8 & 2.67 & 64 & 20 & 1.26 \\ 520 & 0.2840 & 1.2065 & 16.96 & 9.4 & 2.67 & 64 & 20 & 1.26 \\ 520 & 0.2840 & 1.2065 & 18.63 & 9.4 & 2.67 & 64 & 20 & 1.26 \\ 520 & 0.2840 & 1.2065 & 18.94 & 9.4 & 2.67 & 64 & 20 & 1.26 \\ & & & & & & & & \end{array}$


Glycerine-Water Mixture Data For Test 1 (continued)

$\begin{array}{lllllllll}\mathbf{5 3 7} & 0.0454 & 0.8273 & 28.82 & 26.3 & 1.19 & 64 & 20 & 1.26 \\ \mathbf{5 3 7} & 0.0454 & 0.8273 & 29.70 & 26.3 & 1.19 & 64 & 20 & 1.26 \\ \mathbf{5 3 7} & 0.0456 & 0.8273 & 30.43 & 26.2 & 1.19 & 64 & 20 & 1.26 \\ \mathbf{5 3 7} & 0.0861 & 0.9652 & 24.32 & 20.8 & 1.79 & 64 & 20 & 1.26 \\ \mathbf{5 3 7} & 0.0865 & 0.9652 & 22.16 & 20.7 & 1.79 & 64 & 20 & 1.26 \\ \mathbf{5 3} & 0.0873 & 0.9652 & 22.97 & 20.5 & 1.79 & 64 & 20 & 1.26 \\ \mathbf{5 3 7} & 0.1736 & 1.1030 & 18.50 & 15.3 & 2.66 & 64 & 20 & 1.26 \\ \mathbf{5 3 7} & 0.1736 & 1.1030 & 18.74 & 15.3 & 2.66 & 64 & 20 & 1.26 \\ \mathbf{5 3 7} & 0.1736 & 1.1030 & 19.45 & 15.3 & 2.66 & 64 & 20 & 1.26 \\ \mathbf{5 3 7} & 0.3291 & 1.1720 & 14.41 & 10.7 & 3.52 & 64 & 20 & 1.26 \\ 537 & 0.3291 & 1.1720 & 15.21 & 10.7 & 3.52 & 64 & 20 & 1.26 \\ \mathbf{5 3 7} & 0.3322 & 1.1720 & 16.40 & 10.6 & 3.52 & 64 & 20 & 1.26 \\ \mathbf{5 3 7} & 0.3354 & 1.1720 & 13.94 & 10.5 & 3.52 & 64 & 20 & 1.26 \\ 874 & 0.0662 & 0.8273 & 28.74 & 21.2 & 1.40 & 64 & 20 & 1.26 \\ 874 & 0.0681 & 0.8273 & 29.40 & 20.6 & 1.40 & 64 & 20 & 1.26 \\ 874 & 0.0681 & 0.8273 & 30.71 & 20.6 & 1.40 & 64 & 20 & 1.26 \\ 874 & 0.0973 & 0.8962 & 23.17 & 18.4 & 1.79 & 64 & 20 & 1.26 \\ 874 & 0.0973 & 0.8962 & 23.91 & 18.4 & 1.79 & 64 & 20 & 1.26 \\ 874 & 0.1911 & 1.1720 & 21.29 & 13.9 & 2.66 & 64 & 20 & 1.26 \\ 874 & 0.1911 & 1.1720 & 20.25 & 13.9 & 2.66 & 64 & 20 & 1.26 \\ 874 & 0.1925 & 1.1720 & 20.02 & 13.8 & 2.66 & 64 & 20 & 1.26 \\ 874 & 0.3322 & 1.2754 & 17.49 & 10.6 & 3.52 & 64 & 20 & 1.26 \\ 874 & 0.3354 & 1.2754 & 17.70 & 10.5 & 3.52 & 64 & 20 & 1.26 \\ 874 & 0.3386 & 1.2754 & 17.26 & 10.4 & 3.52 & 64 & 20 & 1.26 \\ 968 & 0.0566 & 0.8962 & 29.62 & 21.1 & 1.19 & 64 & 20 & 1.26 \\ 968 & 0.0568 & 0.8962 & 30.17 & 21.0 & 1.19 & 64 & 20 & 1.26 \\ 968 & 0.0571 & 0.8962 & 30.97 & 20.9 & 1.19 & 64 & 20 & 1.26 \\ 968 & 0.0853 & 0.9996 & 25.72 & 17.6 & 1.50 & 64 & 20 & 1.26 \\ 968 & 0.0853 & 0.9996 & 27.23 & 17.6 & 1.50 & 64 & 20 & 1.26 \\ 968 & 0.0863 & 0.9996 & 24.58 & 17.4 & 1.50 & 64 & 20 & 1.26 \\ 968 & 0.1350 & 1.1720 & 22.16 & 15.4 & 2.08 & 64 & 20 & 1.26 \\ 968 & 0.1359 & 1.1720 & 21.60 & 15.3 & 2.08 & 64 & 20 & 1.26 \\ 968 & 0.1359 & 1.1720 & 21.03 & 15.3 & 2.08 & 64 & 20 & 1.26 \\ 968 & 0.2606 & 1.2754 & 18.77 & 11.3 & 2.94 & 64 & 20 & 1.26 \\ 968 & 0.2629 & 1.2754 & 18.88 & 11.2 & 2.94 & 64 & 20 & 1.26 \\ 968 & 0.2629 & 1.2754 & 17.75 & 11.2 & 2.94 & 64 & 20 & 1.26\end{array}$


Glycerine-Water Mixture Data From Test 2

$\begin{array}{ccccccccc}\mathrm{K} & \text { ALR } & \mathrm{Pd} & \mathrm{SMD} & \text { Liquid } & \text { Air } & \text { Surface } & \text { Ta } & \text { Density } \\ c p-s^{(n-1)} & & M P a & \mu m & \text { Mass } & \text { Mass } & \text { Tension } & C & \mathrm{~g} / \mathrm{cm}^{3} \\ & & & & \mathrm{~g} / \mathrm{s} & \mathrm{g} / \mathrm{s} & d y n / \mathrm{cm} & & \end{array}$

$\begin{array}{lllllllll}487 & 0.0427 & 0.8205 & 167.7 & 25.7 & 1.10 & 64 & 28 & 1.26 \\ 487 & 0.0432 & 0.8205 & 162.1 & 25.4 & 1.10 & 64 & 28 & 1.26 \\ 487 & 0.0436 & 0.8205 & 157.2 & 25.2 & 1.10 & 64 & 28 & 1.26 \\ 487 & 0.0821 & 0.9791 & 123.2 & 21.7 & 1.78 & 64 & 28 & 1.26 \\ 487 & 0.0825 & 0.9791 & 118.2 & 21.6 & 1.78 & 64 & 28 & 1.26 \\ 487 & 0.0828 & 0.9791 & 118.8 & 21.5 & 1.78 & 64 & 28 & 1.26 \\ 487 & 0.1154 & 1.1583 & 98.6 & 20.4 & 2.36 & 64 & 28 & 1.26 \\ 487 & 0.1166 & 1.1583 & 97.6 & 20.2 & 2.36 & 64 & 28 & 1.26 \\ 487 & 0.1172 & 1.1583 & 100.3 & 20.1 & 2.36 & 64 & 28 & 1.26 \\ 487 & 0.1674 & 1.2411 & 79.6 & 17.5 & 2.93 & 64 & 28 & 1.26 \\ 487 & 0.1682 & 0.9928 & 83.3 & 14.0 & 2.36 & 64 & 28 & 1.26 \\ 487 & 0.1683 & 1.2411 & 84.4 & 17.4 & 2.93 & 64 & 28 & 1.26 \\ 487 & 0.1683 & 1.2411 & 84.2 & 17.4 & 2.93 & 64 & 28 & 1.26 \\ 487 & 0.1694 & 0.9928 & 83.1 & 13.9 & 2.36 & 64 & 28 & 1.26 \\ 487 & 0.1694 & 0.9928 & 86.7 & 13.9 & 2.36 & 64 & 28 & 1.26 \\ 487 & 0.2037 & 1.3927 & 73.1 & 17.2 & 3.50 & 64 & 28 & 1.26 \\ 487 & 0.2061 & 1.3927 & 73.2 & 17.0 & 3.50 & 64 & 28 & 1.26 \\ 487 & 0.2061 & 1.3927 & 72.4 & 17.0 & 3.50 & 64 & 28 & 1.26 \\ 487 & 0.2502 & 1.3100 & 68.8 & 14.0 & 3.50 & 64 & 28 & 1.26 \\ 487 & 0.2502 & 1.3100 & 68.5 & 14.0 & 3.50 & 64 & 28 & 1.26 \\ 487 & 0.2502 & 1.3100 & 68.7 & 14.0 & 3.50 & 64 & 28 & 1.26 \\ 487 & 0.2525 & 1.0618 & 73.0 & 11.6 & 2.93 & 64 & 28 & 1.26 \\ 487 & 0.2525 & 1.0618 & 70.7 & 11.6 & 2.93 & 64 & 28 & 1.26 \\ 487 & 0.2547 & 1.0618 & 70.0 & 11.5 & 2.93 & 64 & 28 & 1.26 \\ 487 & 0.2613 & 1.5168 & 65.3 & 15.6 & 4.08 & 64 & 28 & 1.26 \\ 487 & 0.2613 & 1.5168 & 65.1 & 15.6 & 4.08 & 64 & 28 & 1.26 \\ 487 & 0.2630 & 1.5168 & 63.6 & 15.5 & 4.08 & 64 & 28 & 1.26 \\ 487 & 0.3274 & 1.1170 & 63.8 & 10.7 & 3.50 & 64 & 28 & 1.26 \\ 487 & 0.3305 & 1.1170 & 62.6 & 10.6 & 3.50 & 64 & 28 & 1.26 \\ 487 & 0.3305 & 1.1170 & 63.1 & 10.6 & 3.50 & 64 & 28 & 1.26 \\ 487 & 0.3322 & 1.6547 & 59.0 & 14.0 & 4.65 & 64 & 28 & 1.26 \\ 487 & 0.3369 & 1.4065 & 59.7 & 12.1 & 4.08 & 64 & 28 & 1.26 \\ 487 & 0.3370 & 1.6547 & 59.1 & 13.8 & 4.65 & 64 & 28 & 1.26 \\ 487 & 0.3397 & 1.4065 & 60.3 & 12.0 & 4.08 & 64 & 28 & 1.26 \\ 487 & 0.3397 & 1.4065 & 60.8 & 12.0 & 4.08 & 64 & 28 & 1.26\end{array}$


Glycerine-Water Mixture Data From Test 2 (continued)

\begin{tabular}{|c|c|c|c|c|c|c|c|c|}
\hline 586 & 0.0423 & 0.7860 & 161.6 & 26.1 & 1.10 & 64 & 25 & 1.26 \\
\hline 586 & 0.0430 & 0.7860 & 137.6 & 25.7 & 1.10 & 64 & 25 & 1.26 \\
\hline 586 & 0.0431 & 0.7860 & 174.2 & 25.6 & 1.10 & 64 & 25 & 1.26 \\
\hline 586 & 0.0829 & 0.9928 & 129.8 & 21.6 & 1.79 & 64 & 25 & 1.26 \\
\hline 586 & $0.0 \leq 33$ & 0.9928 & 132.2 & 21.5 & 1.79 & 64 & 25 & 1.26 \\
\hline 586 & 0.0837 & 0.9928 & 136.2 & 21.4 & 1.79 & 64 & 25 & 1.26 \\
\hline 585 & 0.1196 & 1.1307 & 114.7 & 19.8 & 2.37 & 64 & 25 & 1.26 \\
\hline 586 & 0.1202 & 1.1307 & 107.4 & 19.7 & 2.37 & 64 & 25 & 1.26 \\
\hline 586 & 0.1208 & 1.1307 & 108.9 & 19.6 & 2.37 & 64 & 25 & 1.26 \\
\hline 586 & 0.1667 & 1.0066 & 91.8 & 14.2 & 2.37 & 64 & 25 & 1.26 \\
\hline 586 & 0.1667 & 1.0066 & 90.3 & 14.2 & 2.37 & 64 & 25 & 1.26 \\
\hline 586 & 0.1673 & 1.2686 & 86.2 & 17.6 & 2.94 & 64 & 25 & 1.26 \\
\hline 586 & 0.1683 & 1.2686 & 85.8 & 17.5 & 2.94 & 64 & 25 & 1.26 \\
\hline 586 & 0.1691 & 1.0066 & 87.3 & 14.0 & 2.37 & 64 & 25 & 1.26 \\
\hline 586 & 0.1692 & 1.2686 & 88.1 & 17.4 & 2.94 & 64 & 25 & 1.26 \\
\hline 586 & 0.2106 & 1.42 .03 & 72.8 & 16.9 & 3.56 & 64 & 25 & 1.26 \\
\hline 586 & 0.2131 & 1.4203 & 75.3 & 16.7 & 3.56 & 64 & 25 & 1.26 \\
\hline 586 & 0.2144 & 1.4203 & 76.5 & 16.6 & 3.56 & 64 & 25 & 1.26 \\
\hline 586 & 0.2480 & 1.3100 & 77.9 & 14.2 & 3.52 & 64 & 25 & 1.26 \\
\hline 586 & 0.2498 & 1.3100 & 79.1 & 14.1 & 3.52 & 64 & 25 & 1.26 \\
\hline 586 & 0.2498 & 1.3100 & 80.9 & 14.1 & 3.52 & 64 & 25 & 1.26 \\
\hline 586 & 0.2538 & 1.0756 & 75.5 & 11.6 & 2.94 & 64 & 25 & 1.26 \\
\hline 586 & 0.2560 & 1.0756 & 71.4 & 11.5 & 2.94 & 64 & 25 & 1.26 \\
\hline 586 & 0.2638 & 1.5444 & 64.2 & 15.7 & 4.14 & 64 & 25 & 1.26 \\
\hline 586 & 0.2638 & 1.5444 & 63.9 & 15.7 & 4.14 & 64 & 25 & 1.26 \\
\hline 586 & 0.2655 & 1.5444 & 62.9 & 15.6 & 4.14 & 64 & 2.5 & 1.26 \\
\hline 586 & 0.3387 & 1.4065 & 68.6 & 12.1 & 4.10 & 64 & 25 & 1.26 \\
\hline 586 & 0.3387 & 1.4065 & 71.1 & 12.1 & 4.10 & 64 & 25 & 1.26 \\
\hline 586 & 0.3395 & 1.4065 & 67.6 & 12.2 & 4.14 & 64 & 25 & 1.26 \\
\hline 586 & 0.3399 & 1.6823 & 62.8 & 13.9 & 4.72 & 64 & 25 & 1.26 \\
\hline 586 & 0.3423 & 1.6823 & 62.4 & 13.8 & 4.72 & 64 & 25 & 1.26 \\
\hline 586 & 0.3423 & 1.6823 & 64.0 & 13.8 & 4.72 & 64 & 25 & 1.26 \\
\hline 800 & 0.0825 & 0.9101 & 81.2 & 21.6 & 1.78 & 64 & 23 & 1.26 \\
\hline 800 & 0.0831 & 1.2962 & 70.8 & 28.2 & 2.34 & 64 & 25 & 1.26 \\
\hline 800 & 0.0831 & 1.2962 & 70.2 & 28.2 & 2.34 & 64 & 25 & 1.26 \\
\hline 800 & 0.0832 & 0.9101 & 80.7 & 21.4 & 1.78 & 64 & 28 & 1.26 \\
\hline 800 & 0.0837 & 1.2962 & 72.5 & 28.0 & 2.34 & 64 & 25 & 1.26 \\
\hline 800 & 0.0840 & 0.9101 & 82.3 & 21.2 & 1.78 & 64 & 28 & 1.26 \\
\hline 800 & 0.1005 & 1.5168 & 62.3 & 29.0 & 2.91 & 64 & 25 & 1.26 \\
\hline 800 & 0.1008 & 1.5168 & 61.9 & 28.9 & 2.91 & 64 & 25 & 1.26 \\
\hline 800 & 0.1019 & 1.5168 & 61.8 & 28.6 & 2.91 & 64 & 25 & 1.26 \\
\hline
\end{tabular}


Glycerine-Water Mixture Data From Test 2 (continued)

\begin{tabular}{|c|c|c|c|c|c|c|c|c|}
\hline $\begin{array}{l}800 \\
800 \\
800 \\
800 \\
800 \\
800 \\
800 \\
800 \\
800 \\
800 \\
800 \\
800\end{array}$ & $\begin{array}{l}0.1665 \\
0.1674 \\
0.1674 \\
0.1675 \\
0.1676 \\
0.1682 \\
0.1691 \\
0.1694 \\
0.1694 \\
0.1700 \\
0.1704 \\
0.1711\end{array}$ & $\begin{array}{l}1.1583 \\
1.1583 \\
1.1583 \\
1.4479 \\
1.7237 \\
0.9239 \\
1.4479 \\
0.9239 \\
0.9239 \\
1.4479 \\
1.7237 \\
1.7237\end{array}$ & $\begin{array}{l}52.4 \\
54.5 \\
54.8 \\
50.9 \\
51.8 \\
58.3 \\
50.7 \\
56.1 \\
56.9 \\
51.0 \\
51.8 \\
51.9\end{array}$ & $\begin{array}{l}17.5 \\
17.4 \\
17.4 \\
20.8 \\
24.2 \\
14.0 \\
20.6 \\
13.9 \\
13.9 \\
20.5 \\
23.8 \\
23.7\end{array}$ & $\begin{array}{l}2.91 \\
2.91 \\
2.91 \\
3.48 \\
4.06 \\
2.36 \\
3.48 \\
2.36 \\
2.36 \\
3.48 \\
4.06 \\
4.06\end{array}$ & $\begin{array}{l}64 \\
64 \\
64 \\
64 \\
64 \\
64 \\
64 \\
64 \\
64 \\
64 \\
64 \\
64\end{array}$ & $\begin{array}{l}25 \\
25 \\
25 \\
25 \\
25 \\
28 \\
25 \\
28 \\
28 \\
25 \\
25 \\
25\end{array}$ & $\begin{array}{l}1.26 \\
1.26 \\
1.26 \\
1.26 \\
1.26 \\
1.26 \\
1.26 \\
1.26 \\
1.26 \\
1.26 \\
1.26 \\
1.26\end{array}$ \\
\hline $\begin{array}{l}800 \\
800 \\
800 \\
800 \\
800 \\
800 \\
800 \\
800 \\
800 \\
800 \\
800 \\
800\end{array}$ & $\begin{array}{l}0.2471 \\
0.2471 \\
0.2487 \\
0.2487 \\
0.2489 \\
0.2503 \\
0.2503 \\
0.2503 \\
0.2514 \\
0.2519 \\
0.2525 \\
0.2525\end{array}$ & $\begin{array}{l}1.2411 \\
1.2411 \\
1.7237 \\
1.7237 \\
1.2411 \\
1.4755 \\
1.4755 \\
0.9928 \\
1.7237 \\
1.4755 \\
0.9928 \\
0.9928\end{array}$ & $\begin{array}{l}46.5 \\
46.6 \\
46.8 \\
47.0 \\
47.1 \\
46.0 \\
46.2 \\
49.7 \\
47.4 \\
45.7 \\
48.3 \\
47.9\end{array}$ & $\begin{array}{l}14.1 \\
14.1 \\
18.6 \\
18.6 \\
14.0 \\
16.2 \\
16.2 \\
11.7 \\
18.4 \\
16.1 \\
11.6 \\
11.6\end{array}$ & $\begin{array}{l}3.48 \\
3.48 \\
4.63 \\
4.63 \\
3.48 \\
4.06 \\
4.06 \\
2.93 \\
4.63 \\
4.06 \\
2.93 \\
2.93\end{array}$ & $\begin{array}{l}64 \\
64 \\
64 \\
64 \\
64 \\
64 \\
64 \\
64 \\
64 \\
64 \\
64 \\
64\end{array}$ & $\begin{array}{l}25 \\
25 \\
25 \\
25 \\
25 \\
25 \\
25 \\
28 \\
25 \\
25 \\
28 \\
28\end{array}$ & $\begin{array}{l}1.26 \\
1.26 \\
1.26 \\
1.26 \\
1.26 \\
1.26 \\
1.26 \\
1.26 \\
1.26 \\
1.26 \\
1.26 \\
1.26\end{array}$ \\
\hline $\begin{array}{l}800 \\
800 \\
800 \\
800 \\
800 \\
800 \\
800 \\
800 \\
800 \\
800 \\
800 \\
800\end{array}$ & $\begin{array}{l}0.3328 \\
0.3328 \\
0.3351 \\
0.3352 \\
0.3353 \\
0.3368 \\
0.3375 \\
0.3375 \\
0.3379 \\
0.3401 \\
0.3408 \\
0.3434\end{array}$ & $\begin{array}{l}1.5720 \\
1.5720 \\
1.3376 \\
1.5720 \\
1.8202 \\
1.1170 \\
1.8202 \\
1.8202 \\
1.3376 \\
1.1170 \\
1.3376 \\
1.1170\end{array}$ & $\begin{array}{l}43.9 \\
44.0 \\
41.2 \\
43.3 \\
44.5 \\
42.2 \\
45.2 \\
39.0 \\
43.0 \\
44.1 \\
42.5 \\
43.4\end{array}$ & $\begin{array}{l}13.9 \\
13.9 \\
12.1 \\
13.8 \\
15.5 \\
10.4 \\
15.4 \\
15.4 \\
12.0 \\
10.3 \\
11.9 \\
10.2\end{array}$ & $\begin{array}{l}4.63 \\
4.63 \\
4.06 \\
4.63 \\
5.20 \\
3.50 \\
5.20 \\
5.20 \\
4.06 \\
3.50 \\
4.06 \\
3.50\end{array}$ & $\begin{array}{l}64 \\
64 \\
64 \\
64 \\
64 \\
64 \\
64 \\
64 \\
64 \\
64 \\
64 \\
64\end{array}$ & $\begin{array}{l}25 \\
25 \\
25 \\
25 \\
25 \\
28 \\
25 \\
25 \\
25 \\
28 \\
25 \\
28\end{array}$ & $\begin{array}{l}1.26 \\
1.26 \\
1.26 \\
1.26 \\
1.26 \\
1.26 \\
1.26 \\
1.26 \\
1.26 \\
1.26 \\
1.26 \\
1.26\end{array}$ \\
\hline $\begin{array}{l}800 \\
800 \\
800\end{array}$ & $\begin{array}{l}0.4254 \\
0.4254 \\
0.4254\end{array}$ & $\begin{array}{l}2.1236 \\
2.1236 \\
2.1236\end{array}$ & $\begin{array}{l}42.6 \\
43.2 \\
42.5\end{array}$ & $\begin{array}{l}14.9 \\
14.9 \\
14.9\end{array}$ & $\begin{array}{l}6.34 \\
6.34 \\
6.34\end{array}$ & $\begin{array}{l}64 \\
64 \\
64\end{array}$ & $\begin{array}{l}25 \\
25 \\
25\end{array}$ & $\begin{array}{l}1.26 \\
1.26 \\
1.26\end{array}$ \\
\hline $\begin{array}{l}852 \\
852 \\
852 \\
852 \\
852 \\
852 \\
852\end{array}$ & $\begin{array}{l}0.0511 \\
0.0721 \\
0.0723 \\
0.0739 \\
0.0824 \\
0.0829 \\
0.0832\end{array}$ & $\begin{array}{l}1.3238 \\
1.1859 \\
1.1859 \\
1.1859 \\
0.8274 \\
1.2962 \\
0.8274\end{array}$ & $\begin{array}{l}59.7 \\
80.3 \\
75.7 \\
82.3 \\
62.7 \\
67.6 \\
62.0\end{array}$ & $\begin{array}{l}57.3 \\
28.7 \\
28.6 \\
28.0 \\
21.5 \\
28.4 \\
21.3\end{array}$ & $\begin{array}{l}2.93 \\
2.07 \\
2.07 \\
2.07 \\
1.77 \\
2.36 \\
1.77\end{array}$ & $\begin{array}{l}64 \\
64 \\
64 \\
64 \\
64 \\
64 \\
64\end{array}$ & $\begin{array}{l}28 \\
28 \\
28 \\
28 \\
28 \\
28 \\
28\end{array}$ & $\begin{array}{l}1.26 \\
1.26 \\
1.26 \\
1.26 \\
1.26 \\
1.26 \\
1.26\end{array}$ \\
\hline
\end{tabular}


Glycerine-Water Mixture Data From Test 2 (continued)

\begin{tabular}{|c|c|c|c|c|c|c|c|c|}
\hline $\begin{array}{l}852 \\
852 \\
852 \\
852 \\
852 \\
852 \\
852 \\
852\end{array}$ & $\begin{array}{l}0.0832 \\
0.0835 \\
0.0841 \\
0.1054 \\
0.1069 \\
0.1077 \\
0.1085 \\
0.1109\end{array}$ & $\begin{array}{l}0.8274 \\
1.2962 \\
1.2962 \\
1.4203 \\
1.4203 \\
1.3238 \\
1.4203 \\
1.3238\end{array}$ & $\begin{array}{l}62.0 \\
68.9 \\
69.7 \\
58.8 \\
57.7 \\
60.3 \\
61.4 \\
59.6\end{array}$ & $\begin{array}{l}21.3 \\
28.2 \\
28.0 \\
27.8 \\
27.4 \\
27.2 \\
27.0 \\
26.4\end{array}$ & $\begin{array}{l}1.77 \\
2.36 \\
2.36 \\
2.93 \\
2.93 \\
2.93 \\
2.93 \\
2.93\end{array}$ & $\begin{array}{l}64 \\
64 \\
64 \\
64 \\
64 \\
64 \\
64 \\
64\end{array}$ & $\begin{array}{l}28 \\
28 \\
28 \\
28 \\
28 \\
28 \\
28 \\
28\end{array}$ & $\begin{array}{l}1.26 \\
1.26 \\
1.26 \\
1.26 \\
1.26 \\
1.26 \\
1.26 \\
1.26\end{array}$ \\
\hline $\begin{array}{l}852 \\
852 \\
852 \\
852 \\
852 \\
852 \\
852 \\
852 \\
852 \\
852 \\
852 \\
852 \\
852 \\
852 \\
852 \\
852 \\
852 \\
852\end{array}$ & $\begin{array}{l}0.1673 \\
0.1683 \\
0.1683 \\
0.1684 \\
0.1692 \\
0.1692 \\
0.1703 \\
0.1709 \\
0.1710 \\
0.1713 \\
0.1717 \\
0.1717 \\
0.1735 \\
0.1853 \\
0.1870 \\
0.1870 \\
0.2048 \\
0.2048\end{array}$ & $\begin{array}{l}0.8412 \\
1.1721 \\
1.1583 \\
1.4479 \\
1.4479 \\
1.4479 \\
1.1583 \\
1.4479 \\
0.8412 \\
1.1583 \\
1.4479 \\
1.4479 \\
0.8412 \\
1.6134 \\
1.6134 \\
1.6134 \\
1.1721 \\
1.1721\end{array}$ & $\begin{array}{l}46.1 \\
53.4 \\
52.0 \\
49.7 \\
57.0 \\
49.0 \\
51.3 \\
52.2 \\
45.3 \\
52.0 \\
51.6 \\
51.8 \\
46.5 \\
48.5 \\
49.1 \\
50.4 \\
55.0 \\
53.8\end{array}$ & $\begin{array}{l}14.0 \\
17.4 \\
17.4 \\
20.8 \\
20.7 \\
20.7 \\
17.2 \\
20.5 \\
13.7 \\
17.1 \\
20.4 \\
20.4 \\
13.5 \\
22.0 \\
21.8 \\
21.8 \\
14.3 \\
14.3\end{array}$ & $\begin{array}{l}2.34 \\
2.93 \\
2.93 \\
3.50 \\
3.50 \\
3.50 \\
2.93 \\
3.50 \\
2.34 \\
2.93 \\
3.50 \\
3.50 \\
2.34 \\
4.08 \\
4.08 \\
4.08 \\
2.93 \\
2.93\end{array}$ & $\begin{array}{l}64 \\
64 \\
64 \\
64 \\
64 \\
64 \\
64 \\
64 \\
64 \\
64 \\
64 \\
64 \\
64 \\
64 \\
64 \\
64 \\
64 \\
64\end{array}$ & $\begin{array}{l}28 \\
28 \\
28 \\
28 \\
28 \\
28 \\
28 \\
28 \\
28 \\
28 \\
28 \\
28 \\
28 \\
28 \\
28 \\
28 \\
28 \\
28\end{array}$ & $\begin{array}{l}1.26 \\
1.26 \\
1.26 \\
1.26 \\
1.26 \\
1.26 \\
1.26 \\
1.26 \\
1.26 \\
1.26 \\
1.26 \\
1.26 \\
1.26 \\
1.26 \\
1.26 \\
1.26 \\
1.26 \\
1.26\end{array}$ \\
\hline $\begin{array}{l}852 \\
852 \\
852 \\
852 \\
852 \\
852 \\
852 \\
852 \\
852 \\
852 \\
852 \\
852 \\
852 \\
852 \\
852\end{array}$ & $\begin{array}{l}0.2502 \\
0.2502 \\
0.2512 \\
0.2514 \\
0.2514 \\
0.2517 \\
0.2517 \\
0.2517 \\
0.2520 \\
0.2528 \\
0.2532 \\
0.2532 \\
0.2548 \\
0.2556 \\
0.2698\end{array}$ & $\begin{array}{l}1.2273 \\
1.2273 \\
0.8963 \\
1.7099 \\
1.7099 \\
1.4755 \\
1.4755 \\
1.4755 \\
1.2273 \\
1.7099 \\
1.4755 \\
1.4755 \\
1.4755 \\
0.8963 \\
0.8963\end{array}$ & $\begin{array}{l}48.5 \\
45.8 \\
39.0 \\
47.8 \\
47.3 \\
52.4 \\
55.7 \\
55.5 \\
48.5 \\
46.7 \\
55.0 \\
53.3 \\
53.6 \\
39.7 \\
38.8\end{array}$ & $\begin{array}{l}14.0 \\
14.0 \\
11.6 \\
18.5 \\
18.5 \\
16.2 \\
16.2 \\
16.2 \\
13.9 \\
18.4 \\
16.1 \\
16.1 \\
16.0 \\
11.4 \\
10.8\end{array}$ & $\begin{array}{l}3.50 \\
3.50 \\
2.91 \\
4.65 \\
4.65 \\
4.08 \\
4.08 \\
4.08 \\
3.50 \\
4.65 \\
4.08 \\
4.08 \\
4.08 \\
2.91 \\
2.91\end{array}$ & $\begin{array}{l}64 \\
64 \\
64 \\
64 \\
64 \\
64 \\
64 \\
64 \\
64 \\
64 \\
64 \\
64 \\
64 \\
64 \\
64\end{array}$ & $\begin{array}{l}28 \\
28 \\
28 \\
28 \\
28 \\
28 \\
28 \\
28 \\
28 \\
28 \\
28 \\
28 \\
28 \\
28 \\
28\end{array}$ & $\begin{array}{l}1.26 \\
1.26 \\
1.26 \\
1.26 \\
1.26 \\
1.26 \\
1.26 \\
1.26 \\
1.26 \\
1.26 \\
1.26 \\
1.26 \\
1.26 \\
1.26 \\
1.26\end{array}$ \\
\hline $\begin{array}{l}852 \\
852 \\
852 \\
852 \\
852\end{array}$ & $\begin{array}{l}0.3350 \\
0.3369 \\
0.3370 \\
0.3370 \\
0.3371\end{array}$ & $\begin{array}{l}0.8963 \\
1.3100 \\
1.5444 \\
1.5306 \\
1.8340\end{array}$ & $\begin{array}{l}36.0 \\
43.4 \\
51.1 \\
52.4 \\
45.8\end{array}$ & $\begin{array}{l}10.4 \\
12.1 \\
13.8 \\
13.8 \\
15.5\end{array}$ & $\begin{array}{l}3.48 \\
4.08 \\
4.65 \\
4.65 \\
5.22\end{array}$ & $\begin{array}{l}64 \\
64 \\
64 \\
64 \\
64\end{array}$ & $\begin{array}{l}28 \\
28 \\
28 \\
28 \\
28\end{array}$ & $\begin{array}{l}1.26 \\
1.26 \\
1.26 \\
1.26 \\
1.26\end{array}$ \\
\hline
\end{tabular}


Glycerine-Water Mixture Data From Test 2 (continued)

$\begin{array}{lllllllll}852 & 0.3371 & 1.8340 & 44.7 & 15.5 & 5.22 & 64 & 28 & 1.26 \\ 852 & 0.3371 & 1.8340 & 45.2 & 15.5 & 5.22 & 64 & 28 & 1.26 \\ 852 & 0.3397 & 1.3100 & 43.8 & 12.0 & 4.08 & 64 & 28 & 1.26 \\ 852 & 0.3397 & 1.3100 & 43.4 & 12.0 & 4.08 & 64 & 28 & 1.26 \\ 852 & 0.3445 & 1.5444 & 54.8 & 13.5 & 4.65 & 64 & 28 & 1.26 \\ 852 & 0.3445 & 1.5306 & 54.1 & 13.5 & 4.65 & 64 & 28 & 1.26 \\ 852 & 0.3445 & 1.5306 & 52.4 & 13.5 & 4.65 & 64 & 28 & 1.26 \\ 852 & 0.3471 & 1.5444 & 58.7 & 13.4 & 4.65 & 64 & 28 & 1.26 \\ 852 & 0.3484 & 0.8963 & 35.9 & 10.0 & 3.48 & 64 & 28 & 1.26\end{array}$


Glycerine-Water-Polymer Mixture Data

\begin{tabular}{|c|c|c|c|c|c|c|c|c|c|}
\hline$\underset{p-s^{(n-1)}}{\mathbf{K}}$ & $\mathbf{n}$ & ALR & $\begin{array}{r}P d \\
M P a\end{array}$ & $\begin{array}{l}\text { SMD } \\
\mu m\end{array}$ & $\begin{array}{l}\text { Liq. } \\
\text { Mass } \\
g / s\end{array}$ & $\begin{array}{c}\text { Air } \\
\text { Mass } \\
g / s\end{array}$ & $\begin{array}{l}\text { Surface } \\
\text { Tens. } \\
d y n / c m\end{array}$ & $\begin{array}{l}\mathrm{Ta} \\
\mathrm{C}\end{array}$ & $\begin{array}{l}\text { Densi } \\
\text { ty } \\
\mathrm{g} / \mathrm{cm}^{3}\end{array}$ \\
\hline $\begin{array}{l}400 \\
400 \\
400 \\
400 \\
400 \\
400 \\
400 \\
400\end{array}$ & $\begin{array}{l}0.85 \\
0.85 \\
0.85 \\
0.85 \\
0.85 \\
0.85 \\
0.85 \\
0.85\end{array}$ & $\begin{array}{l}0.0436 \\
0.0437 \\
0.0438 \\
0.0439 \\
0.0441 \\
0.0441 \\
0.0495 \\
0.0496\end{array}$ & $\begin{array}{l}0.9652 \\
0.9652 \\
0.6205 \\
0.6205 \\
0.9652 \\
0.6205 \\
1.1307 \\
1.1307\end{array}$ & $\begin{array}{l}122.9 \\
121.1 \\
134.9 \\
131.0 \\
126.7 \\
136.7 \\
114.8 \\
112.7\end{array}$ & $\begin{array}{l}34.3 \\
34.2 \\
25.1 \\
25.0 \\
33.9 \\
24.9 \\
36.0 \\
35.9\end{array}$ & $\begin{array}{l}1.49 \\
1.49 \\
1.10 \\
1.10 \\
1.49 \\
1.10 \\
1.78 \\
1.78\end{array}$ & $\begin{array}{l}64 \\
64 \\
64 \\
64 \\
64 \\
64 \\
64 \\
64\end{array}$ & $\begin{array}{l}18 \\
18 \\
18 \\
18 \\
18 \\
18 \\
18 \\
18\end{array}$ & $\begin{array}{l}1.13 \\
1.13 \\
1.13 \\
1.13 \\
1.13 \\
1.13 \\
1.13 \\
1.13\end{array}$ \\
\hline $\begin{array}{l}400 \\
400 \\
400 \\
400 \\
400 \\
400 \\
400 \\
400 \\
400 \\
400 \\
400 \\
400 \\
400 \\
400 \\
400 \\
400 \\
400 \\
400 \\
400 \\
400 \\
400 \\
400 \\
400 \\
400 \\
400 \\
400 \\
400 \\
400 \\
400 \\
400\end{array}$ & $\begin{array}{l}0.85 \\
0.85 \\
0.85 \\
0.85 \\
0.85 \\
0.85 \\
0.85 \\
0.85 \\
0.85 \\
0.85 \\
0.85 \\
0.85 \\
0.85 \\
0.85 \\
0.85 \\
0.85 \\
0.85 \\
0.85 \\
0.85 \\
0.85 \\
0.85 \\
0.85 \\
0.85 \\
0.85 \\
0.85 \\
0.85 \\
0.85 \\
0.85 \\
0.85 \\
0.85\end{array}$ & $\begin{array}{l}0.0728 \\
0.0728 \\
0.0728 \\
0.0728 \\
0.0730 \\
0.0736 \\
0.0754 \\
0.0756 \\
0.0758 \\
0.0773 \\
0.0776 \\
0.0784 \\
0.0803 \\
0.0803 \\
0.0805 \\
0.0810 \\
0.0828 \\
0.0832 \\
0.0833 \\
0.0833 \\
0.0853 \\
0.0863 \\
0.0906 \\
0.0914 \\
0.0920 \\
0.0921 \\
0.0924 \\
0.1009 \\
0.1024 \\
0.1034\end{array}$ & $\begin{array}{l}2.0408 \\
2.0408 \\
1.6133 \\
1.6133 \\
1.6133 \\
2.0408 \\
1.8615 \\
1.8615 \\
1.8615 \\
2.1373 \\
2.1373 \\
2.1373 \\
1.6961 \\
1.6961 \\
1.6961 \\
0.7860 \\
0.7860 \\
0.7860 \\
1.3100 \\
1.3100 \\
1.1169 \\
1.1169 \\
1.4065 \\
1.4065 \\
1.4065 \\
1.4065 \\
1.4065 \\
0.8549 \\
0.8549 \\
0.8549\end{array}$ & $\begin{array}{l}80.5 \\
83.1 \\
84.9 \\
87.6 \\
82.7 \\
83.3 \\
83.5 \\
80.7 \\
77.8 \\
78.2 \\
76.4 \\
78.8 \\
81.6 \\
81.8 \\
79.4 \\
94.4 \\
94.9 \\
92.6 \\
89.5 \\
85.2 \\
87.6 \\
84.8 \\
73.9 \\
78.5 \\
78.1 \\
80.4 \\
79.6 \\
84.2 \\
82.7 \\
78.4\end{array}$ & $\begin{array}{l}47.6 \\
47.6 \\
39.8 \\
39.8 \\
39.7 \\
47.1 \\
42.2 \\
42.1 \\
42.0 \\
48.5 \\
48.3 \\
47.8 \\
39.6 \\
39.6 \\
39.5 \\
22.0 \\
21.5 \\
21.4 \\
31.9 \\
31.9 \\
27.6 \\
27.3 \\
32.0 \\
31.7 \\
31.5 \\
31.8 \\
31.7 \\
20.5 \\
20.2 \\
20.0\end{array}$ & $\begin{array}{l}3.47 \\
3.47 \\
2.90 \\
2.90 \\
2.90 \\
3.47 \\
3.18 \\
3.18 \\
3.18 \\
3.75 \\
3.75 \\
3.75 \\
3.18 \\
3.18 \\
3.18 \\
1.78 \\
1.78 \\
1.78 \\
2.66 \\
2.66 \\
2.36 \\
2.36 \\
2.90 \\
2.90 \\
2.90 \\
2.93 \\
2.93 \\
2.07 \\
2.07 \\
2.07\end{array}$ & $\begin{array}{l}64 \\
64 \\
64 \\
64 \\
64 \\
64 \\
64 \\
64 \\
64 \\
64 \\
64 \\
64 \\
64 \\
64 \\
64 \\
64 \\
64 \\
64 \\
64 \\
64 \\
64 \\
64 \\
64 \\
64 \\
64 \\
64 \\
64 \\
64 \\
64 \\
64\end{array}$ & 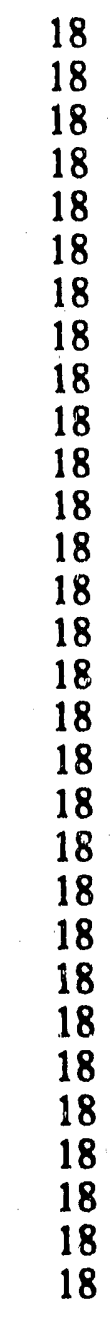 & $\begin{array}{l}1.13 \\
1.13 \\
1.13 \\
1.13 \\
1.13 \\
1.13 \\
1.13 \\
1.13 \\
1.13 \\
1.13 \\
1.13 \\
1.13 \\
1.13 \\
1.13 \\
1.13 \\
1.13 \\
1.13 \\
1.13 \\
1.13 \\
1.13 \\
1.13 \\
1.13 \\
1.13 \\
1.13 \\
1.13 \\
1.13 \\
1.13 \\
1.13 \\
1.13 \\
1.13\end{array}$ \\
\hline $\begin{array}{l}400 \\
400 \\
400 \\
400 \\
400 \\
400\end{array}$ & $\begin{array}{l}0.85 \\
0.85 \\
0.85 \\
0.85 \\
0.85\end{array}$ & $\begin{array}{l}0.1513 \\
0.1520 \\
0.1537 \\
0.1542 \\
0.1547 \\
0.1551\end{array}$ & $\begin{array}{l}1.6892 \\
1.6892 \\
1.5720 \\
1.7926 \\
1.6892 \\
1.6823\end{array}$ & $\begin{array}{l}61.7 \\
55.5 \\
53.8 \\
58.8 \\
53.3\end{array}$ & $\begin{array}{l}22.9 \\
22.8 \\
24.4 \\
28.0 \\
22.4 \\
26.0\end{array}$ & $\begin{array}{l}3.47 \\
3.47 \\
3.75 \\
4.32 \\
3.47 \\
4.03\end{array}$ & $\begin{array}{l}64 \\
64 \\
64 \\
64 \\
64 \\
64\end{array}$ & $\begin{array}{l}18 \\
18 \\
18 \\
18 \\
18 \\
18\end{array}$ & $\begin{array}{l}1.13 \\
1.13 \\
1.13 \\
1.13 \\
1.13 \\
1.13\end{array}$ \\
\hline
\end{tabular}


Glycerine-Water-Polymer Mixture Data (continued)

\begin{tabular}{|c|c|c|c|c|c|c|c|c|}
\hline 400 & 0.85 & 0.1551 & 1.6823 & 54.7 & 26.0 & 4.03 & 64 & 18 \\
\hline 400 & 0.85 & 0.1556 & 1.5720 & 57.1 & 24.1 & 3.75 & 64 & 18 \\
\hline 400 & 0.85 & 0.1559 & 1.7926 & 53.8 & 27.7 & 4.32 & 64 & 18 \\
\hline 400 & 0.85 & 0.1562 & 1.5720 & 56.8 & 24.0 & 3.75 & 64 & 18 \\
\hline 400 & 0.85 & 0.1569 & 1.6823 & 53.8 & 25.7 & 4.03 & 64 & 18 \\
\hline 400 & 0.85 & 0.1576 & 1.7926 & 53.1 & 27.4 & 4.32 & 64 & 18 \\
\hline 400 & 0.85 & 0.1582 & 1.2824 & 58.8 & 21.9 & 3.47 & 64 & 18 \\
\hline 400 & 0.85 & 0.1597 & 1.2824 & 60.6 & 21.7 & 3.47 & 64 & 18 \\
\hline 400 & 0.85 & 0.1619 & 1.2824 & 57.9 & 21.4 & 3.47 & 64 & 18 \\
\hline 400 & 0.85 & 0.1635 & 0.7860 & 65.1 & 14.4 & 2.36 & 64 & 18 \\
\hline 400 & 0.85 & 0.1637 & 1.4065 & 56.0 & 22.9 & 3.75 & 64 & 18 \\
\hline 400 & 0.85 & 0.1646 & 1.0342 & 60.6 & 17.8 & 2.93 & 64 & 18 \\
\hline 400 & 0.85 & 0.1652 & 1.4065 & 56.7 & 22.7 & 3.75 & 64 & 18 \\
\hline 400 & 0.85 & 0.1652 & 1.2962 & 58.0 & 21.2 & 3.50 & 64 & 18 \\
\hline 400 & 0.85 & 0.1658 & 1.1583 & 60.2 & 19.5 & 3.23 & 64 & 18 \\
\hline 400 & 0.85 & 0.1659 & 1.4065 & 57.8 & 22.6 & 3.75 & 64 & 18 \\
\hline 400 & 0.85 & 0.1660 & 1.2962 & 59.4 & 21.1 & 3.50 & 64 & 18 \\
\hline 400 & 0.85 & 0.1664 & 1.0342 & 60.5 & 17.6 & 2.93 & 64 & 18 \\
\hline 400 & 0.85 & 0.1664 & 1.0342 & 60.2 & 17.6 & 2.93 & 64 & 18 \\
\hline 400 & 0.85 & 0.1672 & 0.8963 & 62.5 & 15.8 & 2.64 & 64 & 18 \\
\hline 400 & 0.85 & 0.1675 & 1.1583 & 59.8 & 19.3 & 3.23 & 64 & 18 \\
\hline 400 & 0.85 & 0.1684 & 1.2962 & 60.0 & 20.8 & 3.50 & 64 & 18 \\
\hline 400 & 0.85 & 0.1693 & 1.1583 & 59.7 & 19.1 & 3.23 & 64 & 18 \\
\hline 400 & 0.85 & 0.1694 & 0.7860 & 60.8 & 13.9 & 2.36 & 64 & 18 \\
\hline 400 & 0.85 & 0.1719 & 0.7860 & 62.1 & 13.7 & 2.36 & 64 & 18 \\
\hline 400 & 0.85 & 0.1785 & 0.8963 & 59.7 & 14.8 & 2.64 & 64 & 18 \\
\hline 400 & 0.85 & 0.1848 & 0.8963 & 58.3 & 14.3 & 2.64 & 64 & 18 \\
\hline 400 & 0.85 & 0.2416 & 1.1031 & 46.9 & 14.5 & 3.50 & 64 & 18 \\
\hline 400 & 0.85 & 0.2427 & 1.2272 & 48.9 & 15.7 & 3.81 & 64 & 18 \\
\hline 400 & 0.85 & 0.2439 & 1.4478 & 46.4 & 17.7 & 4.32 & 64 & 18 \\
\hline 400 & 0.85 & 0.2450 & 1.7926 & 44.5 & 21.1 & 5.17 & 64 & 18 \\
\hline 400 & 0.85 & 0.2453 & 1.4478 & 45.0 & 17.6 & 4.32 & 64 & 18 \\
\hline 400 & 0.85 & 0.2461 & 1.7926 & 43.7 & 21.0 & 5.17 & 64 & 18 \\
\hline 400 & 0.85 & 0.2461 & 1.7926 & 44.1 & 21.0 & 5.17 & 64 & 18 \\
\hline 400 & 0.85 & 0.2467 & 1.4478 & 46.9 & 17.5 & 4.32 & 64 & 18 \\
\hline 400 & 0.85 & 0.2467 & 1.6547 & 45.8 & 19.8 & 4.88 & 64 & 18 \\
\hline 400 & 0.85 & 0.2467 & 1.6547 & 44.8 & 19.8 & 4.88 & 64 & 18 \\
\hline 400 & 0.85 & 0.2474 & 1.2272 & 45.9 & 15.4 & 3.81 & 64 & 18 \\
\hline 400 & 0.85 & 0.2474 & 1.2272 & 47.7 & 15.4 & 3.81 & 64 & 18 \\
\hline 400 & 0.85 & 0.2480 & 1.6547 & 44.6 & 19.7 & 4.88 & 64 & 18 \\
\hline 400 & 0.85 & 0.2490 & 1.3237 & 46.7 & 16.2 & 4.03 & 64 & 18 \\
\hline 400 & 0.85 & 0.2501 & 1.5582 & 44.7 & 18.4 & 4.60 & 64 & 18 \\
\hline 400 & 0.85 & 0.2502 & 1.1031 & 47.3 & 14.0 & 3.50 & 64 & 18 \\
\hline 400 & 0.85 & 0.2528 & 1.5582 & 44.2 & 18.2 & 4.60 & 64 & 18 \\
\hline 400 & 0.85 & 0.2532 & 1.3237 & 47.8 & 16.1 & 4.08 & 64 & 18 \\
\hline 400 & 0.85 & 0.2532 & 0.9652 & 48.0 & 12.7 & 3.22 & 64 & 18 \\
\hline 400 & 0.85 & 0.2542 & 1.5582 & 44.1 & 18.1 & 4.60 & 64 & 18 \\
\hline 400 & 0.8 & 0.2548 & 1.3237 & 45.3 & 16.0 & 4.08 & 64 & 18 \\
\hline 400 & 0.85 & 0.2557 & 1.1031 & 46.0 & 13.7 & 3.50 & 64 & 18 \\
\hline
\end{tabular}


Glycerine-Water-Polymer Mixture Data (continued)

\begin{tabular}{|c|c|c|c|c|c|c|c|c|c|}
\hline 400 & 0.85 & 0.2564 & 1.3237 & 47.4 & 15.9 & 4.08 & 64 & 18 & 1.13 \\
\hline 400 & 0.85 & 0.2569 & 1.3237 & 46.4 & 15.7 & 4.03 & 64 & 18 & 1.13 \\
\hline 400 & 0.85 & 0.2585 & 1.3237 & 46.3 & 15.6 & 4.03 & 64 & 18 & 1.13 \\
\hline 400 & 0.85 & 0.2636 & 0.9652 & 49.1 & 12.2 & 3.22 & 64 & 18 & 1.13 \\
\hline 400 & 0.85 & 0.2658 & 0.9652 & 49.6 & 12.1 & 3.22 & 64 & 18 & 1.13 \\
\hline 400 & 0.85 & 0.2712 & 0.8825 & 49.1 & 10.8 & 2.93 & 64 & 18 & 1.13 \\
\hline 400 & 0.85 & 0.2737 & 0.8825 & 47.1 & 10.7 & 2.93 & 64 & 18 & 1.13 \\
\hline 400 & 0.85 & 0.2737 & 0.8825 & 46.7 & 10.7 & 2.93 & 64 & 18 & 1.13 \\
\hline 400 & 0.85 & 0.3156 & 1.3375 & 40.5 & 13.9 & 4.39 & 64 & 18 & 1.13 \\
\hline 400 & 0.85 & 0.3185 & 1.1307 & 42.57 & 11.9 & 3.79 & 64 & 18 & 1.13 \\
\hline 400 & 0.85 & 0.3239 & 1.1307 & 41.72 & 11.7 & 3.79 & 64 & 18 & 1.13 \\
\hline 400 & 0.85 & 0.3239 & 1.1307 & 41.69 & 11.7 & 3.79 & 64 & 18 & 1.13 \\
\hline 400 & 0.85 & 0.3250 & 1.3375 & 40.6 & 13.5 & 4.39 & 64 & 18 & 1.13 \\
\hline 400 & 0.85 & 0.3250 & 1.3375 & 40.2 & 13.5 & 4.39 & 64 & 18 & 1.13 \\
\hline 400 & 0.85 & 0.3259 & 1.8891 & 39.0 & 17.6 & 5.74 & 64 & 18 & 1.13 \\
\hline 400 & 0.85 & 0.3265 & 1.7374 & 39.9 & 16.7 & 5.45 & 64 & 18 & 1.13 \\
\hline 400 & 0.85 & 0.3278 & 1.8891 & 38.2 & 17.5 & 5.74 & 64 & 18 & 1.13 \\
\hline 400 & 0.85 & 0.3278 & 1.8891 & 39.2 & 17.5 & 5.74 & 64 & 18 & 1.13 \\
\hline 400 & 0.85 & 0.3301 & 1.5444 & 39.0 & 14.8 & 4.88 & 64 & 18 & 1.13 \\
\hline 400 & 0.85 & 0.3305 & 1.7374 & 39.0 & 16.5 & 5.45 & 64 & 18 & 1.13 \\
\hline 400 & 0.85 & 0.3310 & 1.4065 & 40.7 & 13.9 & 4.60 & 64 & 18 & 1.13 \\
\hline 400 & 0.85 & 0.3315 & 1.2272 & 39.5 & 12.3 & 4.08 & 64 & 18 & 1.13 \\
\hline 400 & 0.85 & 0.3323 & 1.5444 & 39.9 & 14.7 & 4.88 & 64 & 18 & 1.13 \\
\hline 400 & 0.85 & 0.3323 & 1.5444 & 39.6 & 14.7 & 4.88 & 64 & 18 & 1.13 \\
\hline 400 & 0.85 & 0.3334 & 1.4203 & 38.7 & 13.8 & 4.60 & 64 & 18 & 1.13 \\
\hline 400 & 0.85 & 0.3335 & 1.6133 & 39.6 & 15.5 & 5.17 & 64 & 18 & 1.13 \\
\hline 400 & 0.85 & 0.3336 & 1.0066 & 41.6 & 10.5 & 3.50 & 64 & 18 & 1.13 \\
\hline 400 & 0.85 & 0.3345 & 1.7374 & 38.3 & 16.3 & 5.45 & 64 & 18 & 1.13 \\
\hline 400 & 0.85 & 0.3356 & 1.6133 & 39.0 & 15.4 & 5.17 & 64 & 18 & 1.13 \\
\hline 400 & 0.85 & 0.3358 & 1.4065 & 40.5 & 13.7 & 4.60 & 64 & 18 & 1.13 \\
\hline 400 & 0.85 & 0.3383 & 1.4065 & 40.0 & 13.6 & 4.60 & 64 & 18 & 1.13 \\
\hline 400 & 0.85 & 0.3397 & 1.2272 & 39.7 & 12.0 & 4.08 & 64 & 18 & 1.13 \\
\hline 400 & 0.85 & 0.3397 & 1.2272 & 39.8 & 12.0 & 4.08 & 64 & 18 & 1.13 \\
\hline 400 & 0.85 & 0.3401 & 1.6133 & 38.9 & 15.2 & 5.17 & 64 & 18 & 1.13 \\
\hline 400 & 0.85 & 0.3408 & 1.4203 & 38.8 & 13.5 & 4.60 & 64 & 18 & 1.13 \\
\hline 400 & 0.85 & 0.3434 & 1.4203 & 39.6 & 13.4 & 4.60 & 64 & 18 & 1.13 \\
\hline 400 & 0.85 & 0.3649 & 1.0066 & 40.0 & 9.6 & 3.50 & 64 & 18 & 1.13 \\
\hline 400 & 0.85 & 0.3727 & 1.0066 & 40.6 & 9.4 & 3.50 & 64 & 18 & 1.13 \\
\hline 420 & 0.90 & 0.0386 & 0.7446 & 148.2 & 28.6 & 1.10 & 64 & 2.3 & 1.20 \\
\hline 420 & 0.90 & 0.0386 & 0.7446 & 133.6 & 28.6 & 1.10 & 64 & 23 & 1.20 \\
\hline 420 & 0.910 & 0.0392 & 0.7446 & 149.2 & 28.2 & 1.10 & 64 & 23 & 1.20 \\
\hline 420 & 0.90 & 0.0408 & 1.4065 & 118.0 & 43.9 & 1.79 & 64 & 23 & 1.20 \\
\hline 420 & 0.90 & 0.0412 & 1.4065 & 118.7 & 43.5 & 1.79 & 64 & 23 & 1.20 \\
\hline 420 & 0.90 & 0.0417 & 1.6823 & 121.9 & 49.8 & 2.08 & 64 & 23 & 1.20 \\
\hline 420 & 0.90 & 0.0419 & 0.4136 & 160.8 & 17.8 & 0.75 & 64 & 23 & 1.20 \\
\hline
\end{tabular}


Glycerine-Water-Polymer Mixture Data (continued)

\begin{tabular}{|c|c|c|c|c|c|c|c|c|c|}
\hline 420 & 0.90 & 0.0419 & 1.6823 & 117.9 & 49.6 & 2.08 & 64 & 23 & 1.20 \\
\hline 420 & 0.90 & 0.0421 & 1.4065 & 120.2 & 42.5 & 1.79 & 64 & 23 & 1.20 \\
\hline 420 & 0.90 & 0.0424 & 1.6823 & 120.4 & 49.0 & 2.08 & 64 & 23 & 1.20 \\
\hline 420 & 0.90 & 0.0447 & 1.0066 & 123.6 & 33.6 & 1.50 & 64 & 23 & 1.20 \\
\hline 420 & 0.90 & 0.0448 & 1.0066 & 118.8 & 33.5 & 1.50 & 64 & 23 & 1.20 \\
\hline 420 & 0.90 & 0.0454 & 1.0066 & 122.9 & 33.1 & 1.50 & 64 & 23 & 1.20 \\
\hline 420 & 0.90 & 0.0460 & 1.8340 & 113.6 & 51.5 & 2.37 & 64 & 23 & 1.20 \\
\hline 420 & 0.90 & 0.0462 & 1.8340 & 113.4 & 51.3 & 2.37 & 64 & 23 & 1.20 \\
\hline 420 & 0.90 & 0.0470 & 1.8340 & 112.9 & 50.4 & 2.37 & 64 & 23 & 1.20 \\
\hline 420 & 0.90 & 0.0825 & 1.7236 & 92.3 & 39.2 & 3.23 & 64 & 23 & 1.20 \\
\hline 420 & 0.90 & 0.0833 & 1.7236 & 89.5 & 38.8 & 3.23 & 64 & 23 & 1.20 \\
\hline 420 & 0.90 & 0.0835 & 0.9928 & 93.5 & 24.9 & 2.08 & 64 & 23 & 1.20 \\
\hline 420 & 0.90 & 0.0835 & 1.7236 & 89.7 & 38.7 & 3.23 & 64 & 23 & 1.20 \\
\hline 420 & 0.90 & 0.0844 & 1.5582 & 87.0 & 34.9 & 2.94 & 64 & 23 & 1.20 \\
\hline 420 & 0.90 & 0.0846 & 1.5582 & 85.2 & 34.8 & 2.94 & 64 & 23 & 1.20 \\
\hline 420 & 0.90 & 0.0846 & 1.5582 & 84.5 & 34.8 & 2.94 & 64 & 23 & 1.20 \\
\hline 420 & 0.90 & 0.0849 & 1.8891 & 84.5 & 41.5 & 3.52 & 64 & 23 & 1.20 \\
\hline 420 & 0.90 & 0.0851 & 1.8891 & 88.6 & 41.4 & 3.52 & 64 & 23 & 1.20 \\
\hline 420 & 0.90 & 0.0852 & 0.9928 & 96.3 & 24.4 & 2.08 & 64 & 23 & 1.20 \\
\hline 420 & 0.90 & 0.0853 & 1.8891 & 90.6 & 41.3 & 3.52 & 64 & 23 & 1.20 \\
\hline 420 & 0.90 & 0.0853 & 0.9928 & 87.7 & 24.4 & 2.08 & 64 & 23 & 1.20 \\
\hline 420 & 0.90 & 0.0861 & 1.1445 & 90.5 & 27.5 & 2.37 & 64 & 23 & 1.20 \\
\hline 420 & 0.90 & 0.0870 & 1.1445 & 90.1 & 27.2 & 2.37 & 64 & 23 & 1.20 \\
\hline 420 & 0.90 & 0.0873 & 0.7722 & 96.6 & 20.5 & 1.79 & 64 & 23 & 1.20 \\
\hline 420 & 0.90 & 0.0894 & 0.6481 & 101.3 & 16.8 & 1.50 & 64 & 23 & 1.20 \\
\hline 420 & 0.90 & 0.0894 & 1.2962 & 81.7 & 29.7 & 2.66 & 64 & 23 & 1.20 \\
\hline 420 & 0.90 & 0.0895 & 0.7722 & 103.1 & 20.0 & 1.79 & 64 & 23 & 1.20 \\
\hline 420 & 0.90 & 0.0900 & 0.7722 & 104.3 & 19.9 & 1.79 & 64 & 23 & 1.20 \\
\hline 420 & 0.90 & 0.0900 & 1.2962 & 86.9 & 29.5 & 2.66 & 64 & 23 & 1.20 \\
\hline 420 & 0.90 & 0.0903 & 1.2962 & 85.1 & 29.4 & 2.66 & 64 & 23 & 1.20 \\
\hline 420 & 0.90 & 0.0907 & 1.1445 & 89.6 & 26.1 & 2.37 & 64 & 23 & 1.20 \\
\hline 420 & 0.90 & 0.1592 & 1.0617 & 65.0 & 18.5 & 2.94 & 64 & 23 & 1.20 \\
\hline 420 & 0.90 & 0.1633 & 0.8273 & 70.9 & 14.5 & 2.37 & 64 & 23 & 1.20 \\
\hline 420 & 0.90 & 0.1633 & 1.1996 & 62.1 & 19.8 & 3.23 & 64 & 23 & 1.20 \\
\hline 420 & 0.90 & 0.1644 & 0.8273 & 74.4 & 14.4 & 2.37 & 64 & 23 & 1.20 \\
\hline 420 & 0.90 & 0.1650 & 1.1996 & 61.5 & 19.6 & 3.23 & 64 & 23 & 1.20 \\
\hline 420 & 0.90 & 0.1661 & 1.3375 & 58.3 & 21.2 & 3.52 & 64 & 23 & 1.20 \\
\hline 420 & 0.90 & 0.1663 & 0.6894 & 79.2 & 12.5 & 2.08 & 64 & 23 & 1.20 \\
\hline 420 & 0.90 & 0.1667 & 1.1996 & 65.8 & 19.4 & 3.23 & 64 & 23 & 1.20 \\
\hline 420 & 0.90 & 0.1669 & 1.3375 & 63.6 & 21.1 & 3.52 & 64 & 23 & 1.20 \\
\hline 420 & 0.90 & 0.1670 & 0.9376 & 63.0 & 15.9 & 2.66 & 64 & 23 & 1.20 \\
\hline 420 & 0.90 & 0.1673 & 1.0617 & 63.6 & 17.6 & 2.94 & 64 & 23 & 1.20 \\
\hline 420 & 0.90 & 0.1677 & 0.6894 & 77.8 & 12.4 & 2.08 & 64 & 23 & 1.20 \\
\hline 420 & 0.90 & 0.1679 & 0.8273 & 73.9 & 14.1 & 2.37 & 64 & 23 & 1.20 \\
\hline 420 & 0.90 & 0.1686 & 1.4478 & 62.0 & 22.6 & 3.81 & 64 & 23 & 1.20 \\
\hline
\end{tabular}


Glycerine-Water-Polymer Mixture Data (continued)

\begin{tabular}{|c|c|c|c|c|c|c|c|c|c|}
\hline $\begin{array}{l}420 \\
420 \\
420 \\
420 \\
420 \\
420 \\
420 \\
420 \\
420 \\
420\end{array}$ & $\begin{array}{l}0.90 \\
0.90 \\
0.90 \\
0.90 \\
0.90 \\
0.90 \\
0.90 \\
0.90 \\
0.90 \\
0.90\end{array}$ & $\begin{array}{l}0.1687 \\
0.1687 \\
0.1692 \\
0.1692 \\
0.1693 \\
0.1693 \\
0.1694 \\
0.1702 \\
0.1709 \\
0.1718\end{array}$ & $\begin{array}{l}1.6133 \\
1.6133 \\
0.9376 \\
0.9376 \\
1.3375 \\
1.4478 \\
1.6133 \\
1.0617 \\
1.4478 \\
0.6894\end{array}$ & $\begin{array}{l}61.4 \\
58.3 \\
67.7 \\
66.6 \\
64.3 \\
60.5 \\
62.0 \\
67.3 \\
63.3 \\
77.9\end{array}$ & $\begin{array}{l}24.3 \\
24.3 \\
15.7 \\
15.7 \\
20.8 \\
22.5 \\
24.2 \\
17.3 \\
22.3 \\
12.1\end{array}$ & $\begin{array}{l}4.10 \\
4.10 \\
2.66 \\
2.66 \\
3.52 \\
3.81 \\
4.10 \\
2.94 \\
3.81 \\
2.08\end{array}$ & $\begin{array}{l}64 \\
64 \\
64 \\
64 \\
64 \\
64 \\
64 \\
64 \\
64 \\
64\end{array}$ & $\begin{array}{l}23 \\
23 \\
23 \\
23 \\
23 \\
23 \\
23 \\
23 \\
23 \\
23\end{array}$ & $\begin{array}{l}1.20 \\
1.20 \\
1.20 \\
1.20 \\
1.20 \\
1.20 \\
1.20 \\
1.20 \\
1.20 \\
1.20\end{array}$ \\
\hline $\begin{array}{l}420 \\
420 \\
420 \\
420 \\
420 \\
420 \\
420 \\
420 \\
420 \\
420 \\
420 \\
420 \\
420 \\
420 \\
420 \\
420 \\
420 \\
420 \\
420 \\
420 \\
420 \\
420 \\
420 \\
420\end{array}$ & $\begin{array}{l}0.90 \\
0.90 \\
0.90 \\
0.90 \\
0.90 \\
0.90 \\
0.90 \\
0.90 \\
0.90 \\
0.90 \\
0.90 \\
0.90 \\
0.90 \\
0.90 \\
0.90 \\
0.90 \\
0.90 \\
0.90 \\
0.90 \\
0.90 \\
0.90 \\
0.90 \\
0.90 \\
0.90\end{array}$ & $\begin{array}{l}0.2434 \\
0.2442 \\
0.2454 \\
0.2463 \\
0.2490 \\
0.2493 \\
0.2495 \\
0.2498 \\
0.2507 \\
0.2507 \\
0.2515 \\
0.2521 \\
0.2526 \\
0.2530 \\
0.2541 \\
0.2555 \\
0.2562 \\
0.2566 \\
0.2569 \\
0.2579 \\
0.2586 \\
0.2611 \\
0.2767 \\
0.2826\end{array}$ & $\begin{array}{l}0.8549 \\
1.2410 \\
0.8549 \\
1.1445 \\
1.2410 \\
1.4754 \\
0.8549 \\
1.1445 \\
1.2410 \\
1.4754 \\
1.1445 \\
1.4754 \\
1.0342 \\
1.3375 \\
1.5720 \\
1.5720 \\
1.3375 \\
1.0342 \\
1.5720 \\
0.7860 \\
1.0342 \\
1.3375 \\
0.7860 \\
0.7860\end{array}$ & $\begin{array}{l}57.7 \\
51.9 \\
55.5 \\
57.3 \\
52.7 \\
51.2 \\
56.8 \\
56.5 \\
51.1 \\
50.5 \\
52.9 \\
51.7 \\
53.2 \\
48.8 \\
49.7 \\
50.8 \\
53.2 \\
54.0 \\
51.6 \\
59.5 \\
55.0 \\
51.6 \\
56.5 \\
53.7\end{array}$ & $\begin{array}{l}12.1 \\
15.6 \\
12.0 \\
14.3 \\
15.3 \\
17.6 \\
11.8 \\
14.1 \\
15.2 \\
17.5 \\
14.0 \\
17.4 \\
12.8 \\
16.2 \\
18.4 \\
18.3 \\
16.0 \\
12.6 \\
18.2 \\
10.3 \\
12.5 \\
15.7 \\
9.6 \\
9.4\end{array}$ & $\begin{array}{l}2.94 \\
3.81 \\
2.94 \\
3.52 \\
3.81 \\
4.39 \\
2.94 \\
3.52 \\
3.81 \\
4.39 \\
3.52 \\
4.39 \\
3.23 \\
4.10 \\
4.68 \\
4.68 \\
4.10 \\
3.23 \\
4.68 \\
2.66 \\
3.23 \\
4.10 \\
2.66 \\
2.66\end{array}$ & $\begin{array}{l}64 \\
64 \\
64 \\
64 \\
64 \\
64 \\
64 \\
64 \\
64 \\
64 \\
64 \\
64 \\
64 \\
64 \\
64 \\
64 \\
64 \\
64 \\
64 \\
64 \\
64 \\
64 \\
64 \\
64\end{array}$ & $\begin{array}{l}23 \\
23 \\
23 \\
23 \\
23 \\
23 \\
23 \\
23 \\
23 \\
23 \\
23 \\
23 \\
23 \\
23 \\
23 \\
23 \\
23 \\
23 \\
23 \\
23 \\
23 \\
23 \\
23 \\
23\end{array}$ & $\begin{array}{l}1.20 \\
1.20 \\
1.20 \\
1.20 \\
1.20 \\
1.20 \\
1.20 \\
1.20 \\
1.20 \\
1.20 \\
1.20 \\
1.20 \\
1.20 \\
1.20 \\
1.20 \\
1.20 \\
1.20 \\
1.20 \\
1.20 \\
1.20 \\
1.20 \\
1.20 \\
1.20 \\
1.20\end{array}$ \\
\hline $\begin{array}{l}420 \\
420 \\
420 \\
420 \\
420 \\
420 \\
420 \\
420 \\
420 \\
420 \\
420 \\
420 \\
420 \\
420 \\
420\end{array}$ & $\begin{array}{l}0.90 \\
0.90 \\
0.90 \\
0.90 \\
0.90 \\
0.90 \\
0.90 \\
0.90 \\
0.90 \\
0.90 \\
0.90 \\
0.90 \\
0.90 \\
0.90 \\
0.90\end{array}$ & $\begin{array}{l}0.3202 \\
0.3253 \\
0.3253 \\
0.3299 \\
0.3313 \\
0.3322 \\
0.3324 \\
0.3324 \\
0.3345 \\
0.3349 \\
0.3386 \\
0.3401 \\
0.3401 \\
0.3402 \\
0.3438\end{array}$ & $\begin{array}{l}1.2548 \\
1.2548 \\
1.2548 \\
0.9376 \\
1.1445 \\
1.0480 \\
1.6823 \\
1.6823 \\
1.6823 \\
1.3375 \\
1.0480 \\
1.3375 \\
1.3375 \\
1.1445 \\
1.4478\end{array}$ & $\begin{array}{l}46.2 \\
46.3 \\
46.7 \\
50.4 \\
48.3 \\
48.8 \\
44.7 \\
46.1 \\
44.1 \\
43.4 \\
47.6 \\
45.0 \\
44.2 \\
45.8 \\
43.2\end{array}$ & $\begin{array}{l}12.8 \\
12.6 \\
12.6 \\
9.8 \\
11.5 \\
10.6 \\
15.8 \\
15.8 \\
15.7 \\
13.1 \\
10.4 \\
12.9 \\
12.9 \\
11.2 \\
13.6\end{array}$ & $\begin{array}{l}4.10 \\
4.10 \\
4.10 \\
3.23 \\
3.81 \\
3.52 \\
5.25 \\
5.25 \\
5.25 \\
4.39 \\
3.52 \\
4.39 \\
4.39 \\
3.81 \\
4.68\end{array}$ & $\begin{array}{l}64 \\
64 \\
64 \\
04 \\
64 \\
64 \\
64 \\
64 \\
64 \\
64 \\
64 \\
64 \\
64 \\
64 \\
64\end{array}$ & $\begin{array}{l}23 \\
23 \\
23 \\
23 \\
23 \\
23 \\
23 \\
23 \\
23 \\
23 \\
23 \\
23 \\
23 \\
23 \\
23\end{array}$ & $\begin{array}{l}1.20 \\
1.20 \\
1.20 \\
1.20 \\
1.20 \\
1.20 \\
1.20 \\
1.20 \\
1.20 \\
1.20 \\
1.20 \\
1.20 \\
1.20 \\
1.20 \\
1.20\end{array}$ \\
\hline
\end{tabular}


Glycerine-Water-Polymer Mixture Data (continued)

\begin{tabular}{|c|c|c|c|c|c|c|c|c|c|}
\hline $\begin{array}{l}420 \\
120 \\
420 \\
420 \\
420 \\
420 \\
420 \\
420 \\
420 \\
420\end{array}$ & $\begin{array}{l}0.90 \\
0.90 \\
0.90 \\
0.90 \\
0.90 \\
0.90 \\
0.90 \\
0.90 \\
0.90 \\
0.90\end{array}$ & $\begin{array}{l}0.3439 \\
0.3439 \\
0.3452 \\
0.3463 \\
0.3495 \\
0.3496 \\
0.3515 \\
0.3521 \\
0.3546 \\
0.0839\end{array}$ & $\begin{array}{l}0.9376 \\
0.9376 \\
1.0480 \\
1.4478 \\
1.1445 \\
1.5444 \\
1.4478 \\
1.5444 \\
1.5444 \\
0.6481\end{array}$ & $\begin{array}{r}50.3 \\
50.9 \\
44.9 \\
42.8 \\
45.5 \\
44.1 \\
44.3 \\
43.0 \\
45.1 \\
109.2\end{array}$ & $\begin{array}{r}9.4 \\
9.4 \\
10.2 \\
13.5 \\
10.9 \\
14.2 \\
13.3 \\
14.1 \\
14.0 \\
17.9\end{array}$ & $\begin{array}{l}3.23 \\
3.23 \\
3.52 \\
4.68 \\
3.81 \\
4.96 \\
4.68 \\
4.96 \\
4.96 \\
1.50\end{array}$ & $\begin{array}{l}64 \\
64 \\
64 \\
64 \\
64 \\
64 \\
64 \\
64 \\
64 \\
64\end{array}$ & $\begin{array}{l}23 \\
23 \\
23 \\
23 \\
23 \\
23 \\
23 \\
23 \\
23 \\
23\end{array}$ & $\begin{array}{l}1.20 \\
1.20 \\
1.20 \\
1.20 \\
1.20 \\
1.20 \\
1.20 \\
1.20 \\
1.20 \\
1.20\end{array}$ \\
\hline $\begin{array}{l}450 \\
450 \\
450 \\
450 \\
450 \\
450 \\
450 \\
450 \\
450 \\
450 \\
450 \\
450 \\
450 \\
450 \\
450 \\
450 \\
450 \\
450\end{array}$ & $\begin{array}{l}0.95 \\
0.95 \\
0.95 \\
0.95 \\
0.95 \\
0.95 \\
0.95 \\
0.95 \\
0.95 \\
0.95 \\
0.95 \\
0.95 \\
0.95 \\
0.95 \\
0.95 \\
0.95 \\
0.95 \\
0.95\end{array}$ & $\begin{array}{l}0.0402 \\
0.0407 \\
0.0408 \\
0.0410 \\
0.0410 \\
0.0412 \\
0.0414 \\
0.0416 \\
0.0416 \\
0.0416 \\
0.0417 \\
0.0418 \\
0.0418 \\
0.0418 \\
0.0420 \\
0.0420 \\
0.0422 \\
0.0422\end{array}$ & $\begin{array}{l}0.7997 \\
0.7446 \\
0.7997 \\
0.7446 \\
1.4203 \\
1.4203 \\
1.4203 \\
0.7170 \\
0.7446 \\
1.4203 \\
1.4203 \\
0.7170 \\
0.7997 \\
1.4203 \\
1.4203 \\
1.4203 \\
1.4203 \\
0.7170\end{array}$ & $\begin{array}{l}152.9 \\
135.1 \\
144.7 \\
130.4 \\
119.7 \\
123.6 \\
122.3 \\
131.1 \\
132.6 \\
119.3 \\
121.7 \\
141.6 \\
136.0 \\
114.4 \\
115.2 \\
119.2 \\
114.7 \\
135.2\end{array}$ & $\begin{array}{l}27.3 \\
27.0 \\
26.9 \\
26.8 \\
43.4 \\
43.2 \\
43.0 \\
26.4 \\
26.4 \\
42.8 \\
42.7 \\
26.3 \\
26.3 \\
42.6 \\
42.4 \\
42.4 \\
42.2 \\
26.0\end{array}$ & $\begin{array}{l}1.10 \\
1.10 \\
1.10 \\
1.10 \\
1.78 \\
1.78 \\
1.78 \\
1.10 \\
1.10 \\
1.78 \\
1.78 \\
1.10 \\
1.10 \\
1.78 \\
1.78 \\
1.78 \\
1.78 \\
1.10\end{array}$ & $\begin{array}{l}64 \\
64 \\
64 \\
64 \\
64 \\
64 \\
64 \\
64 \\
64 \\
64 \\
64 \\
64 \\
64 \\
64 \\
64 \\
64 \\
64 \\
64\end{array}$ & $\begin{array}{l}21 \\
21 \\
21 \\
21 \\
21 \\
21 \\
21 \\
21 \\
21 \\
21 \\
21 \\
21 \\
21 \\
21 \\
21 \\
21 \\
21 \\
21\end{array}$ & $\begin{array}{l}1.22 \\
1.22 \\
1.22 \\
1.22 \\
1.22 \\
1.22 \\
1.22 \\
1.22 \\
1.22 \\
1.22 \\
1.22 \\
1.22 \\
1.22 \\
1.22 \\
1.22 \\
1.22 \\
1.22 \\
1.22\end{array}$ \\
\hline $\begin{array}{l}450 \\
450 \\
450 \\
450 \\
450 \\
450 \\
450 \\
450 \\
450 \\
450 \\
450 \\
450 \\
450 \\
450 \\
450 \\
450 \\
450 \\
450 \\
450 \\
450\end{array}$ & $\begin{array}{l}0.95 \\
0.95 \\
0.95 \\
0.95 \\
0.95 \\
0.95 \\
0.95 \\
0.95 \\
0.95 \\
0.95 \\
0.95 \\
0.95 \\
0.95 \\
0.95 \\
0.95 \\
0.95 \\
0.95 \\
0.95 \\
0.95 \\
0.95\end{array}$ & $\begin{array}{l}0.0825 \\
0.0825 \\
0.0825 \\
0.0828 \\
0.0829 \\
0.0829 \\
0.0829 \\
0.0835 \\
0.0835 \\
0.0838 \\
0.0838 \\
0.0841 \\
0.0841 \\
0.0842 \\
0.0842 \\
0.0844 \\
0.0847 \\
0.0848 \\
0.0848 \\
0.0852\end{array}$ & $\begin{array}{l}0.8549 \\
0.8549 \\
1.5720 \\
0.8549 \\
1.2134 \\
1.2134 \\
1.2134 \\
1.2134 \\
1.2272 \\
1.2134 \\
1.2272 \\
1.2134 \\
1.2272 \\
1.5720 \\
1.5857 \\
1.5857 \\
1.5857 \\
0.8549 \\
0.8549 \\
0.8549\end{array}$ & $\begin{array}{c}104.6 \\
98.1 \\
82.5 \\
98.0 \\
87.0 \\
87.5 \\
89.5 \\
86.9 \\
90.1 \\
88.3 \\
91.3 \\
87.5 \\
92.1 \\
85.0 \\
83.4 \\
81.2 \\
82.5 \\
102.1 \\
98.1 \\
95.2\end{array}$ & $\begin{array}{l}21.6 \\
21.6 \\
35.5 \\
21.5 \\
28.4 \\
28.4 \\
28.4 \\
28.2 \\
28.2 \\
28.1 \\
28.1 \\
28.0 \\
28.0 \\
34.8 \\
34.8 \\
34.7 \\
34.6 \\
21.0 \\
21.0 \\
20.9\end{array}$ & $\begin{array}{l}1.78 \\
1.78 \\
2.93 \\
1.78 \\
2.36 \\
2.36 \\
2.36 \\
2.36 \\
2.36 \\
2.36 \\
2.36 \\
2.36 \\
2.36 \\
2.93 \\
2.93 \\
2.93 \\
2.93 \\
1.78 \\
1.78 \\
1.78\end{array}$ & $\begin{array}{l}64 \\
64 \\
64 \\
64 \\
64 \\
64 \\
64 \\
64 \\
64 \\
64 \\
64 \\
64 \\
64 \\
64 \\
64 \\
64 \\
64 \\
64 \\
64 \\
64\end{array}$ & $\begin{array}{l}21 \\
21 \\
21 \\
21 \\
21 \\
21 \\
21 \\
21 \\
21 \\
21 \\
21 \\
21 \\
21 \\
21 \\
21 \\
21 \\
21 \\
21 \\
21 \\
21\end{array}$ & $\begin{array}{l}1.22 \\
1.22 \\
1.22 \\
1.22 \\
1.22 \\
1.22 \\
1.22 \\
1.22 \\
1.22 \\
1.22 \\
1.22 \\
1.22 \\
1.22 \\
1.22 \\
1.22 \\
1.22 \\
1.22 \\
1.22 \\
1.22 \\
1.22\end{array}$ \\
\hline
\end{tabular}


Glycerine-Water-Polymer Mixture Data (continued)

\begin{tabular}{|c|c|c|c|c|c|c|c|c|c|}
\hline $\begin{array}{l}450 \\
450 \\
450 \\
450 \\
450 \\
450 \\
450 \\
450 \\
450\end{array}$ & $\begin{array}{l}0.95 \\
0.95 \\
0.95 \\
0.95 \\
0.95 \\
0.95 \\
0.95 \\
0.95 \\
0.95\end{array}$ & $\begin{array}{l}0.0856 \\
0.0856 \\
0.0856 \\
0.0990 \\
0.0992 \\
0.0995 \\
0.1004 \\
0.1021 \\
0.1024\end{array}$ & $\begin{array}{l}0.8411 \\
0.8411 \\
0.8411 \\
1.7926 \\
1.7926 \\
1.7926 \\
1.7236 \\
1.7236 \\
1.7236\end{array}$ & $\begin{array}{l}93.4 \\
92.7 \\
91.3 \\
71.1 \\
73.7 \\
70.3 \\
72.3 \\
74.7 \\
71.2\end{array}$ & $\begin{array}{l}20.8 \\
20.8 \\
20.8 \\
35.4 \\
35.3 \\
35.2 \\
34.9 \\
34.3 \\
34.2\end{array}$ & $\begin{array}{l}1.78 \\
1.78 \\
1.78 \\
3.50 \\
3.50 \\
3.50 \\
3.50 \\
3.50 \\
3.50\end{array}$ & $\begin{array}{l}64 \\
64 \\
64 \\
64 \\
64 \\
64 \\
64 \\
64 \\
64\end{array}$ & $\begin{array}{l}21 \\
21 \\
21 \\
21 \\
21 \\
21 \\
21 \\
21 \\
21\end{array}$ & $\begin{array}{l}1.22 \\
1.22 \\
1.22 \\
1.22 \\
1.22 \\
1.22 \\
1.22 \\
1.22 \\
1.22\end{array}$ \\
\hline $\begin{array}{l}450 \\
450 \\
450 \\
450 \\
450 \\
450 \\
450 \\
450 \\
450 \\
450 \\
450 \\
450 \\
450 \\
450 \\
450 \\
450 \\
450 \\
450 \\
450 \\
450 \\
450 \\
450 \\
450 \\
450 \\
450 \\
450 \\
450 \\
450 \\
450 \\
450\end{array}$ & $\begin{array}{l}0.95 \\
0.95 \\
0.95 \\
0.95 \\
0.95 \\
0.95 \\
0.95 \\
0.95 \\
0.95 \\
0.95 \\
0.95 \\
0.95 \\
0.95 \\
0.95 \\
0.95 \\
0.95 \\
0.95 \\
0.95 \\
0.95 \\
0.95 \\
0.95 \\
0.95 \\
0.95 \\
0.95 \\
0.95 \\
0.95 \\
0.95 \\
0.95 \\
0.95 \\
0.95\end{array}$ & $\begin{array}{l}0.1618 \\
0.1635 \\
0.1646 \\
0.1655 \\
0.1659 \\
0.1659 \\
0.1659 \\
0.1659 \\
0.1659 \\
0.1668 \\
0.1676 \\
0.1676 \\
0.1676 \\
0.1684 \\
0.1684 \\
0.1685 \\
0.1692 \\
0.1692 \\
0.1692 \\
0.1699 \\
0.1699 \\
0.1703 \\
0.1703 \\
0.1713 \\
0.1713 \\
0.1732 \\
0.1754 \\
0.1758 \\
0.1758 \\
0.1786\end{array}$ & $\begin{array}{l}1.1307 \\
0.8549 \\
1.1307 \\
1.1307 \\
0.8411 \\
0.8411 \\
0.8411 \\
0.8549 \\
0.8549 \\
1.3927 \\
1.3513 \\
1.3927 \\
1.3927 \\
1.3513 \\
1.3513 \\
1.6547 \\
1.6547 \\
1.6547 \\
1.6547 \\
1.6547 \\
1.6547 \\
1.0893 \\
1.0893 \\
1.0893 \\
1.0893 \\
0.8549 \\
1.0893 \\
0.8549 \\
0.8549 \\
1.0893\end{array}$ & $\begin{array}{l}63.4 \\
70.6 \\
64.8 \\
64.1 \\
67.7 \\
69.0 \\
67.7 \\
67.6 \\
66.6 \\
60.4 \\
61.6 \\
60.9 \\
59.1 \\
61.6 \\
60.3 \\
56.4 \\
55.0 \\
57.4 \\
55.3 \\
55.2 \\
57.4 \\
68.6 \\
66.3 \\
64.2 \\
66.0 \\
69.5 \\
61.4 \\
69.3 \\
67.4 \\
61.7\end{array}$ & $\begin{array}{l}18.1 \\
14.4 \\
17.8 \\
17.7 \\
14.2 \\
14.2 \\
14.2 \\
14.2 \\
14.2 \\
21.0 \\
20.9 \\
20.9 \\
20.9 \\
20.8 \\
20.8 \\
24.2 \\
24.1 \\
24.1 \\
24.1 \\
24.0 \\
24.0 \\
17.2 \\
17.2 \\
17.1 \\
17.1 \\
13.6 \\
16.7 \\
13.4 \\
13.4 \\
16.4\end{array}$ & $\begin{array}{l}2.93 \\
2.36 \\
2.93 \\
2.93 \\
2.36 \\
2.36 \\
2.36 \\
2.36 \\
2.36 \\
3.50 \\
3.50 \\
3.50 \\
3.50 \\
3.50 \\
3.50 \\
4.08 \\
4.08 \\
4.08 \\
4.08 \\
4.08 \\
4.08 \\
2.93 \\
2.93 \\
2.93 \\
2.93 \\
2.36 \\
2.93 \\
2.36 \\
2.36 \\
2.93\end{array}$ & $\begin{array}{l}64 \\
64 \\
64 \\
64 \\
64 \\
64 \\
64 \\
64 \\
64 \\
64 \\
64 \\
64 \\
64 \\
64 \\
64 \\
64 \\
64 \\
64 \\
64 \\
64 \\
64 \\
64 \\
64 \\
64 \\
64 \\
64\end{array}$ & $\begin{array}{l}21 \\
21 \\
21 \\
21 \\
21 \\
21 \\
21 \\
21 \\
21 \\
21 \\
21 \\
21 \\
21 \\
21 \\
21 \\
21 \\
21 \\
21 \\
21 \\
21 \\
21 \\
21 \\
21 \\
21 \\
21 \\
21 \\
21 \\
21 \\
21 \\
21\end{array}$ & $\begin{array}{l}1.22 \\
1.22 \\
1.22 \\
1.22 \\
1.22 \\
1.22 \\
1.22 \\
1.22 \\
1.22 \\
1.22 \\
1.22 \\
1.22 \\
1.22 \\
1.22 \\
1.22 \\
1.22 \\
1.22 \\
1.22 \\
1.22 \\
1.22 \\
1.22 \\
1.22 \\
1.22 \\
1.22 \\
1.22 \\
1.22 \\
1.22 \\
1.22 \\
1.22 \\
1.22\end{array}$ \\
\hline $\begin{array}{l}450 \\
450 \\
450 \\
450 \\
450 \\
450 \\
450 \\
450 \\
450\end{array}$ & $\begin{array}{l}0.95 \\
0.95 \\
0.95 \\
0.95 \\
0.95 \\
0.95 \\
0.95 \\
0.95 \\
0.95\end{array}$ & $\begin{array}{l}0.2450 \\
0.2474 \\
0.2482 \\
0.2484 \\
0.2484 \\
0.2486 \\
0.2487 \\
0.2487 \\
0.2501\end{array}$ & $\begin{array}{l}1.1858 \\
1.6271 \\
0.9652 \\
1.18513 \\
1.1858 \\
1.4065 \\
1.6271 \\
1.6271 \\
1.4065\end{array}$ & $\begin{array}{l}51.5 \\
49.5 \\
55.0 \\
51.2 \\
51.8 \\
51.1 \\
49.7 \\
50.1 \\
51.5\end{array}$ & $\begin{array}{l}14.3 \\
18.8 \\
11.8 \\
14.1 \\
14.1 \\
16.4 \\
18.7 \\
18.7 \\
16.3\end{array}$ & $\begin{array}{l}3.50 \\
4.65 \\
2.93 \\
3.50 \\
3.50 \\
4.08 \\
4.65 \\
4.65 \\
4.08\end{array}$ & $\begin{array}{l}64 \\
64 \\
64 \\
64 \\
64 \\
64 \\
64 \\
64 \\
64\end{array}$ & $\begin{array}{l}21 \\
21 \\
21 \\
21 \\
21 \\
21 \\
21 \\
21 \\
21\end{array}$ & $\begin{array}{l}1.22 \\
1.22 \\
1.22 \\
1.22 \\
1.22 \\
1.22 \\
1.22 \\
1.22 \\
1.22\end{array}$ \\
\hline
\end{tabular}


Glycerine-Water-Polymer Mixture Data (continued)

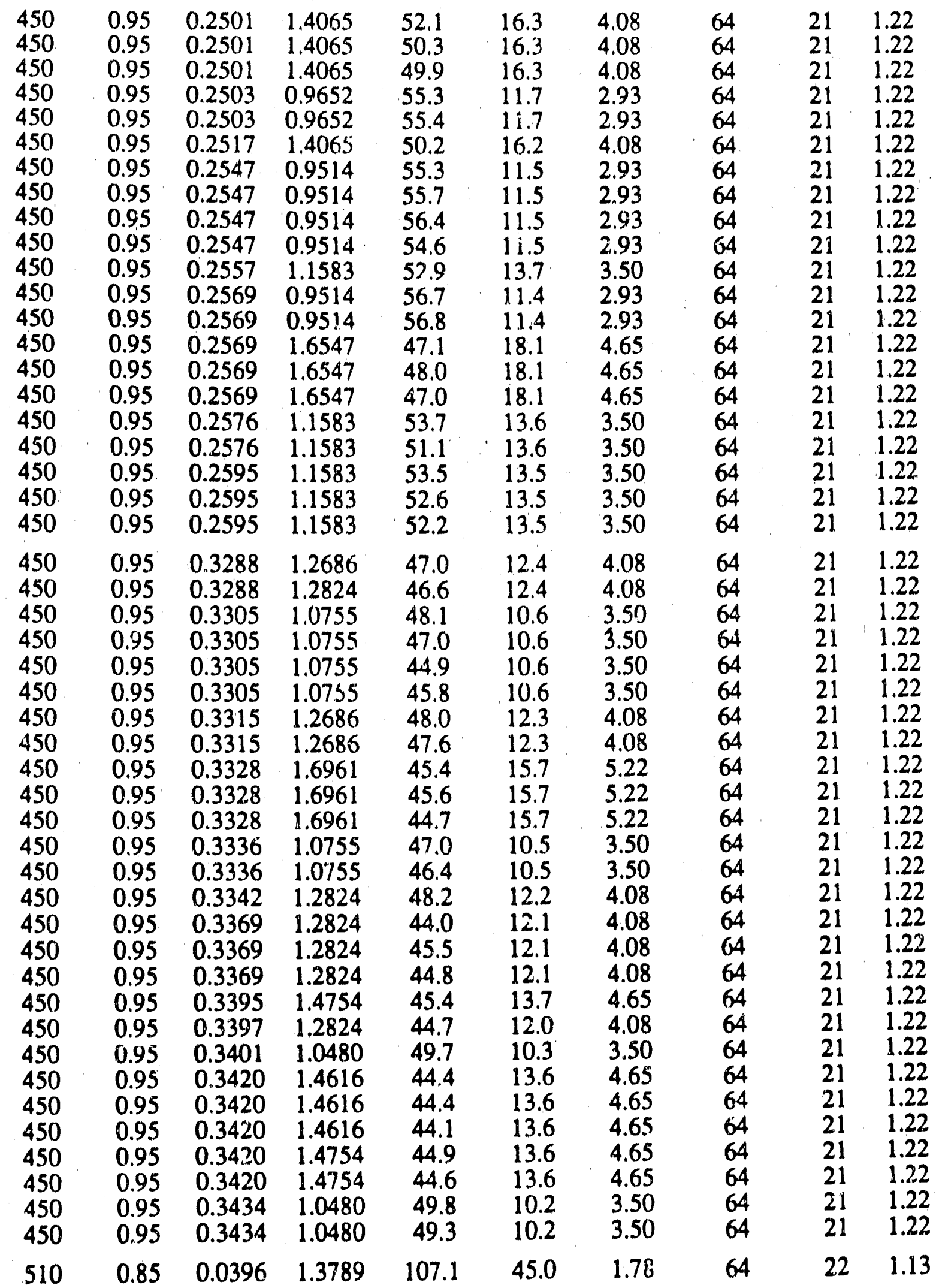


Glycerine-Water-Polymer Mixture Data (continued)

\begin{tabular}{|c|c|c|c|c|c|c|c|c|}
\hline $\begin{array}{l}0.85 \\
0.85 \\
0.85 \\
0.85 \\
0.85 \\
0.85 \\
0.85 \\
0.85\end{array}$ & $\begin{array}{l}0.0401 \\
0.0404 \\
0.0408 \\
0.0419 \\
0.042 ? \\
0.0432 \\
0.0433 \\
0.0434\end{array}$ & $\begin{array}{l}1.3789 \\
1.3789 \\
0.3998 \\
1.0342 \\
1.0342 \\
1.5857 \\
1.5857 \\
1.5857\end{array}$ & $\begin{array}{l}107.8 \\
103.9 \\
149.9 \\
103.3 \\
100.2 \\
104.1 \\
103.7 \\
106.4\end{array}$ & $\begin{array}{l}44.4 \\
44.1 \\
18.4 \\
35.7 \\
35.4 \\
47.9 \\
47.8 \\
47.7\end{array}$ & $\begin{array}{l}1.78 \\
1.78 \\
0.75 \\
1.49 \\
1.49 \\
2.07 \\
2.07 \\
2.07\end{array}$ & $\begin{array}{l}64 \\
64 \\
64 \\
64 \\
64 \\
64 \\
64 \\
64\end{array}$ & $\begin{array}{l}22 \\
22 \\
22 \\
22 \\
22 \\
22 \\
22 \\
22\end{array}$ & $\begin{array}{l}1.13 \\
1.13 \\
1.13 \\
1.13 \\
1.13 \\
1.13 \\
1.13 \\
1.13\end{array}$ \\
\hline $\begin{array}{l}0.85 \\
0.85 \\
0.85 \\
0.85 \\
0.85 \\
0.85 \\
0.85 \\
0.85 \\
0.85 \\
0.85 \\
0.85 \\
0.85 \\
0.85 \\
0.85 \\
0.85 \\
0.85 \\
0.85 \\
0.85 \\
0.85 \\
0.85 \\
0.85 \\
0.85 \\
0.85 \\
0.85\end{array}$ & $\begin{array}{l}0.0829 \\
0.0833 \\
0.0836 \\
0.0841 \\
0.0842 \\
0.0844 \\
0.0846 \\
0.0847 \\
0.0849 \\
0.0849 \\
0.0878 \\
0.0882 \\
0.0899 \\
0.0900 \\
0.0902 \\
0.0905 \\
0.0909 \\
0.0926 \\
0.0957 \\
0.0994 \\
0.1034 \\
0.1358 \\
0.1398 \\
0.1409\end{array}$ & $\begin{array}{l}0.7722 \\
1.2824 \\
1.2824 \\
1.2824 \\
1.6409 \\
1.4203 \\
1.6409 \\
1.0617 \\
1.6409 \\
1.4203 \\
0.7722 \\
0.7722 \\
0.5929 \\
1.8340 \\
1.0617 \\
1.8340 \\
1.0617 \\
0.5929 \\
0.8687 \\
0.8687 \\
0.8687 \\
1.4892 \\
1.4892 \\
1.4892\end{array}$ & $\begin{array}{r}91.3 \\
84.2 \\
86.4 \\
86.2 \\
82.6 \\
82.9 \\
83.1 \\
87.4 \\
82.0 \\
81.4 \\
96.9 \\
94.9 \\
99.7 \\
82.0 \\
84.4 \\
79.2 \\
81.3 \\
103.5 \\
86.3 \\
78.5 \\
84.8 \\
66.5 \\
66.2 \\
68.7\end{array}$ & $\begin{array}{l}21.6 \\
31.7 \\
31.6 \\
31.4 \\
38.2 \\
34.7 \\
38.0 \\
27.8 \\
37.9 \\
34.5 \\
20.4 \\
20.3 \\
16.8 \\
38.7 \\
26.1 \\
38.5 \\
25.9 \\
16.3 \\
21.6 \\
20.8 \\
20.0 \\
27.9 \\
27.1 \\
26.9\end{array}$ & $\begin{array}{l}1.79 \\
2.64 \\
2.64 \\
2.64 \\
3.22 \\
2.93 \\
3.22 \\
2.36 \\
3.22 \\
2.93 \\
1.79 \\
1.79 \\
1.51 \\
3.48 \\
2.36 \\
3.48 \\
2.36 \\
1.51 \\
2.07 \\
2.07 \\
2.07 \\
3.79 \\
3.79 \\
3.79\end{array}$ & $\begin{array}{l}64 \\
64 \\
64 \\
64 \\
64 \\
64 \\
64 \\
64 \\
64 \\
64 \\
64 \\
64 \\
64 \\
64 \\
64 \\
64 \\
64 \\
64 \\
64 \\
64 \\
64 \\
64 \\
64 \\
64\end{array}$ & $\begin{array}{l}22 \\
22 \\
22 \\
22 \\
22 \\
22 \\
22 \\
22 \\
22 \\
22 \\
22 \\
22 \\
22 \\
22 \\
22 \\
22 \\
22 \\
22 \\
22 \\
22 \\
22 \\
22 \\
22 \\
22\end{array}$ & $\begin{array}{l}1.13 \\
1.13 \\
1.13 \\
1.13 \\
1.1 ? \\
1.13 \\
1.13 \\
1.13 \\
1.13 \\
1.13 \\
1.13 \\
1.13 \\
1.13 \\
1.13 \\
1.13 \\
1.13 \\
1.13 \\
1.13 \\
1.13 \\
1.13 \\
1.13 \\
1.13 \\
1.13 \\
1.13\end{array}$ \\
\hline $\begin{array}{l}0.85 \\
0.85 \\
0.85 \\
0.85 \\
0.85 \\
0.85 \\
0.85 \\
0.85 \\
0.85 \\
0.85 \\
0.85 \\
0.85 \\
0.85 \\
0.85 \\
0.85 \\
0.85\end{array}$ & $\begin{array}{l}0.1600 \\
0.1616 \\
0.1631 \\
0.1632 \\
0.1646 \\
0.1672 \\
0.1672 \\
0.1699 \\
0.1705 \\
0.1711 \\
0.1716 \\
0.1726 \\
0.1734 \\
0.1740 \\
0.1750 \\
0.1754\end{array}$ & $\begin{array}{l}0.7860 \\
1.5168 \\
0.8825 \\
1.1169 \\
0.9928 \\
0.6481 \\
0.6481 \\
0.6481 \\
0.8825 \\
1.1169 \\
0.7860 \\
1.5168 \\
1.1858 \\
1.5168 \\
0.8825 \\
0.7860\end{array}$ & $\begin{array}{l}77.8 \\
60.5 \\
68.0 \\
65.0 \\
71.4 \\
79.2 \\
75.2 \\
75.4 \\
71.7 \\
70.5 \\
72.8 \\
63.0 \\
63.9 \\
64.7 \\
71.5 \\
73.4\end{array}$ & $\begin{array}{l}14.8 \\
25.1 \\
16.2 \\
19.7 \\
17.8 \\
12.5 \\
12.5 \\
12.3 \\
15.5 \\
18.8 \\
13.8 \\
23.5 \\
20.2 \\
23.3 \\
15.1 \\
13.5\end{array}$ & $\begin{array}{l}2.37 \\
4.06 \\
2.64 \\
3.22 \\
2.93 \\
2.09 \\
2.09 \\
2.09 \\
2.64 \\
3.22 \\
2.37 \\
4.06 \\
3.50 \\
4.06 \\
2.64 \\
2.37\end{array}$ & $\begin{array}{l}64 \\
64 \\
64 \\
64 \\
64 \\
64 \\
64 \\
64 \\
64 \\
64 \\
64 \\
64 \\
64 \\
64 \\
64 \\
64\end{array}$ & $\begin{array}{l}22 \\
22 \\
22 \\
22 \\
22 \\
22 \\
22 \\
22 \\
22 \\
22 \\
22 \\
22 \\
22 \\
22 \\
22 \\
22\end{array}$ & $\begin{array}{l}1.13 \\
1.13 \\
1.13 \\
1.13 \\
1.13 \\
1.13 \\
1.13 \\
1.13 \\
1.13 \\
1.13 \\
1.13 \\
1.13 \\
1.13 \\
1.13 \\
1.13 \\
1.13\end{array}$ \\
\hline
\end{tabular}


Glycerine-Water-Polymer Mixture Data (continued)

\begin{tabular}{|c|c|c|c|c|c|c|c|c|}
\hline $\begin{array}{l}510 \\
510 \\
510 \\
510 \\
510\end{array}$ & $\begin{array}{l}0.85 \\
0.85 \\
0.85 \\
0.85 \\
0.85\end{array}$ & $\begin{array}{l}0.1757 \\
0.1764 \\
0.1808 \\
0.1914 \\
0.1990\end{array}$ & $\begin{array}{l}1.1169 \\
0.9928 \\
0.9928 \\
1.1858 \\
1.1858\end{array}$ & $\begin{array}{l}66.6 \\
67.0 \\
67.2 \\
61.3 \\
63.7\end{array}$ & $\begin{array}{l}18.3 \\
16.6 \\
16.2 \\
18.3 \\
17.6\end{array}$ & $\begin{array}{l}3.22 \\
2.93 \\
2.93 \\
3.50 \\
3.50\end{array}$ & $\begin{array}{l}64 \\
64 \\
64 \\
64 \\
64\end{array}$ & $\begin{array}{l}22 \\
22 \\
22 \\
22 \\
22\end{array}$ \\
\hline $\begin{array}{l}510 \\
510 \\
510 \\
510 \\
510 \\
510 \\
510 \\
510 \\
510 \\
510 \\
510 \\
510 \\
510 \\
510 \\
510 \\
510 \\
510 \\
510 \\
510 \\
510 \\
510 \\
510 \\
510\end{array}$ & $\begin{array}{l}0.85 \\
0.85 \\
0.85 \\
0.85 \\
0.85 \\
0.85 \\
0.85 \\
0.85 \\
0.85 \\
0.85 \\
0.85 \\
0.85 \\
0.85 \\
0.85 \\
0.85 \\
0.85 \\
0.85 \\
0.85 \\
0.85 \\
0.85 \\
0.85 \\
0.85 \\
0.85\end{array}$ & $\begin{array}{l}0.2383 \\
0.2411 \\
0.2429 \\
0.2445 \\
0.2484 \\
0.2508 \\
0.2510 \\
0.2514 \\
0.2514 \\
0.2517 \\
0.2528 \\
0.2532 \\
0.2532 \\
0.2557 \\
0.2592 \\
0.2592 \\
0.2670 \\
0.2702 \\
0.2749 \\
0.2752 \\
0.2755 \\
0.2804 \\
0.2851\end{array}$ & $\begin{array}{l}1.0755 \\
1.4065 \\
1.1721 \\
1.1721 \\
1.0755 \\
1.4065 \\
1.1721 \\
1.4892 \\
1.4892 \\
0.8687 \\
1.4892 \\
1.2686 \\
0.9376 \\
1.0755 \\
0.7584 \\
0.7584 \\
0.7584 \\
0.9376 \\
0.9376 \\
0.8687 \\
1.2686 \\
0.8687 \\
1.2686\end{array}$ & $\begin{array}{l}60.2 \\
54.0 \\
56.9 \\
56.5 \\
59.6 \\
55.6 \\
57.0 \\
52.4 \\
56.1 \\
55.7 \\
51.1 \\
57.3 \\
58.3 \\
57.8 \\
66.7 \\
61.9 \\
59.6 \\
57.3 \\
59.0 \\
60.0 \\
52.0 \\
60.5 \\
54.0\end{array}$ & $\begin{array}{l}14.7 \\
18.1 \\
15.6 \\
15.5 \\
14.1 \\
17.4 \\
15.1 \\
18.4 \\
18.4 \\
11.7 \\
18.3 \\
16.1 \\
12.7 \\
13.7 \\
10.3 \\
10.3 \\
10.0 \\
11.9 \\
11.7 \\
10.7 \\
14.8 \\
10.5 \\
14.3\end{array}$ & $\begin{array}{l}3.50 \\
4.36 \\
3.79 \\
3.79 \\
3.50 \\
4.36 \\
3.79 \\
4.63 \\
4.63 \\
2.94 \\
4.63 \\
4.08 \\
3.22 \\
3.50 \\
2.67 \\
2.67 \\
2.67 \\
3.22 \\
3.22 \\
2.94 \\
4.08 \\
2.94 \\
4.08\end{array}$ & $\begin{array}{l}64 \\
64 \\
64 \\
64 \\
64 \\
64 \\
64 \\
64 \\
64 \\
64 \\
64 \\
64 \\
64 \\
64 \\
64 \\
64 \\
64 \\
64 \\
64 \\
64 \\
64 \\
64 \\
64\end{array}$ & $\begin{array}{l}22 \\
22 \\
22 \\
22 \\
22 \\
22 \\
22 \\
22 \\
22 \\
22 \\
22 \\
22 \\
22 \\
22 \\
22 \\
22 \\
22 \\
22 \\
22 \\
22 \\
22 \\
22 \\
22\end{array}$ \\
\hline $\begin{array}{l}510 \\
510 \\
510 \\
510 \\
510 \\
510 \\
510 \\
510 \\
510 \\
510 \\
510 \\
510 \\
510 \\
510 \\
510 \\
510 \\
510 \\
510 \\
510 \\
510 \\
510\end{array}$ & $\begin{array}{l}0.85 \\
0.85 \\
0.85 \\
0.85 \\
0.85 \\
0.85 \\
0.85 \\
0.85 \\
0.85 \\
0.85 \\
0.85 \\
0.85 \\
0.85 \\
0.85 \\
0.85 \\
0.85 \\
0.85 \\
0.85 \\
0.85 \\
0.85 \\
0.85\end{array}$ & $\begin{array}{l}0.2981 \\
0.3060 \\
0.3164 \\
0.3212 \\
0.3231 \\
0.3268 \\
0.3270 \\
0.3292 \\
0.3296 \\
0.3296 \\
0.3310 \\
0.3351 \\
0.3351 \\
0.3351 \\
0.3353 \\
0.3354 \\
0.3357 \\
0.3359 \\
0.3397 \\
0.3397 \\
0.3419\end{array}$ & $\begin{array}{l}1.4203 \\
1.4203 \\
1.4203 \\
1.0893 \\
0.9790 \\
1.5995 \\
1.4892 \\
1.4892 \\
1.0893 \\
1.0893 \\
1.5995 \\
0.8963 \\
0.8963 \\
0.8963 \\
1.5995 \\
0.9790 \\
1.2686 \\
1.4892 \\
1.1721 \\
1.1721 \\
0.9790\end{array}$ & $\begin{array}{r}49.8 \\
49.5 \\
49.1 \\
52.1 \\
52.4 \\
47.4 \\
47.3 \\
46.5 \\
50.1 \\
52.2 \\
48.8 \\
52.66 \\
55.47 \\
52.54 \\
44.7 \\
53.5 \\
47.7 \\
50.4 \\
50.7 \\
49.1 \\
52.4\end{array}$ & $\begin{array}{r}15.6 \\
15.2 \\
14.7 \\
11.8 \\
10.9 \\
15.9 \\
15.1 \\
15.0 \\
11.5 \\
11.5 \\
15.7 \\
9.7 \\
9.7 \\
9.7 \\
15.5 \\
10.5 \\
13.0 \\
14.7 \\
12.0 \\
12.0 \\
10.3\end{array}$ & $\begin{array}{l}4.65 \\
4.65 \\
4.65 \\
3.79 \\
3.52 \\
5.20 \\
4.94 \\
4.94 \\
3.79 \\
3.79 \\
5.20 \\
3.25 \\
3.25 \\
3.25 \\
5.20 \\
3.52 \\
4.36 \\
4.94 \\
4.08 \\
4.08 \\
3.52\end{array}$ & $\begin{array}{l}64 \\
64 \\
64 \\
64 \\
64 \\
64 \\
64 \\
64 \\
64 \\
64 \\
64 \\
64 \\
64 \\
64 \\
64 \\
64 \\
64 \\
64 \\
64 \\
64 \\
64\end{array}$ & $\begin{array}{l}22 \\
22 \\
22 \\
22 \\
22 \\
22 \\
22 \\
22 \\
22 \\
22 \\
22 \\
22 \\
22 \\
22 \\
22 \\
22 \\
22 \\
22 \\
22 \\
22 \\
22\end{array}$ \\
\hline
\end{tabular}


Glycerine-Water-Polymer Mixture Data (continued)

\begin{tabular}{|c|c|c|c|c|c|c|c|c|c|}
\hline $\begin{array}{l}510 \\
510 \\
510 \\
520 \\
520 \\
520 \\
520 \\
520 \\
520 \\
520 \\
520 \\
520 \\
520 \\
520\end{array}$ & $\begin{array}{l}0.85 \\
0.85 \\
0.85 \\
0.94 \\
0.94 \\
0.94 \\
0.94 \\
0.84 \\
0.94 \\
0.94 \\
0.94 \\
0.94 \\
0.94 \\
0.94\end{array}$ & $\begin{array}{l}0.3426 \\
0.3491 \\
0.3667 \\
0.0391 \\
0.0395 \\
0.0404 \\
0.0406 \\
0.0407 \\
0.0407 \\
0.0429 \\
0.0431 \\
0.0433 \\
0.0437 \\
0.0445\end{array}$ & $\begin{array}{l}1.1721 \\
1.2686 \\
1.2686 \\
0.7997 \\
0.7997 \\
0.7997 \\
0.8411 \\
0.8411 \\
0.8411 \\
1.4065 \\
1.4065 \\
1.4065 \\
1.4203 \\
1.4203\end{array}$ & $\begin{array}{r}47.4 \\
46.1 \\
45.8 \\
156.3 \\
154.1 \\
158.0 \\
146.8 \\
144.6 \\
147.5 \\
116.7 \\
118.8 \\
125.7 \\
127.9 \\
126.3\end{array}$ & $\begin{array}{l}11.9 \\
12.5 \\
11.9 \\
28.1 \\
27.8 \\
27.2 \\
27.2 \\
27.1 \\
27.1 \\
41.5 \\
41.3 \\
41.1 \\
41.0 \\
40.2\end{array}$ & $\begin{array}{l}4.08 \\
4.36 \\
4.36 \\
1.10 \\
1.10 \\
1.10 \\
1.10 \\
1.10 \\
1.10 \\
1.78 \\
1.78 \\
1.78 \\
1.79 \\
1.79\end{array}$ & $\begin{array}{l}64 \\
64 \\
64 \\
64 \\
64 \\
64 \\
64 \\
64 \\
64 \\
64 \\
64 \\
64 \\
64 \\
64\end{array}$ & $\begin{array}{l}22 \\
22 \\
22 \\
22 \\
22 \\
22 \\
22 \\
22 \\
22 \\
22 \\
22 \\
22 \\
22 \\
22\end{array}$ & $\begin{array}{l}1.13 \\
1.13 \\
1.13 \\
1.22 \\
1.22 \\
1.22 \\
1.22 \\
1.22 \\
1.22 \\
1.22 \\
1.22 \\
1.22 \\
1.22 \\
1.22\end{array}$ \\
\hline $\begin{array}{l}520 \\
520 \\
520 \\
520 \\
520 \\
520 \\
520 \\
520 \\
520 \\
520 \\
520 \\
520 \\
520 \\
520 \\
520 \\
520 \\
520 \\
520 \\
520 \\
520 \\
520\end{array}$ & $\begin{array}{l}0.94 \\
0.94 \\
0.94 \\
0.94 \\
0.94 \\
0.94 \\
0.94 \\
0.94 \\
0.94 \\
0.94 \\
0.94 \\
0.94 \\
0.94 \\
0.94 \\
0.94 \\
0.94 \\
0.94 \\
0.94 \\
0.94 \\
0.94 \\
0.94\end{array}$ & $\begin{array}{l}0.0821 \\
0.0826 \\
0.0828 \\
0.0832 \\
0.0833 \\
0.0839 \\
0.0840 \\
0.0843 \\
0.0843 \\
0.0844 \\
0.0853 \\
0.0854 \\
0.0857 \\
0.0864 \\
0.0874 \\
0.1061 \\
0.1081 \\
0.1081 \\
0.1116 \\
0.1123 \\
0.1123\end{array}$ & $\begin{array}{l}1.2824 \\
1.2824 \\
0.8549 \\
0.8549 \\
0.8687 \\
1.5995 \\
1.2686 \\
1.2686 \\
1.2686 \\
1.5995 \\
0.8687 \\
1.5995 \\
0.8687 \\
1.6133 \\
1.6133 \\
1.7236 \\
1.7236 \\
1.7236 \\
1.6961 \\
1.6961 \\
1.6961\end{array}$ & $\begin{array}{r}91.0 \\
88.3 \\
96.2 \\
96.8 \\
101.3 \\
87.7 \\
96.2 \\
93.2 \\
94.8 \\
88.4 \\
111.0 \\
87.7 \\
104.8 \\
93.2 \\
91.5 \\
73.9 \\
73.8 \\
77.9 \\
79.7 \\
77.6 \\
80.5\end{array}$ & $\begin{array}{l}28.7 \\
28.5 \\
21.5 \\
21.4 \\
21.5 \\
34.9 \\
28.2 \\
28.1 \\
28.1 \\
34.7 \\
21.0 \\
34.3 \\
20.9 \\
34.1 \\
33.7 \\
33.0 \\
32.4 \\
32.4 \\
31.4 \\
31.2 \\
31.2\end{array}$ & $\begin{array}{l}2.36 \\
2.36 \\
1.78 \\
1.78 \\
1.79 \\
2.93 \\
2.37 \\
2.37 \\
2.37 \\
2.93 \\
1.79 \\
2.93 \\
1.79 \\
2.94 \\
2.94 \\
3.50 \\
3.50 \\
3.50 \\
3.50 \\
3.50 \\
3.50\end{array}$ & $\begin{array}{l}64 \\
64 \\
64 \\
64 \\
64 \\
64 \\
64 \\
64 \\
64 \\
64 \\
64 \\
64 \\
64 \\
64 \\
64 \\
64 \\
64 \\
64 \\
64 \\
64 \\
64\end{array}$ & $\begin{array}{l}22 \\
22 \\
22 \\
22 \\
22 \\
22 \\
22 \\
22 \\
22 \\
22 \\
22 \\
22 \\
22 \\
22 \\
22 \\
22 \\
22 \\
22 \\
22 \\
22 \\
22\end{array}$ & $\begin{array}{l}1.22 \\
1.22 \\
1.22 \\
1.22 \\
1.22 \\
1.22 \\
1.22 \\
1.22 \\
1.22 \\
1.22 \\
1.22 \\
1.22 \\
1.22 \\
1.22 \\
1.22 \\
1.22 \\
1.22 \\
1.22 \\
1.22 \\
1.22 \\
1.22\end{array}$ \\
\hline $\begin{array}{l}520 \\
520 \\
520 \\
520 \\
520 \\
520 \\
520 \\
520 \\
520 \\
520 \\
520 \\
520 \\
520\end{array}$ & $\begin{array}{l}0.94 \\
0.94 \\
0.94 \\
0.94 \\
0.94 \\
0.94 \\
0.94 \\
0.94 \\
0.94 \\
0.94 \\
0.94 \\
0.94 \\
0.94\end{array}$ & $\begin{array}{l}0.1624 \\
0.1635 \\
0.1644 \\
0.1651 \\
0.1651 \\
0.1659 \\
0.1684 \\
0.1684 \\
0.1685 \\
0.1685 \\
0.1692 \\
0.1692 \\
0.1693\end{array}$ & $\begin{array}{l}0.8549 \\
0.8549 \\
1.6823 \\
1.6823 \\
1.6823 \\
0.8549 \\
1.4065 \\
1.4065 \\
1.6961 \\
1.6961 \\
1.6961 \\
1.4065 \\
1.4065\end{array}$ & $\begin{array}{l}73.8 \\
70.3 \\
59.4 \\
60.3 \\
60.8 \\
72.7 \\
62.9 \\
59.9 \\
61.1 \\
63.5 \\
61.6 \\
61.8 \\
65.0\end{array}$ & $\begin{array}{l}14.5 \\
14.4 \\
24.8 \\
24.7 \\
24.7 \\
14.2 \\
20.8 \\
20.8 \\
24.2 \\
24.2 \\
24.1 \\
20.7 \\
20.8\end{array}$ & $\begin{array}{l}2.36 \\
2.36 \\
4.08 \\
4.08 \\
4.08 \\
2.36 \\
3.50 \\
3.50 \\
4.08 \\
4.08 \\
4.08 \\
3.50 \\
3.52\end{array}$ & $\begin{array}{l}64 \\
64 \\
64 \\
64 \\
64 \\
64 \\
64 \\
64 \\
64 \\
64 \\
64 \\
64 \\
64\end{array}$ & $\begin{array}{l}22 \\
22 \\
22 \\
22 \\
22 \\
22 \\
22 \\
22 \\
22 \\
22 \\
22 \\
22 \\
22\end{array}$ & $\begin{array}{l}1.22 \\
1.22 \\
1.22 \\
1.22 \\
1.22 \\
1.22 \\
1.22 \\
1.22 \\
1.22 \\
1.22 \\
1.22 \\
1.22 \\
1.22\end{array}$ \\
\hline
\end{tabular}


Glycerine-Water-Polymer Mixture Data (continued)

\begin{tabular}{|c|c|c|c|c|c|c|c|c|c|}
\hline $\begin{array}{l}520 \\
520 \\
520 \\
520 \\
520 \\
520 \\
520 \\
520 \\
520 \\
520 \\
520\end{array}$ & $\begin{array}{l}0.94 \\
0.94 \\
0.94 \\
0.94 \\
0.94 \\
0.94 \\
0.94 \\
0.94 \\
0.94 \\
0.94 \\
0.94\end{array}$ & $\begin{array}{l}0.1693 \\
0.1701 \\
0.1709 \\
0.1712 \\
0.1713 \\
0.1713 \\
0.1716 \\
0.1722 \\
0.1722 \\
0.1741 \\
0.1754\end{array}$ & $\begin{array}{l}1.1307 \\
1.4065 \\
1.4065 \\
1.1307 \\
1.1307 \\
1.1307 \\
0.8687 \\
1.1307 \\
1.1307 \\
0.8687 \\
0.8687\end{array}$ & $\begin{array}{l}63.8 \\
65.8 \\
66.4 \\
67.1 \\
64.7 \\
64.1 \\
76.4 \\
73.2 \\
69.7 \\
73.0 \\
74.9\end{array}$ & $\begin{array}{l}17.3 \\
20.7 \\
20.6 \\
17.2 \\
17.1 \\
17.1 \\
13.8 \\
17.1 \\
17.1 \\
13.6 \\
13.5\end{array}$ & $\begin{array}{l}2.93 \\
3.52 \\
3.52 \\
2.94 \\
2.93 \\
2.93 \\
2.37 \\
2.94 \\
2.94 \\
2.37 \\
2.37\end{array}$ & $\begin{array}{l}64 \\
64 \\
64 \\
64 \\
64 \\
64 \\
64 \\
64 \\
64 \\
64 \\
64\end{array}$ & $\begin{array}{l}22 \\
22 \\
22 \\
22 \\
22 \\
22 \\
22 \\
22 \\
22 \\
22 \\
22\end{array}$ & $\begin{array}{l}1.22 \\
1.22 \\
1.22 \\
1.22 \\
1.22 \\
1.22 \\
1.22 \\
1.22 \\
1.22 \\
1.22 \\
1.22\end{array}$ \\
\hline $\begin{array}{l}520 \\
520 \\
520 \\
520 \\
520 \\
520 \\
520 \\
520 \\
520 \\
520 \\
520 \\
520 \\
520 \\
520 \\
520 \\
520 \\
520 \\
520 \\
520 \\
520 \\
520 \\
520 \\
520 \\
520\end{array}$ & $\begin{array}{l}0.94 \\
0.94 \\
0.94 \\
0.94 \\
0.94 \\
0.94 \\
0.94 \\
0.94 \\
0.94 \\
0.94 \\
0.94 \\
0.94 \\
0.94 \\
0.94 \\
0.94 \\
0.94 \\
0.94 \\
0.94 \\
0.94 \\
0.94 \\
0.94 \\
0.94 \\
0.94 \\
0.94\end{array}$ & $\begin{array}{l}0.2482 \\
0.2486 \\
0.2498 \\
0.2500 \\
0.2501 \\
0.2502 \\
0.2502 \\
0.2503 \\
0.2503 \\
0.2514 \\
0.2514 \\
0.2515 \\
0.2515 \\
0.2517 \\
0.2520 \\
0.2530 \\
0.2538 \\
0.2541 \\
0.2546 \\
0.2555 \\
0.2555 \\
0.2562 \\
0.2583 \\
0.2583\end{array}$ & $\begin{array}{l}0.9652 \\
1.4341 \\
1.1996 \\
1.6823 \\
1.4341 \\
1.1858 \\
1.1858 \\
0.9652 \\
0.9652 \\
1.6823 \\
1.6823 \\
1.1996 \\
1.1996 \\
1.4341 \\
1.1858 \\
1.4203 \\
0.9514 \\
1.6823 \\
1.4203 \\
1.6823 \\
1.6823 \\
1.4203 \\
0.9514 \\
0.9514\end{array}$ & $\begin{array}{l}58.5 \\
51.4 \\
57.0 \\
49.1 \\
52.1 \\
53.9 \\
57.4 \\
59.1 \\
58.2 \\
49.1 \\
49.7 \\
59.8 \\
55.3 \\
51.7 \\
53.8 \\
53.3 \\
61.1 \\
49.2 \\
51.6 \\
50.1 \\
50.0 \\
53.3 \\
61.8 \\
60.6\end{array}$ & $\begin{array}{l}11.8 \\
16.4 \\
14.1 \\
18.6 \\
16.3 \\
14.0 \\
14.0 \\
11.7 \\
11.7 \\
18.5 \\
18.5 \\
14.0 \\
14.0 \\
16.2 \\
13.9 \\
16.2 \\
11.6 \\
18.3 \\
16.1 \\
18.2 \\
18.2 \\
16.0 \\
11.4 \\
11.4\end{array}$ & $\begin{array}{l}2.93 \\
4.08 \\
3.52 \\
4.65 \\
4.08 \\
3.50 \\
3.50 \\
2.93 \\
2.93 \\
4.65 \\
4.65 \\
3.52 \\
3.52 \\
4.08 \\
3.50 \\
4.10 \\
2.94 \\
4.65 \\
4.10 \\
4.65 \\
4.65 \\
4.10 \\
2.94 \\
2.94\end{array}$ & $\begin{array}{l}64 \\
64 \\
64 \\
64 \\
64 \\
64 \\
64 \\
64 \\
64 \\
64 \\
64 \\
64 \\
64 \\
64 \\
64 \\
64 \\
64 \\
64 \\
64 \\
64 \\
64 \\
64 \\
64 \\
64\end{array}$ & $\begin{array}{l}22 \\
22 \\
22 \\
22 \\
22 \\
22 \\
22 \\
22 \\
22 \\
22 \\
22 \\
22 \\
22 \\
22 \\
22 \\
22 \\
22 \\
22 \\
22 \\
22 \\
22 \\
22 \\
22 \\
22\end{array}$ & $\begin{array}{l}1.22 \\
1.22 \\
1.22 \\
1.22 \\
1.22 \\
1.22 \\
1.22 \\
1.22 \\
1.22 \\
1.22 \\
1.22 \\
1.22 \\
1.22 \\
1.22 \\
1.22 \\
1.22 \\
1.22 \\
1.22 \\
1.22 \\
1.22 \\
1.22 \\
1.22 \\
1.22 \\
1.22\end{array}$ \\
\hline $\begin{array}{l}520 \\
520 \\
520 \\
520 \\
520 \\
520 \\
520 \\
520 \\
520 \\
520 \\
520 \\
520 \\
520\end{array}$ & $\begin{array}{l}0.94 \\
0.94 \\
0.94 \\
0.94 \\
0.94 \\
0.94 \\
0.94 \\
0.94 \\
0.94 \\
0.94 \\
0.94 \\
0.94 \\
0.94\end{array}$ & $\begin{array}{l}0.3274 \\
0.3288 \\
0.3315 \\
0.3315 \\
0.3322 \\
0.3336 \\
0.3336 \\
0.3370 \\
0.3370 \\
0.3386 \\
0.3388 \\
0.3393 \\
0.3393\end{array}$ & $\begin{array}{l}1.1031 \\
1.3100 \\
1.3100 \\
1.3100 \\
1.0893 \\
1.1031 \\
1.1031 \\
1.5168 \\
1.5168 \\
1.0893 \\
1.5168 \\
1.7374 \\
1.7512\end{array}$ & $\begin{array}{l}50.1 \\
47.5 \\
46.0 \\
49.5 \\
51.0 \\
50.6 \\
48.2 \\
44.9 \\
45.8 \\
51.7 \\
46.6 \\
43.5 \\
44.8\end{array}$ & $\begin{array}{l}10.7 \\
12.4 \\
12.3 \\
12.3 \\
10.6 \\
10.5 \\
10.5 \\
13.8 \\
13.8 \\
10.4 \\
13.8 \\
15.4 \\
15.4\end{array}$ & $\begin{array}{l}3.50 \\
4.08 \\
4.08 \\
4.08 \\
3.52 \\
3.50 \\
3.50 \\
4.65 \\
4.65 \\
3.52 \\
4.68 \\
5.22 \\
5.22\end{array}$ & $\begin{array}{l}64 \\
64 \\
64 \\
64 \\
64 \\
64 \\
64 \\
64 \\
64 \\
64 \\
64 \\
64 \\
64\end{array}$ & $\begin{array}{l}22 \\
22 \\
22 \\
22 \\
22 \\
22 \\
22 \\
22 \\
22 \\
22 \\
22 \\
22 \\
22\end{array}$ & $\begin{array}{l}1.22 \\
1.22 \\
1.22 \\
1.22 \\
1.22 \\
1.22 \\
1.22 \\
1.22 \\
1.22 \\
1.22 \\
1.22 \\
1.22 \\
1.22\end{array}$ \\
\hline
\end{tabular}


Glycerine-Water-Polymer Mixture Data (continued)

\begin{tabular}{|c|c|c|c|c|c|c|c|c|c|}
\hline $\begin{array}{l}520 \\
520 \\
520 \\
520 \\
520 \\
520 \\
520 \\
520 \\
520 \\
520 \\
520\end{array}$ & $\begin{array}{l}0.94 \\
0.94 \\
0.94 \\
0.94 \\
0.94 \\
0.94 \\
0.94 \\
0.94 \\
0.94 \\
0.94 \\
0.94\end{array}$ & $\begin{array}{l}0.3393 \\
0.3393 \\
0.3395 \\
0.3415 \\
0.3415 \\
0.3415 \\
0.3419 \\
0.3437 \\
0.3438 \\
0.3438 \\
0.3444\end{array}$ & $\begin{array}{l}1.7512 \\
1.7512 \\
1.5168 \\
1.7374 \\
1.3100 \\
1.3100 \\
1.0893 \\
1.7374 \\
1.5168 \\
1.5168 \\
1.3100\end{array}$ & $\begin{array}{l}43.8 \\
44.3 \\
44.7 \\
45.8 \\
49.0 \\
49.0 \\
51.0 \\
44.7 \\
47.6 \\
47.9 \\
49.4\end{array}$ & $\begin{array}{l}15.4 \\
15.4 \\
13.7 \\
15.3 \\
12.0 \\
12.0 \\
10.3 \\
15.2 \\
13.6 \\
13.6 \\
11.9\end{array}$ & $\begin{array}{l}5.22 \\
5.22 \\
4.65 \\
5.22 \\
4.10 \\
4.10 \\
3.52 \\
5.22 \\
4.68 \\
4.68 \\
4.10\end{array}$ & $\begin{array}{l}64 \\
64 \\
64 \\
64 \\
64 \\
64 \\
64 \\
64 \\
64 \\
64 \\
64\end{array}$ & $\begin{array}{l}22 \\
22 \\
22 \\
22 \\
22 \\
22 \\
22 \\
22 \\
22 \\
22 \\
22\end{array}$ & $\begin{array}{l}1.22 \\
1.22 \\
1.22 \\
1.22 \\
1.22 \\
1.22 \\
1.22 \\
1.22 \\
1.22 \\
1.22 \\
1.22\end{array}$ \\
\hline $\begin{array}{l}570 \\
570 \\
570 \\
570 \\
570 \\
570 \\
570 \\
570 \\
570 \\
570 \\
570 \\
570 \\
570 \\
570\end{array}$ & $\begin{array}{l}0.90 \\
0.90 \\
0.90 \\
0.90 \\
0.90 \\
0.90 \\
0.90 \\
0.90 \\
0.90 \\
0.90 \\
0.90 \\
0.90 \\
0.90 \\
0.90\end{array}$ & $\begin{array}{l}0.0415 \\
0.0416 \\
0.0417 \\
0.0417 \\
0.0417 \\
0.0417 \\
0.0419 \\
0.0419 \\
0.0421 \\
0.0422 \\
0.0423 \\
0.0428 \\
0.0434 \\
0.0437\end{array}$ & $\begin{array}{l}0.7170 \\
1.1031 \\
0.7170 \\
1.3789 \\
1.1031 \\
1.1031 \\
0.4136 \\
0.4136 \\
1.3789 \\
0.4136 \\
1.3789 \\
1.6547 \\
1.6547 \\
1.6547\end{array}$ & $\begin{array}{r}133.9 \\
113.4 \\
129.7 \\
107.3 \\
113.3 \\
116.9 \\
146.8 \\
144.0 \\
100.8 \\
148.8 \\
104.0 \\
96.2 \\
98.7 \\
102.5\end{array}$ & $\begin{array}{l}26.6 \\
35.9 \\
26.5 \\
42.7 \\
35.8 \\
35.8 \\
17.7 \\
17.7 \\
42.3 \\
17.6 \\
42.1 \\
48.3 \\
47.7 \\
47.3\end{array}$ & $\begin{array}{l}1.10 \\
1.49 \\
1.10 \\
1.78 \\
1.49 \\
1.49 \\
0.74 \\
0.74 \\
1.78 \\
0.74 \\
1.78 \\
2.07 \\
2.07 \\
2.07\end{array}$ & $\begin{array}{l}64 \\
64 \\
64 \\
64 \\
64 \\
64 \\
64 \\
64 \\
64 \\
64 \\
64 \\
64 \\
64 \\
64\end{array}$ & $\begin{array}{l}21 \\
21 \\
21 \\
21 \\
21 \\
21 \\
21 \\
21 \\
21 \\
21 \\
21 \\
21 \\
21 \\
21\end{array}$ & $\begin{array}{l}1.20 \\
1.20 \\
1.20 \\
1.20 \\
1.20 \\
1.20 \\
1.20 \\
1.20 \\
1.20 \\
1.20 \\
1.20 \\
1.20 \\
1.20 \\
1.20\end{array}$ \\
\hline $\begin{array}{l}570 \\
570 \\
570 \\
570 \\
570 \\
570 \\
570 \\
570 \\
570 \\
570 \\
570 \\
570 \\
570 \\
570 \\
570 \\
570 \\
570 \\
570 \\
570 \\
570 \\
570 \\
570\end{array}$ & $\begin{array}{l}0.90 \\
0.90 \\
0.90 \\
0.90 \\
0.90 \\
0.90 \\
0.90 \\
0.90 \\
0.90 \\
0.90 \\
0.90 \\
0.90 \\
0.90 \\
0.90 \\
0.90 \\
0.90 \\
0.90 \\
0.90 \\
0.90 \\
0.90 \\
0.90 \\
0.90\end{array}$ & $\begin{array}{l}0.0837 \\
0.0837 \\
0.0839 \\
0.0841 \\
0.0841 \\
0.0842 \\
0.0844 \\
0.0844 \\
0.0847 \\
0.0850 \\
0.0853 \\
0.0857 \\
0.0863 \\
0.0866 \\
0.0869 \\
0.0869 \\
0.0879 \\
0.0905 \\
0.0910 \\
0.0915 \\
0.1009 \\
0.1029\end{array}$ & $\begin{array}{l}1.5857 \\
1.7650 \\
1.5857 \\
1.4065 \\
1.4065 \\
1.7650 \\
1.7650 \\
1.4065 \\
1.5857 \\
1.1858 \\
0.8273 \\
0.8273 \\
1.1858 \\
1.1858 \\
0.6756 \\
0.6756 \\
0.6756 \\
1.8477 \\
1.8477 \\
1.8477 \\
0.9101 \\
0.9101\end{array}$ & $\begin{array}{l}76.2 \\
72.7 \\
75.2 \\
71.6 \\
68.5 \\
75.5 \\
75.7 \\
69.9 \\
72.5 \\
69.5 \\
90.7 \\
83.3 \\
71.8 \\
73.0 \\
85.5 \\
84.1 \\
82.8 \\
72.2 \\
72.8 \\
71.3 \\
72.8 \\
69.1\end{array}$ & $\begin{array}{l}35.0 \\
38.4 \\
34.9 \\
31.4 \\
31.4 \\
38.2 \\
38.1 \\
31.3 \\
34.6 \\
27.7 \\
21.0 \\
20.9 \\
27.3 \\
27.2 \\
17.2 \\
17.2 \\
17.0 \\
38.7 \\
38.5 \\
38.3 \\
20.5 \\
20.1\end{array}$ & $\begin{array}{l}2.93 \\
3.22 \\
2.93 \\
2.64 \\
2.64 \\
3.22 \\
3.22 \\
2.64 \\
2.93 \\
2.36 \\
1.79 \\
1.79 \\
2.36 \\
2.36 \\
1.49 \\
1.49 \\
1.49 \\
3.50 \\
3.50 \\
3.50 \\
2.07 \\
2.07\end{array}$ & $\begin{array}{l}64 \\
64 \\
64 \\
64 \\
64 \\
64 \\
64 \\
64 \\
64 \\
64 \\
64 \\
64 \\
64 \\
64 \\
64 \\
64 \\
64 \\
64 \\
64 \\
64 \\
64 \\
64\end{array}$ & $\begin{array}{l}21 \\
21 \\
21 \\
21 \\
21 \\
21 \\
21 \\
21 \\
21 \\
21 \\
21 \\
21 \\
21 \\
21 \\
21 \\
21 \\
21 \\
21 \\
21 \\
21 \\
2.1 \\
21\end{array}$ & $\begin{array}{l}1.20 \\
1.20 \\
1.20 \\
1.20 \\
1.20 \\
1.20 \\
1.20 \\
1.20 \\
1.20 \\
1.20 \\
1.20 \\
1.20 \\
1.20 \\
1.20 \\
1.20 \\
1.20 \\
1.20 \\
1.20 \\
1.20 \\
1.20 \\
1.20 \\
1.20\end{array}$ \\
\hline
\end{tabular}


Glycerine-Water-Polymer Mixture Data (continued)

\begin{tabular}{|c|c|c|c|c|c|c|c|c|c|}
\hline $\begin{array}{l}570 \\
570 \\
570 \\
570 \\
570 \\
570 \\
570 \\
570 \\
570 \\
570 \\
570 \\
570 \\
570 \\
570 \\
570 \\
570 \\
570 \\
570 \\
570 \\
570 \\
570 \\
570 \\
570\end{array}$ & $\begin{array}{l}0.90 \\
0.90 \\
0.90 \\
0.90 \\
0.90 \\
0.90 \\
0.90 \\
0.90 \\
0.90 \\
0.90 \\
0.90 \\
0.90 \\
0.90 \\
0.90 \\
0.90 \\
0.90 \\
0.90 \\
0.90 \\
0.90 \\
0.90 \\
0.90 \\
0.90 \\
0.90\end{array}$ & $\begin{array}{l}0.1624 \\
0.1633 \\
0.1658 \\
0.1658 \\
0.1664 \\
0.1671 \\
0.1674 \\
0.1676 \\
0.1676 \\
0.1678 \\
0.1683 \\
0.1684 \\
0.1684 \\
0.1692 \\
0.1694 \\
0.1700 \\
0.1703 \\
0.1713 \\
0.1716 \\
0.1716 \\
0.1723 \\
0.1738 \\
0.1797\end{array}$ & $\begin{array}{l}1.2548 \\
0.8549 \\
1.2548 \\
1.2548 \\
1.6409 \\
1.6409 \\
1.0893 \\
1.3513 \\
1.3513 \\
1.6409 \\
0.9652 \\
1.3513 \\
1.4892 \\
1.4892 \\
0.9652 \\
1.4892 \\
1.0893 \\
1.0893 \\
0.8549 \\
0.8549 \\
0.7032 \\
0.7032 \\
0.9652\end{array}$ & $\begin{array}{l}52.3 \\
60.4 \\
50.8 \\
51.7 \\
53.7 \\
51.2 \\
54.3 \\
53.0 \\
50.8 \\
53.7 \\
52.3 \\
50.8 \\
50.2 \\
49.6 \\
53.8 \\
53.4 \\
53.0 \\
51.2 \\
56.5 \\
58.9 \\
55.3 \\
56.2 \\
52.3\end{array}$ & $\begin{array}{l}19.8 \\
14.5 \\
19.4 \\
19.4 \\
24.5 \\
24.4 \\
17.5 \\
20.9 \\
20.9 \\
24.3 \\
15.7 \\
20.8 \\
22.5 \\
22.4 \\
15.6 \\
22.3 \\
17.2 \\
17.1 \\
13.8 \\
13.8 \\
12.0 \\
11.9 \\
14.7\end{array}$ & $\begin{array}{l}3.22 \\
2.37 \\
3.22 \\
3.22 \\
4.08 \\
4.08 \\
2.93 \\
3.50 \\
3.50 \\
4.08 \\
2.64 \\
3.50 \\
3.79 \\
3.79 \\
2.64 \\
3.79 \\
2.93 \\
2.93 \\
2.37 \\
2.37 \\
2.07 \\
2.07 \\
2.64\end{array}$ & $\begin{array}{l}64 \\
64 \\
64 \\
64 \\
64 \\
64 \\
64 \\
64 \\
64 \\
64 \\
64 \\
64 \\
64 \\
64 \\
64 \\
64 \\
64 \\
64 \\
64 \\
64 \\
64 \\
64 \\
64\end{array}$ & $\begin{array}{l}21 \\
21 \\
21 \\
21 \\
21 \\
21 \\
21 \\
21 \\
21 \\
21 \\
21 \\
21 \\
21 \\
21 \\
21 \\
21 \\
21 \\
21 \\
21 \\
21 \\
21 \\
21 \\
21\end{array}$ & $\begin{array}{l}1.20 \\
1.20 \\
1.20 \\
1.20 \\
1.20 \\
1.20 \\
1.20 \\
1.20 \\
1.20 \\
1.20 \\
1.20 \\
1.20 \\
1.20 \\
1.20 \\
1.20 \\
1.20 \\
1.20 \\
1.20 \\
1.20 \\
1.20 \\
1.20 \\
1.20 \\
1.20\end{array}$ \\
\hline $\begin{array}{l}570 \\
570 \\
570 \\
570 \\
570 \\
570 \\
570 \\
570 \\
570 \\
570 \\
570 \\
570 \\
570 \\
570 \\
570 \\
570 \\
570 \\
570 \\
570 \\
570 \\
570 \\
570 \\
570 \\
570\end{array}$ & $\begin{array}{l}0.90 \\
0.90 \\
0.90 \\
0.90 \\
0.90 \\
0.90 \\
0.90 \\
0.90 \\
0.90 \\
0.90 \\
0.90 \\
0.90 \\
0.90 \\
0.90 \\
0.90 \\
0.90 \\
0.90 \\
0.90 \\
0.90 \\
0.90 \\
0.90 \\
0.90 \\
0.90 \\
0.90\end{array}$ & $\begin{array}{l}0.2173 \\
0.2467 \\
0.2477 \\
0.2484 \\
0.2484 \\
0.2493 \\
0.2508 \\
0.2516 \\
0.2517 \\
0.2527 \\
0.2528 \\
0.2532 \\
0.2537 \\
0.2555 \\
0.2567 \\
0.2569 \\
0.2573 \\
0.2583 \\
0.2590 \\
0.2613 \\
0.2613 \\
0.2629 \\
0.2642 \\
0.2677\end{array}$ & $\begin{array}{l}1.0342 \\
1.0893 \\
1.2952 \\
1.0893 \\
1.0893 \\
1.2962 \\
1.5030 \\
0.8273 \\
1.3927 \\
1.2962 \\
1.6271 \\
1.0342 \\
1.5030 \\
1.6271 \\
1.5030 \\
1.6271 \\
1.0342 \\
0.9238 \\
0.8273 \\
1.3927 \\
1.3927 \\
0.9238 \\
0.8273 \\
0.9238\end{array}$ & $\begin{array}{l}45.2 \\
44.6 \\
42.7 \\
45.5 \\
44.6 \\
43.7 \\
42.4 \\
49.8 \\
43.4 \\
43.5 \\
42.5 \\
46.0 \\
42.1 \\
42.5 \\
42.3 \\
41.7 \\
44.9 \\
48.2 \\
48.7 \\
40.9 \\
41.2 \\
47.5 \\
47.3 \\
45.8\end{array}$ & $\begin{array}{l}14.8 \\
14.2 \\
15.3 \\
14.1 \\
14.1 \\
15.2 \\
17.4 \\
10.5 \\
16.2 \\
15.0 \\
18.4 \\
12.7 \\
17.2 \\
18.2 \\
17.0 \\
18.1 \\
12.5 \\
11.4 \\
10.2 \\
15.6 \\
15.6 \\
11.2 \\
10.0 \\
11.0\end{array}$ & $\begin{array}{l}3.22 \\
3.50 \\
3.79 \\
3.50 \\
3.50 \\
3.79 \\
4.36 \\
2.64 \\
4.08 \\
3.79 \\
4.65 \\
3.22 \\
4.36 \\
4.65 \\
4.36 \\
4.65 \\
3.22 \\
2.94 \\
2.64 \\
4.08 \\
4.08 \\
2.94 \\
2.64 \\
2.94\end{array}$ & $\begin{array}{l}64 \\
64 \\
64 \\
64 \\
64 \\
64 \\
64 \\
64 \\
64 \\
64 \\
64 \\
64 \\
64 \\
64 \\
64 \\
64 \\
64 \\
64 \\
64 \\
64 \\
64 \\
64 \\
64 \\
64\end{array}$ & $\begin{array}{l}21 \\
21 \\
21 \\
21 \\
21 \\
21 \\
21 \\
21 \\
21 \\
21 \\
21 \\
21 \\
21 \\
21 \\
21 \\
21 \\
21 \\
21\end{array}$ & $\begin{array}{l}1.20 \\
1.20 \\
1.20 \\
1.20 \\
1.20 \\
1.20 \\
1.20 \\
1.20 \\
1.20 \\
1.20 \\
1.20 \\
1.20 \\
1.20 \\
1.20 \\
1.20 \\
1.20 \\
1.20 \\
1.20 \\
1.20 \\
1.20 \\
1.20 \\
1.20 \\
1.20 \\
1.20\end{array}$ \\
\hline $\begin{array}{l}570 \\
570 \\
570\end{array}$ & $\begin{array}{l}0.90 \\
0.90 \\
0.90\end{array}$ & $\begin{array}{l}0.3239 \\
0.3296 \\
0.3296\end{array}$ & $\begin{array}{l}1.1721 \\
1.1721 \\
1.1721\end{array}$ & $\begin{array}{l}39.1 \\
39.0 \\
39.7\end{array}$ & $\begin{array}{l}11.7 \\
11.5 \\
11.5\end{array}$ & $\begin{array}{l}3.79 \\
3.79 \\
3.79\end{array}$ & $\begin{array}{l}64 \\
64 \\
64\end{array}$ & $\begin{array}{l}21 \\
21 \\
21\end{array}$ & $\begin{array}{l}1.20 \\
1.20 \\
1.20\end{array}$ \\
\hline
\end{tabular}


Glycerine-Water-Polymer Mixture Data (continued)

\begin{tabular}{|c|c|c|c|c|c|c|c|c|c|}
\hline $\begin{array}{l}570 \\
570 \\
570 \\
570 \\
570 \\
570 \\
570 \\
570 \\
570 \\
570 \\
570 \\
570 \\
570 \\
570 \\
570 \\
570 \\
570 \\
570 \\
570 \\
570 \\
570\end{array}$ & $\begin{array}{l}0.90 \\
0.90 \\
0.90 \\
0.90 \\
0.90 \\
0.90 \\
0.90 \\
0.90 \\
0.90 \\
0.90 \\
0.90 \\
0.90 \\
0.90 \\
0.90 \\
0.90 \\
0.90 \\
0.90 \\
0.90 \\
0.90 \\
0.90 \\
0.90\end{array}$ & $\begin{array}{l}0.3322 \\
0.3359 \\
0.3371 \\
0.3382 \\
0.3383 \\
0.3393 \\
0.3395 \\
0.3397 \\
0.3405 \\
0.3415 \\
0.3419 \\
0.3420 \\
0.3421 \\
0.3436 \\
0.3455 \\
0.3463 \\
0.3484 \\
0.3557 \\
0.3573 \\
0.3613 \\
0.3707\end{array}$ & $\begin{array}{l}1.4754 \\
1.5995 \\
1.7098 \\
1.5995 \\
1.3927 \\
1.7098 \\
1.4754 \\
1.2548 \\
1.5995 \\
1.7098 \\
1.0342 \\
1.4754 \\
0.9652 \\
1.3927 \\
1.2548 \\
1.3927 \\
1.2548 \\
1.0342 \\
0.9652 \\
0.9652 \\
1.0342\end{array}$ & $\begin{array}{l}37.8 \\
37.7 \\
37.6 \\
38.2 \\
38.3 \\
38.8 \\
37.6 \\
38.5 \\
37.2 \\
37.8 \\
39.5 \\
37.0 \\
41.2 \\
37.4 \\
36.9 \\
37.7 \\
36.2 \\
39.8 \\
41.0 \\
40.9 \\
40.3\end{array}$ & $\begin{array}{r}14.0 \\
14.7 \\
15.5 \\
14.6 \\
12.9 \\
15.4 \\
13.7 \\
12.0 \\
14.5 \\
15.3 \\
10.3 \\
13.6 \\
9.4 \\
12.7 \\
11.8 \\
12.6 \\
11.7 \\
9.9 \\
9.0 \\
8.9 \\
9.5\end{array}$ & $\begin{array}{l}4.65 \\
4.94 \\
5.22 \\
4.94 \\
4.36 \\
5.22 \\
4.65 \\
4.08 \\
4.94 \\
5.22 \\
3.52 \\
4.65 \\
3.22 \\
4.36 \\
4.08 \\
4.36 \\
4.08 \\
3.52 \\
3.22 \\
3.22 \\
3.52\end{array}$ & $\begin{array}{l}64 \\
64 \\
64 \\
64 \\
64 \\
64 \\
64 \\
64 \\
64 \\
64 \\
64 \\
64 \\
64 \\
64 \\
64 \\
64 \\
64 \\
64 \\
64 \\
64 \\
64\end{array}$ & $\begin{array}{l}21 \\
21 \\
21 \\
21 \\
21 \\
21 \\
21 \\
21 \\
21 \\
21 \\
21 \\
21 \\
21 \\
21 \\
21 \\
21 \\
21 \\
21 \\
21 \\
21 \\
21\end{array}$ & $\begin{array}{l}1.20 \\
1.20 \\
1.20 \\
1.20 \\
1.20 \\
1.20 \\
1.20 \\
1.20 \\
1.20 \\
1.20 \\
1.20 \\
1.20 \\
1.20 \\
1.20 \\
1.20 \\
1.20 \\
1.20 \\
1.20 \\
1.20 \\
1.20 \\
1.20\end{array}$ \\
\hline $\begin{array}{l}780 \\
780 \\
780 \\
780 \\
780 \\
780\end{array}$ & $\begin{array}{l}0.90 \\
0.90 \\
0.90 \\
0.90 \\
0.90 \\
0.90\end{array}$ & $\begin{array}{l}0.0381 \\
0.0385 \\
0.0386 \\
0.0458 \\
0.0461 \\
0.0465\end{array}$ & $\begin{array}{l}0.9238 \\
0.9238 \\
0.9238 \\
1.1721 \\
1.1721 \\
1.1721\end{array}$ & $\begin{array}{c}105.3 \\
109.7 \\
96.9 \\
92.7 \\
86.2 \\
83.6\end{array}$ & $\begin{array}{l}29.0 \\
28.7 \\
28.6 \\
32.8 \\
32.6 \\
32.3\end{array}$ & $\begin{array}{l}1.10 \\
1.10 \\
1.10 \\
1.50 \\
1.50 \\
1.50\end{array}$ & $\begin{array}{l}64 \\
64 \\
64 \\
64 \\
64 \\
64\end{array}$ & $\begin{array}{l}22 \\
22 \\
22 \\
22 \\
22 \\
22\end{array}$ & $\begin{array}{l}1.20 \\
1.20 \\
1.20 \\
1.20 \\
1.20 \\
1.20\end{array}$ \\
\hline $\begin{array}{l}780 \\
780 \\
780 \\
780 \\
780 \\
780 \\
780 \\
780 \\
780 \\
780 \\
780 \\
780 \\
780 \\
780 \\
780 \\
780 \\
780 \\
780 \\
780 \\
780 \\
780\end{array}$ & $\begin{array}{l}0.90 \\
0.90 \\
0.90 \\
0.90 \\
0.90 \\
0.90 \\
0.90 \\
0.90 \\
0.90 \\
0.90 \\
0.90 \\
0.90 \\
0.90 \\
0.90 \\
0.90 \\
0.90 \\
0.90 \\
0.90 \\
0.90 \\
0.90 \\
0.90\end{array}$ & $\begin{array}{l}0.0842 \\
0.0842 \\
0.0845 \\
0.0849 \\
0.0852 \\
0.0853 \\
0.0855 \\
0.0857 \\
0.0861 \\
0.0896 \\
0.0896 \\
0.0901 \\
0.0913 \\
0.0922 \\
0.0925 \\
0.1027 \\
0.1034 \\
0.1037 \\
0.1168 \\
0.1172 \\
0.1175\end{array}$ & $\begin{array}{l}1.1307 \\
1.1307 \\
1.1307 \\
0.9376 \\
1.2824 \\
0.9376 \\
1.2824 \\
0.9376 \\
1.2824 \\
1.4754 \\
1.4754 \\
1.4754 \\
1.4065 \\
1.4065 \\
1.4065 \\
1.6547 \\
1.6547 \\
1.6547 \\
1.6961 \\
1.6961 \\
1.6961\end{array}$ & $\begin{array}{l}69.4 \\
78.1 \\
69.3 \\
70.8 \\
72.5 \\
71.4 \\
66.6 \\
67.4 \\
72.2 \\
72.9 \\
68.8 \\
72.3 \\
67.3 \\
65.9 \\
65.1 \\
64.0 \\
67.3 \\
67.3 \\
62.3 \\
63.3 \\
65.5\end{array}$ & $\begin{array}{l}24.7 \\
24.7 \\
24.6 \\
21.1 \\
27.8 \\
21.0 \\
27.7 \\
20.9 \\
27.5 \\
32.7 \\
32.7 \\
32.5 \\
29.1 \\
28.8 \\
28.7 \\
31.3 \\
31.1 \\
31.0 \\
30.0 \\
29.9 \\
29.8\end{array}$ & $\begin{array}{l}2.08 \\
2.08 \\
2.08 \\
1.79 \\
2.37 \\
1.79 \\
2.37 \\
1.79 \\
2.37 \\
2.93 \\
2.93 \\
2.93 \\
2.66 \\
2.66 \\
2.66 \\
3.22 \\
3.22 \\
3.22 \\
3.50 \\
3.50 \\
3.50\end{array}$ & $\begin{array}{l}64 \\
64 \\
64 \\
64 \\
64 \\
64 \\
64 \\
64 \\
64 \\
64 \\
64 \\
64 \\
64 \\
64 \\
64 \\
64 \\
64 \\
64 \\
04 \\
64 \\
64\end{array}$ & $\begin{array}{l}22 \\
22 \\
22 \\
22 \\
22 \\
22 \\
22 \\
22 \\
22 \\
22 \\
22 \\
22 \\
22 \\
22 \\
22 \\
22 \\
22 \\
22 \\
22 \\
22 \\
22\end{array}$ & $\begin{array}{l}1.20 \\
1.20 \\
1.20 \\
1.20 \\
1.20 \\
1.20 \\
1.20 \\
1.20 \\
1.20 \\
1.20 \\
1.20 \\
1.20 \\
1.20 \\
1.20 \\
1.20 \\
1.20 \\
1.20 \\
1.20 \\
1.20 \\
1.20 \\
1.20\end{array}$ \\
\hline
\end{tabular}


Glycerine-Water-Polymer Mixture Data (continued)

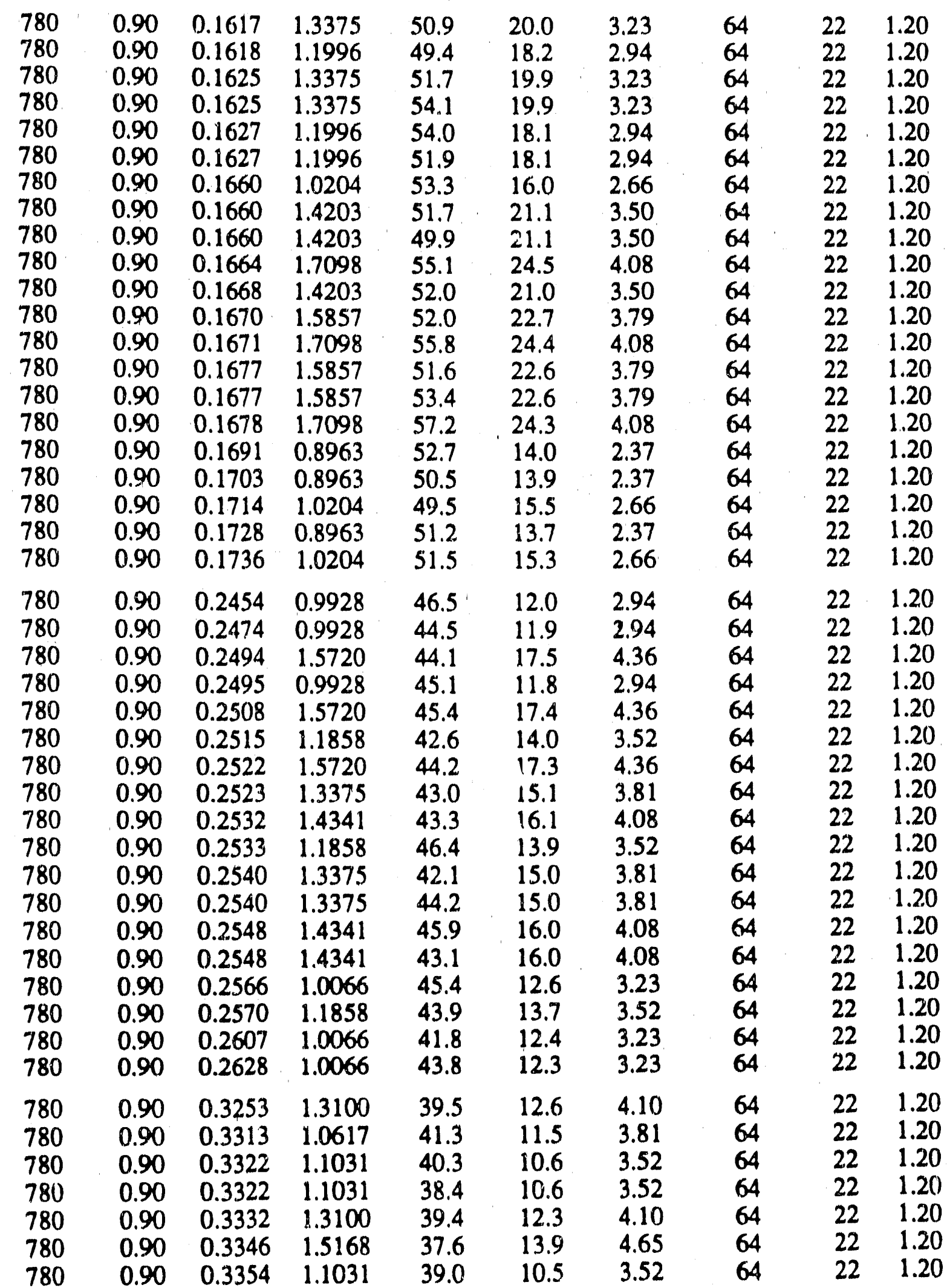


Glycerine-Water-Polymer Mixture Data (continued)

\begin{tabular}{|c|c|c|c|c|c|c|c|c|c|}
\hline $\begin{array}{l}780 \\
780 \\
780 \\
780 \\
780 \\
780 \\
780 \\
780 \\
780 \\
780 \\
780\end{array}$ & $\begin{array}{l}0.90 \\
0.90 \\
0.90 \\
0.90 \\
0.90 \\
0.90 \\
0.90 \\
0.90 \\
0.90 \\
0.90 \\
0.90\end{array}$ & $\begin{array}{l}0.3359 \\
0.3370 \\
0.3370 \\
0.3372 \\
0.3372 \\
0.3405 \\
0.3453 \\
0.3477 \\
0.3482 \\
0.3510 \\
0.3567\end{array}$ & $\begin{array}{l}1.3100 \\
1.5168 \\
1.5168 \\
1.0617 \\
1.0617 \\
1.6133 \\
1.6133 \\
1.6133 \\
1.4065 \\
1.4065 \\
1.4065\end{array}$ & $\begin{array}{l}39.2 \\
41.0 \\
38.4 \\
38.1 \\
38.9 \\
40.6 \\
41.2 \\
40.1 \\
37.6 \\
38.3 \\
39.6\end{array}$ & $\begin{array}{l}12.2 \\
13.8 \\
13.8 \\
11.3 \\
11.3 \\
14.5 \\
14.3 \\
14.2 \\
12.6 \\
12.5 \\
12.3\end{array}$ & $\begin{array}{l}4.10 \\
4.65 \\
4.65 \\
3.81 \\
3.81 \\
4.94 \\
4.94 \\
4.94 \\
4.39 \\
4.39 \\
4.39\end{array}$ & $\begin{array}{l}64 \\
64 \\
64 \\
64 \\
64 \\
64 \\
64 \\
64 \\
64 \\
64 \\
64\end{array}$ & $\begin{array}{l}22 \\
22 \\
22 \\
22 \\
22 \\
22 \\
22 \\
22 \\
22 \\
22 \\
22\end{array}$ & $\begin{array}{l}1.20 \\
1.20 \\
1.20 \\
1.20 \\
1.20 \\
1.20 \\
1.20 \\
1.20 \\
1.20 \\
1.20 \\
1.20\end{array}$ \\
\hline 840 & 0.94 & 0.0427 & 0.8963 & 87.0 & 25.7 & 1.10 & 64 & 22 & 1.22 \\
\hline $\begin{array}{l}840 \\
840 \\
840 \\
840 \\
840 \\
840 \\
840 \\
840 \\
840\end{array}$ & $\begin{array}{l}0.94 \\
0.94 \\
0.94 \\
0.94 \\
0.94 \\
0.94 \\
0.94 \\
0.94 \\
0.94\end{array}$ & $\begin{array}{l}0.0840 \\
0.0840 \\
0.0844 \\
0.0869 \\
0.0872 \\
0.0879 \\
0.0892 \\
0.1191 \\
0.1231\end{array}$ & $\begin{array}{l}0.9928 \\
0.9928 \\
0.9928 \\
1.3513 \\
1.3513 \\
1.3513 \\
1.2686 \\
1.4341 \\
1.4341\end{array}$ & $\begin{array}{l}68.4 \\
68.3 \\
66.9 \\
84.8 \\
32.4 \\
82.1 \\
70.5 \\
77.9 \\
64.5\end{array}$ & $\begin{array}{l}21.2 \\
21.2 \\
21.1 \\
271 \\
27.0 \\
26.8 \\
26.4 \\
24.6 \\
23.8\end{array}$ & $\begin{array}{l}1.78 \\
1.78 \\
1.78 \\
2.36 \\
2.36 \\
2.36 \\
2.36 \\
2.93 \\
2.93\end{array}$ & $\begin{array}{l}64 \\
64 \\
64 \\
64 \\
64 \\
64 \\
64 \\
64 \\
64\end{array}$ & $\begin{array}{l}22 \\
22 \\
22 \\
22 \\
22 \\
22 \\
22 \\
22 \\
22\end{array}$ & $\begin{array}{l}1.22 \\
1.22 \\
1.22 \\
1.22 \\
1.22 \\
1.22 \\
1.22 \\
1.22 \\
1.22\end{array}$ \\
\hline $\begin{array}{l}840 \\
840 \\
840 \\
840 \\
840 \\
840 \\
840 \\
840 \\
840 \\
840 \\
840 \\
840 \\
840 \\
840 \\
840 \\
840 \\
840\end{array}$ & $\begin{array}{l}0.94 \\
0.94 \\
0.94 \\
0.94 \\
0.94 \\
0.94 \\
0.94 \\
0.94 \\
0.94 \\
0.94 \\
0.94 \\
0.94 \\
0.94 \\
0.94 \\
0.94 \\
0.94 \\
0.94\end{array}$ & $\begin{array}{l}0.1629 \\
0.1660 \\
0.1664 \\
0.1668 \\
0.1670 \\
0.1674 \\
0.1682 \\
0.1682 \\
0.1694 \\
0.1703 \\
0.1723 \\
0.1969 \\
0.1979 \\
0.1989 \\
0.1998 \\
0.2008 \\
0.2018\end{array}$ & $\begin{array}{l}1.5306 \\
1.5306 \\
1.1996 \\
1.5306 \\
0.9652 \\
1.1996 \\
0.9376 \\
0.9652 \\
0.9652 \\
1.2272 \\
1.2272 \\
1.6133 \\
1.6133 \\
1.6133 \\
1.6133 \\
1.6133 \\
1.6133\end{array}$ & $\begin{array}{l}69.5 \\
68.6 \\
59.1 \\
69.3 \\
54.1 \\
62.7 \\
55.9 \\
50.9 \\
49.7 \\
54.0 \\
53.7 \\
54.6 \\
56.0 \\
63.0 \\
61.6 \\
54.8 \\
62.6\end{array}$ & $\begin{array}{l}21.5 \\
21.1 \\
17.6 \\
21.0 \\
14.1 \\
17.5 \\
14.0 \\
14.0 \\
13.9 \\
17.2 \\
17.0 \\
20.7 \\
20.6 \\
20.5 \\
20.4 \\
20.3 \\
20.2\end{array}$ & $\begin{array}{l}3.50 \\
3.50 \\
2.93 \\
3.50 \\
2.36 \\
2.93 \\
2.36 \\
2.36 \\
2.36 \\
2.93 \\
2.93 \\
4.08 \\
4.08 \\
4.08 \\
4.08 \\
4.08 \\
4.08\end{array}$ & $\begin{array}{l}64 \\
64 \\
64 \\
64 \\
64 \\
64 \\
64 \\
64 \\
64 \\
64 \\
54 \\
64 \\
64 \\
64 \\
64 \\
64 \\
64\end{array}$ & $\begin{array}{l}22 \\
22 \\
22 \\
22 \\
22 \\
22 \\
22 \\
22 \\
22 \\
22 \\
22 \\
22 \\
22 \\
22 \\
22 \\
22 \\
22\end{array}$ & $\begin{array}{l}1.22 \\
1.22 \\
1.22 \\
1.22 \\
1.22 \\
1.22 \\
1.22 \\
1.22 \\
1.22 \\
1.22 \\
1.22 \\
1.22 \\
1.22 \\
1.22 \\
1.22 \\
1.22 \\
1.22\end{array}$ \\
\hline $\begin{array}{l}840 \\
840 \\
840 \\
840 \\
840 \\
840 \\
840 \\
840\end{array}$ & $\begin{array}{l}0.94 \\
0.94 \\
0.94 \\
0.94 \\
0.94 \\
0.94 \\
0.94 \\
0.94\end{array}$ & $\begin{array}{l}0.2487 \\
0.2487 \\
0.2500 \\
0.2502 \\
0.2502 \\
0.2503 \\
0.2503 \\
0.2514\end{array}$ & $\begin{array}{l}1.7374 \\
1.7374 \\
1.7374 \\
1.2686 \\
1.2686 \\
1.0480 \\
1.0480 \\
1.7236\end{array}$ & $\begin{array}{l}54.5 \\
54.4 \\
52.9 \\
49.4 \\
49.6 \\
45.0 \\
42.5 \\
53.1\end{array}$ & $\begin{array}{l}18.7 \\
18.7 \\
18.6 \\
14.0 \\
14.0 \\
11.7 \\
11.7 \\
18.5\end{array}$ & $\begin{array}{l}4.65 \\
4.65 \\
4.65 \\
3.50 \\
3.50 \\
2.93 \\
2.93 \\
4.65\end{array}$ & $\begin{array}{l}64 \\
64 \\
64 \\
64 \\
64 \\
64 \\
64 \\
64\end{array}$ & $\begin{array}{l}22 \\
22 \\
22 \\
22 \\
22 \\
22 \\
22 \\
22\end{array}$ & $\begin{array}{l}1.22 \\
1.22 \\
1.22 \\
1.22 \\
1.22 \\
1.22 \\
1.22 \\
1.22\end{array}$ \\
\hline
\end{tabular}


Glycerine-Water-Polymer Mixture Jata (continued)

\begin{tabular}{|c|c|c|c|c|c|c|c|c|c|}
\hline $\begin{array}{l}840 \\
840 \\
840 \\
840 \\
840 \\
840 \\
840 \\
840 \\
840 \\
840 \\
840 \\
840 \\
840 \\
840\end{array}$ & $\begin{array}{l}0.94 \\
0.94 \\
0.94 \\
0.94 \\
0.94 \\
0.94 \\
0.94 \\
0.94 \\
0.94 \\
0.94 \\
0.94 \\
0.94 \\
0.94 \\
0.94\end{array}$ & $\begin{array}{l}0.2520 \\
0.2525 \\
0.2525 \\
0.2532 \\
0.2541 \\
0.2548 \\
0.2548 \\
0.2548 \\
0.2557 \\
0.2557 \\
0.2569 \\
0.2576 \\
0.2584 \\
0.2597\end{array}$ & $\begin{array}{l}1.2686 \\
1.0204 \\
1.0480 \\
1.4892 \\
1.7236 \\
1.4892 \\
1.4892 \\
1.4892 \\
1.2548 \\
1.2548 \\
1.0204 \\
1.2548 \\
1.7236 \\
1.4892\end{array}$ & $\begin{array}{l}52.7 \\
47.9 \\
46.3 \\
55.7 \\
55.2 \\
56.4 \\
46.7 \\
53.9 \\
46.0 \\
45.6 \\
48.3 \\
45.2 \\
54.9 \\
46.7\end{array}$ & $\begin{array}{l}13.9 \\
11.6 \\
11.6 \\
16.1 \\
18.3 \\
16.0 \\
16.0 \\
16.0 \\
13.7 \\
13.7 \\
11.4 \\
13.6 \\
18.0 \\
15.7\end{array}$ & $\begin{array}{l}3.50 \\
2.93 \\
2.93 \\
4.08 \\
4.65 \\
4.08 \\
4.08 \\
4.08 \\
3.50 \\
3.50 \\
2.93 \\
3.50 \\
4.65 \\
4.08\end{array}$ & $\begin{array}{l}64 \\
64 \\
64 \\
64 \\
64 \\
64 \\
64 \\
64 \\
64 \\
64 \\
64 \\
64 \\
64 \\
64\end{array}$ & $\begin{array}{l}22 \\
22 \\
22 \\
22 \\
22 \\
22 \\
22 \\
22 \\
22 \\
22 \\
22 \\
22 \\
22 \\
22\end{array}$ & $\begin{array}{l}1.22 \\
1.22 \\
1.22 \\
1.22 \\
1.22 \\
1.22 \\
1.22 \\
1.22 \\
1.22 \\
1.22 \\
1.22 \\
1.22 \\
1.22 \\
1.22\end{array}$ \\
\hline $\begin{array}{l}840 \\
840 \\
840 \\
840 \\
840 \\
840 \\
840 \\
840 \\
840 \\
840 \\
840 \\
840 \\
840 \\
840 \\
840 \\
840 \\
840 \\
840 \\
840 \\
840\end{array}$ & $\begin{array}{l}0.94 \\
0.94 \\
0.94 \\
0.94 \\
0.94 \\
0.94 \\
0.94 \\
0.94 \\
0.94 \\
0.94 \\
0.94 \\
0.94 \\
0.94 \\
0.94 \\
0.94 \\
0.94 \\
0.94 \\
0.94 \\
0.94 \\
0.94\end{array}$ & $\begin{array}{l}0.3245 \\
0.3286 \\
0.3307 \\
0.3328 \\
0.332 .8 \\
0.3349 \\
0.3368 \\
0.3368 \\
0.3369 \\
0.3395 \\
0.3397 \\
0.3397 \\
0.3397 \\
0.3397 \\
0.3397 \\
0.3401 \\
0.3420 \\
0.3445 \\
0.3503 \\
0.3503\end{array}$ & $\begin{array}{l}1.8064 \\
1.8064 \\
1.8064 \\
1.7926 \\
1.7926 \\
1.7926 \\
1.1307 \\
1.1307 \\
1.3375 \\
1.5582 \\
1.2962 \\
1.2962 \\
1.2962 \\
1.3375 \\
1.3375 \\
1.1307 \\
1.5582 \\
1.5582 \\
1.1307 \\
1.1307\end{array}$ & $\begin{array}{l}49.8 \\
47.8 \\
49.6 \\
49.1 \\
50.3 \\
47.0 \\
40.4 \\
40.1 \\
42.9 \\
49.3 \\
40.7 \\
40.8 \\
40.3 \\
43.8 \\
42.6 \\
41.4 \\
49.3 \\
48.3 \\
44.8 \\
42.8\end{array}$ & $\begin{array}{l}16.1 \\
15.9 \\
15.8 \\
15.7 \\
15.7 \\
15.6 \\
10.4 \\
10.4 \\
12.1 \\
13.7 \\
12.0 \\
12.0 \\
12.0 \\
12.0 \\
12.0 \\
10.3 \\
13.6 \\
13.5 \\
10.0 \\
10.0\end{array}$ & $\begin{array}{l}5.22 \\
5.22 \\
5.22 \\
5.22 \\
5.22 \\
5.22 \\
3.50 \\
3.50 \\
4.08 \\
4.65 \\
4.08 \\
4.08 \\
4.08 \\
4.08 \\
4.08 \\
3.50 \\
4.65 \\
4.65 \\
3.50 \\
3.50\end{array}$ & $\begin{array}{l}64 \\
64 \\
64 \\
64 \\
64 \\
64 \\
64 \\
64 \\
64 \\
64 \\
64 \\
64 \\
64 \\
64 \\
64 \\
64 \\
64 \\
64 \\
64 \\
64\end{array}$ & $\begin{array}{l}22 \\
22 \\
22 \\
22 \\
22 \\
22 \\
22 \\
22 \\
22 \\
22 \\
22 \\
22 \\
22 \\
22 \\
22 \\
22 \\
22 \\
22 \\
22 \\
22\end{array}$ & $\begin{array}{l}1.22 \\
1.22 \\
1.22 \\
1.22 \\
1.22 \\
1.22 \\
1.22 \\
1.22 \\
1.22 \\
1.22 \\
1.22 \\
1.22 \\
1.22 \\
1.22 \\
1.22 \\
1.22 \\
1.22 \\
1.22 \\
1.22 \\
1.22\end{array}$ \\
\hline $\begin{array}{l}930 \\
930 \\
930 \\
930 \\
930 \\
930\end{array}$ & $\begin{array}{l}0.86 \\
0.86 \\
0.86 \\
0.86 \\
0.86 \\
0.86\end{array}$ & $\begin{array}{l}0.0365 \\
0.0383 \\
0.0388 \\
0.0440 \\
0.0445 \\
0.0449\end{array}$ & $\begin{array}{l}0.9101 \\
0.9101 \\
0.9101 \\
1.4616 \\
1.4616 \\
1.4616\end{array}$ & $\begin{array}{l}137.4 \\
136.1 \\
140.1 \\
107.1 \\
109.5 \\
109.7\end{array}$ & $\begin{array}{l}30.1 \\
28.7 \\
28.3 \\
40.5 \\
40.0 \\
39.7\end{array}$ & $\begin{array}{l}1.10 \\
1.10 \\
1.10 \\
1.78 \\
1.78 \\
1.78\end{array}$ & $\begin{array}{l}64 \\
64 \\
64 \\
64 \\
64 \\
64\end{array}$ & $\begin{array}{l}25 \\
25 \\
25 \\
25 \\
25 \\
25\end{array}$ & $\begin{array}{l}1.13 \\
1.13 \\
1.13 \\
1.13 \\
1.13 \\
1.13\end{array}$ \\
\hline $\begin{array}{l}930 \\
930 \\
930 \\
930 \\
930 \\
930 \\
930\end{array}$ & $\begin{array}{l}0.86 \\
0.86 \\
0.86 \\
0.86 \\
0.86 \\
0.86 \\
0.86\end{array}$ & $\begin{array}{l}0.0788 \\
0.0793 \\
0.0821 \\
0.0823 \\
0.0837 \\
0.0849 \\
0.0854\end{array}$ & $\begin{array}{l}1.2824 \\
1.2824 \\
1.2324 \\
1.5995 \\
1.5995 \\
1.6133 \\
1.5995\end{array}$ & $\begin{array}{l}87.6 \\
90.3 \\
92.0 \\
77.7 \\
74.7 \\
82.7 \\
75.5\end{array}$ & $\begin{array}{l}29.9 \\
29.7 \\
28.7 \\
35.6 \\
35.0 \\
34.5 \\
34.3\end{array}$ & $\begin{array}{l}2.36 \\
2.36 \\
2.36 \\
2.93 \\
2.93 \\
2.93 \\
2.93\end{array}$ & $\begin{array}{l}64 \\
64 \\
64 \\
64 \\
64 \\
64 \\
64\end{array}$ & $\begin{array}{l}25 \\
25 \\
25 \\
25 \\
25 \\
25 \\
25\end{array}$ & $\begin{array}{l}1.13 \\
1.13 \\
1.13 \\
1.13 \\
1.13 \\
1.13 \\
1.13\end{array}$ \\
\hline
\end{tabular}


Glycerine-Water-Polymer Mixture Data (continued)

\begin{tabular}{|c|c|c|c|c|c|c|c|c|c|}
\hline $\begin{array}{l}930 \\
930 \\
930 \\
930 \\
930 \\
930 \\
930 \\
930 \\
930\end{array}$ & $\begin{array}{l}0.86 \\
0.86 \\
0.86 \\
0.86 \\
0.86 \\
0.86 \\
0.86 \\
0.86 \\
0.86\end{array}$ & $\begin{array}{l}0.0854 \\
0.0856 \\
0.0864 \\
0.0877 \\
0.0882 \\
0.1001 \\
0.1036 \\
0.1043 \\
0.1043\end{array}$ & $\begin{array}{l}1.6133 \\
0.8549 \\
1.6133 \\
0.8549 \\
0.8549 \\
1.7788 \\
1.7512 \\
1.7512 \\
1.7512\end{array}$ & $\begin{array}{r}82.9 \\
96.4 \\
80.2 \\
100.8 \\
93.4 \\
76.2 \\
67.9 \\
72.7 \\
70.6\end{array}$ & $\begin{array}{l}34.3 \\
20.8 \\
33.9 \\
20.3 \\
20.2 \\
35.0 \\
33.8 \\
33.6 \\
33.6\end{array}$ & $\begin{array}{l}2.93 \\
1.78 \\
2.93 \\
1.78 \\
1.78 \\
3.50 \\
3.50 \\
3.50 \\
3.50\end{array}$ & $\begin{array}{l}64 \\
64 \\
64 \\
64 \\
64 \\
64 \\
64 \\
64 \\
64\end{array}$ & $\begin{array}{l}25 \\
25 \\
25 \\
25 \\
25 \\
25 \\
25 \\
25 \\
25\end{array}$ & $\begin{array}{l}1.13 \\
1.13 \\
1.13 \\
1.13 \\
1.13 \\
1.13 \\
1.13 \\
1.13 \\
1.13\end{array}$ \\
\hline $\begin{array}{l}930 \\
930 \\
930 \\
930 \\
930 \\
930 \\
930 \\
930 \\
930 \\
930 \\
930 \\
930 \\
930 \\
930 \\
930 \\
930 \\
930 \\
930 \\
930\end{array}$ & $\begin{array}{l}0.86 \\
0.86 \\
0.86 \\
0.86 \\
0.86 \\
0.86 \\
0.86 \\
0.86 \\
0.86 \\
0.86 \\
0.86 \\
0.86 \\
0.86 \\
0.86 \\
0.86 \\
0.86 \\
0.86 \\
0.86 \\
0.86\end{array}$ & $\begin{array}{l}0.1624 \\
0.1037 \\
0.1644 \\
0.1664 \\
0.1664 \\
0.1668 \\
0.1668 \\
0.1670 \\
0.1670 \\
0.1671 \\
0.1676 \\
0.1678 \\
0.1678 \\
0.1693 \\
0.1703 \\
0.1709 \\
0.1719 \\
0.1758 \\
0.1798\end{array}$ & $\begin{array}{l}0.8273 \\
1.3789 \\
1.6547 \\
1.6547 \\
1.1169 \\
1.3789 \\
1.3789 \\
0.8273 \\
0.8273 \\
1.6547 \\
1.3789 \\
1.6547 \\
1.6547 \\
1.1169 \\
1.1169 \\
1.3789 \\
0.8549 \\
0.8549 \\
0.8549\end{array}$ & $\begin{array}{l}77.9 \\
67.3 \\
54.8 \\
64.7 \\
69.3 \\
58.1 \\
63.2 \\
75.1 \\
80.0 \\
59.1 \\
67.1 \\
59.5 \\
55.0 \\
67.2 \\
71.6 \\
58.8 \\
84.3 \\
78.8 \\
81.2\end{array}$ & $\begin{array}{l}14.5 \\
21.4 \\
24.8 \\
24.5 \\
17.6 \\
21.0 \\
21.0 \\
14.1 \\
14.1 \\
24.4 \\
20.9 \\
2.4 .3 \\
24.3 \\
17.3 \\
17.2 \\
20.5 \\
13.7 \\
13.4 \\
13.1\end{array}$ & $\begin{array}{l}2.36 \\
3.50 \\
4.08 \\
4.08 \\
2.93 \\
3.50 \\
3.50 \\
2.36 \\
2.36 \\
4.08 \\
3.50 \\
4.08 \\
4.08 \\
2.93 \\
2.93 \\
3.50 \\
2.36 \\
2.36 \\
2.36\end{array}$ & $\begin{array}{l}64 \\
64 \\
64 \\
64 \\
64 \\
64 \\
64 \\
64 \\
64 \\
64 \\
64 \\
64 \\
64 \\
64 \\
64 \\
64 \\
64 \\
64 \\
64\end{array}$ & $\begin{array}{l}25 \\
25 \\
25 \\
25 \\
25 \\
25 \\
25 \\
25 \\
25 \\
25 \\
25 \\
25 \\
25 \\
25 \\
25 \\
25 \\
25 \\
25 \\
25\end{array}$ & $\begin{array}{l}1.13 \\
1.13 \\
1.13 \\
1.13 \\
1.13 \\
1.13 \\
1.13 \\
1.13 \\
1.13 \\
1.13 \\
1.13 \\
1.13 \\
1.13 \\
1.13 \\
1.13 \\
1.13 \\
1.13 \\
1.13 \\
1.13\end{array}$ \\
\hline $\begin{array}{l}930 \\
930 \\
930 \\
930 \\
930 \\
930 \\
930 \\
930 \\
930 \\
930 \\
930 \\
930 \\
930 \\
930 \\
930 \\
930\end{array}$ & $\begin{array}{l}0.86 \\
0.86 \\
0.86 \\
0.86 \\
0.86 \\
0.86 \\
0.86 \\
0.86 \\
0.86 \\
0.86 \\
0.86 \\
0.86 \\
0.86 \\
0.86 \\
0.86 \\
0.86\end{array}$ & $\begin{array}{l}0.2471 \\
0.2474 \\
0.2487 \\
0.2525 \\
0.2528 \\
0.2541 \\
0.2569 \\
0.2569 \\
0.2576 \\
0.2580 \\
0.2584 \\
0.2597 \\
0.2598 \\
0.2614 \\
0.2614 \\
0.2663\end{array}$ & $\begin{array}{l}1.2824 \\
1.6271 \\
1.6271 \\
0.9238 \\
1.6271 \\
1.5857 \\
0.9238 \\
0.9238 \\
1.1445 \\
1.2824 \\
1.5857 \\
1.2824 \\
1.5857 \\
1.1445 \\
1.1445 \\
0.9101\end{array}$ & $\begin{array}{l}52.1 \\
54.5 \\
54.1 \\
66.4 \\
55.4 \\
46.7 \\
64.5 \\
68.4 \\
53.5 \\
53.2 \\
46.5 \\
55.6 \\
46.7 \\
58.9 \\
58.0 \\
58.4\end{array}$ & $\begin{array}{l}16.5 \\
18.8 \\
18.7 \\
11.6 \\
18.4 \\
18.3 \\
11.4 \\
11.4 \\
13.6 \\
15.8 \\
18.0 \\
15.7 \\
17.9 \\
13.4 \\
13.4 \\
11.0\end{array}$ & $\begin{array}{l}4.08 \\
4.65 \\
4.65 \\
2.93 \\
4.65 \\
4.65 \\
2.93 \\
2.93 \\
3.50 \\
4.08 \\
4.65 \\
4.08 \\
4.65 \\
3.50 \\
3.50 \\
2.93\end{array}$ & $\begin{array}{l}64 \\
64 \\
64 \\
64 \\
64 \\
64 \\
64 \\
64 \\
64 \\
64 \\
64 \\
64 \\
64 \\
64 \\
64 \\
64\end{array}$ & $\begin{array}{l}25 \\
25 \\
25 \\
25 \\
25 \\
25 \\
25 \\
25 \\
25 \\
25 \\
25 \\
25 \\
25 \\
25 \\
25 \\
25\end{array}$ & $\begin{array}{l}1.13 \\
1.13 \\
1.13 \\
1.13 \\
1.13 \\
1.13 \\
1.13 \\
1.13 \\
1.13 \\
1.13 \\
1.13 \\
1.13 \\
1.13 \\
1.13 \\
1.13 \\
1.13\end{array}$ \\
\hline $\begin{array}{l}930 \\
930 \\
930\end{array}$ & $\begin{array}{l}0.86 \\
0.86 \\
0.86\end{array}$ & $\begin{array}{l}0.3286 \\
0.3286 \\
0.3322\end{array}$ & $\begin{array}{l}1.6685 \\
1.6685 \\
1.4341\end{array}$ & $\begin{array}{l}41.2 \\
42.5 \\
48.1\end{array}$ & $\begin{array}{l}15.9 \\
15.9 \\
14.0\end{array}$ & $\begin{array}{l}5.22 \\
5.22 \\
4.65\end{array}$ & $\begin{array}{l}64 \\
64 \\
64\end{array}$ & $\begin{array}{l}25 \\
25 \\
25\end{array}$ & $\begin{array}{l}1.13 \\
1.13 \\
1.13\end{array}$ \\
\hline
\end{tabular}


Glycerine-Water-Polymer Mixture Data (continued)

$\begin{array}{llllllllll}930 & 0.86 & 0.3336 & 1.0204 & 53.7 & 10.5 & 3.50 & 64 & 25 & 1.13 \\ 930 & 0.86 & 0.3368 & 1.0204 & 55.2 & 10.4 & 3.50 & 64 & 25 & 1.13 \\ 930 & 0.86 & 0.3401 & 1.0480 & 57.3 & 10.3 & 3.50 & 64 & 25 & 1.13 \\ 930 & 0.86 & 0.3426 & 1.2272 & 50.4 & 11.9 & 4.08 & 64 & 25 & 1.13 \\ 930 & 0.86 & 0.3434 & 1.0204 & 54.8 & 10.2 & 3.50 & 64 & 25 & 1.13 \\ 930 & 0.86 & 0.3460 & 1.6547 & 47.9 & 15.1 & 5.22 & 64 & 25 & 1.13 \\ 930 & 0.86 & 0.3460 & 1.6547 & 47.1 & 15.1 & 5.22 & 64 & 25 & 1.13 \\ 930 & 0.86 & 0.3460 & 1.6547 & 44.0 & 15.1 & 5.22 & 64 & 25 & 1.13 \\ 930 & 0.86 & 0.3471 & 1.4341 & 49.4 & 13.4 & 4.65 & 64 & 25 & 1.13 \\ 930 & 0.86 & 0.3484 & 1.2272 & 51.6 & 11.7 & 4.08 & 64 & 25 & 1.13 \\ 930 & 0.86 & 0.3497 & 1.4341 & 49.7 & 13.3 & 4.65 & 64 & 25 & 1.13 \\ 930 & 0.86 & 0.3515 & 1.2272 & 53.0 & 11.6 & 4.08 & 64 & 25 & 1.13 \\ 930 & 0.86 & 0.3633 & 1.4065 & 42.0 & 12.8 & 4.65 & 64 & 25 & 1.13\end{array}$


Coal-Water Slurry Mixture Data

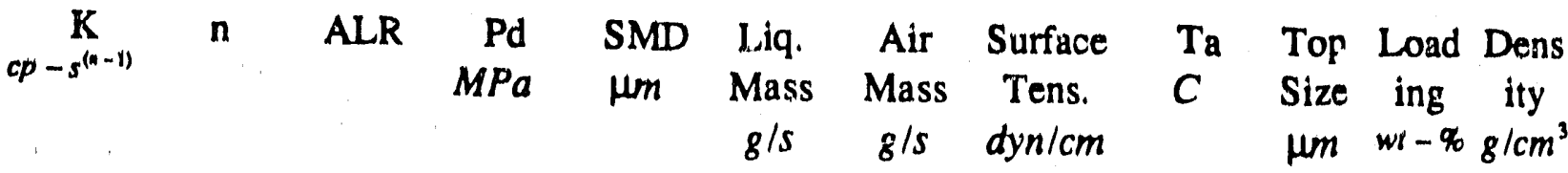

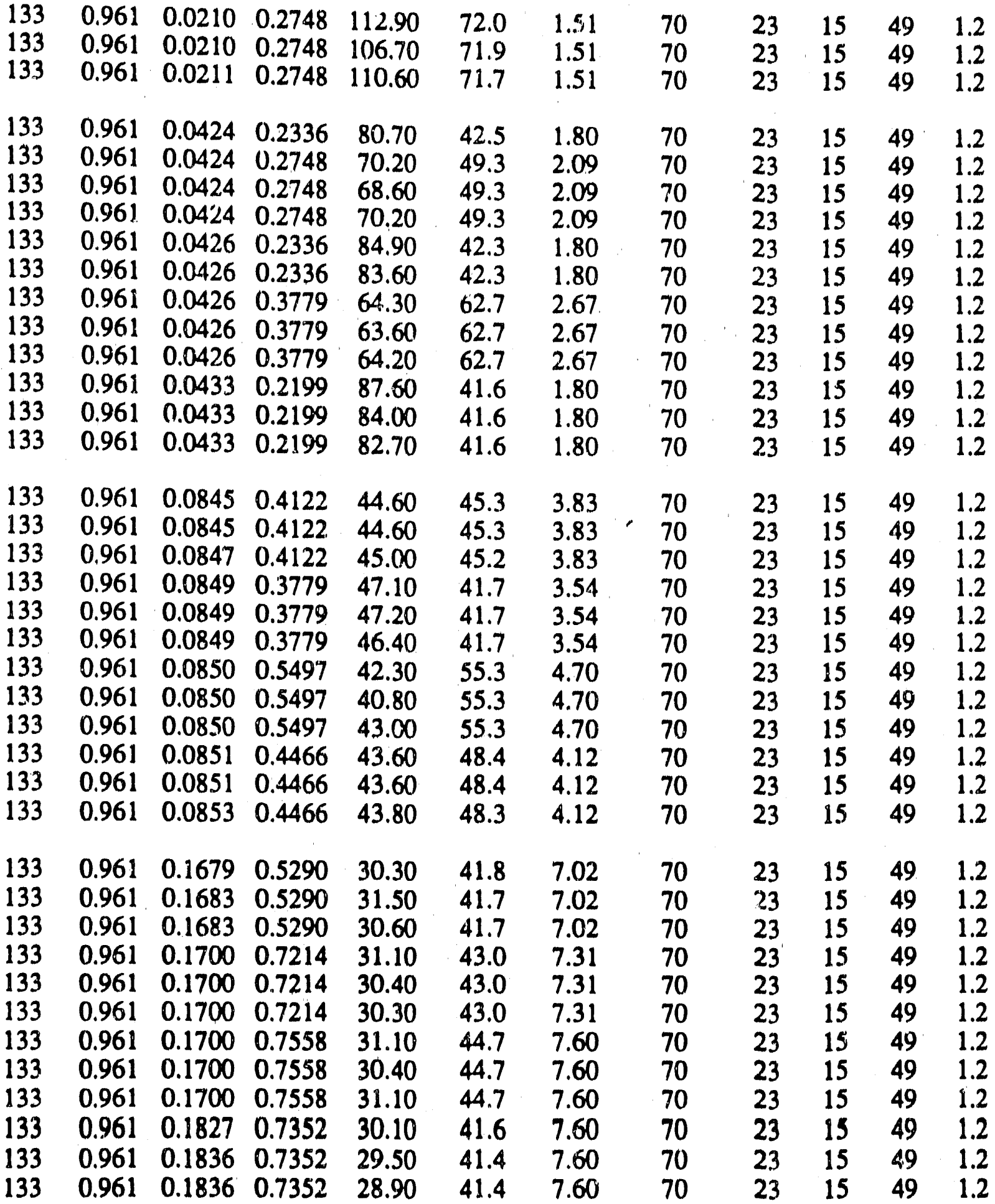


Coal-Water Slurry Mixture Data (continued)

\begin{tabular}{|c|c|c|c|c|c|c|c|c|c|c|c|}
\hline 80.9 & 1.033 & 0.0187 & 0.2061 & 133.00 & 40.2 & 0.75 & 54 & 24 & 45 & 65 & 1.2 \\
\hline 180.9 & 1.033 & 0.0187 & 0.2061 & 127.70 & 40.2 & 0.75 & 54 & 24 & 45 & 65 & 1.2 \\
\hline 80.9 & 1.033 & 0.0187 & 0.2061 & 132.50 & 40.2 & 0.75 & 54 & 24 & 45 & 65 & 1.2 \\
\hline 80.9 & 1.033 & 0.0205 & 0.1924 & 106.80 & 40.9 & 0.84 & 54 & 24 & 45 & 65 & 1.2 \\
\hline 180.9 & 1.033 & 0.0206 & 0.1924 & 114.70 & 40.7 & 0.84 & 54 & 24 & 45 & 65 & 1.2 \\
\hline 180.9 & 1.033 & 0.0207 & 0.1924 & 113.00 & 40.6 & 0.84 & 54 & 24 & 45 & 65 & 1.2 \\
\hline 80.9 & .033 & 0.0374 & 0.2817 & 68.30 & 40.4 & 1.51 & 54 & 24 & 45 & 65 & \\
\hline 180.9 & 1.033 & 0.0374 & 0.2817 & 67.10 & 40.4 & 1.5 & 54 & 24 & 45 & 65 & \\
\hline 180.9 & 1.033 & 0.0374 & 0.2817 & 68.40 & 40.4 & 1.51 & 54 & 24 & 45 & 65 & 2 \\
\hline 180.9 & 1.033 & 0.0422 & 0.3435 & 66.50 & 42.7 & 1.00 & 34 & 24 & 45 & 65 & 2 \\
\hline 180.9 & 1.033 & 0.0424 & 0.4260 & 62.20 & 49.3 & 2.09 & 54 & 24 & 45 & 65 & 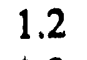 \\
\hline 180.9 & 1.033 & 0.0424 & 0.4260 & 60.80 & 49.3 & 2.09 & 54 & 24 & 45 & 65 & 1.2 \\
\hline 180.9 & 1.033 & 0.0424 & 0.4260 & 62.30 & 49.3 & 2.09 & 5 & 24 & 45 & 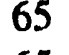 & .2 \\
\hline 180.9 & 1.033 & 0.0425 & 0.3435 & 64.90 & 42.4 & 1.8 & 5 & & 45 & 5 & 1.2 \\
\hline 180.9 & 1.033 & 0.0426 & 0.3435 & 64.60 & 42.3 & 1.0 & 5 & & 45 & 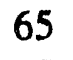 & .2 \\
\hline 180.9 & 1.033 & 0.0426 & 0.6184 & 63.00 & 62.7 & 2.67 & 5 & 24 & 45 & 65 & 1.2 \\
\hline 180.9 & 1.033 & 0.0426 & 0.6184 & 62.80 & 62.7 & 2.67 & 5 & 24 & 45 & 65 & .2 \\
\hline 180.9 & 1.033 & 0.0426 & 0.6184 & 62.60 & 62.7 & $2.6 \%$ & 5 & 24 & 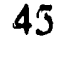 & 65 & 1.2 \\
\hline 180.9 & 1.033 & 0.0844 & 0.6871 & 45.80 & 48.8 & .12 & 5 & & 5 & 65 & \\
\hline 180.9 & 1.033 & 0.0846 & 0.6871 & 45.40 & 48.7 & 112 & 5 & & 45 & 5 & 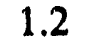 \\
\hline 180.9 & 1.033 & 0.0846 & 0.6871 & 46.20 & 48.7 & 12 & & & 5 & 5 & .2 \\
\hline 180.9 & 1.033 & 0.0848 & 0.8039 & 44.70 & 55.4 & 4.70 & & & 5 & 5 & .2 \\
\hline 180.9 & 1.033 & 0.0848 & 0.8039 & 44.20 & 55.4 & 4.7 & 5 & 24 & 5 . & 65 & .2 \\
\hline 180.9 & 1.033 & 0.0849 & 0.6321 & 46.90 & 45. & 3.8 & 5 & & 5 & 65 & .2 \\
\hline 180.9 & 1.033 & 0.0849 & 0.6321 & 46.10 & 45.1 & 3.83 & & & 5 & 65 & 1.2 \\
\hline 180.9 & 1.033 & 0.0849 & 0.6321 & 47.00 & 45.1 & 3 & & 24 & 5 & 65 & 1.2 \\
\hline 180.9 & 1.033 & 0.0850 & 0.8039 & 44.00 & 55.3 & 4.70 & 5 & 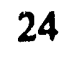 & 45 & 65 & 1.2 \\
\hline 180.9 & 1.033 & 0.0861 & 0.5497 & 46.90 & 41.1 & 3.54 & 5 & 4 & 45 & 65 & .2 \\
\hline 180.9 & 1033 & 0.0866 & 0.5497 & 47.10 & 40.9 & 3.54 & 54 & 24 & 45 & 65 & 1.2 \\
\hline 180.9 & 1.033 & 0.0868 & 0.5497 & 47.10 & 40.8 & 3.54 & 5 & 24 & 45 & 65 & 1.2 \\
\hline 180.9 & 1 & & 63 & 31.90 & 44.9 & 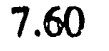 & 5 & & 45 & 5 & 1.2 \\
\hline 180.9 & 1.033 & 0.1696 & 0.9619 & 32.00 & 43.1 & 7.31 & $\mathrm{~J}$ & 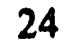 & 45 & 35 & 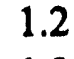 \\
\hline 180.9 & 1.033 & 0.1696 & 0.9963 & 31.90 & 44.8 & 7.60 & 5 & 24 & 45 & 65 & 1.2 \\
\hline 180.9 & 1.033 & 0.1696 & 0.9963 & 31.70 & 44.8 & 7.60 & 5 & 24 & 45 & 5 & 1.2 \\
\hline 180.9 & 1.033 & 0.1700 & 0.9619 & 32.00 & 43.0 & 7.31 & & 0 & 45 & 65 & 1.2 \\
\hline 180.9 & 1.033 & 0.1700 & 0.9619 & 31.90 & 43.0 & 7.31 & 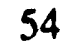 & 24 & 45 & 65 & 1.2 \\
\hline 180.9 & 1.033 & 0.1721 & 0.9276 & 32.00 & 40.8 & 7.02 & 5 & 24 & 45 & 65 & 1.2 \\
\hline 180.9 & 1.033 & 0.1725 & 0.9276 & 32.10 & 40.7 & 7.0 & 5 & 2 & 45 & 65 & 1.2 \\
\hline 180.9 & 1.033 & 0.1733 & 0.9276 & 32.20 & 40.5 & 7.02 & 54 & 24 & 45 & 65 & 1. \\
\hline
\end{tabular}


Coal-Water Slurry liiixture Data (continued)

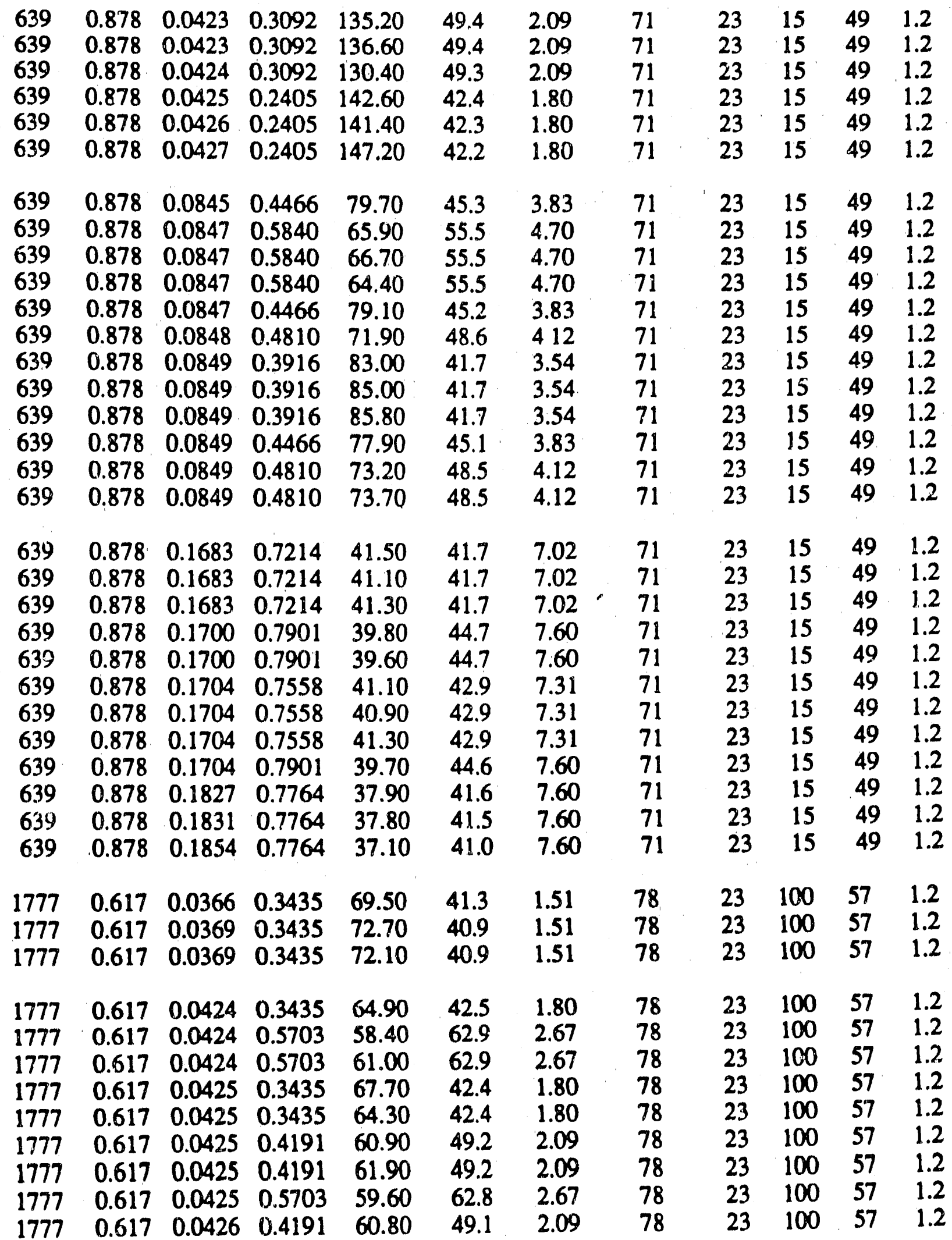


Coal-Water Slurry Mixture Data (continued)

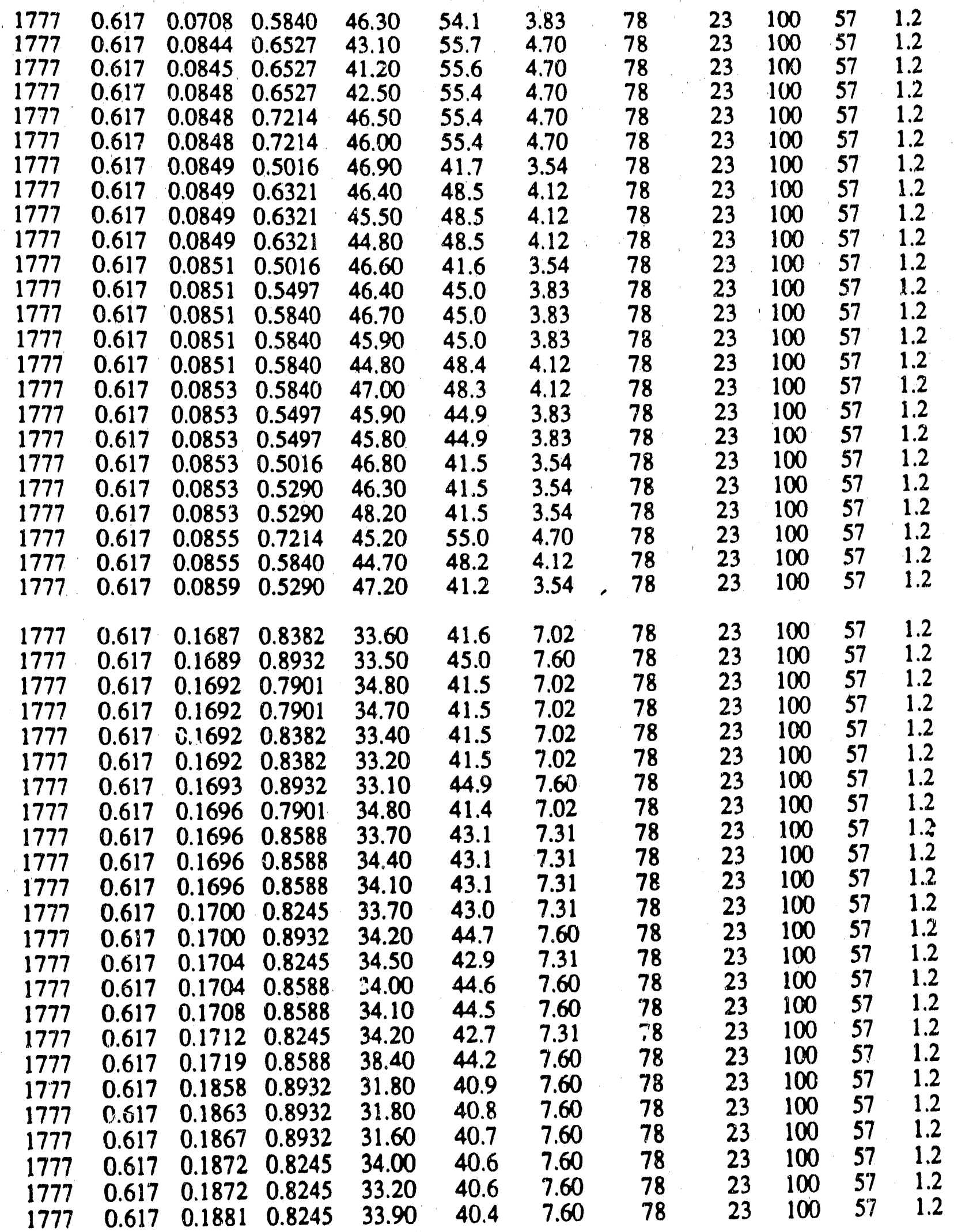


Coal-Water Slurry Mixture Data (continued)

\begin{tabular}{|c|c|c|c|c|c|c|c|c|c|c|}
\hline $\begin{array}{l}1964 \\
1964 \\
1964\end{array}$ & $\begin{array}{l}0.763 \\
0.763 \\
0.763\end{array}$ & $\begin{array}{l}0.0368 \\
0.0370 \\
0.0372\end{array}$ & $\begin{array}{l}0.2473 \\
0.2473 \\
0.2473\end{array}$ & $\begin{array}{l}58.30 \\
56.30 \\
57.70\end{array}$ & $\begin{array}{l}41.0 \\
40.8 \\
40.6\end{array}$ & $\begin{array}{l}1.51 \\
1.51 \\
1.51\end{array}$ & $\begin{array}{l}72 \\
72 \\
72\end{array}$ & $\begin{array}{l}25 \\
25 \\
25\end{array}$ & $\begin{array}{l}15 \\
15 \\
15\end{array}$ & $\begin{array}{l}58 \\
58 \\
58\end{array}$ \\
\hline $\begin{array}{l}1964 \\
1964 \\
1964 \\
1964 \\
1964 \\
1964 \\
1964 \\
1964 \\
1964\end{array}$ & $\begin{array}{l}0.763 \\
0.763 \\
0.763 \\
0.763 \\
0.763 \\
0.763 \\
0.763 \\
0.763 \\
0.763\end{array}$ & $\begin{array}{l}0.0420 \\
0.0422 \\
0.0422 \\
0.0422 \\
0.0423 \\
0.0424 \\
0.0424 \\
0.0425 \\
0.0426\end{array}$ & $\begin{array}{l}0.4122 \\
0.4122 \\
0.5153 \\
0.5153 \\
0.5153 \\
0.4122 \\
0.4466 \\
0.4466 \\
0.4466\end{array}$ & $\begin{array}{l}51.60 \\
53.20 \\
50.70 \\
51.20 \\
49.10 \\
53.40 \\
51.30 \\
51.20 \\
51.60\end{array}$ & $\begin{array}{l}42.9 \\
42.7 \\
63.2 \\
63.2 \\
63.1 \\
42.5 \\
49.3 \\
49.2 \\
49.1\end{array}$ & $\begin{array}{l}1.80 \\
1.80 \\
2.67 \\
2.67 \\
2.67 \\
1.80 \\
2.09 \\
2.09 \\
2.09\end{array}$ & $\begin{array}{l}72 \\
72 \\
72 \\
72 \\
72 \\
72 \\
72 \\
72 \\
72\end{array}$ & $\begin{array}{l}25 \\
25 \\
25 \\
25 \\
25 \\
25 \\
25 \\
25 \\
25\end{array}$ & $\begin{array}{l}15 \\
15 \\
15 \\
15 \\
15 \\
15 \\
15 \\
15 \\
15\end{array}$ & $\begin{array}{l}58 \\
58 \\
58 \\
58 \\
58 \\
58 \\
58 \\
58 \\
58\end{array}$ \\
\hline $\begin{array}{l}1964 \\
1964 \\
1964 \\
1964 \\
1964 \\
1964 \\
1964 \\
1964 \\
1964 \\
1964 \\
1964 \\
1964\end{array}$ & $\begin{array}{l}0.763 \\
0.763 \\
0.763 \\
0.763 \\
0.763 \\
0.763 \\
0.763 \\
0.763 \\
0.763 \\
0.763 \\
0.763 \\
0.763\end{array}$ & $\begin{array}{l}0.0841 \\
0.0843 \\
0.0845 \\
0.0845 \\
0.0847 \\
0.0849 \\
0.0849 \\
0.0849 \\
0.0849 \\
0.0850 \\
0.0850 \\
0.0851\end{array}$ & $\begin{array}{l}0.5153 \\
0.5153 \\
0.5290 \\
0.5290 \\
0.5290 \\
0.5153 \\
0.5703 \\
0.5703 \\
0.5703 \\
0.6596 \\
0.6596 \\
0.6596\end{array}$ & $\begin{array}{l}39.70 \\
39.50 \\
39.50 \\
40.20 \\
39.60 \\
39.50 \\
39.20 \\
38.80 \\
38.50 \\
38.20 \\
38.60 \\
38.70\end{array}$ & $\begin{array}{l}42.1 \\
42.0 \\
45.3 \\
45.3 \\
45.2 \\
41.7 \\
48.5 \\
48.5 \\
48.5 \\
55.3 \\
55.3 \\
55.2\end{array}$ & $\begin{array}{l}3.54 \\
3.54 \\
3.83 \\
3.83 \\
3.83 \\
3.54 \\
4.12 \\
4.12 \\
4.12 \\
4.70 \\
4.70 \\
4.70\end{array}$ & $\begin{array}{l}72 \\
72 \\
72 \\
72 \\
72 \\
72 \\
72 \\
72 \\
72 \\
72 \\
72 \\
72\end{array}$ & $\begin{array}{l}25 \\
25 \\
25\end{array}$ & $\begin{array}{l}15 \\
15 \\
15 \\
15 \\
15 \\
15\end{array}$ & $\begin{array}{l}58 \\
58 \\
58 \\
58 \\
58\end{array}$ \\
\hline $\begin{array}{l}1964 \\
1964 \\
1964 \\
1964 \\
1964 \\
1964 \\
1964 \\
1964 \\
1964\end{array}$ & $\begin{array}{l}0.763 \\
0.763 \\
0.763 \\
0.763 \\
0.763 \\
0.763 \\
0.763 \\
0.763 \\
0.763 \\
0.763 \\
0.763 \\
0.763\end{array}$ & $\begin{array}{l}0.1704 \\
0.1704 \\
0.1708 \\
0.1708 \\
0.1708 \\
0.1708 \\
0.1716 \\
0.1721 \\
0.1725 \\
0.1872 \\
0.1872 \\
0.1895\end{array}$ & $\begin{array}{l}0.8795 \\
0.8795 \\
0.9138 \\
0.9138 \\
0.9138 \\
0.8795 \\
0.8245 \\
0.8245 \\
0.8245 \\
0.9069 \\
0.9069 \\
0.9069\end{array}$ & $\begin{array}{l}28.30 \\
28.20 \\
28.00 \\
28.30 \\
28.50 \\
28.40 \\
28.80 \\
28.70 \\
28.70 \\
27.20 \\
27.40 \\
2680\end{array}$ & $\begin{array}{l}42.9 \\
42.9 \\
44.5 \\
44.5 \\
44.5 \\
42.8 \\
40.9 \\
40.8 \\
40.7 \\
40.6 \\
40.6\end{array}$ & $\begin{array}{l}7.31 \\
7.31 \\
7.60 \\
7.60 \\
7.60 \\
7.31 \\
7.02 \\
7.02 \\
7.02 \\
7.60\end{array}$ & $\begin{array}{l}72 \\
72 \\
72 \\
72 \\
72 \\
72 \\
72 \\
72 \\
72 \\
72\end{array}$ & $\begin{array}{l}25 \\
25 \\
25 \\
25 \\
25 \\
25 \\
25 \\
25 \\
25 \\
25 \\
25\end{array}$ & $\begin{array}{l}15 \\
15 \\
15 \\
15 \\
15 \\
15 \\
15 \\
15 \\
15 \\
15 \\
15\end{array}$ & $\begin{array}{l}58 \\
58 \\
58 \\
58 \\
58 \\
58 \\
58 \\
58 \\
58 \\
58 \\
58 \\
58\end{array}$ \\
\hline
\end{tabular}



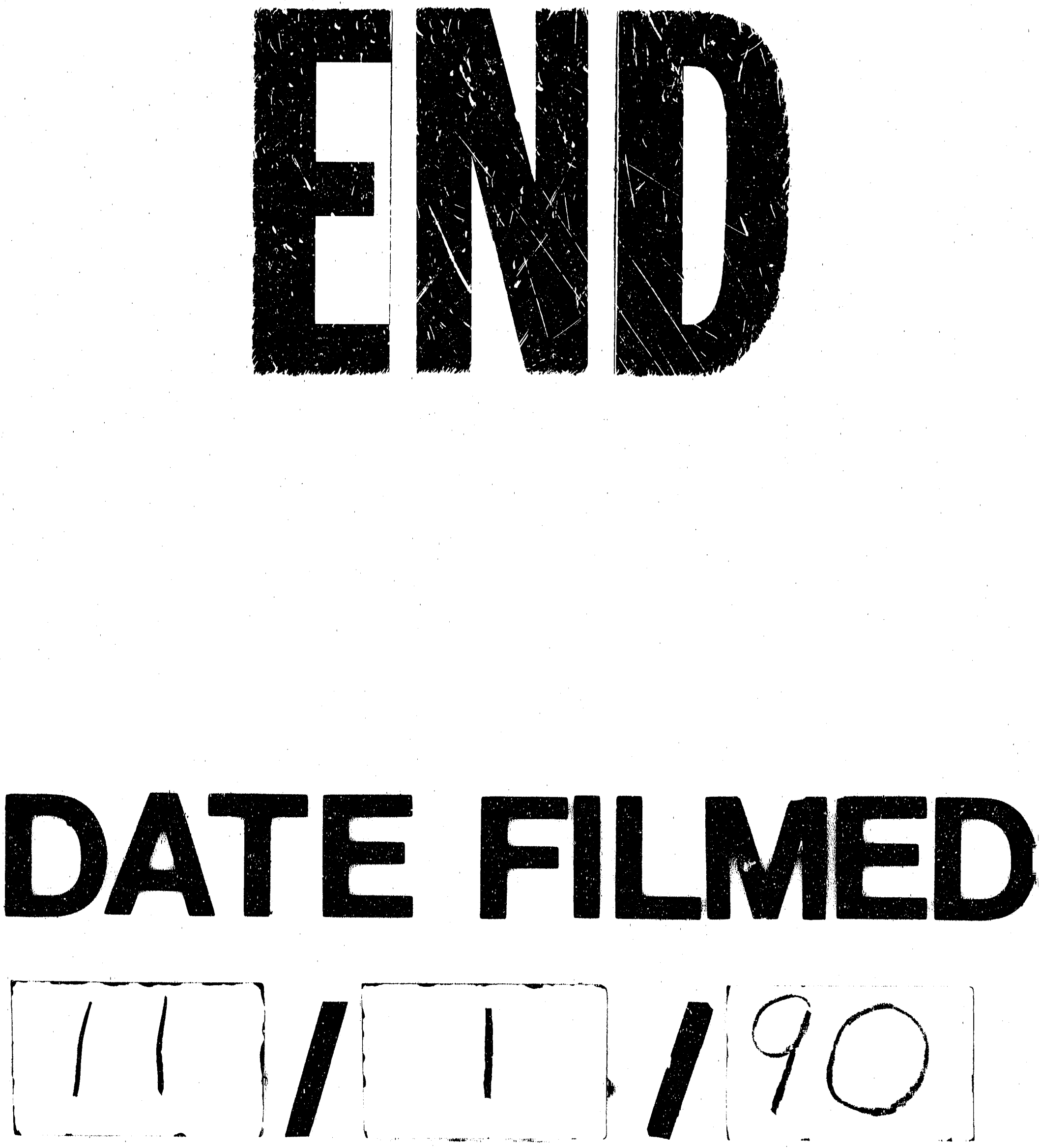


\section{.}

